\title{
An Architecture of Terroir
}

Cultivating a Sense of Place in a Globalized World 

AN ARCHITECTURE OF TERROIR

CULTIVATING A SENSE OF PLACE IN A GLOBALIZED WORLD

by

Douglas Peterson-Hui

Bachelor of Architectural Science, Ryerson University, 2017

A thesis

presented to Ryerson University

in partial fulfillment of the

requirements for the degree of

Master of Architecture

in the program of

Architecture

Toronto, Ontario, Canada, 2020

(C) Douglas Peterson-Hui 2020 


\section{AUTHOR'S DECLARATION}

I hereby declare that I am the sole author of this thesis. This is a true copy of the thesis, including any required final revisions, as accepted by my examiners.

I authorize Ryerson University to lend this thesis to other institutions or individuals for the purpose of scholarly research.

I further authorize Ryerson University to reproduce this thesis by photocopying or by other means, in total or in part, at the request of other institutions or individuals for the purpose of scholarly research.

I understand that my thesis may be made electronically available to the public. 


\section{ABSTRACT}

An Architecture of Terroir:

Cultivating a Sense of Place in a Globalized World

Master of Architecture 2020

Douglas Peterson-Hui

Ryerson University

Evolution of human estrangement from nature has run parallel with globalization and the technological framework through which we experience the world. As globalized Western culture continues to influence consumer products, landscapes, and consequently the built environment, it has guided the homogenization of places. This thesis investigates architectural strategies grounded in the concept of terroir as a way to counteract homogenization while re-establishing a dialogue with the nature of place. Terroir, as a concept which bears insights into the culture-nature relationship, is the starting point for which to establish place driven architecture. By understanding how terroir as an architectural concept can reflect the naturally rich and culturally distinct characteristics of our environments, this approach considers ways in which the built environment can help us reconnect with nature, informed by the context and specificity of place. 


\section{ACKNOWLEDGMENTS}

Thank you to Mark Gorgolewski for your insightful knowledge and guidance into a topic I have wanted to pursue. Your patience and thoughtfullness has helped me grow throughout the process and inspired me to further develop my work and improve in both my career and personal life.

Thank you to Jenn McArthur for pushing me to develop my work, and refine areas where it was much needed. Your expertise helped me narrow my focus when I began to stray.

Thank you to Jurii Leshchyshyn for your feedback throughout my thesis milestones. Your suggestions and ideas have been helpful throughout my design research.

Finally, thank you to my friends and family for being by my side these past couple years, and encouraging me when I needed it the most. 


\section{TABLE OF CONTENTS}

iii. Author's Declaration

v. Abstract

vii. Acknowledgments

ix. Table of Contents

xi. List of Figures

xix. List of Appendices

1. Introduction

3. Framework

PART 1. GLOBALIZATION, ARCHITECTURE, LANDSCAPE

1.0 Globalization

1.1 Sense of Place and Placelessness

1.2 Defining Landscape

1.2.1 Landscape

1.3 Mass Tourism and Landscapes

1.4 The Evolution of Architecture and Globalization

PART 2. EXPLORING TERROIR IN ARCHITECTURE

2.0 An Introduction to Terroir

2.1 Dwelling
2.2 The Fourfold

2.3 The Bridge

2.4 Tourists and Dwelling

2.5 The Taskscape

2.6 Overview

PART 3. ARCHITECTURAL TERROIR: A WINEMAKER'S PERSPECTIVE

3.0 An Introduction to Wineries

3.1 New World Wine and a Return to Terroir 3.1.1 An Architecture of the Old World

3.1.2 An Architecture of the New World

3.1.3 Blurring Boundaries

3.2 The Terre of Terroir

3.2.1 Slope: Topogenesis in Architecture

3.2.2 Texture and Structure: A Tactile Experience of place

3.2.3 Weathering: The Ephemeral Qualities of Place

3.2.4 Compost: Decay in Architecture

\section{PART 4. PRECEDENTS}

4.0 Introduction

4.1 Jackson Triggs Winery 
4.2 Mission Hill Winery

4.3 Cellars Plže

4.4 Personal Wine Cellar

4.5 Personal Wine Cellar 2

4.6 Summary

PART 5. SITE ANALYSIS

5.0 The Okanagan Valley

5.0.1 A Brief History

5.1 Viticultural Regions

5.2. Bighorn Ridge

5.2.1 Grape Varieties
PART 7. CONCLUSION

7.0 Closing Remarks

PART 6. DESIGN

6.0 Design Concepts

6.1 The Lithic Gardiner

6.1.1 Flora

6.2 The Taskscape

6.3 Architectural Fermentation

6.4 Climate 


\section{LIST OF FIGURES}

Figure 1.0: A Suburb In Texas

Source: https://www.geo41.com/changing-identities-cultures

Figure 1.1: City of Dubai

Source: https://www.videoblocks.com/video/timelapse-view-on-skyscrapers-at-waterfront-residential-buildings-in-jumeirah-lake-towers-reflected-in-water-in-dubai-uae-the-jlt-is-a-largedevelopment-which-consists-of-79-towers-with-3-bpnjwinlinh6ctib

Figure 1.2: City of Dalian

Source: http://www.skyscrapercenter.com/building/eton-place-dalian-tower-2/644

Figure 1.3: City of Vancouver

Source: http://www.citiestips.com/view/-107029

Figure 1.4: An Example of Terra Incognita in the Built Environment.

Source: https://mathieuhelie.files.wordpress.com/2008/06/tract-housing.jpg

Figure 1.5: A Manicured landscape and Disneyland Castle in Paris.

Source: https://pursuitist.com/the-architecture-of-disneyland-paris-photo-tour/ (disneyland castle)

Figure 1.6: English Tourists on the Grand Tour of Europe.

Source: Cicerone on The Grand Tour http://www.romeacrosseurope.com/? $p=6998$ \#sthash. aakkusUO.WofqoFLO.dpbs

Figure 1.7: Car Culture and Placelessness.

Source: https://www.uncleguidosfacts.com/2014/07/commercial-stripsamerican.html

Figure 1.8: The Okanagan Valley's New Landscape Aesthetic: Canadian C grade apples. Source: https://www.ebay.ie/itm/APPLE-CRATE-LABEL-CANADIAN-1950S-VINTAGE-ORIGINAL-ORCHARD-SUMMERLAND-B-C-/232631691379? hash=item3629ede873

Figure 1.9: Laugier's Primitive Hut.

Source: https://danielstilwell.wordpress.com/2015/06/29/the-primitive-hut/

Figure 1.10: The Toronto-Dominon Center, by Mies van der Rohe, is a Famous Example of the International Style.

Source: https://nowtoronto.com/news/td-centre-god-is-in-the-details/

Figure 2.0: Rammed Earth

Source: https://sirewall.com/texture-maps-for-architects-designers/ 
Figure 2.1: The Interlocking Concepts of Terroir by Steve Charters Source: Charters, S. (2008). Wine and society: The social and cultural context of a drink. Amsterdam: Elsevier/Butterworth-Heinemann.

Figure 2.2: The courtyard in the Azuma Row House.

Source: http://www.jbdesign.it/idesignpro/azumahouse.html

Figure 2.3: A Trestle Bridge in the Okanagan Valley.

Source: Author

Figure 3.0: Jackson Triggs Crush Pad

Source: Author

Figure 3.1: Ames Gate Lodge.

Source: https://farm6.static.flickr.com/5521/12695780655_e27a31c68e_b.jpg

Figure 3.2: Dry Stone Walls in the Yorkshire Countryside.

Source: https://www.cravenherald.co.uk/daleslife/10643177.ancient-skill-of-dry-stone-walling-is-alive-and-well-in-the-dales/

Figure 3.3: Faux Stone Wall.

Source: https://www.avinylfence.com/product/Allegheny-8ft.php

Figure 3.4: Interior of Dominus Winery.

Source: http://www.architectureweek.com/2007/0620/index.html

Figure 3.5: Dominus Winery Wall Detail.

Source: https://www.crimsonlee.com/2012-The-Wall

Figure 3.6: Falling Water Acknowledges the Topography of its Site.

Source: http://architectureassociate.blogspot.com/2012/12/fallingwater.html

Figure 3.7: Peter Zumthor's Therme Vals.

Source: http://www.whitelinehotels.com/journal/switzerland/peter-zumthors-therme-vals

Figure 3.8: The Sibu Pavillion with Wash Basins.

Source: http://www.small-projects.com/p42.php

Figure 4.0: Drainage at Mission Hill Winery,

Source: Author

XII 
Figure 4.1: Agrarian Features Expressed in the Jackson Triggs Winery. Source: Author

Figure 4.2: A View From the Top of the Building's Exterior Ramp.

Source: Author

Figure 4.3: View From Production Facility.

Source: Author

Figure 4.4: Production Facility.

Source: Author

Figure 4.5 Mission Hill Entrance Gates.

Source: https://www.google.com/maps/

Figure 4.6: Threshold Into the Winery's Courtyard With Bell Tower. Source: Author

Figure 4.7: Bell Tower Drainage.

Source: Author

Figure 4.8: Exposed Volcanic Rock.

Source: Author

Figure 4.9: The Meeting Point of the Three Lanes.

Source: Author

Figure 4.10: The Cellars Along the Central Lane.

Source: Author

Figure 4.1 1: Saint Urban of Langres in a Personal Czech Wine Cellar. Source: Author

Figure 4.12: Cellars in Dolni Bojanovice.

Source: Author

Figure 5.0: Bighorn Ridge Ecological Reserve

Source: Author

Figure 5.1: BC's 6 Wine Regions.

Source: Author 
Figure 5.2: Glenmore Valley Prior to Orchard Development, Circa 1909. Source: https://royalbcmuseum.bc.ca/exhibits/living-landscapes/thomp-ok/irrigating-of-okanagan/photo/photol0.html

Figure 5.3. Newly Planted Orchards in Glenmore Valley, Circa 1914. Source: https://royalbcmuseum.bc.ca/exhibits/living-landscapes/thomp-ok/irrigating-of-okanagan/photo/photo 1 1.html

Figure 5.4: Vernacular Architecture by Osoyoos Lake.

Source: Author

Figure 5.5: The Okanagan's 6 Viticulture Regions.

Source: Author

Figure 5.6: Winery Locations and Fault Lines in the Okanagan Valley. Source: Author

Figure 5.7: Soil Suitability Map of Skaha Lake (Green Indicates Optimal Growing Conditions) Source: https://a100.gov.bc.ca/pub/acat/public/viewReport.do? reportld=25881

Figure 5.8: Fault Lines and Terrace Location.

Source: Author

Figure 5.9: Entering Bighorn Ridge.

Source: Author

Figure 5.10: Preserved Vegetation on Bighorn Ridge.

Source: Author

Figure 5.11: Existing Site Conditions.

Source: Author

Figure 5.12: Images of Existing Site Conditions.

Source: Author

Figure 5.13: A Yellow Bellied Marmot Stands Near Rattlesnake Rock.

Source: Author

Figure 5.14: Storage Building to the Left, Camp Area to the Right.

Source: Author

XIV 
Figure 5.15: Land Excavated for Wine Cellar.

Source: Author

Figure 5.16: Soil Map of Bighorn Ridge.

Source: Author

Figure 6.0: Jackson Triggs Winery Structural Members.

Figure 6.1: The Original Location and New Location for the Winery (Image Facing East). Source: Image by Author

Figure 6.2: Soil Map of Bighorn Ridge.

Source: Drawing by Author

Figure 6.3: The Flora of Bighorn Ridge.

Source: Drawing by Author

Figure 6.4: The Site's Layout Encourages Landscape Exploration.

Source: Drawing by Author

Figure 6.5: Tourist lodging and campsite.

Source: Drawing by Author

Figure 6.6: Hiking Trail Up the Ecological Reserve

Source: Drawing by Author

Figure 6.7: Pathway to the Winery.

Source: Drawing by Author

Figure 6.8: Site Context

Source: Drawing by Author

Figure 6.9: Winery Entrance.

Source: Drawing by Author

Figure 6.10:Massing and Parti.

Source: Drawing by Author

Figure 6.11: Section Perspective.

Source: Drawing by Author 
Figure 6.12: Axonometric of the Two External Corridors.

Source: Drawing by Author

Figure 6.13: Level 4.

Source: Drawing by Author

Figure 6.14: Level 2 and 3.

Source: Drawing by Author

Figure 6.15: Level 0 and 1.

Source: Drawing by Author

Figure 6.16: Section Through the Building's Outdoor Theater.

Source: Drawing by Author

Figure 6.17: The Fermentation Room and External Theater.

Source: Drawing by Author

Figure 6.18: Cellar and Event Room.

Source: Drawing by Author

Figure 6.19: Tasting room and Greenhouse.

Source: Drawing by Author

Figure 6.20: Composting Area.

Source: Drawing by Author

Figure 6.21: Staff Room and Courtyard Adjacent to Fermentation Tanks.

Source: Drawing by Author

Figure 6.22: Programmatic Axonometric.

Source: Drawing by Author

Figure 6.23: Elevation Showing Layers of the Building Facade

Source: Drawing by Author

Figure 6.24: New Structure.

Source: Drawing by Author

Figure 6.25: Gradual Decay, Source: Drawing by Author

$\mathrm{XVI}$ 
Figure 6.26: Cellar Detail Showing the Building's Relationship to the Earth. Source: Drawing by Author

Figure 6.27: Fermentation Room Overhang.

Source: Drawing by Author

Figure 6.28: Tasting Room and Greenhouse (Bottom).

Source: Drawing by Author

Figure 6.29: External Hall and Native Species.

Source: Drawing by Author

Figure 6.30: Sun Study.

Source: Drawing by Author

Figure 6.31: Trough (Indicated In Red)

Source: Drawing by Author

Figure 7.0: Mission Hill Winery and Cellar Exit. Source: Author 
XVIII 


\section{LIST OF APPENDICES}

Appendix A: Site Exploration

Appendix B: Design Explorations

Appendix C: Physical Models 



\section{INTRODUCTION}

Globalization and the technological framework through which we view the world have permeated into the everyday life of modern society. Through innovations in transportation and communication technologies, globalization has been praised for enriching the standards of life, transcending physical boundaries, and enabling the flow of both people and information to other parts of the world. Yet as a worldwide phenomenon that looks to achieve a universal standard of living, it has also been criticized for enabling the loss of culture, the destruction of ecological diversity, and the homogenization of the built environment.

Evident in the architecture that characterizes many North American environments today, globalization has imposed a universal language of design, regardless of context. If according to Winston Churchill's statement, "we shape our buildings; thereafter they shape us", then the places of the globalized world surely suggest an environmental crisis, where our built environment, which communicates an indifference to the naturally rich places of the world, is also reflective of our cultural attitudes towards place (Churchill 1940, as cited in Danesi, 2006, p.223). In the age of the Anthropocene, where human culture has become the dominant influence on the environment, we need to bring out the rich and distinct characteristics of places in order to grapple with our impact on the earth, to reorient ourselves within the landscape, and to better understand the environment around us.

A consciousness of our environmental impact, despite it being recognized as early as 1873 by Italian Geologist, Antonio Stoppani, has only recently come to fruition with the environmental revolution of the early 1960s (Crutzen, 2002). In response, the common solution has been to seek quantitative ways in which to apply sustainable technologies to architecture. Less widely discussed however, is the qualitative component of sustainability and the fundamental connection between people and place, perhaps due to its ambiguous nature. Although it is no less important. Without orientation to place we lose identity and become disoriented. Orientation, according to Christian Norberg-Schulz, is a psychological function which gives man "an existential foothold" in relation to his environment (Schulz, 1996, pg. 19). In the built world, orientation may be classified through a "node", "path", or "district", which constitute an "environmental image"; a perceived interrelationship of elements. Often derived from a natural structure, a good environmental image provides one with "emotional security" (Lynch as cited in Schulz, 1996, pg. 19). The interrelationship of natural elements becomes imbalanced when we come to understand the world in purely quantitative and superficial ways and thus "the more superficial a society's knowledge of the real dimensions of the land it occupies becomes, the more vulnerable the land is to exploitation, to manipulation for short-term gain" (Lopez, 1990).

Given the possible issue of placelessness, it is perhaps important to acknowledge architecture's potential as a medium that connects people and their environment. Although every location to some extent has a sense of place, the degree of which one place is distinguishable from another is important. How might the distinct characteristics of a place enable the appreciation of our environment? In questioning architecture's role as a placemaker, it becomes evident that 
living with, and experiencing the world merely through sustainable technologies is not enough to sustain ourselves if we do not feel a deep affection towards the places which we visit or live in. The current dilemma suggests that perhaps this is the time for the built environment to rediscover something more poetic about itself, shifting from construction influenced by purely technological and globalized means, to the revelation of places. Through this transition, our relationship with the environment remains affectual. "The phenomenon of place is precisely that which will provide the fortitude to press ahead into the unknown with an unflinching commitment to sustainability and an integral understanding of environmental design. In this way, the problem of sustainability might be simply phrased as the prioritizing of place in our world" (Teal, 2008, pg.66).

As a concept which counteracts globalized tendencies of homogenization, terroir plays a crucial role in differentiating the qualities of place. Terroir is a French term commonly used in viticulture to describe the complete natural environment in which a particular wine is produced, including factors such as the soil, topography, and climate; but more broadly, it encompasses the relationship between people, landscape, nature, culture, and in the context of this thesis, architecture (Terroir, 2019). Paradoxically, as globalization and tourism has enabled more people to travel the world in search of the authentic place, it has led to an identity crisis among destinations. Modern advancements have given us the privilege of experiencing many places, but in a world of rapid mobility is this experience truly authentic? Perhaps through an architecture of terroir, we can begin to explore how such factors may influence one's understanding of the authentic place. The Okanagan Valley, Located in British Columbia's Southern Interior is the region through which architectural strategies of place and terroir are explored. The Valley's semi-arid landscape composed of rare sagebrush, Prickly Pear cactus, diverse ecotones, endangered species, and rich history, make it geographically and culturally unique to Canada. As a result, the region has drawn excessive tourism, and land driven development which has been further accelerated by the globalization of its wine industry. Although economically beneficial, these factors threaten the very characteristics that make the region so desirable. With the valley's superficial architecture eager to attract tourists, and excessive alteration to the landscape, the Okanagan has transformed from a brown sagebrush desert, to a hydrologically enhanced artificial oasis. It has become "in short, a magnificent garden, a colonial vision of paradise imposed on a real place that is, at best, only selectively known" (Lopez, 1990).

The current situation requires a new architectural vision that preserves the Okanagan's distinct cultural and natural identity while contributing to an enhanced experience of the valley's agrarian landscapes. By creating a winery grounded in the concept of terroir, through winemaking and building, this thesis hopes to create a sustainable architecture that balances the global requirements of economic prosperity as well as the unique characteristics local to site in order to secure the valley's well-being. 


\section{FRAMEWORK}

\section{Part 1. Globalization, Architecture, Landscape}

Part 1 investigates globalization's impact on our understanding of place through architecture and landscape. As a global phenomenon, and as a means of experiencing place, tourism stands as an important component of the architectural intervention for guiding the current nature/culture dialogue in modern society. The growth of homogeneous mass tourist destinations questions what architectures role is in creating the authentic place experience.

\section{Part 2. Exploring Terroir in Architecture}

Part 2 examines the role of terroir as a concept which re-contextualizes place and its interpretation in an architectural setting. As a medium which counteracts the homogenizing forces of globalization, terroir stands as a key concept through which we may understand the uniquely varied environments of our world, both culturally and naturally.

\section{Part 3. Architectural Terroir: A Winemaker's Perspective}

Part 3 looks at terroir's etymological origins in soil and the philosophies behind the new and old wine world as they relate to placemaking. As the field of viticulture often claims a sense of place through the means of terroir, the winemaker's perspective is used to help form an architectural approach sensitive to a site's geological context.

\section{Part 4. Precedents}

Part 4 refers to a series of case studies that I have experienced as a tourist in both Canada and Europe and their impacts on my connection to place. The case studies also include examples that I have not visited but express the terroir through design.

\section{Part 5. Site Analysis}

Elements of terroir specific to the Okanagan Valley are explored as a way to create a Winery that reflects the region's true characteristics. As a new wine world, the Okanagan's terroir stand $s$ in competition with land driven development, the tourism industry, and the cultural reproduction of architecture, reflecting "elicit images of tradition in a wine region where, in reality, relatively little existed" (Dougherty, 2012, pg.88).

\section{Part 6. Design}

Part 6 features the architectural intervention.

\section{Part 7. Conclusion}




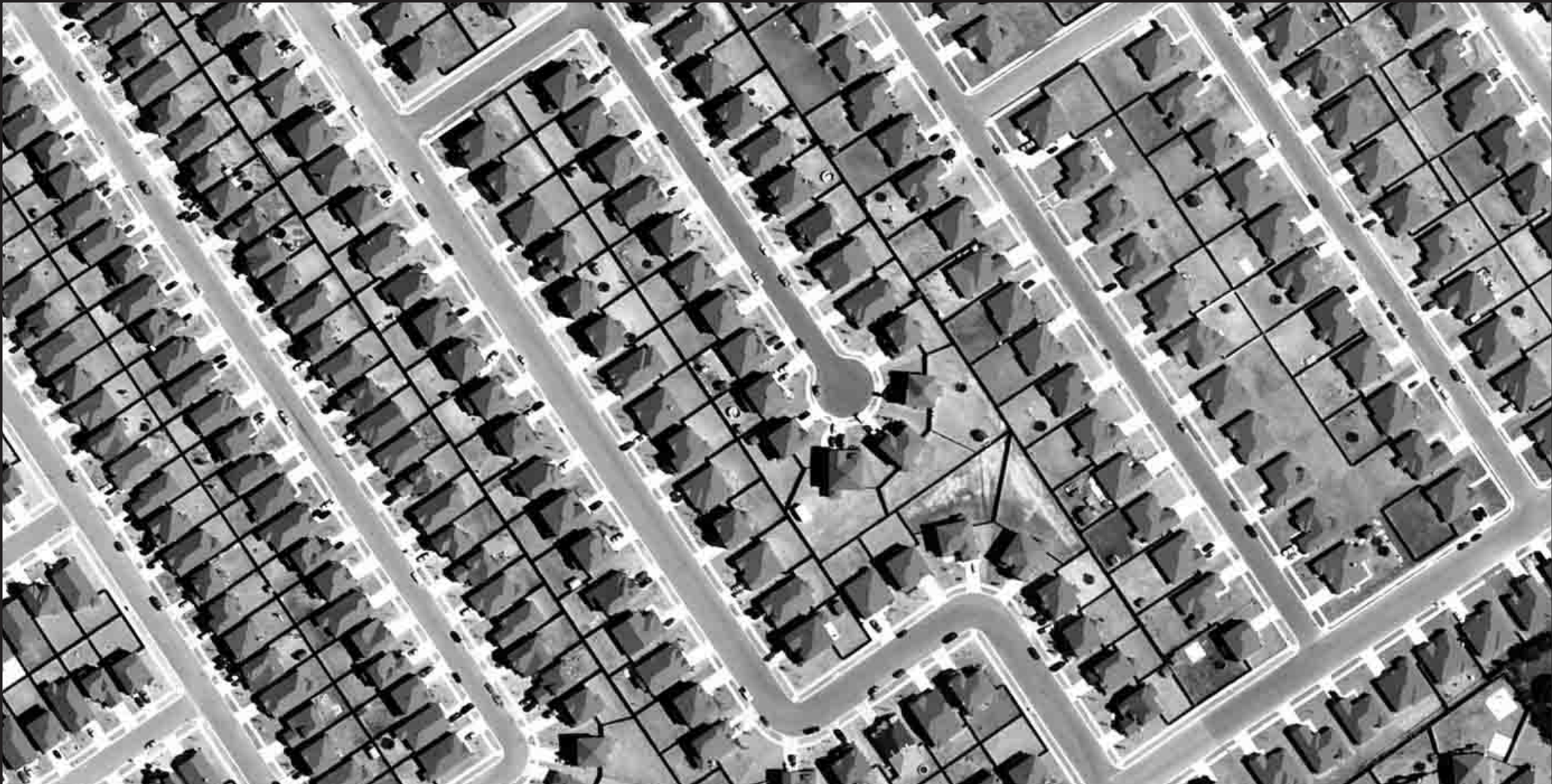




\subsection{GLOBALIZATION}

Globalization is a term commonly associated with the contemporary phenomena of economy, politics, environment, the movement of people, information, goods, and more amorphously, cultural identity (Mirsepassi, 2006, pg. 16). As an overarching concept, "globalization has been grasped as "the compression of the world and the intensification in the consciousness of the world as a whole" (Robertson, 1992, pg.8). It also encapsulates "worldwide social relations which link distant localities in such a way that local happenings are shaped by events occurring many miles away and vice-versa" (Giddens, 1990, pg.64). While many regard globalization as a more recent occurrence, historically, its roots run deep. From the earliest of times, peoples desire to link disparate locations to one another allowed for the exchange of information, products, and cultural ideas. It is not until recently however, with advancements in technology, transportation, and the spread of Western culture, that globalization has been brought into the limelight, redefining the era we live in today.

Through these advancements, globalization has been praised for increasing the standards of living, job markets, the rapid communication of information, and a universal idea of living. Improvements in transportation have brought mass tourism which has enabled us to visit many places and acquire goods from distant countries within record time. The universal language implemented through globalization has introduced a shared understanding for the sciences, physics, math, and technology, and has been seen as a phenomena that continues to fulfill humanities desire for progress.

Despite such advancements, these benefits are not without consequence. Critics have expressed concern for the growth of monoculture through the spread of Western ideals and tradition, while many worry about the loss of ecologically unique parts of the world through the growth of capitalism which has given many companies unprecedented control over nature (Kaplinski, 2003). Natural resources lie at the mercy of large companies and places are not seen for what they are, but as raw goods to be extracted in order to keep up with consumer demand. We thus become less susceptible to the regulating rules of nature and in return less susceptible to our own understanding of place.

Discussions on globalization often revolve around the social, political, and economic aspects of modern society; nevertheless its presence has a significant impact on architecture and landscape, influencing the way we experience places of today. Our experiences of place, or lack of them, are molded through the environments we dwell in, whether that be at home, at the office, in a park, or a forest. "Architecture is Identified as an important driver and narrator of place, a role in which it is currently vastly underestimated" (Yeoman, 2015, pg.89). It can be said that much of what we are experiencing in today's built environment is "placelessness"; a term defined by Chang-Shan Huang as "the phenomenon of increasing similarity among places of different geographic locations or the lack of distinguishable local character in places." To create placelessness is to encourage the ignorance of "specific regional or local character or contexts, and the lack of adaptation of local conditions, both natural and cultural" (Huang, 
1995). As the issue of place becomes evermore profound, creating a sense of place within a globalized context has arisen as a concern within the fields of design, such as architecture and landscape architecture.

Although images of different cities with different cultures, figures 1.1, 1.2, and 1.3 share common characteristics of placelessness, evident in their architectural language. The pancake slab, glass curtain wall, and concrete core, which have become synonymous with the Western skyscraper model, is a common occurrence in many cities. As cities become globalized they "tend to result more in the convergence of metropolitan form than in differences or distinctiveness" (Knox \& Pain, 2010, pg.418).
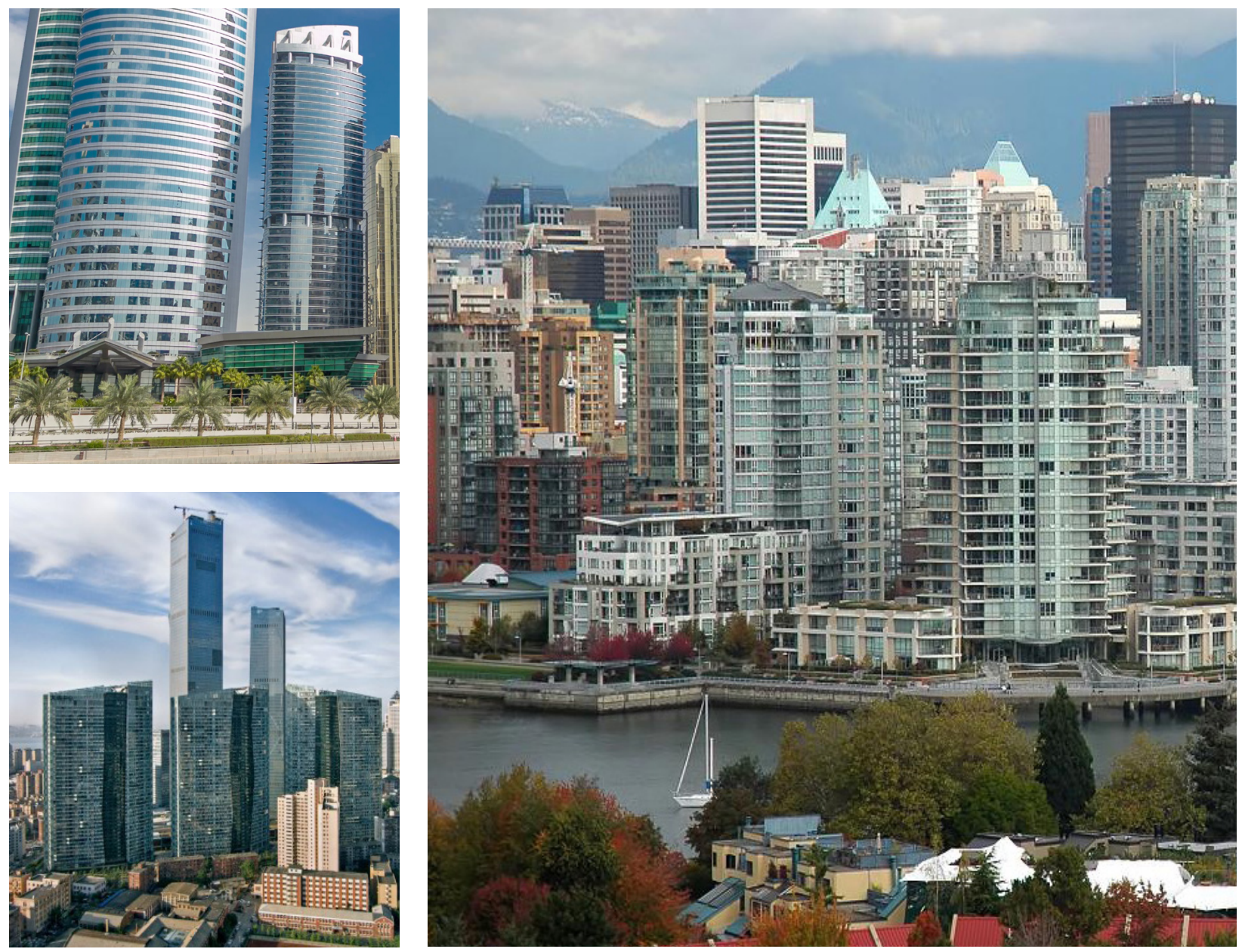

1.1: City of Dubai (Top Left)

1.2: City of Dalian (Bottom Left) 1.3: City of Vancouver (Far right) 


\subsection{SENSE OF PLACE AND PLACELESSNESS}

A sense of place, also known as "Genius Loci," is an ambiguous term that covers many different facets, but nevertheless, plays an important role in modern society. It refers to the attachments and meanings that individuals give to a place, which can help foster appreciation and emotional attachment to the surrounding environment, whether that environment be agricultural, urban, natural, or rural. In viticulture for example, creating a notion around a sense of place, is the idea that factors such as soil, climate, geography, and winemaking techniques, all come together to proclaim, a wine's sense of belonging to a specific location. A sense of place is what makes the physical environment in which we dwell worth caring about. A sense of place embodies the qualitative aspects of sustainable architecture.

Genius loci is not the result of purely physical characteristics but also the emotional relationship between people and the characteristics of place. "Place carries emotional and symbolic meanings for residents. It can be considered a social category whose members are a group of people defined by their geographical location" (Twigger-Ross \& Uzzell, 1996, as cited in Tartaglia \& Rossi, 2015, pg. 108). Thus, sense of place is experienced differently for each person, based on their cultural background, life experiences, the places they've lived in, and their knowledge of a particular place. For example, a visitor's sense of place tends to be more superficial than a local's. Francis Sparshott, professor of philosophy, defines some basic concepts which describe ways in which we understand our being in place. Two of these concepts are the "self to setting" and "traveler to scene"(Sparshott, as cited in Carlson, 2006, pg.79). Sparshott refers to the traveler/ visitor as the appreciation of "the transient." He states, "a transient takes in the gross forms and qualities, or explores the detail of what is there to be seen; but a resident reacts rather to what has taken shape in his mind." Furthermore, "to the transient what he sees is mere facade with no inside and no past; to the resident it is the outcome of how it got there and the outside of what goes on inside" (Sparshott, as cited in Carlson, 2006, pg.80). Part of this influences the aesthetic experience and appreciation of site. By aesthetic experience, Sparshott does not mean purely superficial phenomena, but rather a full sensory experience in which kinesthetic engagement mediates the relationship between people and site. Allen Carlson states that this appreciation comes from "looking with an eye and mind that have been educated about the history and the function of environments" (Carlson, 2006, pg.80). This education is built from an intimate connection with the landscape, and place, which manifests through time.

Increasing human mobility as a result of globalization has enabled us to visit more places as a transient, then ever before. Yet, with such rapid mobility, It is not as common to stay in one place as long as it used to be. "Short-stay and day trips became popular and made use of the modern advances in transport technology" (Gyr, 2010). Taking in the qualities and characteristics of the environments around us have been diminished with the speed at which we move through them. The ever-increasing experience of place as a "transient" rather than "resident" becomes an important consideration for the challenges contemporary architecture must consider in placemaking and the balance between local and global. Tourism, as a global phenomenon, has in many ways influenced the way we experience the landscape and the built 
environment around us, and thus the tourist becomes an important demographic in the discussion of placemaking and landscapes. Before discussing the tourist's experience of landscape, it is important to define what landscape is, what it means for our understanding of place, and its current relationship to architecture. 


\subsection{DEFINING LANDSCAPE}

Prior to architecture, landscape was the original dwelling. "Humans evolved among plants and animals, under the sky, upon the earth, near the water," and "landscapes were the first human texts, read before the invention of other signs and symbols" (Spirn, 2000, pg. 15). At the time sense of place was indeed a critical part of living. Human life was in dialogue with nature through the need to survive. The clouds, sun, and wind indicated the weather to come, the sound of birds warned of predators, and caves were a place to take shelter. Yet the human condition is no longer dependent on literacy of the landscape, or so many believe. The hermetically sealed buildings and placeless environments within the globalized context cut us off from this dialogue. The relationship between nature and culture is treated as separate. Nature is seen as "other".

This relationship between nature and culture is vital as they influence one another. For many nature has been imagined as a term which defines something "separate or prior to human activity". Yet there is no environment on earth that remains in some way or another untouched by man (Jack, 2014, pg.255). Cosgrove points out this symbiotic relationship when he describes landscapes as a production of the intersection between nature and culture. We cultivate new relationships to place through the way we interact with, and alter these landscapes, and therefore how we manage them and understand them are crucial to our own well-being (Cosgrove 1984).

\subsubsection{Landscape}

What exactly though does one mean by landscape? If one looks up the definition Online, the term landscape as a noun means "all the visible features of an area of land, often considered in terms of their aesthetic appeal." As a verb, it means "to make (a garden or other area of ground) more attractive by altering the existing design, adding ornamental features, and planting trees and shrubs" (Landscape: Definition of Landscape by Lexico, n.d.). In this sense, the term landscape talks about an environment that has been intervened by man, cultivated and modified for one's own benefit. In both definitions, the term "landscape" is reduced to merely visual phenomena. Yet, landscapes embody many meanings as a place of cultural exchange, social constructs, and our relationship to nature, making it a slippery term that is difficult to define. We often refer to landscape as a singular entity, yet it usually encompasses a multitude of factors. It is what affects our lived experiences of place. As our impact on the environments in which we dwell continues to influence landscape significantly, Cosgrove's definition of landscape is referenced, which "denotes an environment that has been modified, cultivated, enhanced, or exploited through human activity" (Cosgrove, as cited in Gieseking, n.d.). Cosgrove's definition of landscape will be a reoccurring theme throughout as the tension between processes both natural and man-made are characteristic of the notions behind terroir.

The loss of culture and ecological devastation as a side effect of globalization has created placelessness in the landscape. Paul Crutzen states we are treading in territory know as "Terra 
Incognita"; a term he uses to define the condition of today's landscapes. Crutzen's version of the term 'Terra Incognita' describes the disappearance of our ecologically diverse landscapes such as rainforests, grasslands, and wetlands (Crutzen, 2002). Every landscape and environment we encounter has been influenced in some way or another by human activity, whether directly or indirectly. In essence, John Jackson describes the contemporary landscape as "never simply a natural space" or " a feature of the natural environment", but rather a "place where we establish our own human organization of space and time" (Jackson, 1984, pg. 156). In doing so, landscape is a useful term through which we can look at the relations between humans (culture) and the non-human world (nature).

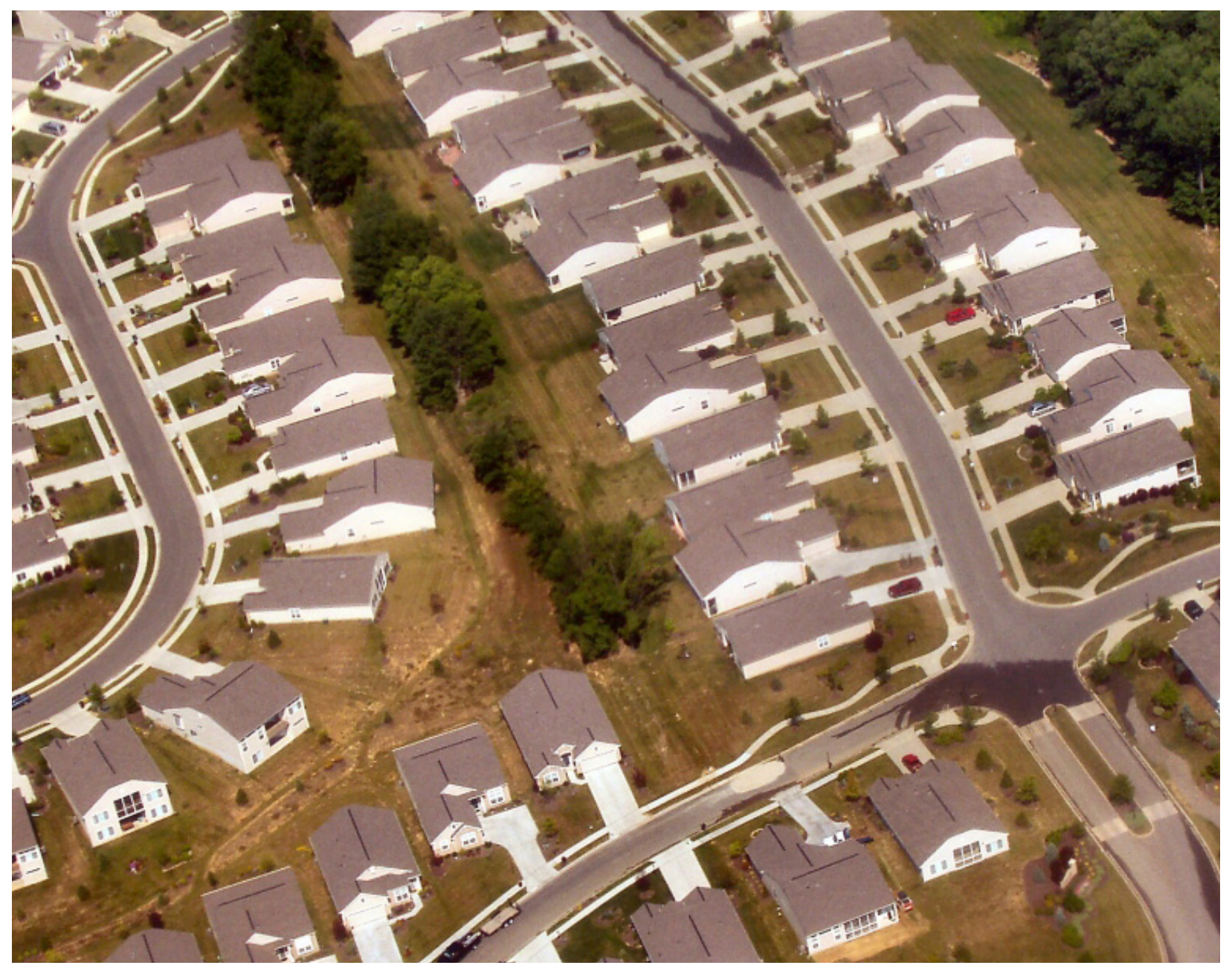




\subsection{MASS TOURISM AND LANDSCAPES}

Tourism constitutes a major contemporary force in terms of landscape modification by creating a means for the exchange of cultural and physical contact on a large scale. Globalization has helped pave the way for the mass tourism we know today. It has emerged as a prolific force in the 21 st century as a way for people to experience places and culture, and is an important actor in the geological transformation of our environment. The Oxford Dictionary defines a tourist as "a person who is traveling or visiting a place for pleasure," and tourism as "the commercial organization and operation of holidays and visits to places of interest" (Tourism: Definition of Tourism by Lexico, n.d.). Tourism for the majority has only recently become viable through the rapid growth of transportation and communication technologies, seen as "a global phenomenon with an almost incomprehensibly massive infrastructure" (Gyr, 2010). Its importance is relevant in society, politics, culture, environment, economy, and architecture. This is exemplified by statistics from the World Tourism Organization (WTO) which states that in 2007 there were approximately "904 million tourists who spent 855 billion US dollars"(WTO as cited in Gyr, 2010).

As a global phenomena, tourism crosses borders that are cultural, spatial, temporal, and social. Gyr points out that its worldwide implementation has brought with it a variety of different views from approval for its "enriching self-realization combined with recreation," to negative criticisms "due to the belief that it causes harm through systematic dumbing down of entertainment and avoidable environmental destruction" (Gyr, 2010). The landscape and built environment, which is the determining factor for many holiday locations, is transformed both materially and symbolically to serve the interests of tourists and its industry. The use of imagery in marketing campaigns conveys desirable tourist destinations through a place's architecture, nature, and culture.

Barry Lopez explains the problem of this transformation when he states "the politics and advertising that seek a national audience must project a national geography; to be broadly useful that geography must, inevitably, be generalized and it is often romantic. It is therefore frequently misleading and im-
1.5: A Manicured landscape and Disneyland castle in Paris (top).>
1.6 English tourists on the Grand Tour of Europe (bot- tom). > 

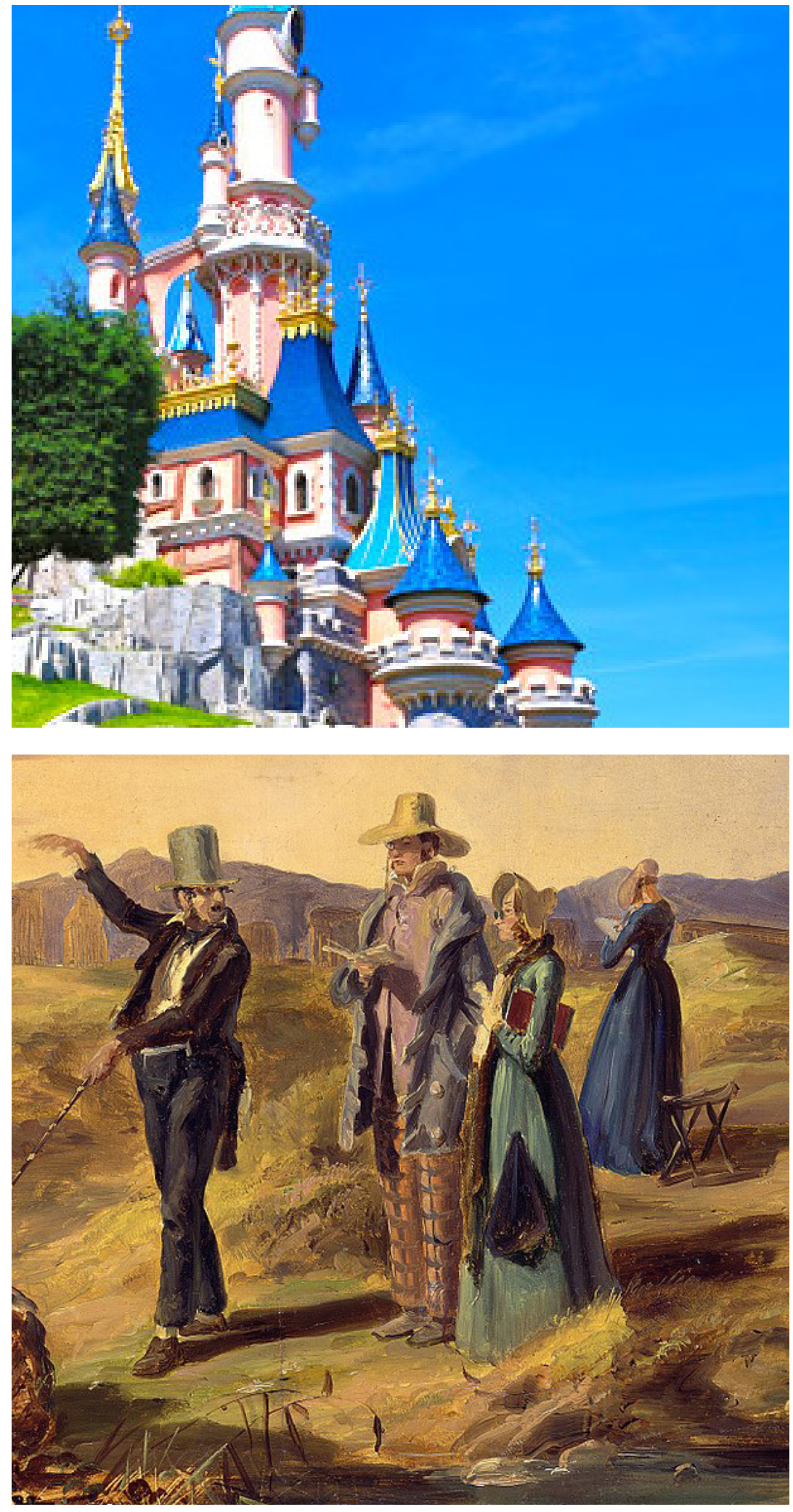

precise" (Lopez, 1990). This generalization is often transferred to consumer places in architecture and landscape as a way to appeal to a larger demographic. From all-inclusive resort chains, to Disneyland Castles, theme parks, and other artificial creations, these environments, made up of hyper-realities and simulated landscapes, define a significant portion of the modern tourist experience.

Prior to modern tourism was the Grand Tour, which was a cultural pilgrimage undertaken by young nobles between the 16th and 18th centuries. The goals of the Grand Tour revolved around broadening one's knowledge to develop social graces and appropriate etiquette. Each Grand Tour was guided with the help of a cicerone who was someone educated in the fields of architecture, classical antiquity and the Renaissance period. However, as time passed. the goals of tourism also came to include leisure and pleasure. This paradigm shift created a dichotomy in travel "as an art" and as "an end in itself," implied by the desire for amusement and entertainment (Gyr, 2010). Although not the only reason for travel, entertainment and leisure became more popular as tourism evolved. 
Following the Grand Tour were Bildungsreisen (educational journeys) which took place between the enlightenment era and the 19th century (Gyr, 2010). Bildungreisen were important to the development of modern tourism as these journeys became popular among the middle class. Tourism was no longer an activity reserved exclusively for the wealthy, although it still remained prominent among those of the upper class. It also expanded the popularity of shorter trips and a desire to learn about technological advancements, culture, nature, and industry.

The introductory phase of modern tourism occurred between the first third of the 19th century and the 1950s referring to the innovations in technology and infrastructure as they benefited to its rapid growth. Mass tourism became realized with new labor rights, social changes and shifts in consumer demand. Increased mobility made short-stays and day trips achievable. Railroads appeared in Scotland in 1812, England in 1825, Germany, Switzerland, France and many other European countries during the early 19th century (Gyr, 2010). Although the railways were not built for tourist purposes, they helped fuel it. At the time traveling still remained a privilege but it was only another century before lower middle, and working class populations could go on vacation regularly.

Guidebooks were made for the middle-class traveler as tourism increased in popularity and became available to a wider demographic. Karl Baedeker (1801-1859) was most successful in the creation of his German guidebooks. These were known as "The Baedeker". Through his work, Baedeker established a new style of travel that went beyond simply information and educational experiences but included tourist attractions. "Tourist attractions soon became touristic obligations; sightseeing became a must" (Gyr, 2010).

The postwar period of tourism development to the current day has presented many tourists with what is known as an artificial holiday destination, not necessarily reflective of the ecological or cultural particularities of place. Examples include Disneyland, Port Aventura, and Europa Park, where place is an artificial construct. This stands in opposition to Stephen Smith who states "A key element of mindful tourism is an awareness of the place (including culture, environment, and residents) the person is visiting; such awareness is conveyed through the story(ies) represented by the place" (Smith, 2015, pg.225). The criticisms pertaining to tourism, and avoidable environmental destruction, advocate for mindfulness when visiting. Thus, the link between culture, nature, place, and the tourist experience should be a key part of the tourist destination. However, Smith states, "Ironically, though, tourism - in which place is a central concept - has paid little attention to this concept" (Smith, 2015, pg.220).

Furthermore, a disconnect from place grew with the introduction of the automobile. As another way for tourists to travel, the automobile brought with it a paradigm which changed the tourist experience of place. No longer were journeys a slow-paced endeavor, landscapes and architecture had now morphed to accommodate the automobile. The commercial strip, and architectural style known as "Googie", became synonymous with the North American landscape, 


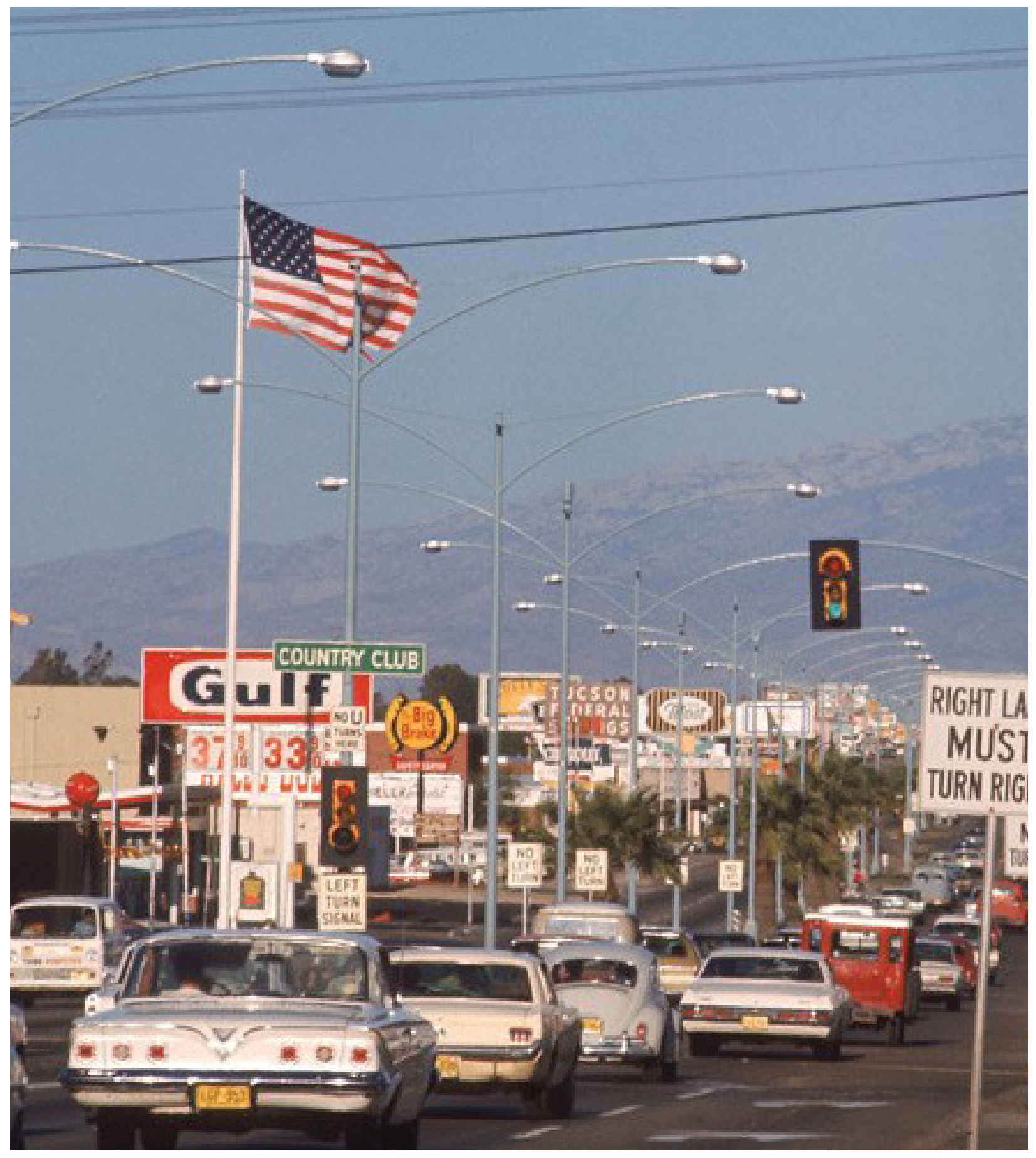

1.7: Car culture and Placelessness. 
cluttered with big box stores, signage and parking lots, clearing anything and everything out of its way during development. In this era "the traditional touristic consumption of symbols (sights, other worlds) have been extended or replaced by an experience-laden entertainment culture that is part of a new way of perceiving the world" (Gyr, 2010). This had significant global characteristics that dissolved boundaries and facilitated different modes of experience. As a result, the automobile contributed to placelessness; modern day society became disconnected from the landscape.

Landscapes in some tourist destinations have come to embody artificiality and hyper-reality as a way to attract visitors and market products. As the global world revolves around a visual consumer culture, the landscape has also been used to assist in the marketing of products and lifestyles, whether that be wine, food products, furniture, or tourist packages.

One example is the Okanagan Valley. Well known for its wine industry, it has been well established through the marketing of its landscape, conveying the idea of an idyllic destination in a scenic part of British Columbia's Interior. "Since this first marketing of the region as a lifestyle of health and beauty, a singular vision has presented the idea of a place, one that is perhaps more myth than reality" (Schwann, 2018, pg. 175). "This filtered lens impacts the manner in which development and land use are managed and stewarded" (Wagner, 2008, as cited in Schwann, 2018, pg. 175). A landscape aesthetic which developed during the early 20th century was displayed on fruit boxes when the Okanagan was primarily focused on Orchard production. Although the marketing varied in the early images conveying a product and terroir unique to a specific area, imagery "eventually coalesced around a particular motif that emphasized the seductive qualities of sun and fruit, as well as orderly, green rows of fruit trees, and panoramic views of the lake, or mountains, or both" (Wagner, 2008, pg.28).

Images and branding create a particular expectation of place and an artificial idea around the real landscape of the Okanagan. In return, the tourist experience may also create a shift in activities that take place in order to fulfill these artificial expectations. "The tourist experience is dominated by the meanings these expectations give to places, rather than physical encounters alone" (Leader-Elliot, 2004).

As with this single idea of a consumer product, Daniel Arreola observes, "when this homogenization is transferred from consumer products to consumer places, as happens in the case of tourism, the effect is not only to homogenize and destroy authentic cultural spaces, but also the physical environment surrounding them" (Arreola, 2005, pg. 116). Thus, through the construction of tourist infrastructure, such as hotels and resorts by large scale global investment companies, the built environment becomes uniform and placeless. Tourism as an increasingly significant mediator of spatial identity and place is coming to play an important role in the globalized context of the built world and the landscape. 


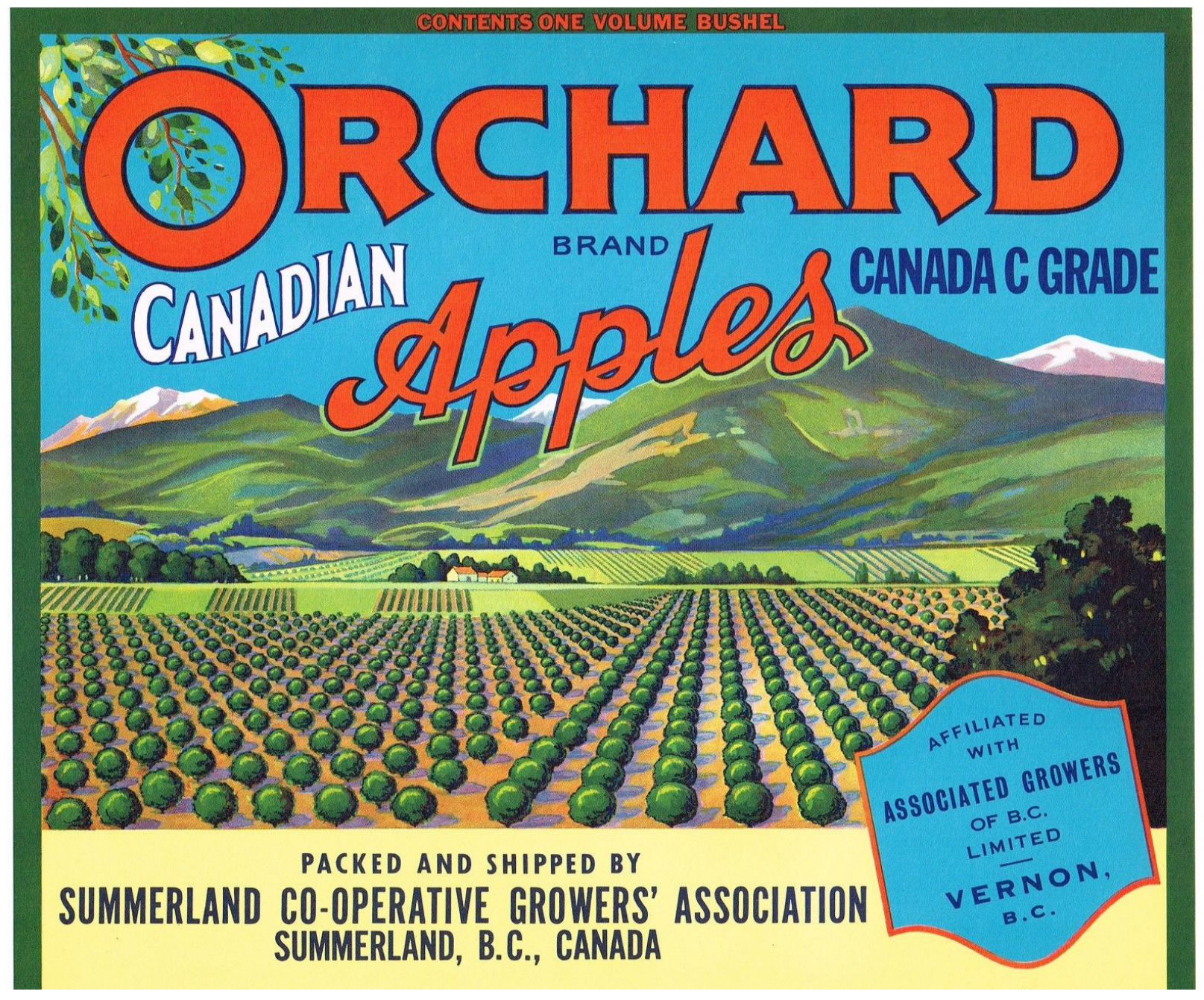

1.8: The Okanagan Valley's new Landscape Aesthetic: Canadian C Grade Apples. 
"The main goal of tourism development is enhancing marketability and the volume of clients through the construction of landscapes that satisfy the needs of the users" (Arreola, 2005, pg $.116-117)$. Tourists are more comfortable in familiar places and thus tourism becomes more profitable in built environments that are homogeneous. This presents a serious problem where the production of placeless landscapes create sites devoid of cultural or natural diversity, exemplified by tourist accommodation such as the Sandals all inclusive resorts in the Caribbean, or the replacement of natural and cultural landscapes with vineyards in the Okanagan Valley. "What local people object is mass tourism enhancement, as it impairs landscape values such as intactness, simplicity and traditionality"(Sooväli, 2003, pg.932).

As architecture becomes a homogenized product of consumer places through travel marketing and globalization what does it say about our relationship to the landscape? How has the technological framework which we view our world through influence our understanding of the very places we dwell in? How does this singular idea of a landscape influence how we build?

Lopez (1990) states that:

In the wake of this loss of personal and local knowledge from which a real geography is derived, the knowledge on which a country must ultimately stand, has become something hard to define but I think sinister and unsettling--the packaging and marketing of land as a form of entertainment. An incipient industry, capitalizing on the nostalgia Americans feel for the imagined virgin landscapes of their fathers, and on a desire for adventure, now offers people a convenient though sometimes incomplete or even spurious geography as an inducement to purchase a unique experience. But the line between authentic experience and a superficial exposure to the elements of experience is blurred. And the real landscape, in all its complexity, is distorted even further in the public imagination. No longer innately mysterious and dignified, a ground from which experience grows, it becomes a curiously generic backdrop on which experience is imposed (para. 12). 


\subsection{THE EVOLUTION OF ARCHITECTURE AND GLOBALIZATION}

From the beginning, architecture's fundamental qualities have been to shelter man from nature, to protect him in the landscape. To keep one dry and to shield him/her from the elements. These fundamental qualities where expressed in Architectural theory by (Abbé) Marc-Antoine Laugier during the enlightenment area around 1750-1850. Laugier conceptualized what is known as the primitive hut (Craven, 2017).

Since primordial times, a shelter's location relied on the specific qualities of the landscape to provide building material, food, and security. The Primitive Hut was a shorthand for architecture's essential qualities, and is an exploration of the anthropological relationship between man and nature. An illustration by Charles Dominique Eisen shows an idyllic woman who is the personification of architecture, pointing out the hut to a young child. The message conveyed by the image indicates a return to architectural origins. According to Laugier man wants nothing more than to be sheltered from sun and rain, stating that "man is willing to make himself an abode which covers but not buries him" (Laugier, as cited in Basar, 2016). This back to basics understanding grounded the Primitive Hut in place. Suitable to its local conditions and made with available material from the immediate landscape, the Hut presents the ideal architecture as a manifestation of what is natural and intrinsic; a product of a specific landscape.

Laugier's hut is important as it supports a back to basics philosophy and considers the evolution of human estrangement from nature. His theories materialized as a reaction against the excessive ornamentation of Baroque architecture and is a relevant topic in the 21 st century for an architecture of place (Basar, 2016). Laugier summarizes that architecture must return to its fundamental qualities, to its origins. Perhaps through proclaiming these origins, architecture offers some form of resistance to the global market in the built world.

Much of the 18th century architecture that Laugier discusses conceptualized nature and the connection to its landscape in a different way, which was around the same time that Paul Crutzen and Eugene Stoermer claimed the beginning of the Anthropocene ("Gaia Theory Anthropocene," n.d.). During the 18th century, both Baroque architecture and gardens illustrated the power of man over nature. Laid out in geometric patterns, perfectly manicured bushes and heavy ornamentation classified this era. Man did not live with the earth but mastered over it. Laugier stood in opposition, believing that a noble architecture consisted of its true underlying fundamentals rather than excessive luxury.

The rise of Globalization during the 20th century helped realize Modern Architecture. As manval labor was replaced with large-scale industry, architects were introduced with the availability of new materials from other parts of the world, and placed in a new cultural environment. These industrial processes influenced famous architects such as Le-Corbusier and Mies van der Rohe, whose interests were in steel and concrete, to establish the modern style. The developments of such architecture made way for what is known as the "international style", which appeared in the 1920s and 30s, becoming the dominate tendency of the many Western cities we see today. 


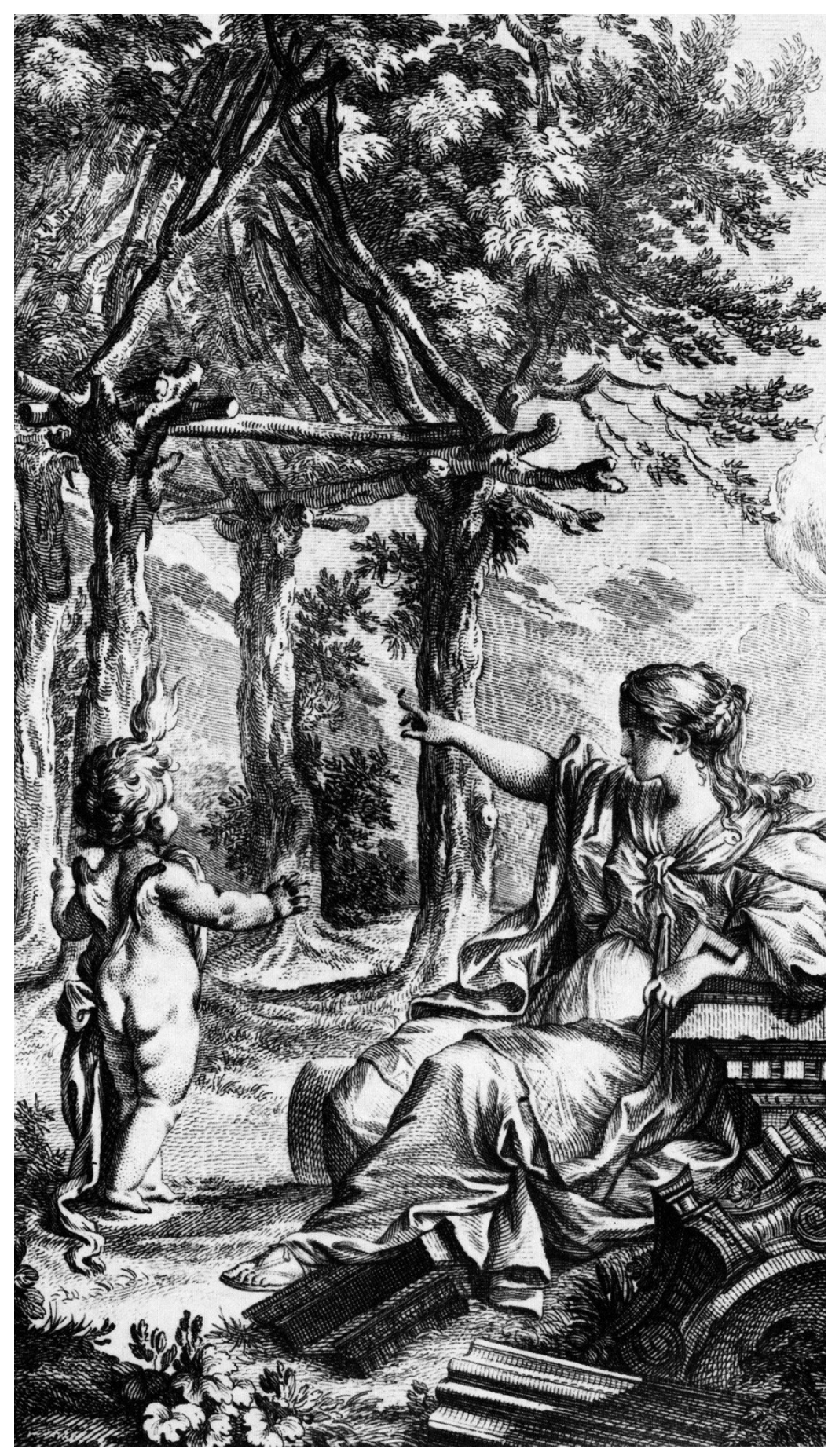

1.9: Laugier's Primitive Hut
(Britannica, 2016)

Large scale industry, new building techniques, and a universal architectural ideal allowed for the replication of glass and steel structures across the world regardless of context (figure 1.8). Older neighborhoods that grew organically over time became viewed as obsolete and were cleared for master planned utopian projects. High-rises sprouted from large plazas with floor to ceiling glazing. It represented a optimistic view into the future that brought clean higher standards of living, but also the erasure of history, place, nature, culture, and memories. With its presence still defining much of our built world "the character of the present day environment is usually distinguished by monotony. If any variety is found, it is usually due to elements left over from the past" (Norberg-Schulz, 1996, pg.190). The architecture of this era was also hermetically sealed allowing the interior climate to be controlled with the touch of a button. Vernacular strategies became irrelevant and human estrangement from nature had reached a new high. A dialogue with the landscape became lost. "After the second World War "places were 
subject to profound change." Schulz goes on to state that "a distinct figure ground relationship no more exists; the continuity of the landscape is interrupted," and "in general, the symptoms indicate a loss of place" (Norberg-Schulz, 1996, pg. 189-190).

Postmodernism emerged in the 1960s as a reaction against international and modern styles due to its homogenizing effects and its lack of empathy towards local cultures and contexts. A renewed interest in ornamentation had come forth, with architects experimenting with layers and variation as a way to create novel effects (Britannica, 2016). The results were often playful and symbolic, however postmodernism was not exempt from criticism. Its architecture was classified as superficial, with many describing it as ugly, superficial, and unoriginal.

More recently, architects have shifted their interests to regional architecture and vernacular forms, experimenting with "local sustainable materials, environmental consciousness and afford-ability" (Martin-McAuliffe, 2016, pg.12). A prioritization has been given to local materials

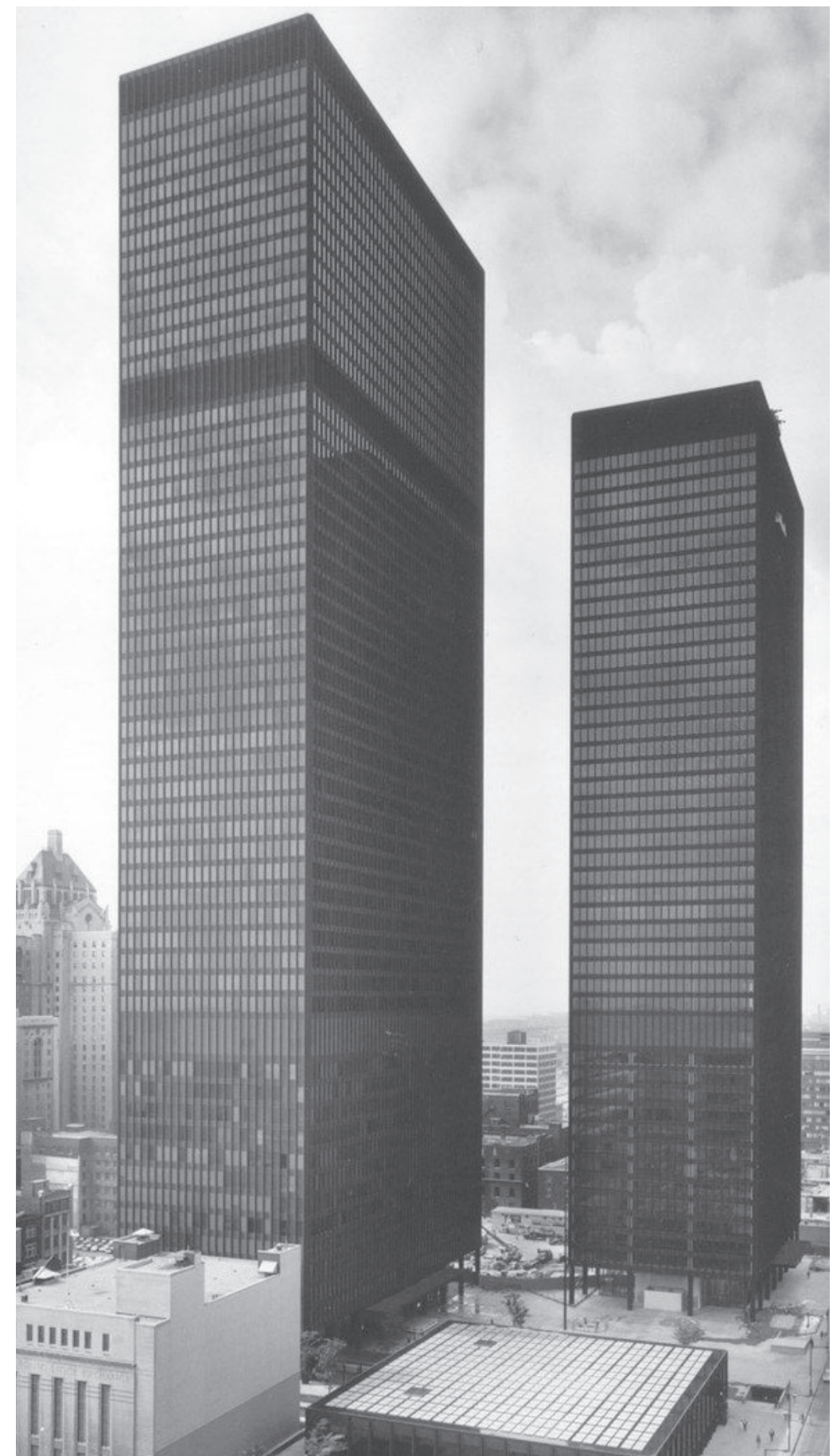

1.10: The Toronto-Dominon Center by Mies van der Rohe is a Famous Example of the International Style. 
and techniques, and architects have begun to experiment with architecture "where an emphasis is placed on time-honored practices as well as connectedness to place, that is, an acute awareness and consideration of the wider context of a finished product, principally the given landscape and its attendant culture" (Martin-McAuliffe, 2016. pg. 18). Despite the efforts, our built world still requires a fundamental shift if we are to bridge the gap between landscape and building. 


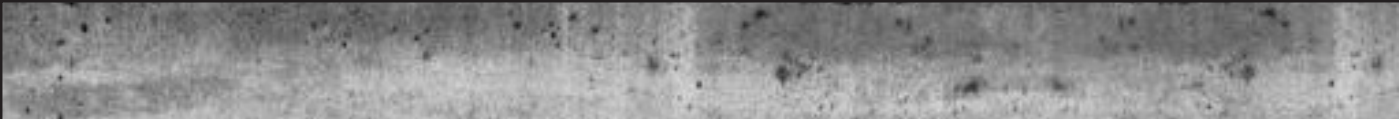

\section{PART 2. EXPLORING TERROIR IN ARCHITECTURE}

\section{0: Rammed Earth}




\subsection{AN INTRODUCTION TO TERROIR}

In response to the issues discussed, the term "terroir" was employed as a way to understand an architecture of place. Broadly speaking, terroir is said to define a sense of place, but more accurately, terroir is a French term, meaning land/earth, and is commonly used in a viticultural context to describe the environmental factors which determine the quality and taste of a wine. "It has been suggested that terroir is becoming increasingly important in an age of globalization as a counter movement" and thus implies a direction for a regionalist approach to architecture (Charters, 2008, pg. 107). Being a word that is not directly translatable to English, it has been interpreted in a number of ways and has come to take on a new meaning in response to globalization.

Terroir is defined by the Oxford Dictionary as "the complete natural environment in which a particular wine is produced, including factors such as the soil, topography, and climate" (Terroir, 2019). Although this definition limits terroir to merely the physical characteristics of place, there has been a paradigm shift which recognizes an additional metaphysical dimension through "the joys, the heartbreaks, the pride, the sweat, and the frustrations" that come through dwelling in a specific place, according to James E. Wilson (1998, pg.54). Christy Wampole states more abstractly that, "terroir is a concept whose main purpose is to re-contextualize" (Wampole, 2016, pg. 144). Her definition is open-ended, but suggests that terroir can perhaps help foster intimate connections with the land. Matt Harvey's definition identifies terroir as "an expression of the interaction between man and environment" (Harvey, 2017, pg.352). Steve Charters argues that "terroir is conceived as a tension between the physical (or viticulture), the mystical sense of place, and its role in marketing - with the use of terroir to make distinctions the unifying factor. Distinctions reflect diverse viticulture environments, they fix identity, and they are used as a means of promoting the wine as one which stands out from all others" (Chaters, 2008, pg. 108)(figure 2.1). Finally, Samantha L. Martin-McAuliffe suggests that "such an inclusive definition, which enfolds the complexities of 'deep ecology', should resonate among theoreticians and practitioners of architecture engaged in critically questioning the rapport between the environment and buildings" (Martin-McAuliffe, 2016, pg.26). With many interpretations, questions arise such as how can terroir create a sense of place in an architectural context, how does terroir influence architectural intent, and can terroir be narrowed down to something more specific?

Although terroir's polysemous nature is abstruse, it is important to note that terroir, in a contemporary context, consists of overlapping meanings. This section will looks at the work of Martin Heidegger, Bernard Tschumi, and Tim Ingold, as their philosophy helps to build a better understanding for the links between terroir, and its interpretation in architecture. Heidegger's philosophy is deeply rooted in both the notions of wine, architecture, and place. As an advocate for dwelling, his work is closely associated with the harvesting of grapes and building, whereas Tim Ingold discusses events, landscape, and the making of place as an equally important aspect to the cultural and natural components of terroir. Bernard Tschumi's architecture as a discourse of events helps us to understand ways in which architecture can create a sense of place through 


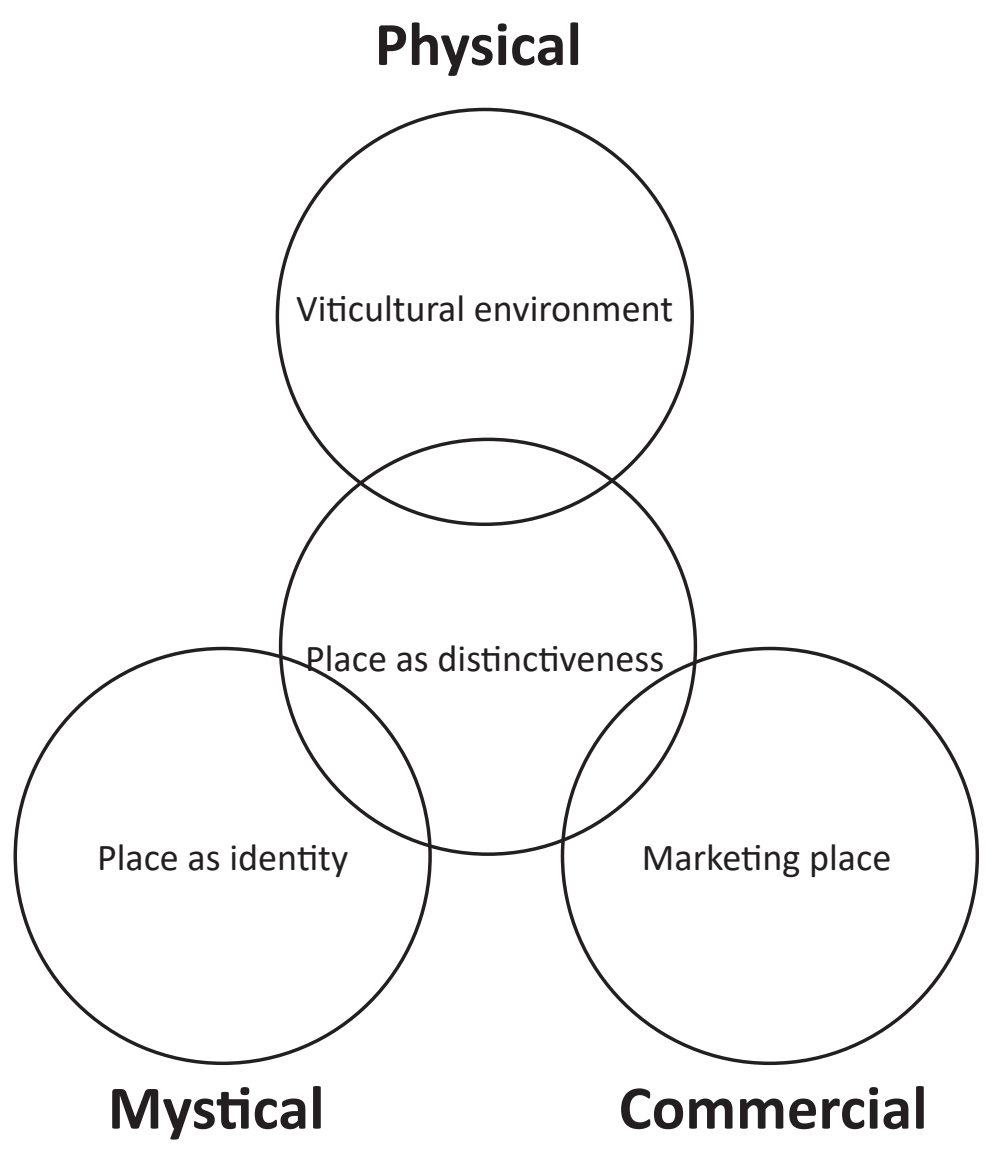

the interaction with its landscape. Together, their work encapsulates the dialogue between nature and culture, suggesting directions for architectural terroir. 


\subsection{DWELLING}

We are entering a new age in earth's history that calls for a rethinking of the way we interpret nature and our place within it. This relationship may best be explored in Martin Heidegger's work titled 'Building, Dwelling, Thinking'. Heidegger's work is an important consideration as his philosophy questions the "reductive proclivities of the Western metaphysical tradition," and uses a 'sense of place' as the basis for his thinking (Teal, 2008, pg. 2).

The term dwelling is relevant to place as it helps man to orientate himself and identify with the environment in which he lives. In 'Building, Dwelling, Thinking,' Heidegger's definition of dwelling means to "spare, to preserve," it is an act that in "itself is always a staying with things" (Heidegger, 1951, pg.150-151). The "thing" in this case is something which gathers the world, and the "sparing and preserving" is achieved through a relationship which is characterized by nurturing and enabling the world as it is (Heidegger, 1951).

Through the modern framework, 'things' reveal themselves as resources for human ends, or as Heidegger refers to it, "standing-reserves." To give an example, the valley is not seen as valley but as a convenient place for a bypass; old growth trees are not seen as trees, but as timber; dandelions are not seen as dandelions, but as weeds to be removed. This view of things as a means to an end disconnects us from the 'real' of place. To use the bypass as another example, "technological man does not appreciate his journey to work, the motorway is there only to convey him from A to $B^{\prime \prime}$ (James, n.d.). This is not to disregard the technological and global paradigm, but rather, to question the predominant way in which we see the world through pure efficiency and extraction. In an architectural context, much like the bypass, "the more architecture resembles a realm entirely of human design and manufacture, with hardly any constitutive features acknowledging the 'otherness' of the earth, which is unavoidably co-constitutive of human embodiment, the more it becomes a domain which alienates humans from their ineluctable bond with the earth" (Olivier, 2011, pg.3).

To dwell is to counteract our estrangement from the naturally rich places of the world. The actions of dwelling encourage us to care for the earth, to cherish it through the cultivation of crops, tending to the land, and the pouring of wine from a jug. It is through dwelling that the winemaker, is particularly attuned to the site's terroir. Other acts that constitute dwelling include building. Heidegger references the German word "baven," whose contemporary meaning is" inating from the word "buan", which was an earlier verb, meaning to stay in place, to dwell (Heidegger, 1971, pg. 147). These actions reinforce the notion that a sense of place is associated more with dwelling than architecture itself. His definition implies that dwelling is not the final product of shelter, nor is it limited to the home, It is the space where life occurs. In this case, perhaps an architecture of terroir must look to the notion of dwelling for direction. It is not a finished artifact, but rather part of a dynamic process in the everyday events of life. 


\subsection{THE FOURFOLD}

The act of dwelling helps to broaden our view of the earth, experience the 'otherness' of nature, and embrace spirituality and deep rooted connections in everyday experiences of place.

When the evening light, slanting into

the woods somewhere, bathes the tree

trunks in gold...(Heidegger, 1971, pg.13)

When the wind, shifting quickly, grumbles

in the rafters of the cabin, and the

weather threatens to become nasty...(1971, pg.8)

The immaterial and material phenomena of these statements introduces us to Heidegger's concept of the "fourfold," defined as the unity of the "earth and sky, divinity and mortals," central to dwelling. To dwell means to keep "the fourfold in that with which mortals stay: in things" (Heidegger, 2010, pg.353). Heidegger summarizes the elements of the fourfold as follows.

Earth is the serving bearer, blossoming and fruiting, spreading out in rock and water, rising up into plant and animal. When we say earth, we are already thinking the other three along with it, but we give no thought to the simple oneness of the four.

The fourfold balances the material and the immaterial world and their importance in holding together the significance of place. So how may the fourfold contribute to a sustainable built environment?

The sky is the vaulting path of the sun, the course of the changing moon, the wandering glitter of the stars, the year's seasons and their changes, the light and dusk of day, the gloom and glow of night, the clemency and inclemency of the weather, the drifting clouds and the blue depth of the ether. When we say sky, we are already thinking the other three along with it, but we give no thought to the simple oneness of the four.

The divinities are the beckoning messengers of the godhead. Out of the holy sway of the godhead, the god appears in his presence or withdraws into his concealment. When we speak of the divinities, we are already thinking the other three along with it, but we give no thought to the simple oneness of the four.

The mortals are the human beings. They are called mortals because they can die. To die means to be capable of death as death. Only man dies and indeed continually, as long as he remains on the earth, under the sky, before the divinities. When we speak of the mortals, we are already thinking the other three along with it, but we give no thought to the simple oneness of the four.

This simple oneness of the four we call the fourfold. Mortals are in the fourfold by dwelling." (Heidegger, 1971, pg.147-148) 
Through the simple oneness, dwelling is the way in which mortals are on the earth. They dwell in place by sparing the earth and viewing it as an 'ends' rather than a 'means' to exploitation. In dwelling, mortals accept things for what they are. The sky as sky, and the earth as earth along with their blessings and atrocities. Dwelling also comes into being through the recognition of our limited existence, and therefore a recognition for the temporal dimensions of place. Recognizing the fourfold through a temporal perspective is important to the making of place as it prevents place from becoming a mere nostalgic snapshot. Instead, it presents us with a better understanding, and reveals the changes of the sky, landforms, and ecologies.

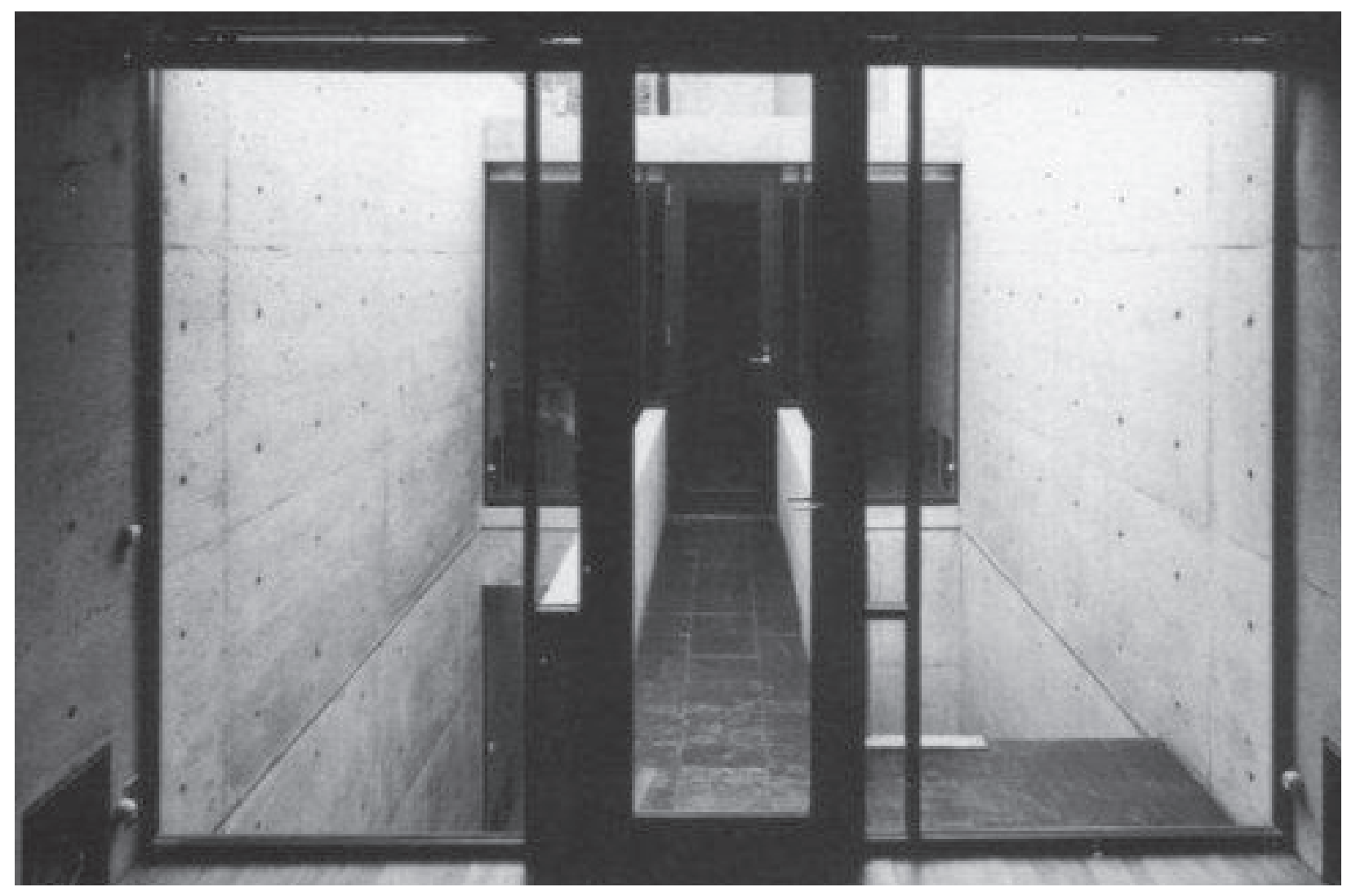

2.2: The Courtyard in the Azuma Row House. 
Tadao Ando expresses these ephemeral qualities in the Azuma Row House in Sumiyoshi. The house features a narrow courtyard that plays with changes in the wind and light. The house challenges the idea of everyday life and our coexistence with nature, despite the building's urban location. To get to the other side of the home, one must pass through the courtyard, experiencing changes in environment, whether rain, wind, or sun. The house does not give priority to convenience, but to the connection with weather. 


\subsection{THE BRIDGE}

As an intangible concept, how might the fourfold relate to physical building? Heidegger uses a bridge, explaining that the bridge is more than just its physical qualities; it is a thing which gathers the fourfold. The foundations of the bridge are rooted in the earth, its structure reaches towards the sky, and the path of mortals over the bridge sits between the two realms. A bridge gathers the banks of a body of water. Through gathering, a particular relationship between the two banks is formed and place is experienced as meaningful. "The bridge lets the stream run its course and at the same time grants mortals their way, so that they may come and go from shore to shore" (Sharr, 2007, pg.47). The place does not exist before the bridge, but rather comes into existence through its construction. Through building, the bridge is not just a physical entity, but an event in itself.

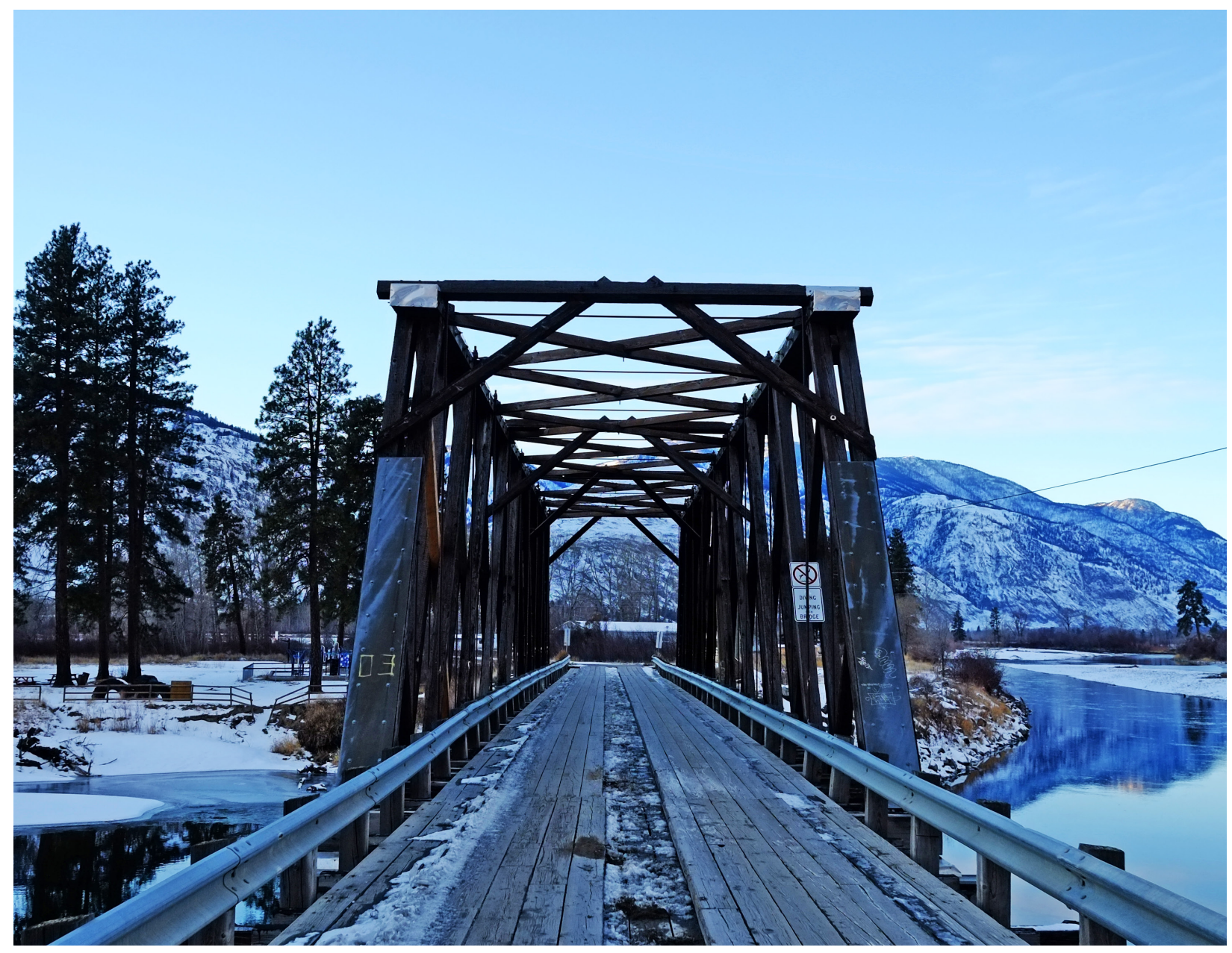

2.3: A Trestle Bridge in the Okanagan Valley. 
Not all building is dwelling however. In contrast, a hydro plant may be considered anti-fourfold. "The hydroelectric plant is not built into the Rhine River as was the old wooden bridge that joined bank with bank for hundreds of years. Rather the river is damned up into the power plant. What the river is now, namely a water power supplier, derives from the essence of the power station," whereas "the hydroelectric plant treats the river as merely a supply of energy to be exploited with maximum efficiency, the bridge respects the river as river, and allows it to flow on its own terms"(Rentmeester, 2016, pg. 73).

Heidegger isn't suggesting that we merely refrain from the utilization of nature for resources but rather that we consider the ways we view nature as more than just a mere entity. As Simon James stated, "perhaps what we need to foster is rather an intimacy with the natural world founded on a sensuous, bodily appreciation of things" (James, 2002). An alternative may be the old windmill which generates power from wind but allows the wind to be wind. "In dwelling, one respects the ways in which beings naturally unfold and still uses them as resources" (Rentmeester, 2016, pg. 73).

Observing things as a standing reserve, disregards the notion of being, which is further reinforced and extended by the dynamics of the global market according to Arran Gare. From his work, Gare explains that the standing reserve mindset is legitimized by management theory, mainstream economic theory, and general science which creates a "world view of scientific (or mechanistic) materialism" (Gare, 2004, pg.3). Through this framework, even the highest of art forms from the cultural industry are commodified. The same goes for tourism, where any particular place that shows any signs of authentic dwelling, quickly becomes marketed to attract the tourist dollar.

In this case, the use of terroir as a marketing tool in many wine regions today risks becoming a mere attraction, used to label place as authentic, rather than focus on the real qualities of the land. This does not mean terroir has to be limited to marketing schemes. According to Steve Charters, "It has been suggested that terroir is becoming increasingly important in an age of globalization as a counter movement, patrimonialization' develops" (Charters, 2008 pg. 107). Patrimonialization of place in a viticultural setting suggests that a place's local heritage, including agricultural products such as food and wine, are worth defending. This is instilled in those that cultivate the land, dedicated consumers, environmentalists, and other high involvement participants. Yet, the question still stands as to how the tourist; one who is susceptible to the experience of a superficial landscape, and to only taking in the gross forms and qualities of place, can become engaged in the notion of terroir. 


\subsection{TOURISTS AND DWELLING}

David Harvey defines dwelling in terms of "repeated encounters with places" and a connection with nature "deepened by time," and "qualified by memory" ( Harvey, 1996, as cited in Foley, 2016, pg. 141). Thus for Harvey, dwelling is perhaps connected with the local and with home. To be sedentary is to associate with place. Yet, tourists as mobile actors often do the exact opposite in order to experience the authentic place. Their visits are often short-lived and thus "being a tourist has been fundamentally connected to the idea of being on the move without deep attachment to any one place" (Mclntyre, 2006, pg. 145). Can tourists dwell? Can architecture be a catalyst for experiencing the authentic place?

At the moment, the marketing of architecture and landscape as a tourist destination seeks an international audience, and therefore its terroir becomes generalized. "We "travel" forward in time to places only known through visual images, experiencing in one's imagination in advance what we imagine the atmosphere of place to be" (Chambers, 2007, pg. x). We move quickly through prescribed hot spots and attractions. As globalized society becomes increasingly mobile, the idea of home may change to include multiple locations for one person. Through the regular occurrence of visiting specific places, one grows an attachment for them.

Catherine Palmer takes a stance in opposition to sedentary dwelling, stating that "dwelling should be set free from its association with stasis and the idea of living for long periods of time in one place, what anthropologists refer to as sedentism, and re-conceptualized as a holistic expression of human existence" (Palmer, 2018). In a world where it is increasingly hard to avoid the modern ways of life, Palmer's statement is perhaps an important consideration in contemporary architecture, as place itself is not so much fixed or sedentary "but is itself implicated within complex networks by which hosts, guests, buildings, objects, and machines are contingently brought together so as to enable contingently certain tourist performances in certain places at certain times" (Chambers, 2007, pg. x).

Place is expressed through temporality and the constant change of people and the activities that happen within these settings. Place changes hourly, daily, weekly, yearly; it is this temporality that gives place a sense of place. In this sense, an architecture of place is perhaps not one that is envisioned as a static artifact but something that facilities the dynamic processes/ activities of place and landscape; one that changes with its people and environment over time.

An example of tourist activity that encompasses dwelling, building, and place is camping. As Charlie Hailey states, "camping practices remind us that our places, our built environments, our homes are being made, constructed, and always coming. The resolute incompleteness of camping parallels our immersion in process." In a way camping is building, it is "baven", It is a process of placemaking where one dwells by "siting, clearing, making and breaking" (Hailey, 2008, pg.229). The process of camping is not like conventional building where one levels or excavates the ground for a foundation. Camping is an architecture of duration and place, that instead negotiates the terroir. The contour, the texture of the soil, its firmness, and other geo- 
graphical characteristics makes negotiating the ground a part of siting when setting up camp.

Hailey refers to camping as "an architecture of the unfinished"(2008, pg.59). Its incompleteness does not imply a lack of organization, rather many architectural possibilities, and the opportunity to dwell. This could apply to a tent, an trailer, or a bunkie, but is not limited to these typologies. The transient nature of dwelling and camping correlates with Heidegger's example of the truck driver. "The truck driver is at home on the highway, but he does not have his lodgings there" (Heidegger, 2010, pg. 347). Dwelling can happen regardless of structure, whether permanent or temporary, just like housing may provide accommodation, but is not in itself a guarantee for dwelling (Heidegger, 2010, pg. 348). 
"A place owes its character to the experience it affords to those who spend time there - to the sights, sounds and indeed smells that constitute its specific ambience. And these, in turn, depend on the kinds of activities in which its inhabitants engage. It is from this relational context of people's engagement with the world, in the business of dwelling, that each place draws its unique significance."

(Ingold, 2011, pg. 192) 


\subsection{THE TASKSCAPE}

As described by Heidegger and Hailey, activities often take precedence over physical characteristics in place association. They are vital to the understanding of our environment, preserving and sparing of the earth. When describing an event or activity we often refer to it as "taking place," and thus associate place with activity, much in the same way architect Bernard Tschumi observes that architecture is not "a passive object of contemplation" rather it should be something articulated as "place that confronts spaces and actions" (Tschumi, 1994, pg.141). In Tschumi's work, his architecture becomes the discourse of events. He states "I have always felt, as an architect, that it was more exciting to be designing conditions for events than to be conditioning designs," expressing a desire to accommodate dwelling, and understanding it as an action that establishes place rather than merely creating prescribed space (Tschumi, 2000, pg.ix).

In the same way that Tschumi sees architecture as a place that confronts space and action, the social anthropologist Tim Ingold coined the term "Taskscape" to visualize a place of dwelling activities. Ingold states, "just as the landscape is an array of related features, so - by analogy - the taskscape is an array of related activities..... the taskscape is to labor as the landscape is to land", expressing the dynamic qualities that are physical, quantitative, qualitative, and heterogeneous (Ingold, 2011 , pg.195). "Tasks are the constitutive acts of dwelling," the taskscape only exists as long as people are engaged in the activities of dwelling (2011, pg.195). "Dwelling cannot be happily represented or understood in terms of a fixed gaze upon a framed landscape. Rather it should suggest an embodied practiced, contextualized experience within that landscape" (Cloke \& Jones, 2001, pg.664). If the landscape is the material phenomena of earth and sky, and the taskscape is the immaterial phenomena of mortals and divinities, an architecture of terroir is perhaps that, which embodies a holistic view of these elements.

Tomas Wikström states architecture "does not achieve full magnitude until it is taken into use. Architecture is not "realized" until it becomes part of the taskscape of those who have reasons to employ its potential" (Wikström, n.d.). The importance of dwelling in the landscape is that we perceive temporality through our engagement with it; not as spectators, but as participants through the performance of tasks. As a result, we cannot view the landscape's terroir as an object if we are to understand it. The landscape is living and constantly changing form. Therefore architecture may approach the landscape's ephemeral qualities by creating a place where people are not spectators but instead participants. 


\subsection{OVERVIEW}

Heidegger and Ingold's relevance to architectural terroir is that their work investigates the connection between human and earth, and the act of dwelling and task, which contribute to one's understanding of place. Furthermore, their philosophy lingers in the architectural realm, as we dwell through building, and through making, much like the winemaker comes to know terroir through the tilling of the soil and the cultivating of the vine. Such intimate connections act as a foundation for which to guide an architectural direction, but also gives one a general idea of the overarching concepts of place, and terroir's importance in them.

The taskscape and dwelling are useful concepts for setting an architectural framework, however, a terroir perspective was selected for this thesis. The reason being that dwelling has connotations purely in locality, favoring more traditional ways of being, and often romanticizing more rural areas over others. Terroir, although a concept that recognizes its roots in the local landscape, extends beyond the boundaries of territory to include the flows of people, consumer trends, climate, and its impacts on the local landscape. It thus recognizes external forces of globalization in a holistic manner and considers the issues of our time. Furthermore, terroir puts emphasis on more than just the visual experience of place but includes other sensory experiences such as taste and smell, suggesting an enhanced sensory experience unique to a particular site. Finally, like the taskscape, "terroir offers a theory of how people and place, cultural tradition and landscape ecology, are mutually constituted over time" (Paxson, 2010, pg.444). It focuses on people and the productive qualities of landscape which help realize the earth as the "serving bearer" which "rises up into plant and animal" (Heidegger, 1951). In this sense terroir represents "the earth considered from the point of view of agriculture", and thus the following section looks at terroir from the winemaker's perspective and its etymological origins so to further narrow its polysemous nature (Larousse, as cited in Trubek, 2008, pg.73). 


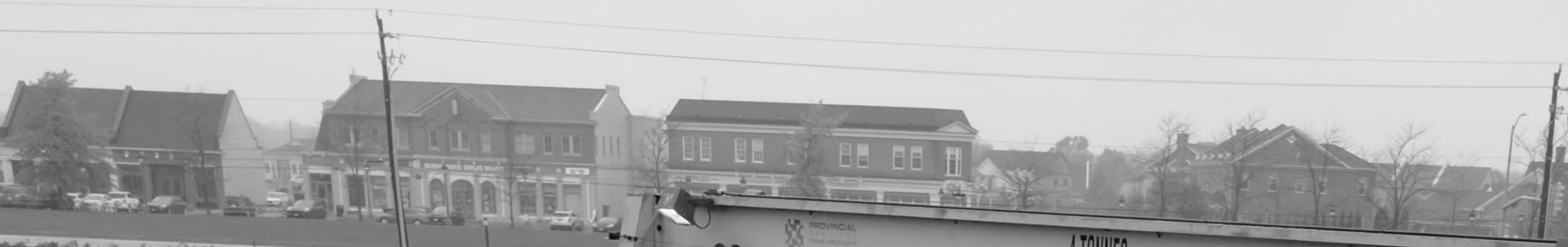

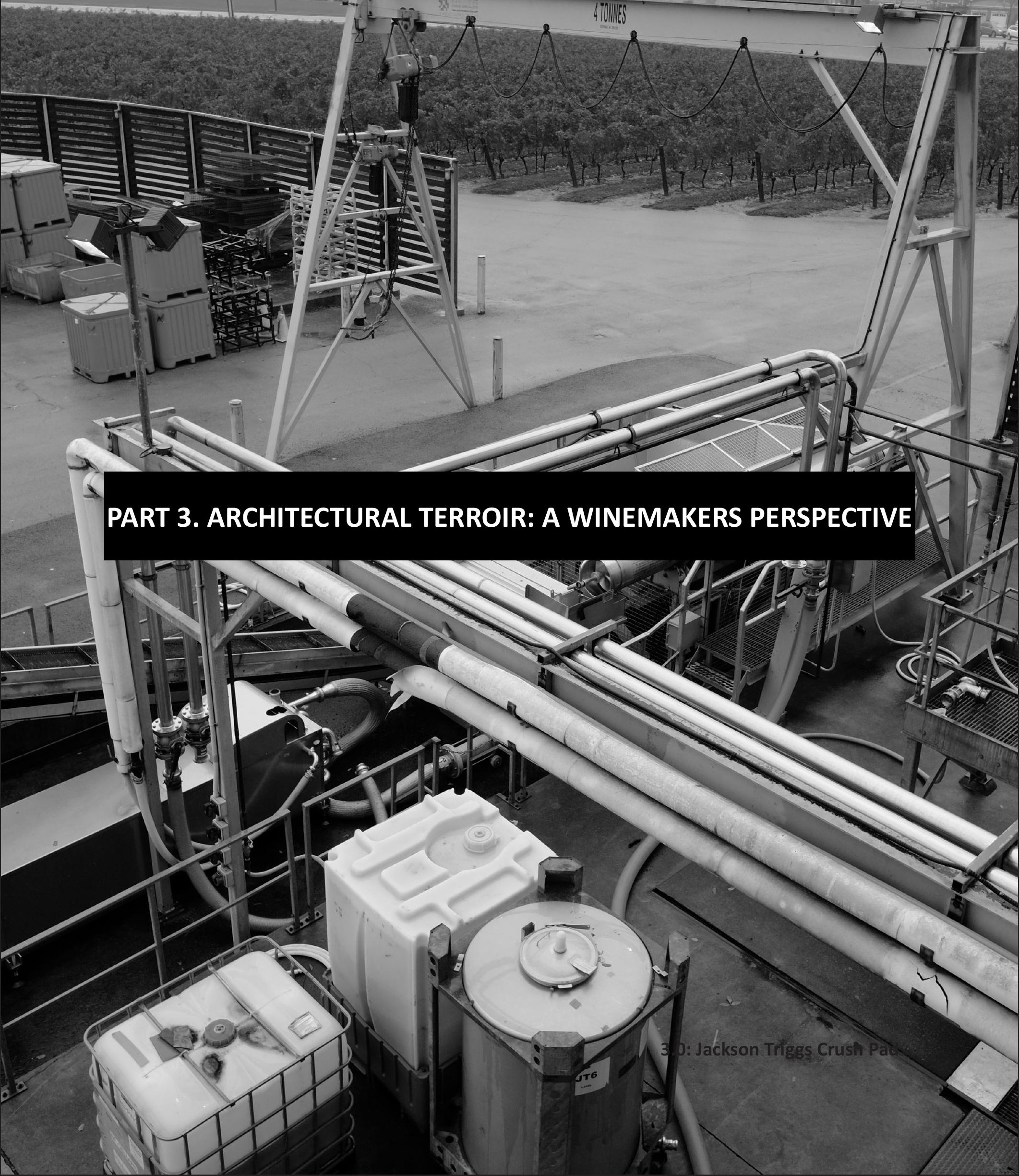




\subsection{AN INTRODUCTION TO WINERIES}

Wineries emerged as an appropriate typology to test the creation of a "terroirchitecture" following architectural strategies of place. The winery is a place that gathers the fourfold, earth, sky, mortals, and divinities, where the winemaker's craft is its own form of dwelling, where those that visit, and those who work the land build an intimate connection with it, where the pragmatic and poetic qualities of place flourish, and where the grapevine stands proudly as a product of the earth and sky. Architect Scott Johnson states that "winemaking has archaic references and an immediate attachment to the earth - it's a basic process with many subtle variations. It's a perfect program for architecture, like religion - an opportunity to create something that lifts the spirits as well as serving practical needs" (Johnson as cited in Webb, 2005, pg.7).

Historically, architecture was merely a tool used to house the winemaker and facilitate the production of wine, thus dwelling in the vineyard was an act limited to the winemaker. Winemaking activities were often relegated to agrarian structures that were not purpose built, but had their own vernacular language, responding to the environmental and geological conditions of the site. It wasn't until 1525 that the first purpose built structure, famously known as Château Haut-Brion at Pessac, was constructed (Polo, 2001). However, in recent decades the growth of wine tourism, as a result of globalization, has shifted winery design from purely utilitarian structures to unorthodox buildings, featuring additional program to accommodate the tourist and the marketing of authentic visitor experiences. "Architecture thus became an agent for the narration of terroir and an instrument for increased profit margins" but has never really integrated the notion of terroir past visual phenomena (Harvey, 2014, pg.423). In an attempt to attract visitors, some wineries have chosen to express high-tech innovations, showcasing new advancements in the wine world, while others have taken a purely regional stance in opposition, often interpreted as "rustic" or "traditional". This bifurcation has presented two extremes in the cultural and natural landscapes of the wine world; one striving for global recognition, and the other for locality and romanticism.

While it is important that terroir and geographical specificities of place be maintained, global tendencies cannot be ignored and remain a crucial component within local contexts. "Upholding uniquely one extreme, if unchecked and unbalanced, has profound consequences for the built world: we risk homogenized human landscapes if only global values are pushed, factionalism and provincialism if only local values are prioritized" (Martin-McAuliffe, 2016, pg. 30). To find balance between these two realms, an architecture of terroir should acknowledge the earth from which it originates but also recognize that globalization is very much a part of the modern day landscape. The current dichotomy between wineries with high-tech innovation, and those with traditional values rooted in soil, can be seen in the heavily contested debate between the realm of the new (global oriented) and old wine world (terroir oriented). Although the lines are becoming increasingly blurred between terroir and technology in contemporary winemaking, architecture has been slow to combine the two realms. 


\subsection{NEW WORLD WINE AND A RETURN TO TERROIR}

The most recent growth in wine-related tourism and leisure has led to the transformation of both cultures and territories. As new world wines begin to grow through marketing, technology, and branding, wine has become less dependent on geography, and more dependent on image, leading many winemakers, to reconsider the notion of terroir. In order to provide visitors with a product and experience unique to place, some wineries have begun to market their wines as single-varietal, rather than blended, in an attempt to regain a regional identity expressive of their soil.

Old world wine refers to wine made in established areas with a history in viticulture, such as France, Austria, and parts of the Middle East. Through centuries of cultivation and knowledge passed down through generations, the old world has a layered history and an intimate knowledge of the land. In the old world, terroir is expressed as naturally as possible, and a sense of place is emphasized in both product and architecture; thus the wines that come from the old world are often regarded as "terroir wines" (Seguin, 2006, pg. 3). These are wines which claim a specific geographical location and are expressive of the soil and climate from which they originate. "Three centuries ago, a consumer who enjoyed a bottle of Lafite could visit the vines which produced the fruit, know when the wine was made and bottled and meet the people involved in its production" (Seguin, 2006, pg. 3).

New world wine refers to wine made in countries which have more recently established viticultural practices. Some examples include Ontario's Niagara Region in Canada, California's Napa Valley in the USA, or New Zealand's Marlborough region. In the new world, there is less emphasis on traditional methods and more focus on technological innovation. Experimentation is encouraged and methods of production vary drastically. Here, terroir is not as central to the driving force behind wines, and the wines that come from the new world are commonly labeled as "branded wines" (Seguin, 2006, pg. 3). As many of the new wine regions are unknown to those outside the local area, sommeliers rely on marketing, branding, and standardization of wine products which appeal to a global demographic, making the traceable origins of a wine much more difficult.

New and old worlds exemplify different philosophies in regards to terroir, yet as the new world begins to achieve maturity and confidence in their soil, and the old world gradually inherits technological innovations, their dichotomy becomes blurred. It is a much needed balance that considers the locality of place and the global era in which we live. Recently, an architectural culture grounded in both realms has begun to grow, guiding the direction for terroirchitecture in the modern world. 


\subsubsection{AN ARCHITECTURE OF THE OLD WORLD}

The Ames Gate Lodge by Henry Hobsen Richardson, who was regarded as one of the first truly regional American architects, is an architecture that is representative of the old world philosophy (figure 3.1)(Martin-McAuliffe, 2016). The buildings materiality and tectonics play off the history of the New England Potato; the name English farmers gave rocks which emerged in their fields as a result of intensive deforestation and topsoil erosion. The stones wreaked havoc on farm equipment and the farmers. In response, farmers would regularly clear the fields of stone, stacking them along the edge of the property. These piles of stone eventually formed walls creating a significant mark on the New England Landscape only after a century of colonial settlement (figure 3.2).

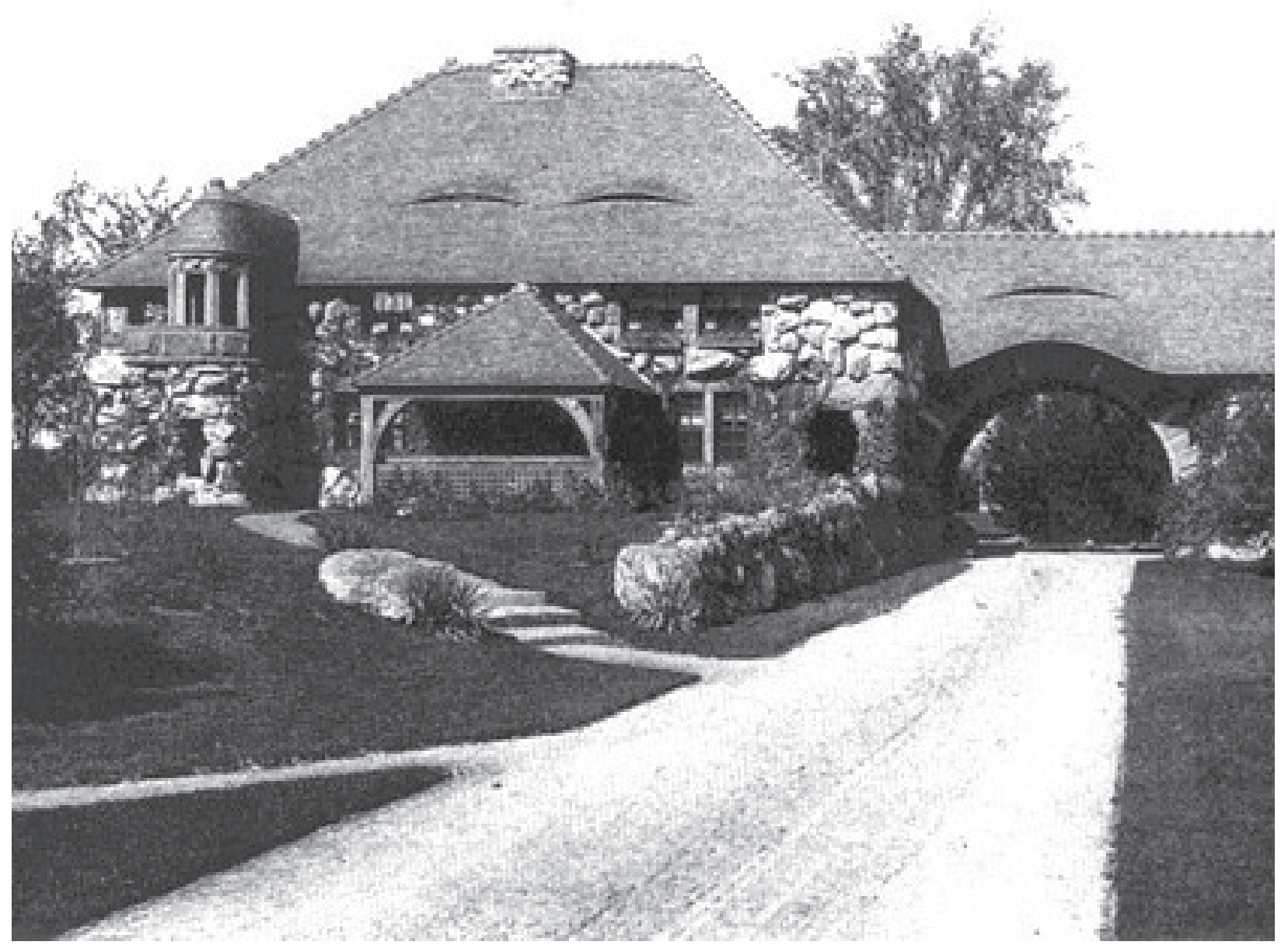

3.1: Ames Gate Lodge. 
Overtime, the stone walls took on new meaning, becoming a symbol of wealth. Stones were used to construct homes and other structures. Creating a take on the ubiquitous New England stonewall, Richardson implemented stones evocative of the glacial remains on the surrounding site, grounding the Ames Gated lodge in place. It is one example that Martin-McAuliffe refers to as "terroirchitecture", a building representative of a time and place with roots traceable to the geological processes of its site (Martin-McAuliffe, 2016).

\subsubsection{AN ARCHITECTURE OF THE NEW WORLD}

Like architecture, wine is not exempt from the forces of globalization. In many parts of the world, winemaking has shifted from the hands of local vintners to what Martin-McAuliffe calls the "Alchemists". Alchemists produce wine with predictable results, standardized to meet commercial expectations that are pleasurable to the mass market known as branded wines. Blends come from remote parts of the world and are heavily worked to meet a desired outcome predicted by surveys and popular demand. Martin-McAuliffe refers to this wine as " 'alchemi-

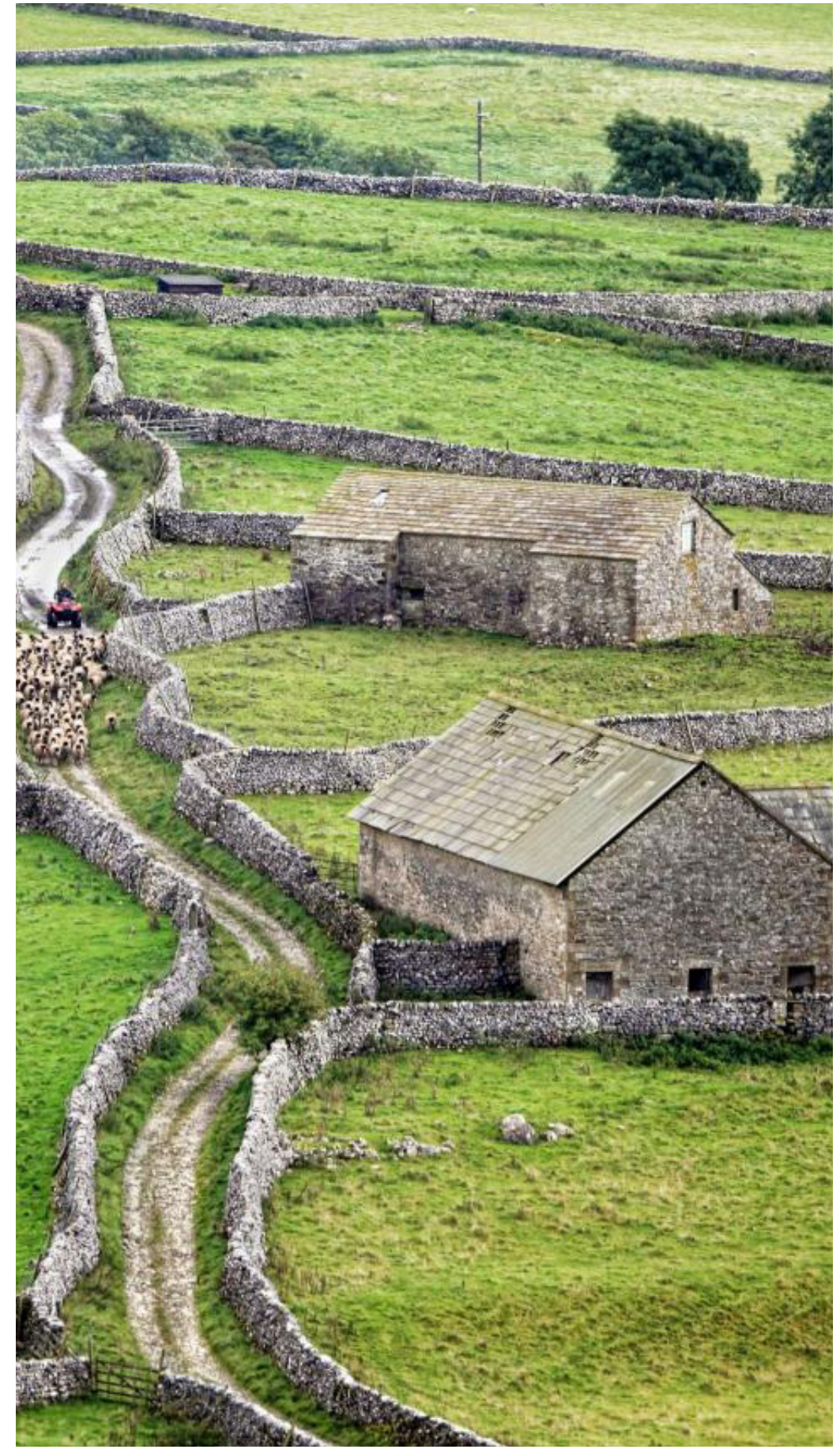

3.2: Dry Stone Walls in the Yorkshire Countryside. 
cal' because it captures this heavy-handed type of winemaking, wherein technology obfuscates any traceable semblance of specific environmental qualities" (Martin-McAuliffe, 2016, pg. 27). The qualities inherent to a specific grape varietal are lost as a result, and so are the characteristics of place from which the grape originated.

If we take the Ames Gate Lodge as the embodiment of terroir driven wine, then the suburban stone wall is perhaps the alchemical equivalent of architectural terroir. The suburban stone wall (figure 3.3) is representative of the current dilemma around traceability and place. In many cases the wall is not actually stone, but is instead a veneer, composed of rubber or plastic to look like stone. Lacking locality, the implementation of these constructions are standardized, and a generic design language takes over. In the context of gastronomy, the suburban wall would be the equivalent of a block of dehydrated supermarket cheese, the outcome of production techniques that have no tie to tradition or place, but are instead implemented to meet market demands for a longer shelf life and economic feasibility.

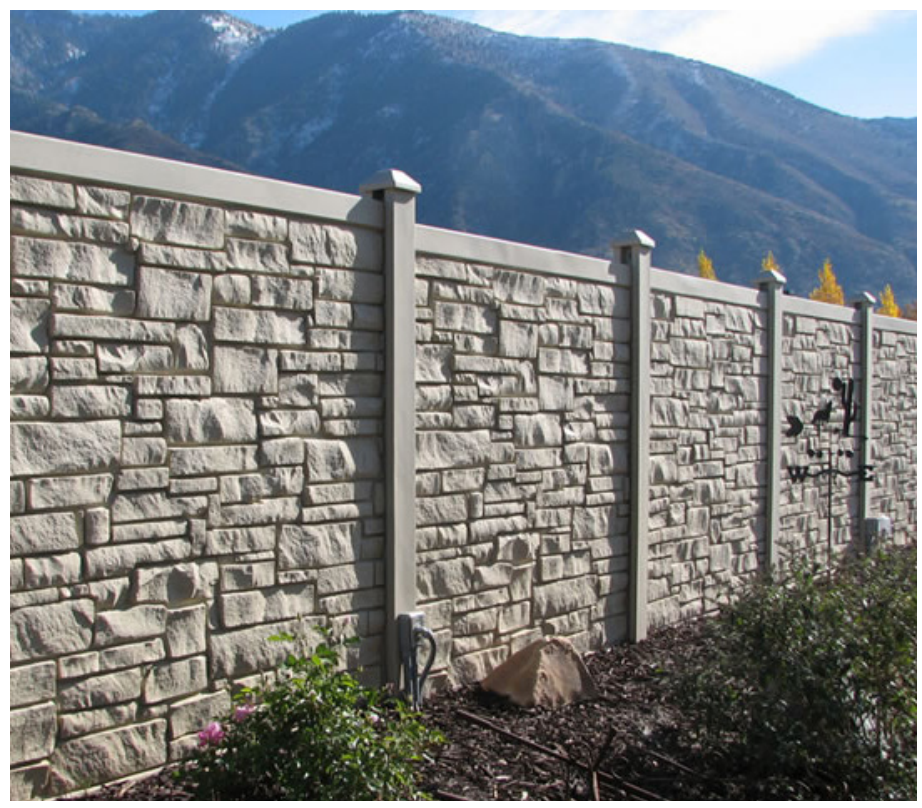

Figure 3.3: Faux Stone Wall. 


\subsubsection{BLURRING BOUNDARIES}

The Dominus Winery by Herzog and Demuron in California's Napa Valley is an example of winery architecture in the new world that takes inspiration from both terroir and advancements in technology, expressing a global language, while acknowledging terroir. It is a change from the neo-traditional forms of architecture in the new world which often end up as cultural reproductions of places in the old world.

The building features a rational geometry encased with gabion walls that are filled with darkgreen basalt stones, sourced from a nearby canyon (No.15: The Dominus Winery, 2009). The loose fitting stones allow for air and light to pass through and helps the structure to dissolve into the vineyard. The gabions, common in infrastructural projects throughout the world, nod to the fact that the wine industry, although inextricably linked to terroir, is very much a part of the global market. The Dominus winery "evinces the complexity of our contemporary built environment and the frequent collusion of local and global forces present" (Martin-McAuliffe, 2016, pg.34).
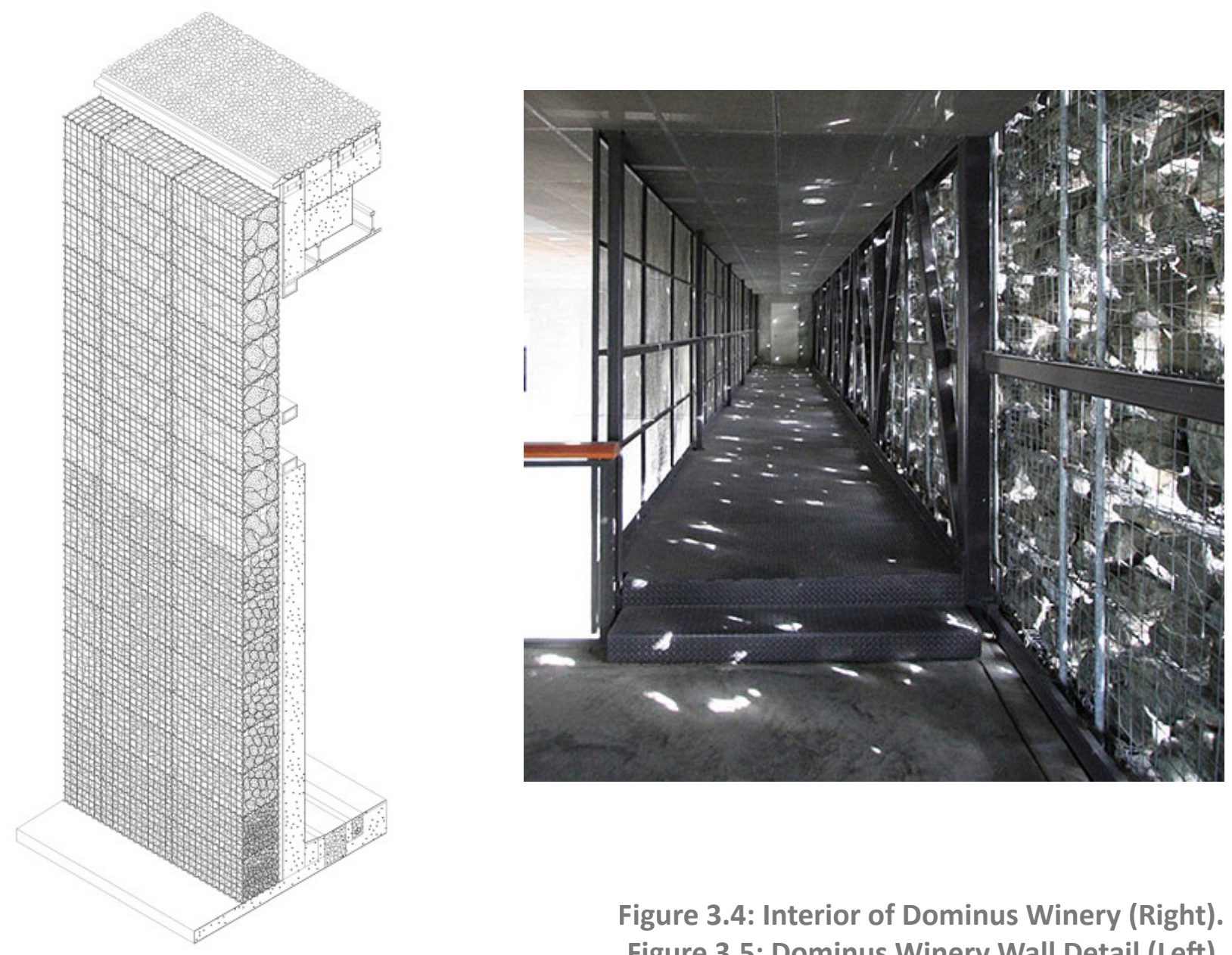

Figure 3.4: Interior of Dominus Winery (Right). Figure 3.5: Dominus Winery Wall Detail (Left). 
"Soil is the land in hand, a specific place. Soil embodies the meeting, is the meat of weather and rock; remembers them into trees and kingfishers, salamanders and salal."

(Tom Jay, pg.3) 


\subsection{THE TERRE OF TERROIR}

It is clear that terroir is a polysemous word, whose morphing definition has run parallel with the growth of globalization, encompassing both the physical and metaphysical characteristics of place. To express the origins of a site specific terroir, it is perhaps best to focus on the word "terre"; the French word for earth. Earth, with respect to the grapevine, is fundamental to the concept of terroir, and there is perhaps no other branch of agriculture that praises soil as enthusiastically as viticulture. The following looks to soil (terre), and its implications for the vineyard and architecture. How might the geological concepts behind terroir be expressed in an architecture of place?

"The soil becomes a substrate that contains the constitutive elements that permit the development of the vine and is the locus for multitudinous biological, physical and chemical activities" (Tomasi, 2013, pg.65). For winemakers, the soil is said to influence the sensory experience of a final product. It can be measured, felt, tilled, and smelled. A good wine proclaims a sense of place through taste and smell which is attributed to the soil in which it grows. Soil is symbolic of time and place; it is as Bazzoffi refers to it, "a structured entity, but it is open and in continuous evolution; it is not therefore a stable, isolated material, but a fragile substance extremely sensitive to the intervention of man" (Bazzoffi et al. 2009, as cited in Tomasi, 2013, pg.65). Terroir exists regardless of human factors, however "left uncultivated, the best soil is no different to poor soil" (Schuilenberg, 2011, pg.26). Viticulture is a human activity and thus the relationship between soil and people is as important as its agronomic counterparts.

When considering a suitable site to plant grape vines, the winemaker will take into account drainage, aspect, slope, soil texture, and structure. These are some of the factors which give the wine its terroir and influence taste. To an extent, the farmer's understanding of the soil as a key component to the placement of crops, is similar to the architect's understanding of the ground as a key component to how one situates a building.

\subsubsection{SLOPE: Topogenesis in Architecture}

Slope, also refereed to as aspect, is a critical component of terroir. Slope provides air drainage which helps protect vines from frost damage, and determines the amount of sunlight a vine may receive. To optimize grapevine health and production, the degree of the slope is taken into consideration. Too much slope and the vineyard becomes difficult to manage with farming equipment and excessive soil erosion, too little and sunlight distribution becomes inadequate. "The best part of the slope for vineyards is the mid-slope, which is given the colloquial term of "belly," or sometimes "navel" (Wilson, 1998, pg.22). The belly is desirable as it is generally concave, trapping slope wash for nutrient rich soils and providing adequate drainage. Altitude, and aspect also influence the microclimate, contributing to variations in wine within the same agricultural plot. This is especially the case "in cool regions, where it is difficult to achieve grape ripeness" (Seguin, 2006, pg.5). 


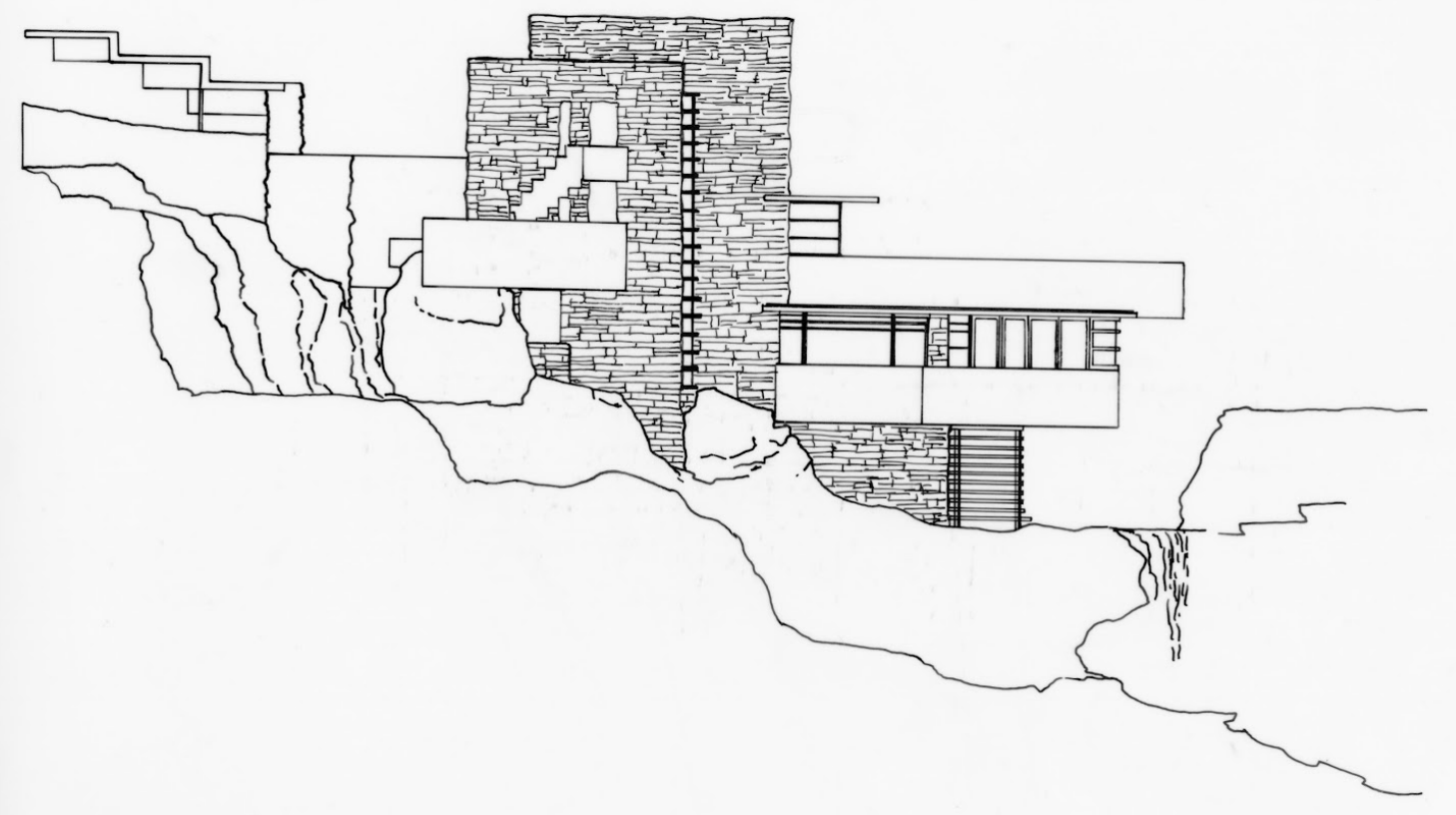

3.6: Falling Water Acknowledges the Topography of its Site. 
To be in dialogue with the slope is to understand the way in which soil interacts with gravity. "Landslides are dialogues among rain, rock, soil, building and living ...people cut into such slopes to make level ground, then build streets and houses, weighing down soil.....cutting, building, and watering are deliberate acts, but often not recognized as dialogues with slope and soil" (Spirn, 1998, pg. 39). This dialogue is expressed in the work of Frank Lloyd Wright whose low slung buildings acknowledged the horizontality of the American prairies, and whose tiered composition of Falling Water, creates a connection between the layered elements of stone. David Leatherbarrow describes Wright's architectural vision, "whereby the designer, as "emissary of the ground," would serve the site's self-manifestation, as if architecture were horticulture in stone, the architect a lithic gardener. From terrain to terrace or riverbed to plastered walls" (Leatherbarrow, 2000, pg.189). If one were to look at the ways in which Wright grounded his buildings, it would be predominantly topographical. In the case of his project "Taliesin," the "lines of the hills were the lines of the roofs" (Wright, as cited in Leatherbarrow, 2002, pg. 187), the same place where he also coordinated plans for the vineyards, and gardens in relation to the degree of the slope. In a winery, this surface relief can be translated into architectural program, aiding the flow of wine through the production process without the use of mechanical pumps.

\subsubsection{TEXTURE and STRUCTURE: A Tactile Experience of Place}

Texture and structure are terms which are closely related, but describe different physical properties of the soil. Texture describes the way the soil feels, and constitutes a percentage of clay and sand mixture which has an impact on wine composition and must, whereas structure influences a soils ability to drain and hold groundwater, either encouraging deep root penetration or restricting it. The surface texture of a soil plays a part in the success of a vineyards terroir as it influences the microclimates around grapevines. Surface has an impact on the rate at which the soil warms up, influencing the grapes ripening process. A stony soil is often desired as it is not only an indication of good soil drainage but the stones themselves also serve as reflectors, bouncing diffuse light onto the underside of the vine canopy.

Texture in architecture influences the way we visualize light and space, creating a phenomenological experience of place. To recognize the importance of texture is to recognize that a sense of place comes through a holistic experience of the senses. Whereas the scenic gaze is detached and distanced, tactile experience grounds the user in place. Texture can define space without the use of boundaries and optical texture can influence the way we visualize light in relation to materials, much in the same way texture aids the ripening of grapes by reflecting diffuse light onto the underside of its leaf canopy. 


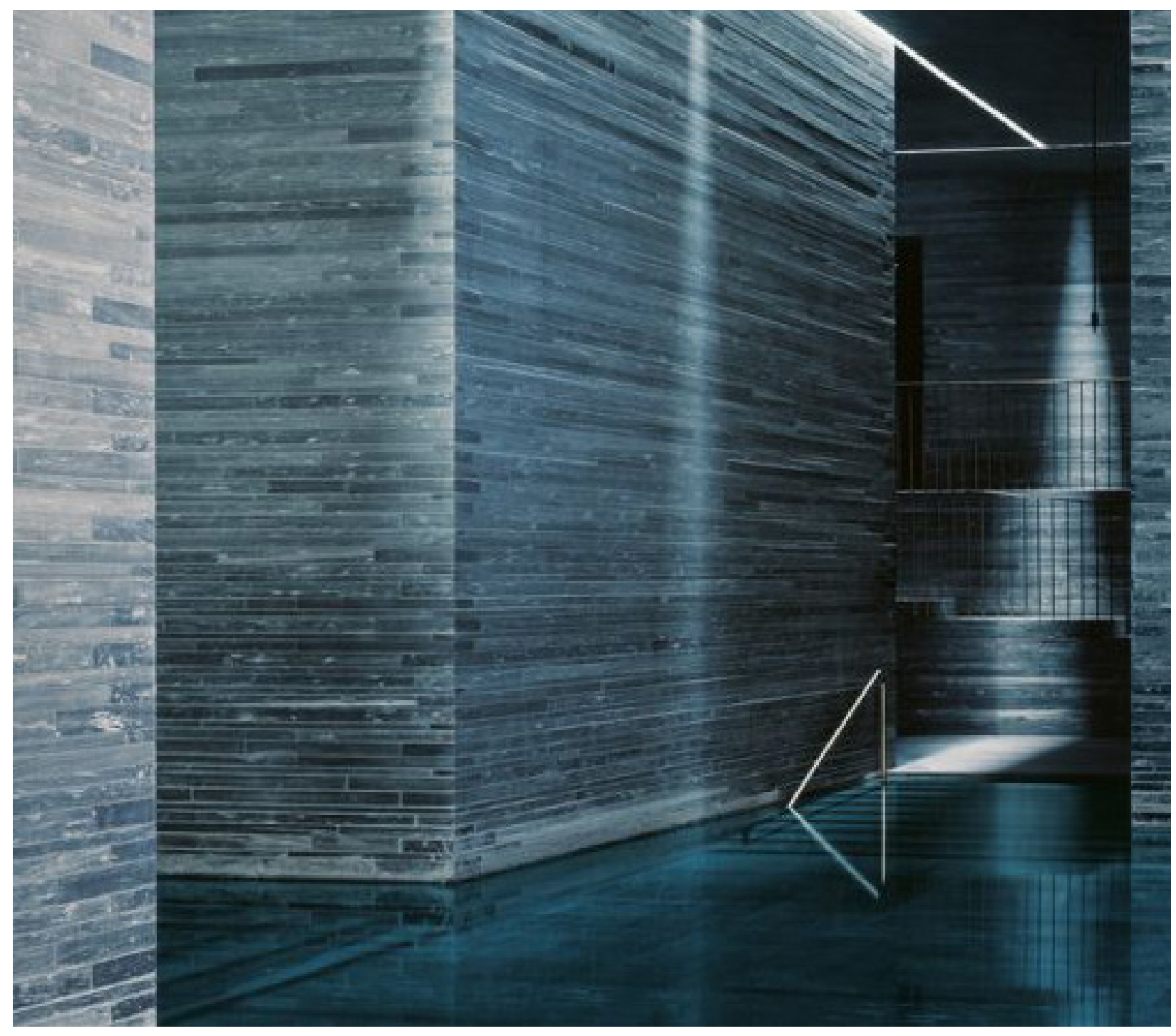

3.7: Peter Zumthor's Therme Vals. 
Peter Zumthor's Therme Vals in Switzerland exemplifies the use of optical and tactile texture by employing the use of Valser Gneiss; a stone from a local quarry which characterizes the nearby Swiss terre (Frearson, 2017). The building's form acts as an extension of the mountain on which it sits. Slicing between floor and ceiling allows light to bathe the stone walls while reflecting and refracting light into the water below. The interplay between rough and smooth as part of the Therme Vals experience is an excellent example of texture and structure in architecture, achieved through the expression of geological origins.

\subsubsection{WEATHERING: The Ephemeral Qualities of Place}

Parent material, from which the soil derives is the result of weathering. Weathering carves canyons and defines mountains, reflecting a place's geological history. It is an inevitable process for both architecture and terroir, with unpredictable outcomes, aided by surface relief, time, organisms and climate.

Leatherbarrow points out the importance of weathering, stating that "the final finishing of a building is through its interaction with the environment", and therefore the way in which it weathers is an important consideration (Leatherbarrow, as cited in Alvarez, 2009). Rather than view weathering as something that subtracts, weathering is viewed instead as a process that adds to, and characterizes architecture. Embracing the rawness of materials, void of coatings and treatments, is to appreciate its intrinsic qualities, much in the same way a good wine comes from a soil without fertilizers and chemicals.

\subsubsection{COMPOST: Decay in Architecture}

In addition to the parent material that makes up terroir, compost as a byproduct which nourishes the vine is also an important consideration. Pomace is the result of leftover grape skins and stems once grapes have been pressed and processed. "Just as cow manure is an extension of the dairy herd and belongs to the reality of the farm, so, too, pomace belongs to the vineyard and needs to find a worthwhile place as part of the winemaking process" (Nature Institute, 2015, pg.8). As a substance high in organic matter, pomace makes a desirable compost, providing the vineyard with the necessary nutrients. Unlike soluble fertilizers and nitrites which contradict the notion of terroir, "compost is taking all the living matter which is issued off the land ......it is not food, it is not an additive" (Mills, 2014, Video File).

The Sibu Pavilion, in Kuala Lumpar, by Kevin Low, exemplifies the unlikely use of compost as a building material, using soil and organic matter directly from the site. The pavilion, designed as a public toilet facility within a park, challenges the notions of what a public washroom facility can be. For most, the public washroom may be visualized as 4 walls with high windows and a door. It is typically a non-place, imposing a universal aesthetic regardless of location, yet the front of the pavilion challenges this notion using a steel mesh wall filled with compost consist- 


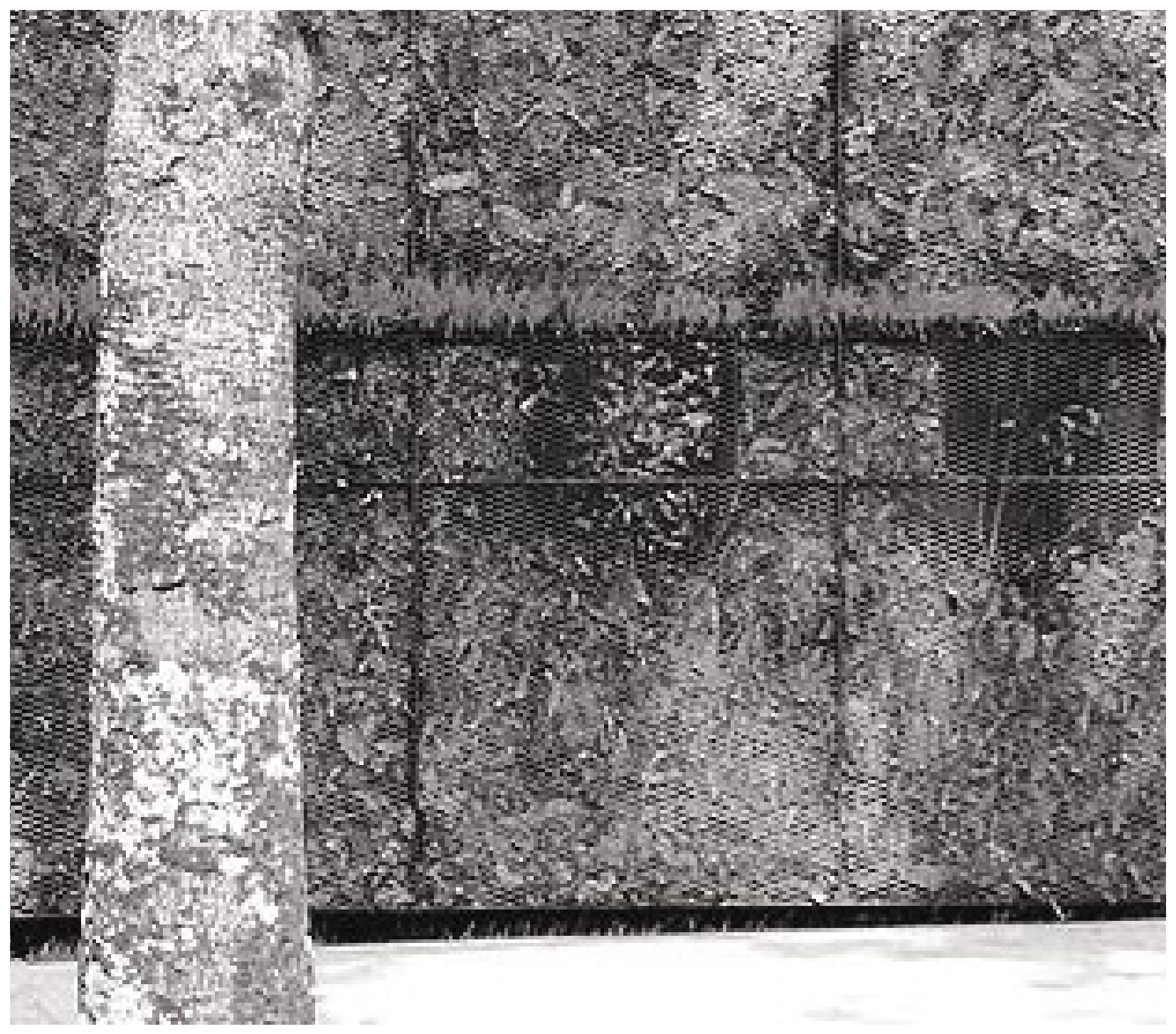

3.8: The Sibu Pavillion with Wash Basins. 
ing of dead leaves and other organic matter collected from the surrounding park. The matter provides privacy for the facilities, and the wall with built in wash basins not only functions as a place to wash hands, but as a waste receptacle for park maintenance while providing nutrients for the soil (Eba, 2013). It is an ephemeral architecture representative of the park's terroir, exemplifying decay and rebirth. 
PART 4. PRECEDENTS

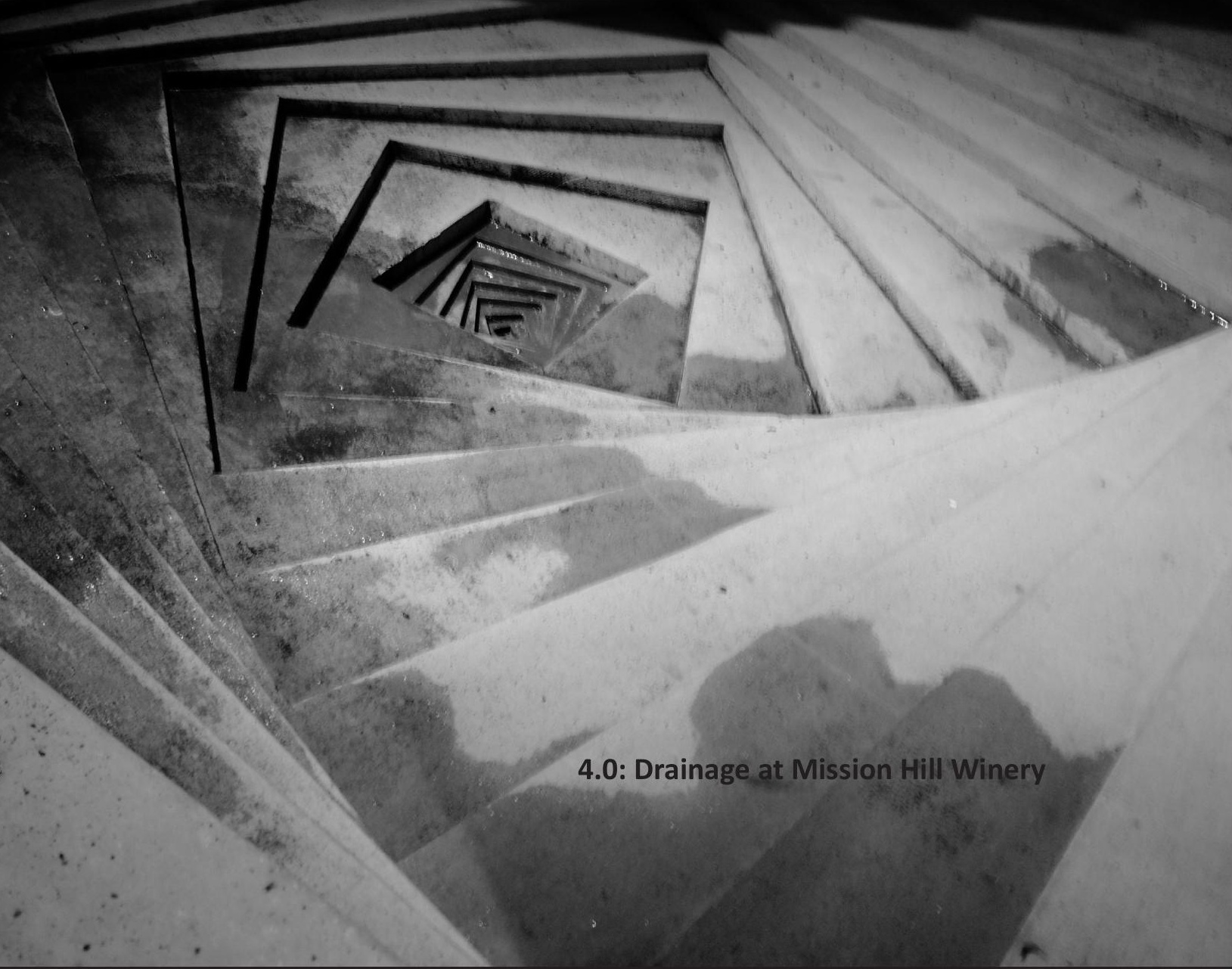




\subsection{INTRODUCTION}

Following the background research, further research was conducted within the immediate vicinity of wineries themselves. A precedent analysis started by taking a look at wineries within Canada, such as the Jackson-Triggs Winery, in the Niagara Region of Ontario, and Mission Hill Winery, in British Columbia's Okanagan Valley. Wineries were also explored on an international scale, such as Cellars Plže in the Czech Republic. As the material and immaterial phenomena of terroir can only be experienced through the physical presence of such environments, research was conducted not only online, but in person for each of the following precedents.

Questions arose, such as what are the particular qualities of this place that make it desirable/undesirable, connected/disconnected. Does one get a sense of terroir through these places? How does the architecture connect with the landscape, the geology? Does it express the temporal characteristics of place? Do these wineries embody a sense of place through the expression of terroir? 
"We try to experience nature deeply, expressing the spirit of the mountains, stony soils and a lack of water, the brightness of the sun and the clarity of the air, the shifts from heat to cold, and the changing seasons. Each site has its own features so all our wineries are different"

(Mario Yanzon, as cited in Webb, 2005, pg.82) 


\subsection{JACKSON TRIGGS WINERY}

Location: Niagra-on-the-Lake, ON, Canada

Architect: KPMB Architects

Year: 2001

Located in the Niagara region of Ontario, Jackson-Triggs Winery was designed to connect the consumer to the production process. KPMB architects were given three main objectives by the client. The building should be agrarian in nature, $\mathrm{CO}_{2}$ emissions should be minimized, and the building should reflect the conservative process of wine making (Saragosa, n.d., pg.2).

Approaching the building, these objectives are evident in the winery's agrarian features, such as the large glass barn doors that mark the entrance, structural timber, and a water feature reminiscent of a horse trough. The winery is a representation of a leap into the new wine world while still holding true to the traditional notions of terroir. It is quintessentially Canadian, reflecting the region's agricultural vernacular through its simplicity in form and use of timber.

For visitors, architectural elements are placed to draw the eye to the vineyard on the building's South side. Furthermore, the glass atrium, contrasted with the heaviness of
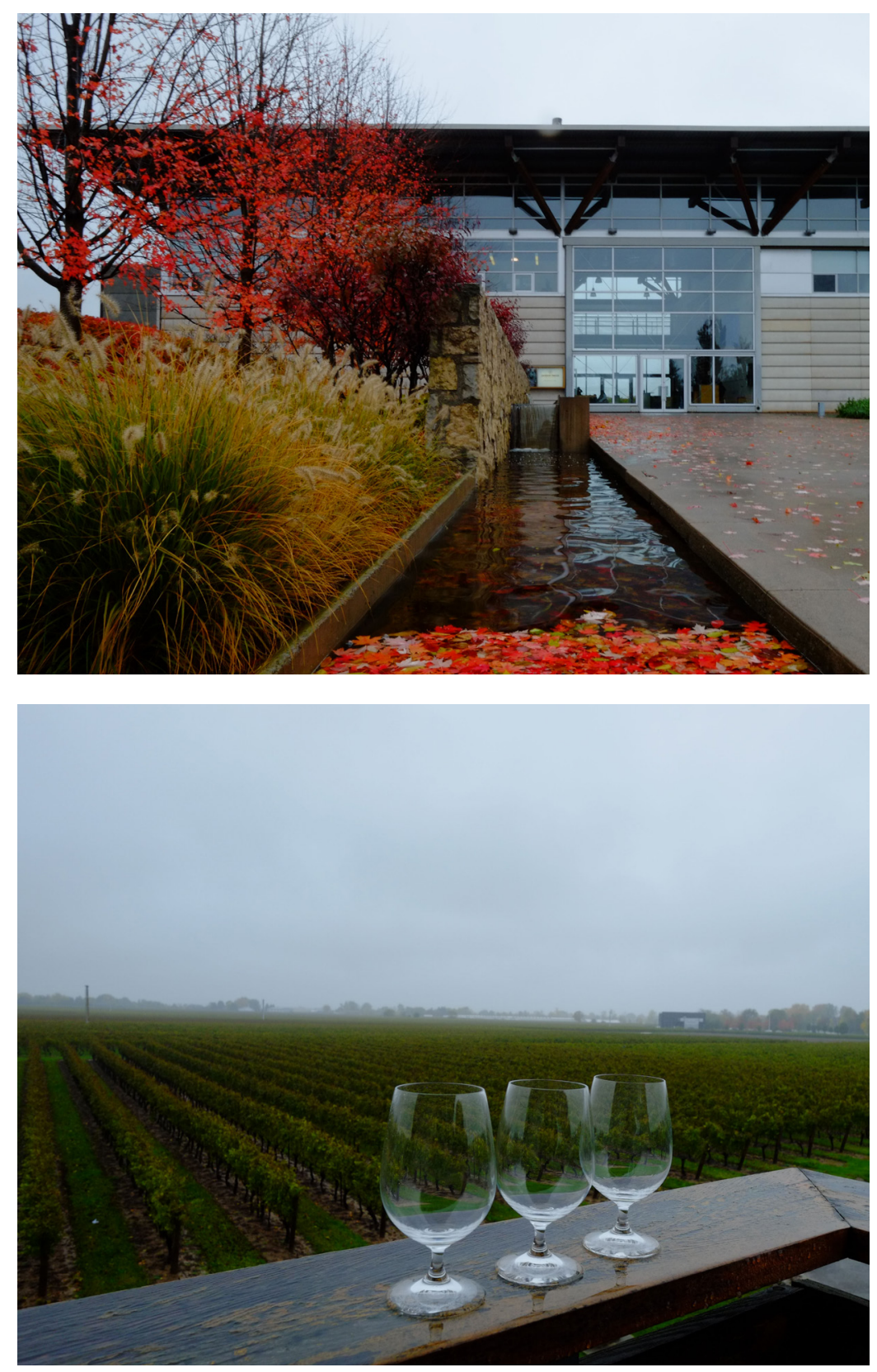

4.1: Agrarian Features Expressed in the Jackson Triggs Winery (Top). 4.2: A View From the Top of the Building's Exterior Ramp (Bottom). 

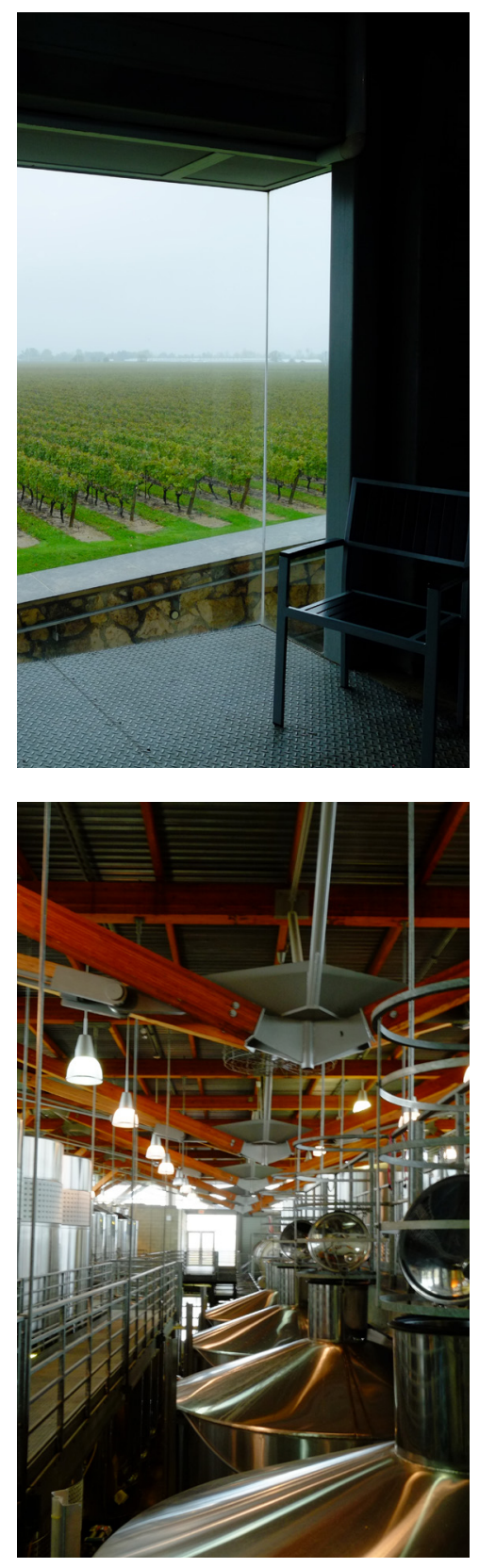

\section{3: View From Production Facility (Top).} 4.4: Production Facility (Bottom). the concrete cladding, is simple, yet effective in communicating its programmatic layout; with production to the West of the glass entrance and administrative and entertainment areas to the East.

Despite the building's monolithic size, the dimensions of its cladding create the illusion that it is much smaller than it really is (figure 4.1). Within the glass atrium one is given a direct view of the vineyard, and during the summer months the winery's glass doors slide open, blurring the separation between indoors and outdoors. Materials are presented in their raw form, consisting of wood, stone, and earthy plaster. An exterior ramp leads visitors up to the production facility where one can experience the landscape from a different perspective (figure 4.2).

Terroir was considered in the winery's siting, with the building placed to "maximize the area of arable land and to align parallel to the Niagara Escarpment and perpendicular to the north-south axis of the vineyards" (Polo, 2001). The start of the production facility begins on the West end of the building where grapes are crushed and eventually make their way to the Eastern side, where fermentation and storage takes place. The design of production facilities is considered as carefully as tasting areas, with views of the landscape, attention to tectonic expression, and a thoughtful layout, making the production process clear to those that visit (figure 4.3 and 4.4).

The Jackson-Trigss Winery is an example of architecture thats considerate of its context, rational in form, and is a sensitive example of new world architecture that holds true to its agricultural heritage. Although the main focus is not terroir, it certainly displays a connection to the land on which it sits. 


\subsection{MISSION HILL WINERY}

Location: West Kelowna, BC, Canada

Architect: Tom Kundig

Year: 2002

Mission Hill Winery, by Tom Kundig, proclaims its own sense of place despite its presence among the homogenized suburbs of West Kelowna. Located at the end of a suburban street, the winery is much larger in scale than the surrounding buildings, yet its presence is humble; so much so that its gates could be mistaken for another residence (figure 4.5). Upon entering the gates one transitions into a drastically different environment where the suburban landscape disappears and the Okanagan Lake takes precedence.

A series of thresholds create a transition between the initial moment of entrance into the parking lot, to the time one arrives at the cellar (figure 4.6). Mission Hill winery is "a place where life slows down. Deliberately, the entry gates force cars to slow their speed in order to pass through. An allée of oak trees helps transition the visitor from the hurried pace of daily life to the timeless world of winemaking" (Kundig, n.d.). According to Kundig, Mission Hill is very much about stopping
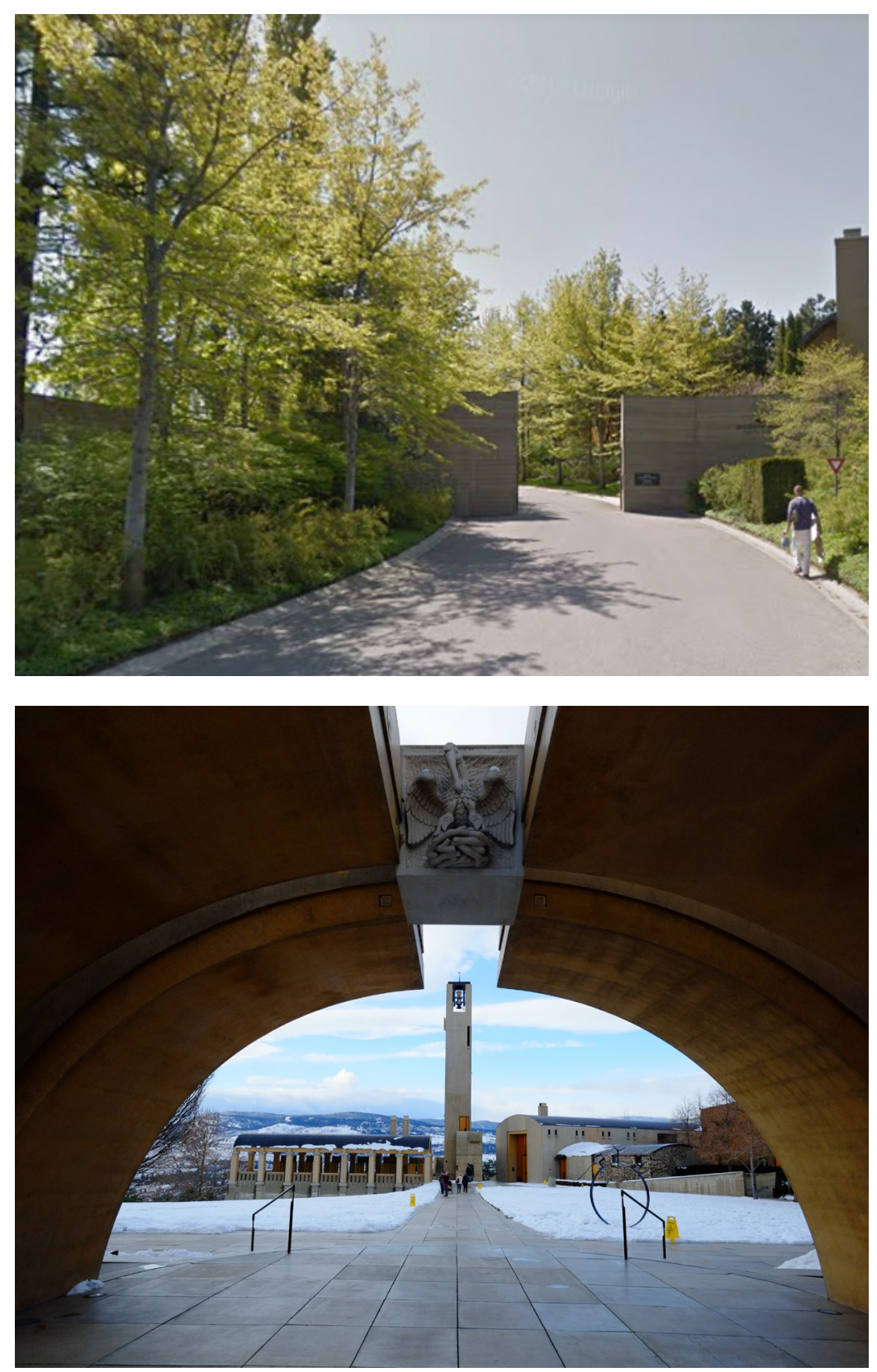

4.5: Mission Hill Entrance Gates (Top). 4.6: Threshold Into the Winery's Courtyard with Bell Tower

(Bottom). 

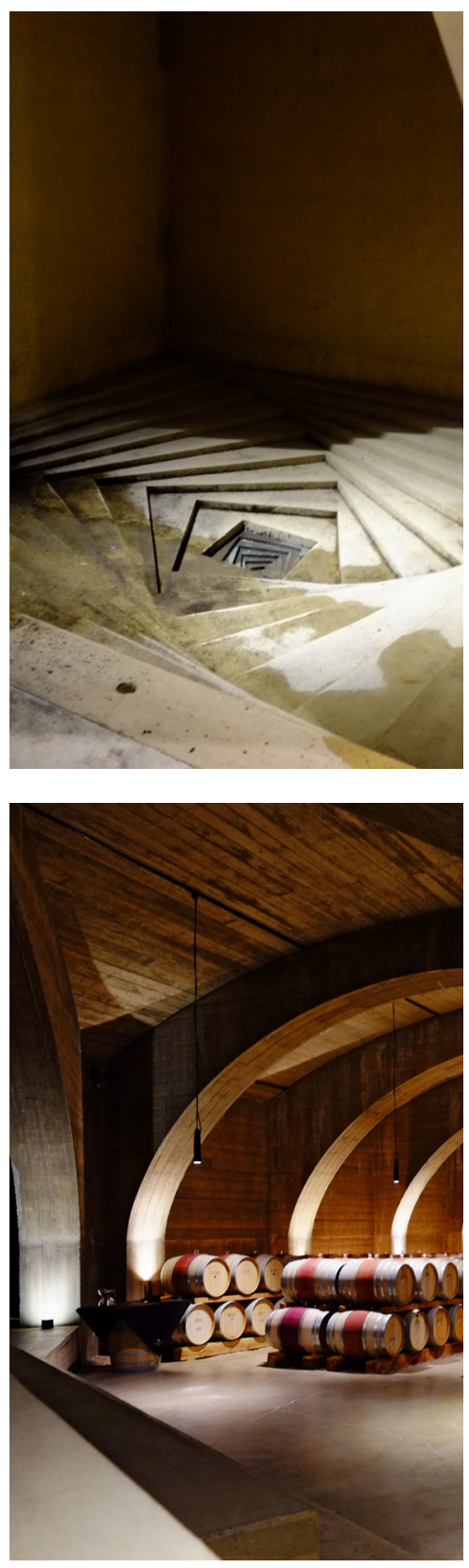

4.7: Bell Tower Drainage

(Top).

\section{8: Exposed Volcanic Rock}

(Bottom). and looking at one's surroundings, while framing views which take advantage of the landscape. "The architecture becomes second to the landscape with design work that eschews festival-like architecture in favor of a timeless, monastic quality" ("Olson Kundig - Mission Hill Family Estate", n.d.).

These Monastic qualities are reflected in the bell tower which draws guests into the winery's courtyard. Despite the heavy European influence from Kundig's childhood the winery's cellar is unmistakably a product of the Okanagan's geological heritage (figure 4.6). Descending down the bell tower into the cellar, visitors come across architectural features which embrace the soil, sunlight, and rain (figure 4.7). The cellar is blasted into volcanic rock, which classifies the terroir to the West of Okanagan Lake, and the architectural language is paired back expressing only what is necessary and essential to the space. Concrete floors offset from the volcanic rock walls, create a respectful transition between man made elements and the earth. 


\subsection{CELLARS PLŽE}

Location: South Moravia, Slovácko, Czech Republic

Architect: N/A

Year: 15th Century - Present

Although the Czech Republic is famous for its beer, it also has two bustling wine regions known as Bohemia and Moravia; with most production taking place in Moravia. As a result, Czech wine is more commonly referred to as Moravian wine.

Cellars Plže in South Moravia, features unique visual characteristics and a peculiar layout. Dating back as early as the 15th century, the wine cellars are arranged along three lanes which radiate from a small central square (figure 4.9). Each cellar is individually owned, with some featuring exterior seating areas where owner and guest can sit outside, socialize and enjoy a glass of wine during the summer months. The regularly spaced, but individually unique cellars, create a dynamic cultural landscape, where one's curiosity is aroused by its winding lanes and peculiar architecture (figure 4.10).

A layer of earth over each cellar provides favorable conditions for storing wine but also encourages visitors to venture
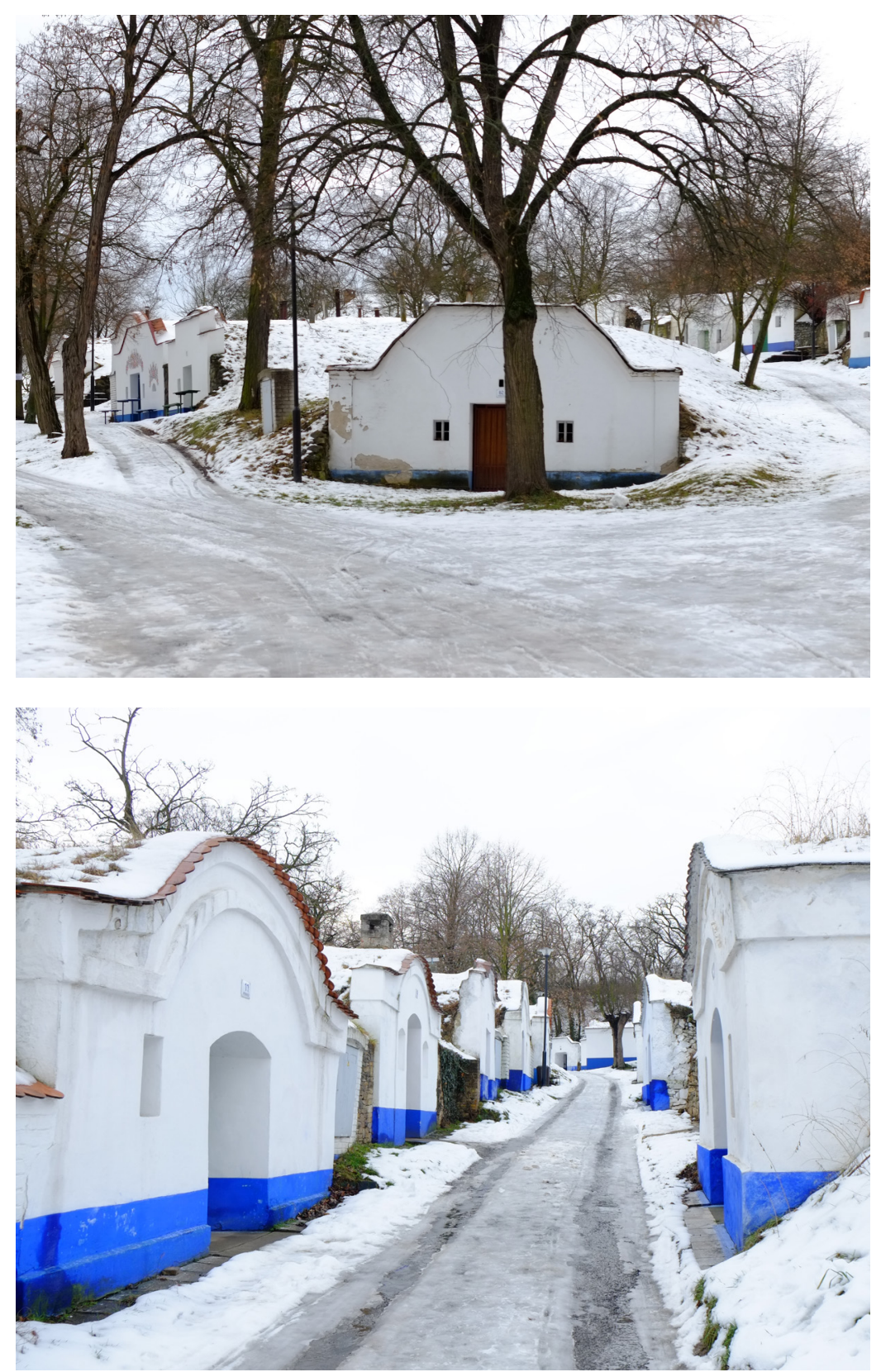

4.9: The Meeting Point of the Three Lanes (Top). 4.10: The Cellars Along the Central Lane (Bottom). 
onto the rooftops, providing a better view of their surroundings. The structures give the landscape dimension, and cellars have been added onto, renovated, replaced, or restored over the past centuries, linking the cellars to various places in time.

According to a local Winemaker the White and Blue Colors of the cellars is a common recurrence throughout the Czech Republic, indicating the buildings purpose as a wine cellar. Although the reason for this color choice remains unclear, this simple color application gives many of the cellars their Genius Loci, and attract thousands of visitors each year. 


\subsection{PERSONAL WINE CELLAR}

Location: Mackovice, South Moravia, Czech Republic

Architect: N/A

Year: N/A

In South Moravia, it is common to see a mix of personal and commercial wine cellars. These small cellars are typical of the region and belong to vintners and hobby winemakers, which are passed down through generations. They are often located in villages without a permanent residential population. In South Moravia it isn't uncommon to find 10 small professional wineries side by side within a town of less than a thousand inhabitants. The close proximity of each cellar allows for the vintner and visitors to learn from one another about the winemaking process, while experiencing social events, which often take place as result of the cellar's close proximity.

Architecturally, a common feature in each of these wine cellars is an alcove dedicated to Saint Urban of Langres, a French Bishop and Saint (figure 4.11 ). In the year 374, Saint Urban took his position as a Bishop and political turmoil followed shortly after, forcing Saint Urban to hide in a vineyard from his persecutors. The vineyard workers helped keep Urban concealed, later

developing his affinity for those in the wine industry (Urban of Langres, n.d.). Ever since, Urban has been the Patron Saint for sommeliers, and can be found within many cellars throughout South Moravia. His presence is said to help ward off frost and blight, known to plague vineyards throughout Europe. Other religious figures and small chapels dot the landscape of Mackovice, as well as other small towns within the South Moravian region; a distinct feature of the cultural landscape.

Although Saint Urban does not have a direct impact on the architecture of South Moravia (aside from the dedicated coves), he plays an important role in the people's spirit. Like religion, terroir requires faith. Despite the planning that goes into vineyards, there is no guarantee that the wine will be good, and thus Saint Urban is placed to bring well-being to the vineyards in which he resides.

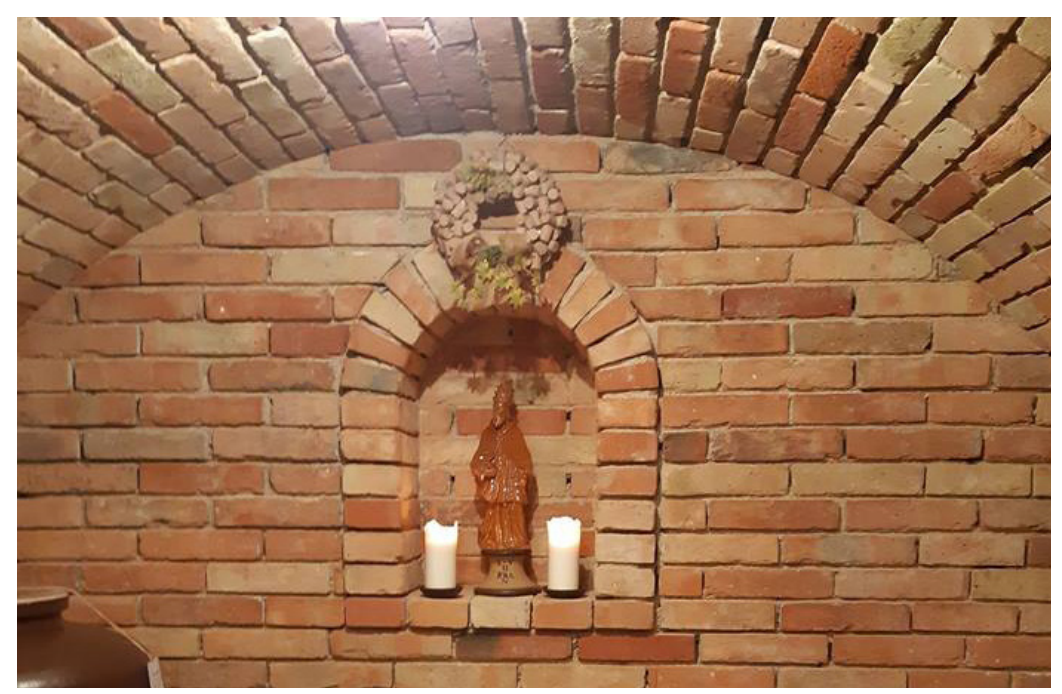

4.11: Saint Urban of Langres in a Personal Czech Wine Cellar 


\subsection{PERSONAL WINE CELLAR 2}

Location: Dolni Bojanovice, Czech Republic

Architect: N/A

Year: N/A

The architectural character of Dolni Bojanovice is humble, yet features a strong sense of place. The scattering of cellar lanes within close proximity of one another, and the human scale of streets encourages the transient and resident alike to explore by foot. Life slows down in the town of Dolni Bojanoivce and visitors often stay overnight with families and winemakers. Slow food and wine correlates with the pace of life here, and the structural language of the cellar takes a back to basics approach that is in touch with readily available materials and the land.

Pavel, the owner of this particular Wine Cellar in Dolni Bojanovice, presents guest with wine he makes himself , along with cheese from his cousin's farm. Its taste is distinct and fresh, with an assortment of food carefully selected from places near to Pavel, falling very much in line with the slow food movement. This movement goes against the standardization of culture and taste, introduced through globalization, and instead focuses on locality, place, quality, and the protection of biodi- versity, and the environment. It is as much importance to the quality of the food as terroir is to wine.

While speed is the essence of globalization, it is perhaps the slow movement which deserves a greater recognition. From the slow food movement, a series of other movements such as slow living, slow travel, and even slow architecture have emerged. This does not mean doing everything at a slow pace, but considering a place's locality and seeking to experience that place at an appropriate pace. The same principals apply for ones understanding of terroir. With the earth morphing at an unbelievable pace, we need to recover slowness more than ever to identify with place.

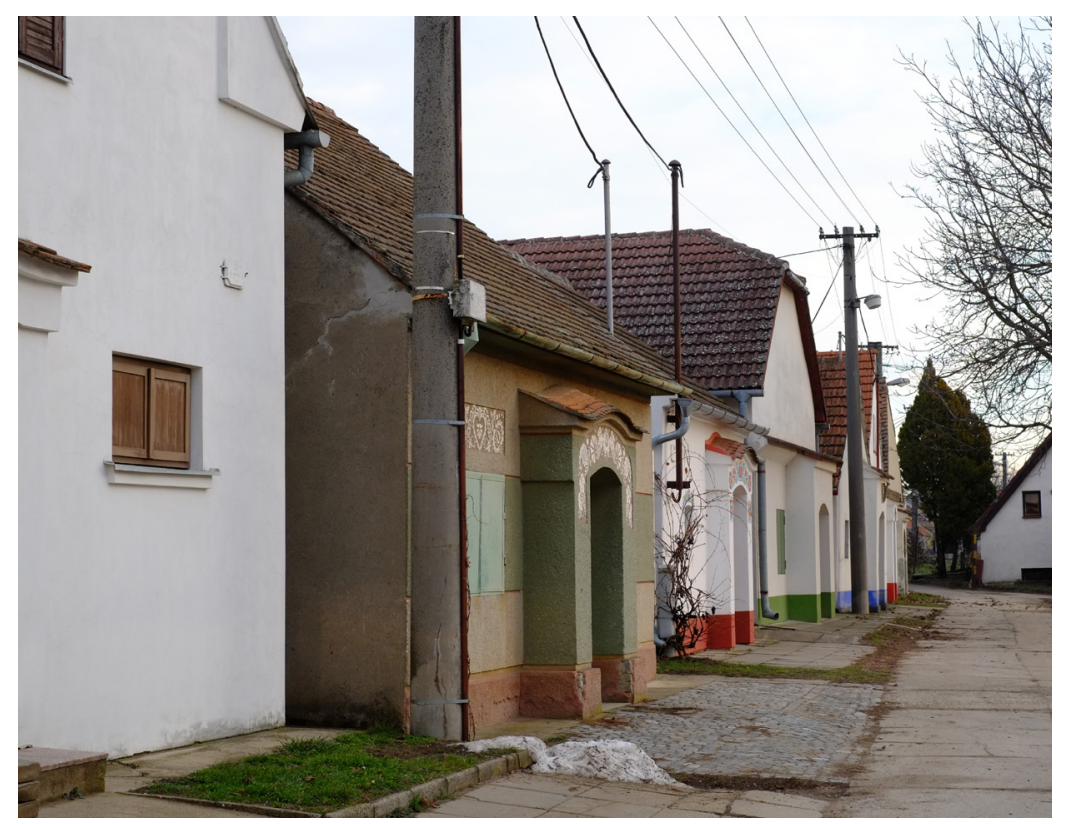

4.12: Cellars in Dolni Bojanovice. 


\subsection{SUMMARY}

Through research conducted at a variety of wineries and cellars, it is clear that it is not only the architectural language which contributes to ones memories and understanding of place, but also the social interaction with locals and residents as a way of understanding terroir. Through architecture's ability to foster social interaction and slow the pace of life, one can get a better understanding of what it means to be in a country, region, neighborhood, or micro-climate, taste the local wines, learn about the area's vernacular architecture, and interact with those who have a deep connection to the land. 

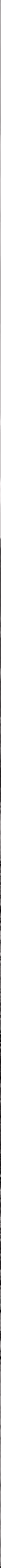
"Imagine soil as the context, the textural background of other imaginations, an other darker nature grounding culture, personality, language."

(Tom Jay, pg.1) 


\subsection{THE OKANAGAN VALLEY}

"Through the interaction of surface relief, vegetation, and water, characteristic totalities of places are formed which constitute the basic elements of landscapes" (Norberg-Schulz, 1996, pg.37). These landscapes are material amalgamation, layered over time, that speak to the land's history and its terroir. "Far from being uniform, homogeneous, and pre-prepared, the ground is variegated, composite, and undergoes continuous generation" (Ingold, 2010, pg.s121). It is an expression of what is specific to a particular site. Therefore, it is helpful to think of place as being in constant flux, influenced by a multitude of external factors which give it its spirit. Terroir as an architectural concept brings forth this continuous generation, through the local, the specific, the temporal, and the interaction between building and landscape.

British Columbia's Okanagan Valley was selected as a potential candidate to experiment with architectural terroir (figure 5.1). As a region in the midst of significant natural and cultural change, it became a suitable place to address the concerns discussed in this thesis. The valley is a

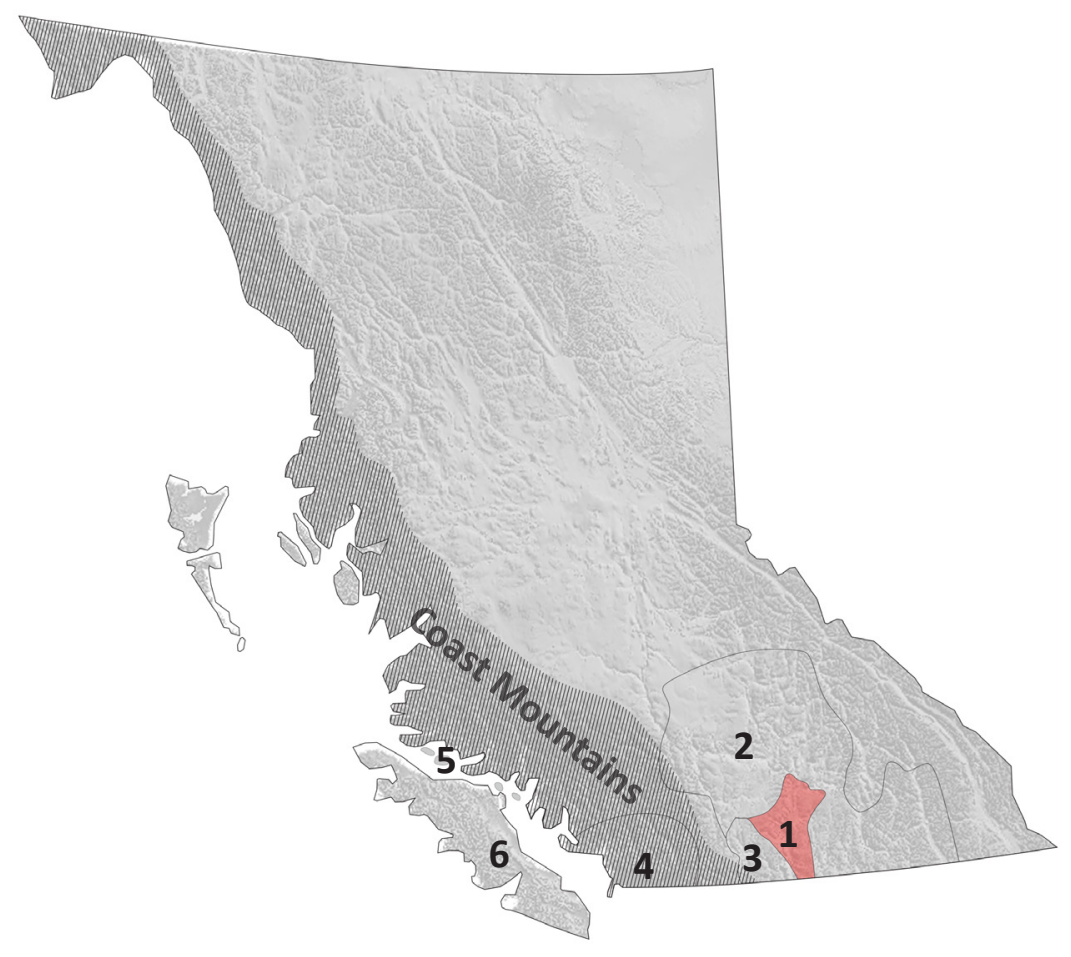

1. Okanagan Valley

2. Emergin Regions

3. Similkameen Valley

4. Fraser Valley

5. Gulf Islands

6. Vancouver Island

5.1: BC's 6 Wine Regions. 
geographically unique region, known for being Canada's only desert (More accurately described as a semi-arid shrub-steppe), where one of its largest assets (winemaking) is transitioning from a local market to a global one. As a result, an influx of tourism has followed, allowing for a prosperous economy, but threatening the very qualities of place that draw people here to begin with.

The valley stands in contrast to other regions of British Columbia and their common affiliation with rainy weather and lush rain-forests, due to its geographical location, which lies in the rain shadow of the Cascade mountain range. As a result, the Okanagan region experiences considerably less rainfall than other regions, giving the landscape its desert like appearance, characterized by Antelope brush, Ponderosa Pine, dry earth, and even the occasional cactus.

During the Pleistocene Epoch the valley was shaped by glaciers which sculpted the mountains, created lakes, and helped deposit sediment into fertile terraces so sought after in the agricultural community today (Glaciation, 2014). Furthermore, the West and East sides of the valley have a drastically different terroir due to the Okanagan fault line which was created by an uplift of Metamorphic and Plutonic rock (Geological History, 2014). As a result, the West side contains Sedimentary ,Volcanic, and Plutonic rock, whereas the East side is known for its Metamorphic, and Plutonic rock types. Asides from the valley's fertile terraces, its lakes also help moderate the climate and draw tourists, making it an ideal place for vineyards and water sports.

\subsubsection{A BRIEF HISTORY}

Prior to European Settlement in the early 1800s, The Okanagan Valley was initially inhabited by the Okanagan first nations of the interior Salish who gave the Valley its name. Roughly translated, "Okanagan" means "place of water" (Marsh, 2006). Following European arrival, missionaries built the first settlements in 1840 near Okanagan lake, and a second settlement near what is now known as Kelowna in 1859 (Marsh, 2006). The Fraser Canyon Gold Rush of 1858 helped attract more people to the area, and following the gold rush, ranching became the new way to make a living (Marsh, 2006). Ranching gradually transitioned to orchard farming (Marsh, 2006). At the time, irrigation technologies were poor and crops did not fare well. However, the 1930s brought with it improved irrigation technologies, transforming the sagebrush landscape into a lush oasis, and introducing the first commercial plantings of grapes. Winemaking eventually became a lucrative business in the 1960s and characterizes the Okanagan Valley to this day.

Currently, the Valley is home to a variety of rare, endangered ecosystems, and a thriving agricultural industry; two features of the Okanagan which make it so desirable, but also compete with one another. Its climate makes it an ideal setting for grape vines, while "wineries and tree fruit production form the mosaic of the present day cultural landscape" (Schwann, 2018, pg. 173). Its rural beauty, featuring highly cultivated land, appeals to visitor's and resident's 
ideals of a rich and vibrant landscape. It is a tourist hot spot that has grown rapidly through landscape marketing, globalization, and wine.

Over the past few decades the valley's wine industry has moved towards global distribution, competing with other wines around the world. This is exemplified through the more than 2,100 international awards given to wineries within the Okanagan Valley and British Columbia in 2013 alone (Cattaneo, 2014). This worldwide recognition has increased the number of tourists looking to taste wine and experience the landscape. According to the official 2017 Kelowna Tourism Report Survey, some of the most popular attractions for tourists in the Okanagan Valley are sightseeing and wine tourism (Tourism Research, 2017).

Unfortunately, with the valley's economic success and influx of tourism comes ecological degradation where "land use decisions and public policy continue to be driven by an unfettered hunger for land, not necessarily in the long-term interest of delivering sustainable or socially equitable development models" (Schwann, 2018, pg.173)(figure 5.2 and 5.3). This in return could lead to a "period of economic deficit (the bust) and a parallel depression of the land" (Schwann, 2018, pg.173).

The architectural intervention for this thesis looks to provide support for the Okanagan's economic growth, but in a sustainable and suitable way that addresses the region's geological fragility, and its unique terroir.
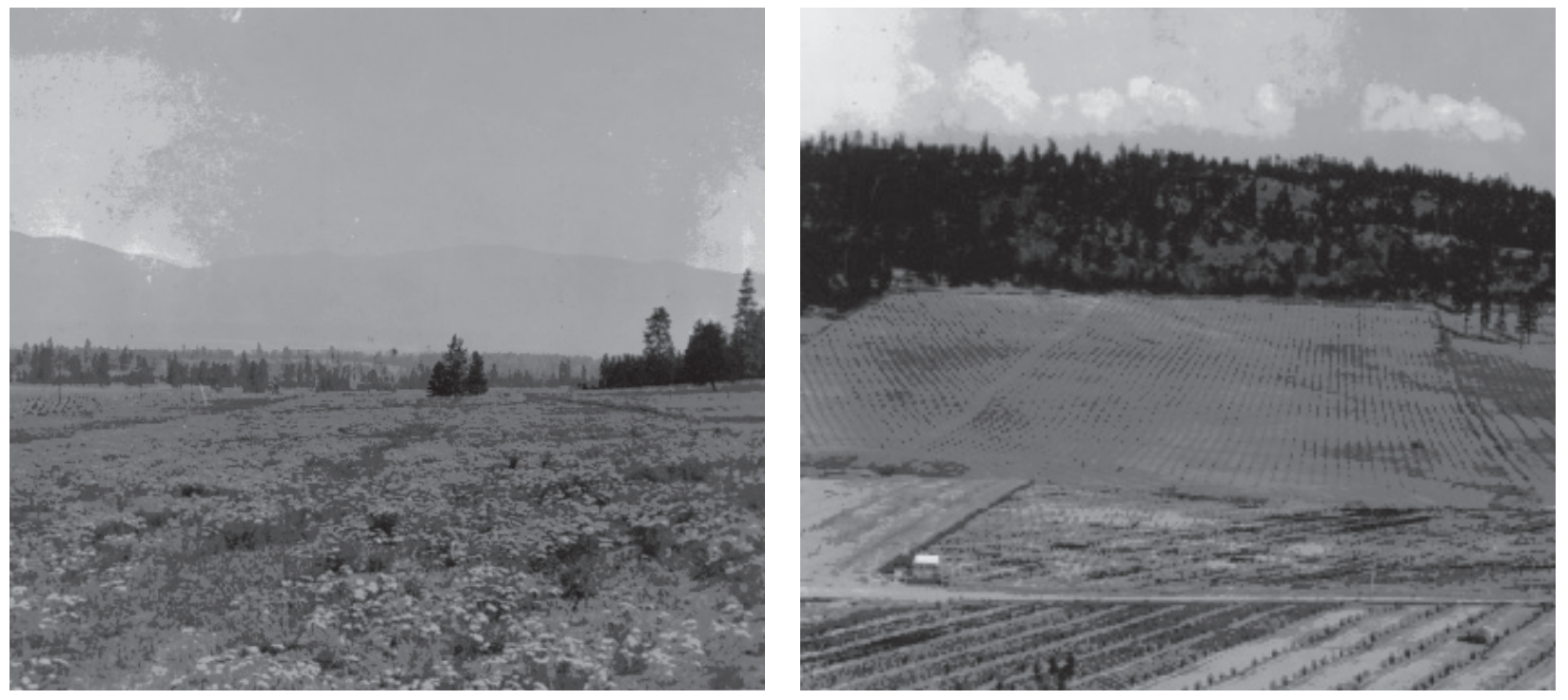

5.2: Glenmore Valley Prior to Orchard Development, Circa 1909 (Left). 5.3: Newly Planted Orchards in Glenmore Valley, Circa 1914 (Right). 


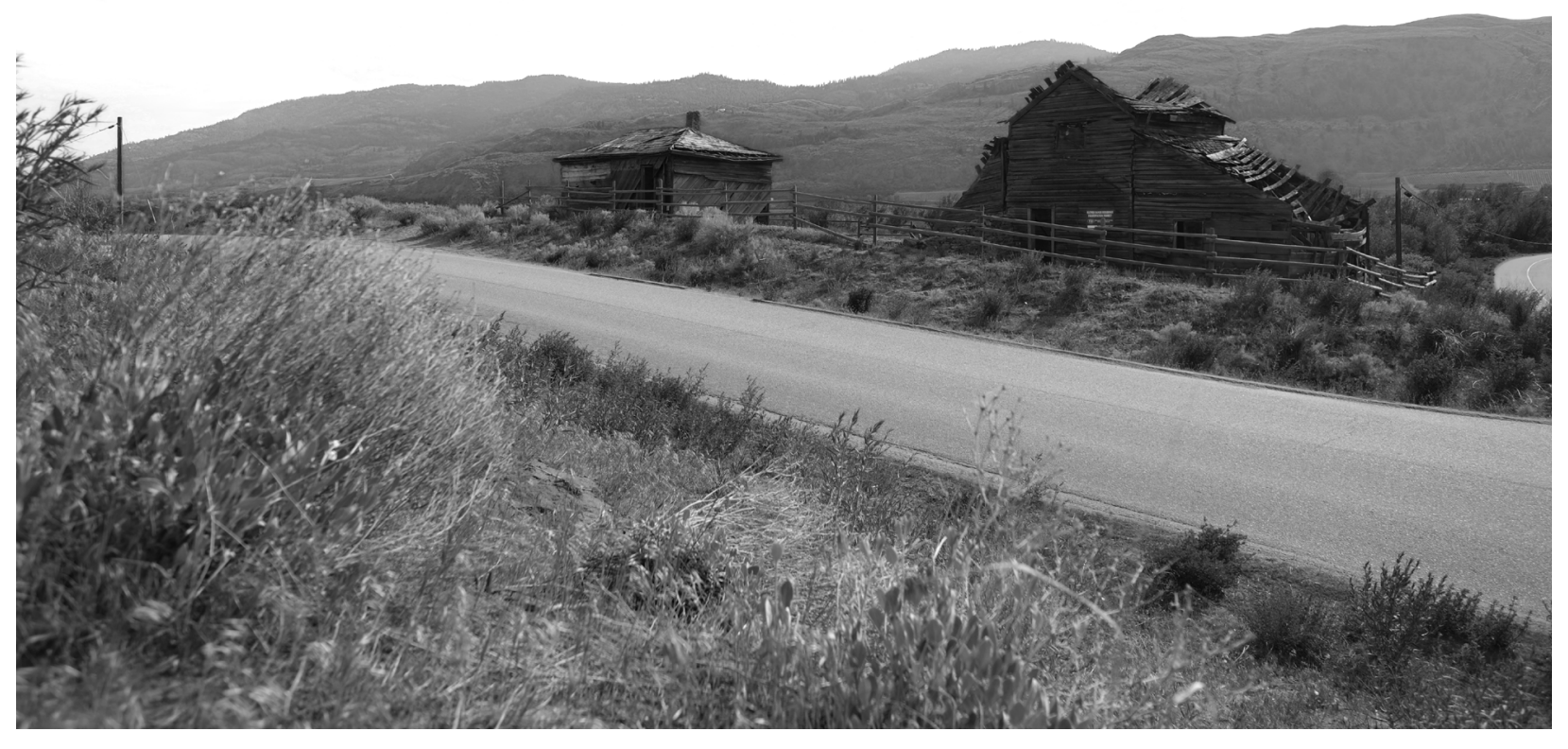

5.4: Vernacular Architecture by Osoyoos Lake. 


\subsection{VITICULTURAL REGIONS}

Site selection started by examining existing agricultural land so not to disturb any ecologically sensitive sites. As the Okanagan and neighboring Similkameen Valley are diverse and complex in terms of their ecotones, terrains, and micro-climates, it was imperative that these features be taken into account. Further site considerations acknowledged proximity to major towns and other vineyards, tourist accessibility, appropriate soil conditions, and climate. Orientation, slope, water supply, drainage, and agricultural zoning were also addressed during site selection.

Recognizing the difficulty that comes with selecting grape varieties, and land within the Okanagan's highly complex landscape, Geoscience Canada divided the Valley into 6 Viticulture regions, which reflect general conditions for each area, defined by land forms and climate. The six regions: Kelowna, Penticton, Vasseaux - Oliver, Golden Mile, Black Sage - Osoyoos, and Similkameen, all feature highly diverse geological characteristics due to glacial advances with took place during, and prior, to the late Pleistocene (Fulton, 1978). Eroded bedrock and redistrib-

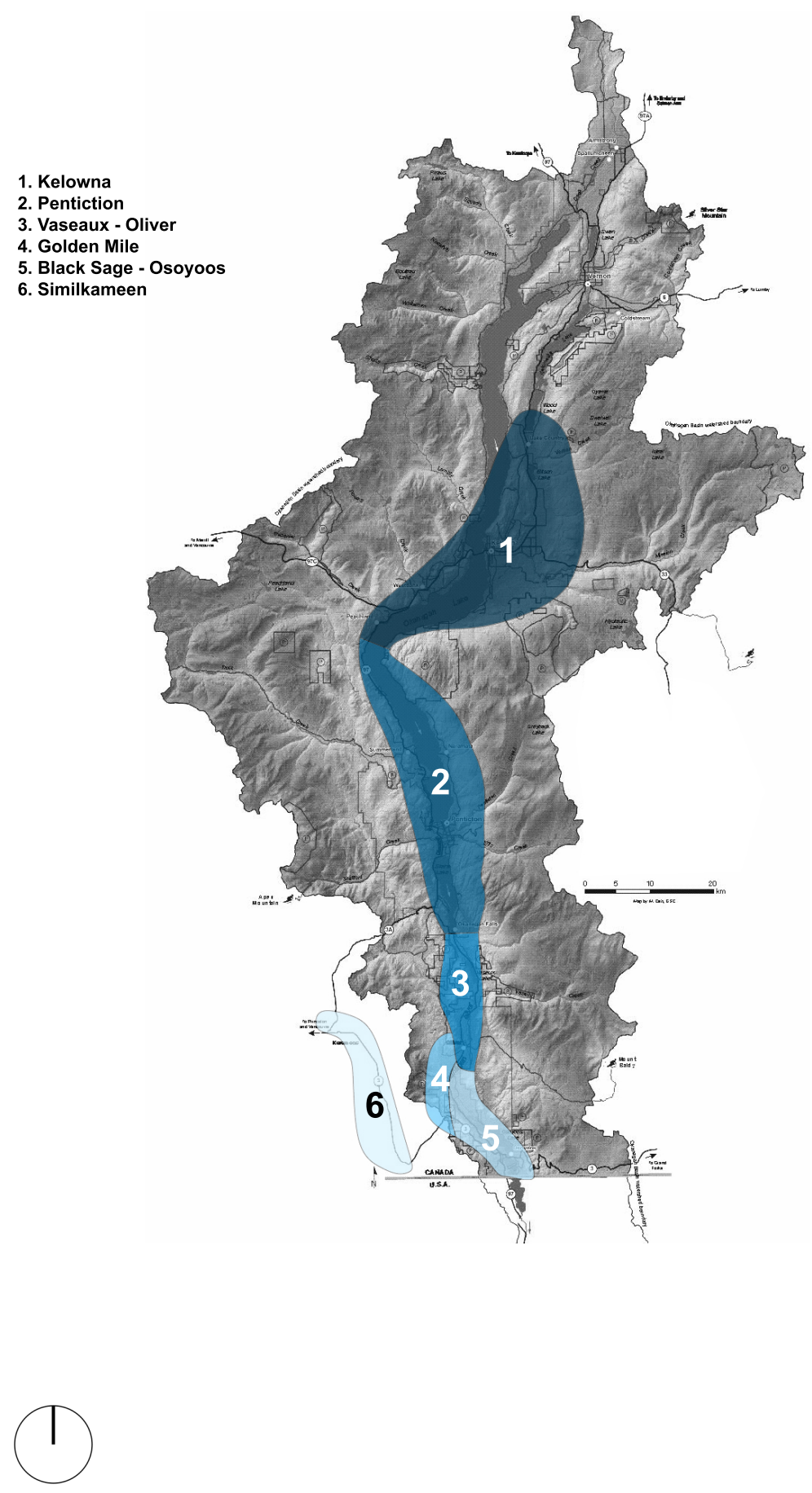

5.5: The Okanagan's 6 Viticulture Regions. 


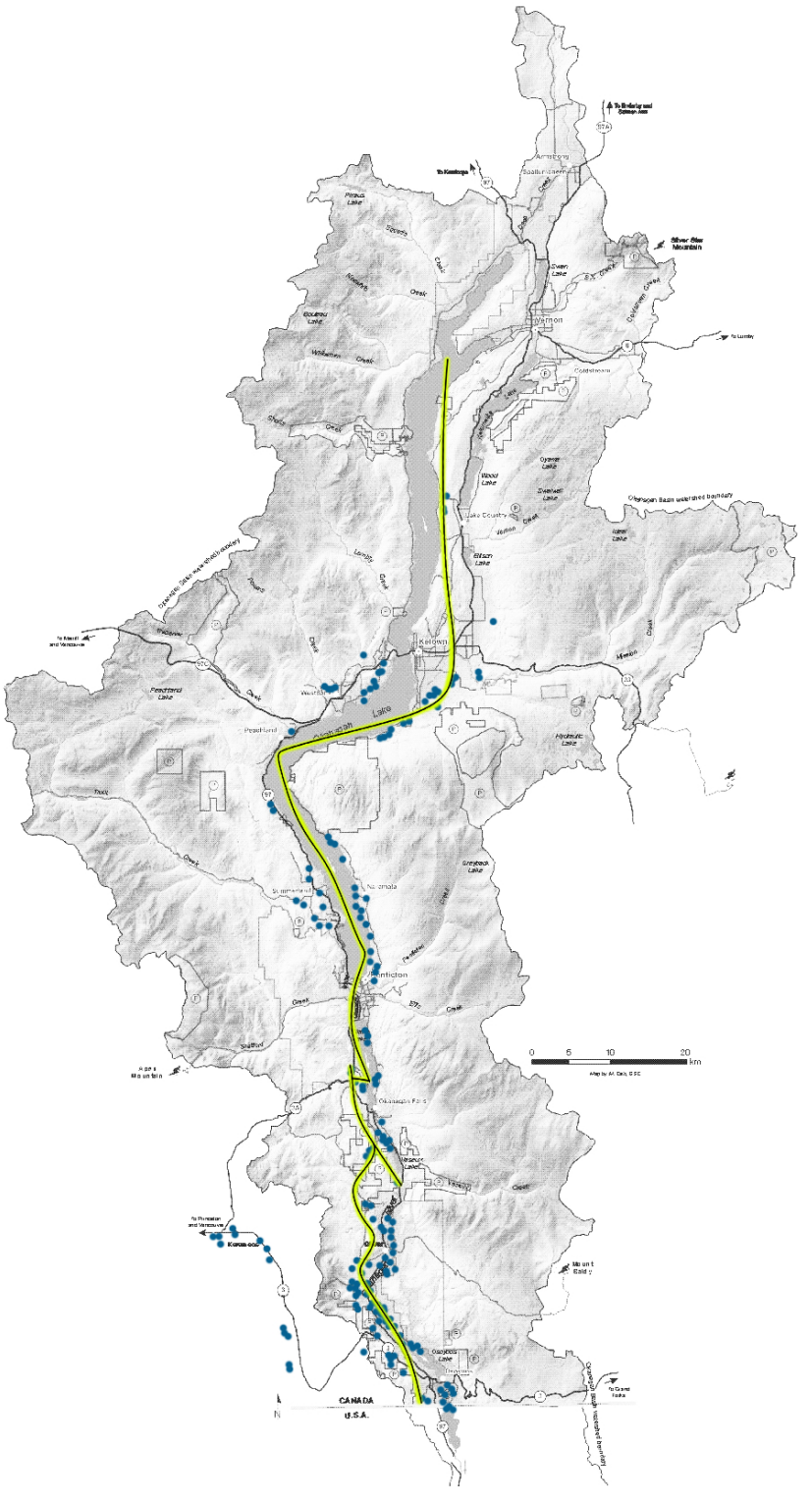

5.6: Winery Locations and Fault Lines in the Okanagan Valley. uted unconsolidated elements sit near the bottom of the valley, creating heterogeneous soil conditions suitable for a wide range of grape varieties, with most vineyards established on glaciofluvial and fluvial terraces (Fulton, 2003). Land availability proved to be scarce in the region due to the extensive amount of viticultural development, wineries, and limited fertile land, which was restricted by rocky outcrop, mountains, human development, and lakes (figure 5.6).

A final decision was made to place the winery in the Penticton region based on its growing potential for a variety of grape types. Furthermore, the region has two major town centers, Oliver and Penticton, placing it as a desirable tourist destination. Finally, despite heavy development, there is still existing orchard land available for vineyard conversion.

Site selection was then narrowed down to the Southern half of the region due to its proximity to the nearby town of Okanagan Falls (figure 5.7). Additionally, the Southernmost area features a high number of growing degree days and is home to Skaha Lake; A freshwater lake that 
features a dichotomous East and West terroir, attributed to the Okanagan fault line. Skaha lake is also the last lake that contains the Okanagan fault line before it detours through Osoyoos and into Washington state (figure 5.8).

The East side of Skaha lake is highly desirable due to its adequate air drainage and orientation, thus it was important to find land East of the lake. Furthermore, Skaha's Eastern fertile terrace will be classified as part of the Skaha Sub GI (Geographic Indicator) which will come into effect as of 2019 (Smith, 2018) (See figure 5.8 for location of Sub Gl). A Sub Gl gives winemakers the ability to associate their product with a distinct designation and identity; a key part of proclaiming a sense of place within the wine community. Within the Sub Gl a map was consulted showing the suitability of the land for vineyards, with level 1 (Green) being the most suitable area for vineyards, and level 5 (Red) being the least suitable (figure 5.7). An existing cherry farm within the level 1 suitability area on the East side of Skaha Lake near the end of the Sub Gl became the chosen site for the architectural intervention.

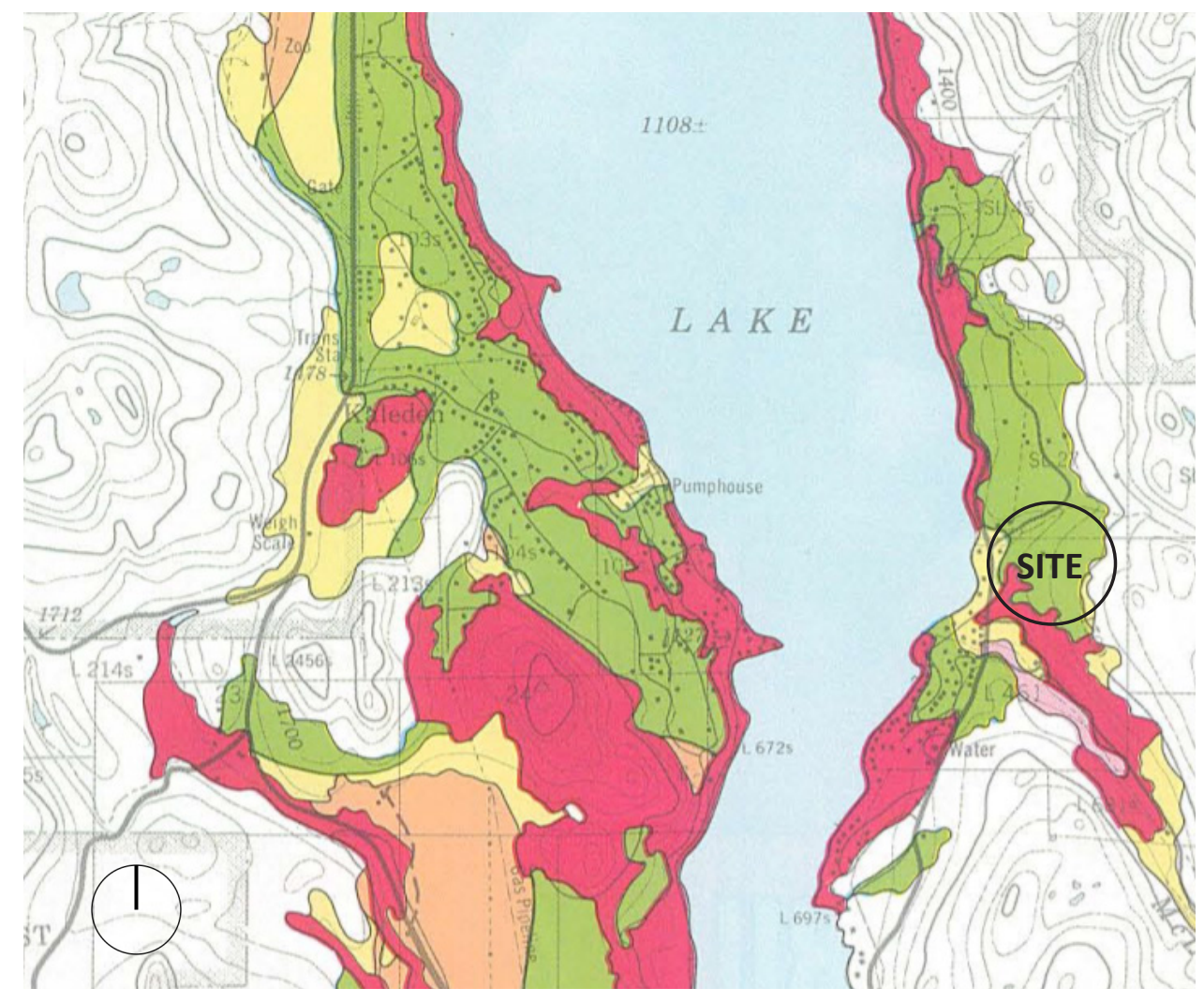

5.7: Soil Suitability Map of Skaha Lake (Green Indicates Optimal Conditons). 

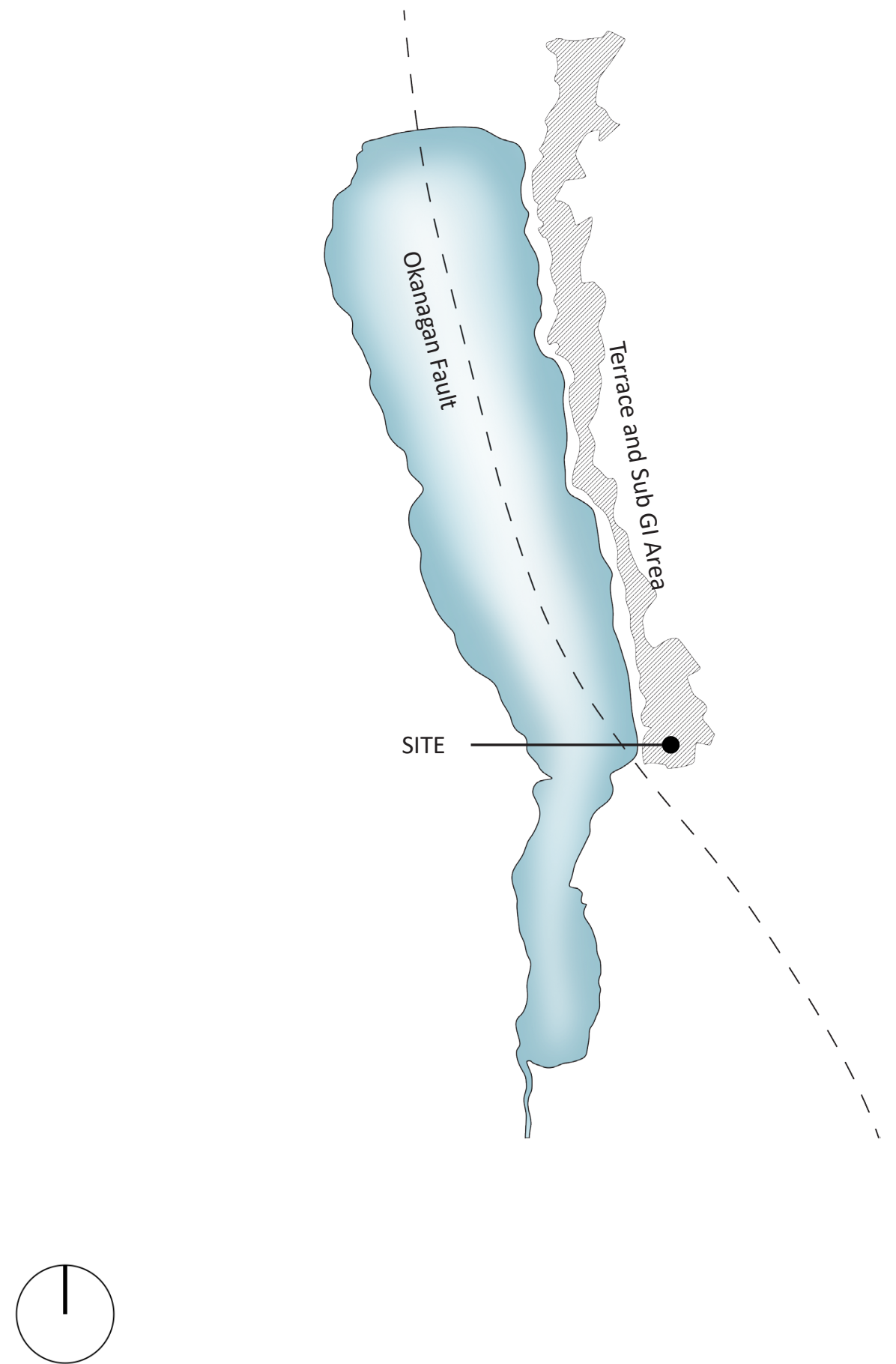

5.8: Fault Lines and Terrace Location. 


\subsection{BIGHORN RIDGE}

The selected site is a Cherry farm, referred to as "Bighorn Ridge", which is named after the California bighorn sheep that once roamed the nearby hills. The site features a view of the lake, with a variety of unique landscape characteristics. Located at 449 Parsons Road near Skaha Bluffs, the site sits in close proximity to Eastside Rd, which connects Penticton and the Okanagan Falls area. Furthermore, the Eastern side of Skaha lake, on which the site is located, is preferable for vineyards, as land sloping West has excellent air drainage, providing a relatively high number of frost-free days.

The site has strong topographical characteristics, sloping drastically near the edges of the property, and leveling out in the center for the planting of crops. The total arable land under class 1 suitability (ideal planting soil) is 22 acres, and the soil is classified as a Sandy Loam. Land farther to the South East corner of the site consists of Rocky outcrops and sagebrush vegetation (figure 5.10). A riparian ecosystem with Ponderosa Pine native to the Valley marks the entrance into the winery and acts as the site's threshold. Upon entering the site, one travels up
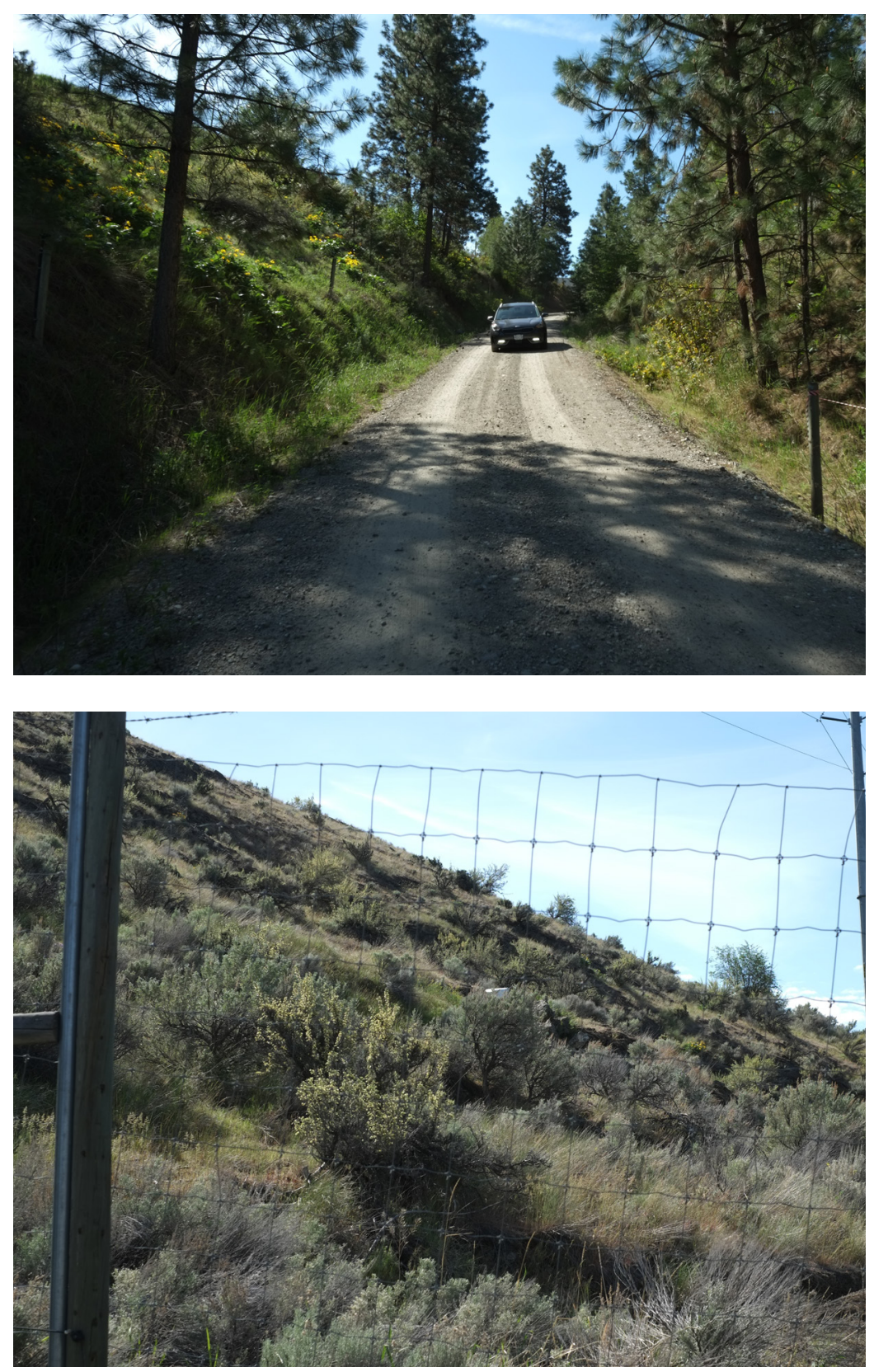

5.9: Entering Bighorn Ridge (Top). 5.10: Preserved Vegetation on Bighorn Ridge (Bottom). 


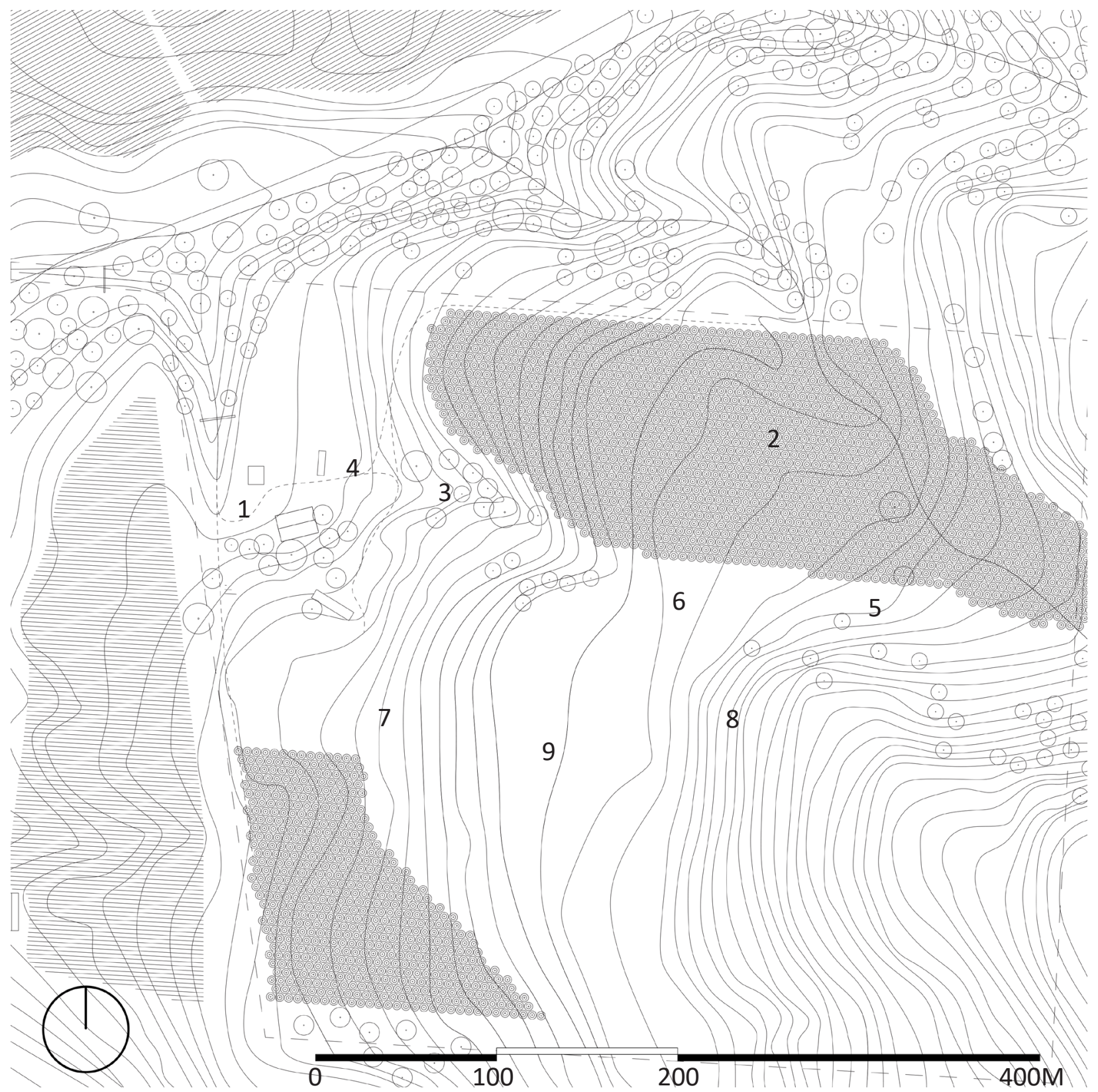

5.11: Existing Site Conditions. 

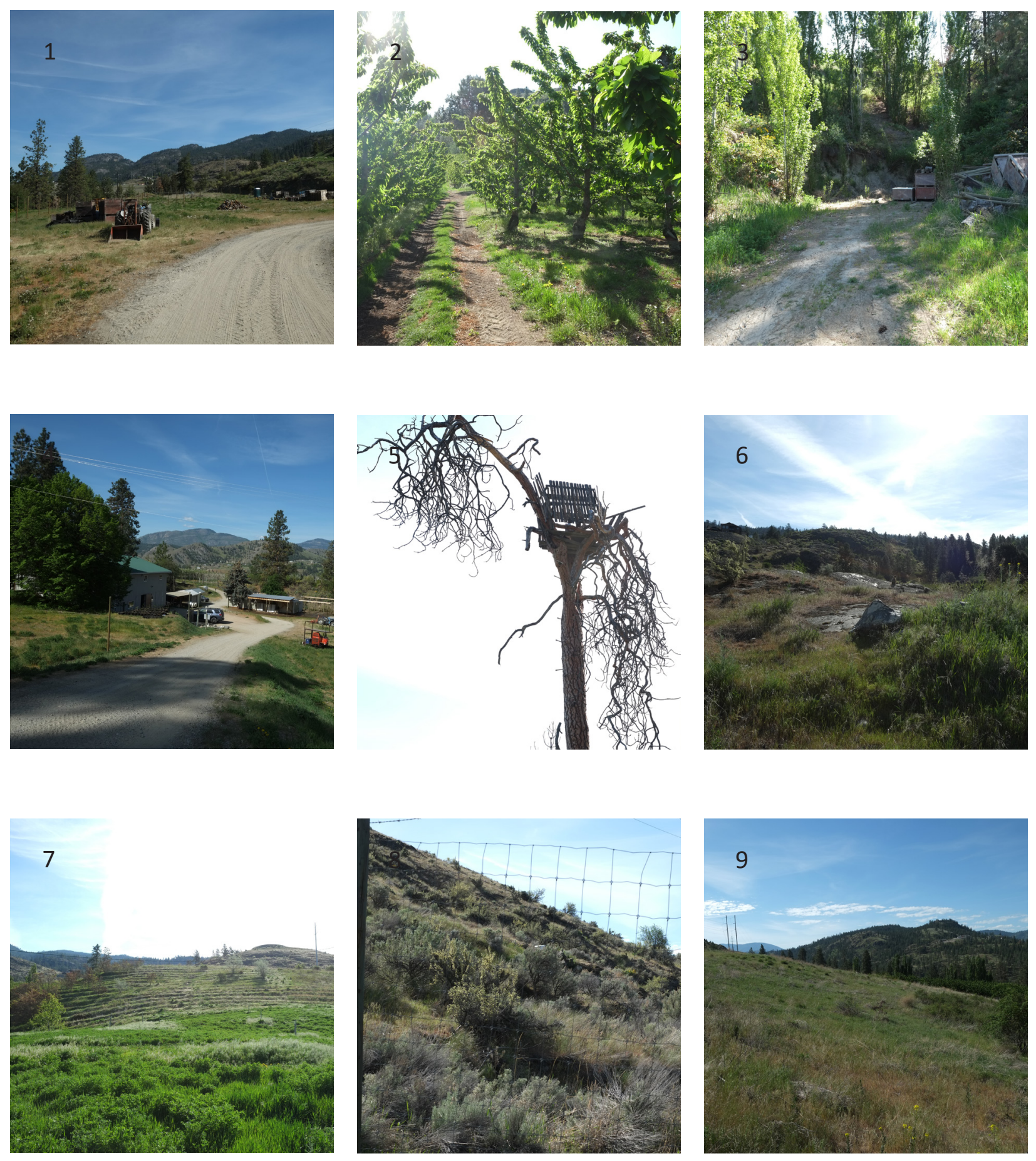

5.12: Images of Existing Site Conditions. 

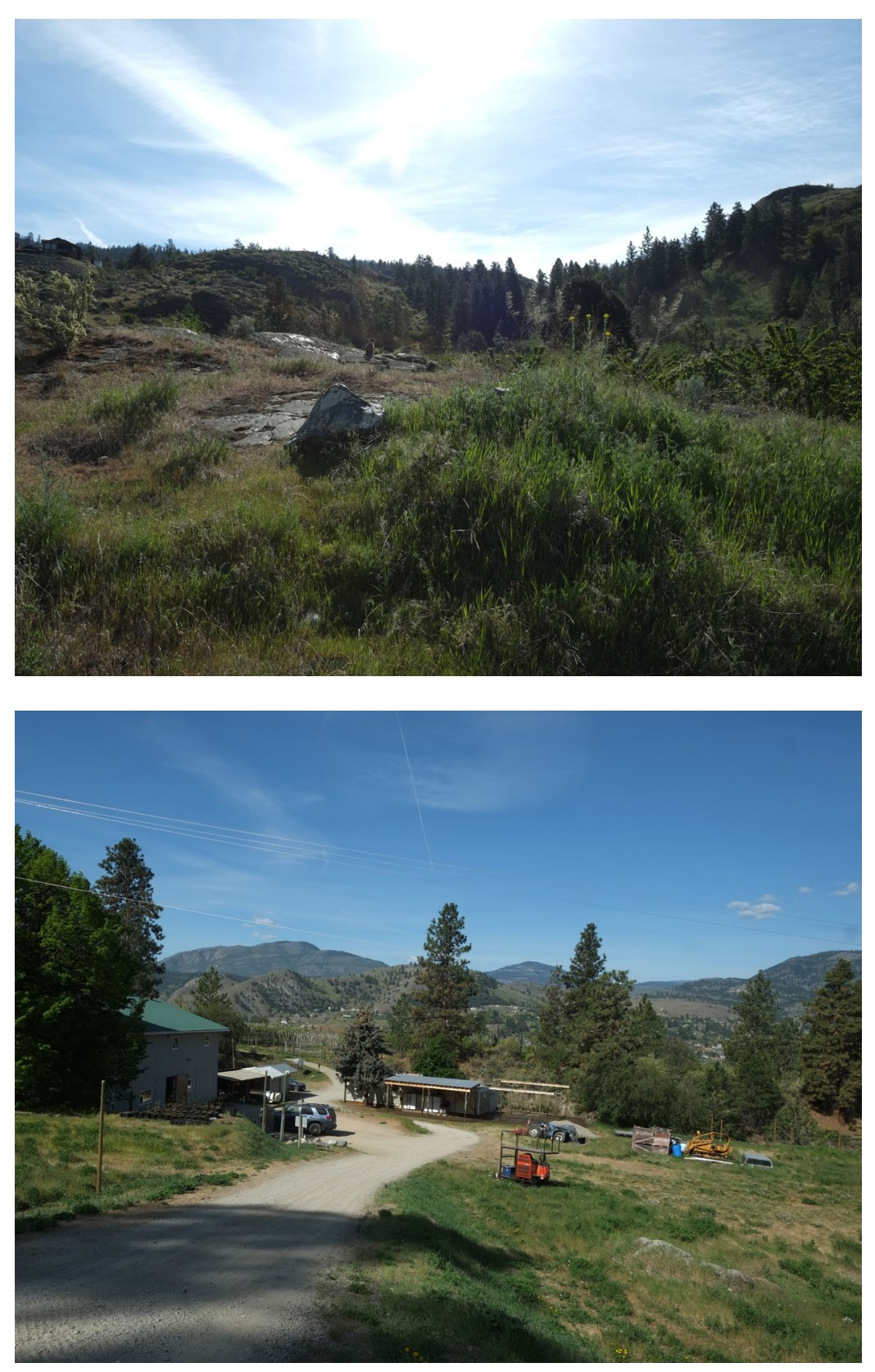

5.13: A Yellow Bellied Marmot Stands Near Rattlesnake Rock (Top).

5.14: Storage Building to the Left, Camp Area to the Right (Bottom). through a small valley (figure 5.9) before emerging into an open field; a feature which gradually reveals Skaha lake.

Purchased by the owner in 1992, Bighorn Ridge boasts naturally rich landscape features, bordering the Northernmost tip of the Antelope Brush habitat. Areas of the site have been named by the owner himself, such as Rattlesnake Rock; influenced by a pair of rattlesnakes that he found near the top of the property's hill (Anonymous, Personal communication, May 11, 2019)(figure 5.13). According to the owner, it was imperative that these ecological reserves be preserved, and the winery be placed near the top of the hill on soil that has already been significantly altered (Anonymous, Personal communication, May 11 , 2019).

The bottom of the site has an area for workers and visitors to camp which is accessible by transit, bike, and car (figure 5.14). Due to the extensive amount of flat land near the bottom of the site, surface parking for visitors proved to be feasible. A nearby hillside has also been dug out for a wine cellar, leaving the opportunity to include a sepa- 
rate cellar, solely for tourist lodging and camping (figure 5.15).

Initial site analysis shows that there are four different types of parent soil material and sediment that make up the property. These include Glaciofluvial, Fluvial, Eolian, and Colluvial parent materials (figure 5.16). The site's highest elevation consists of Colluvial parent material. This is soil classified as unconsolidated elements that consist of "sharp angular rock fragments accumulated at the base of steep slopes" (Soil Formation and Parent Material, n.d.). Farther down is Glaciofluvial which makes up the bulk of the site's available arable land. Glaciofluvial consists of "coarse to medium grained sand and gravel.....deposited by glacial melt-water in a floodplain environment" (Soil Formation and Parent Material, n.d.). Along the ravine are fluvial deposits which is "soil that has been transported by the action of water in streams and rivers and has been deposited in the stream channel" (Soil Formation and Parent Material, n.d.). Finally, at the base of the site lies Eolian. "Eolian (or aeolian) sediments are wind deposited materials that consist primarily of sand
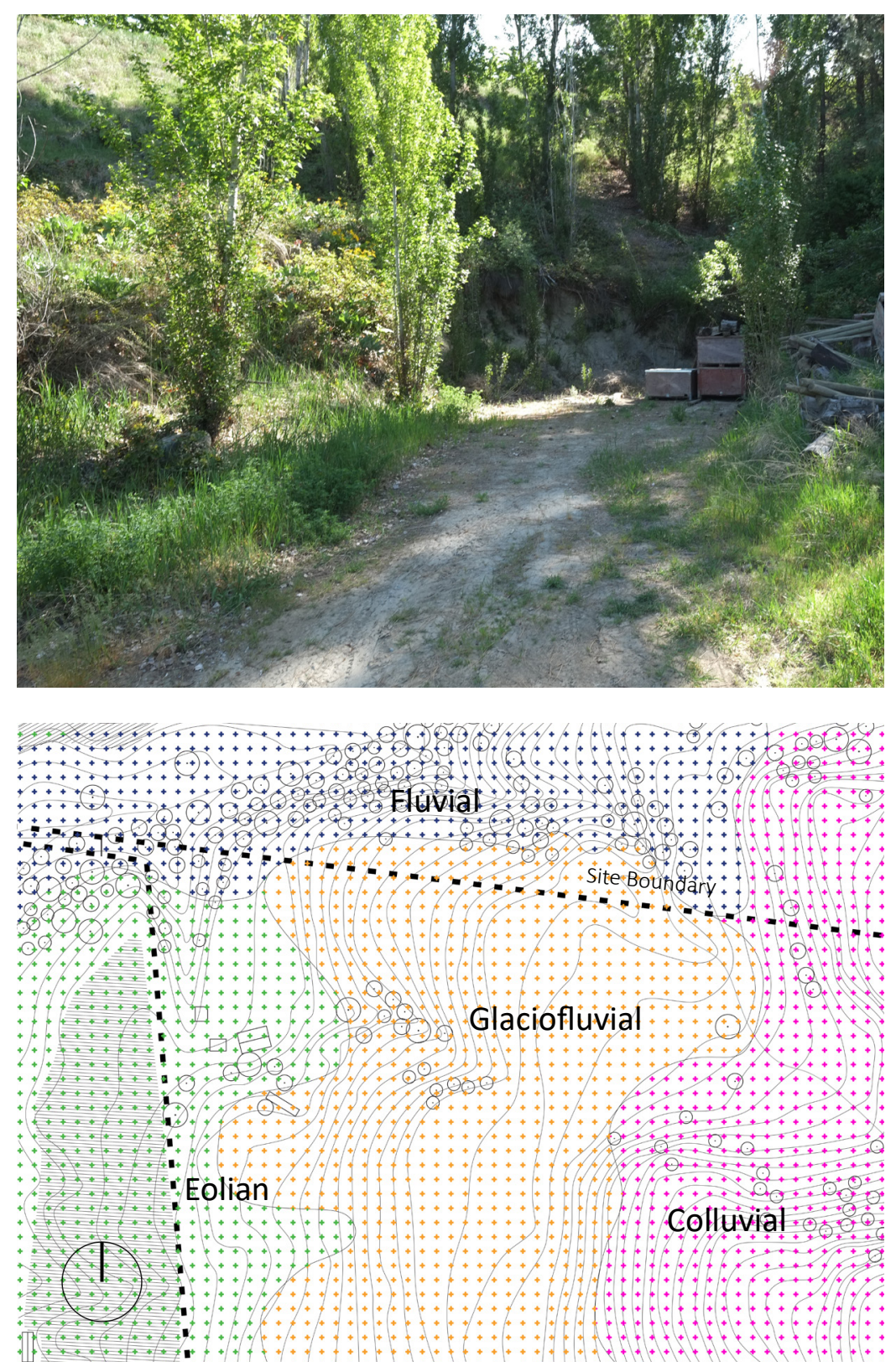

5.15: Land Excavated for Wine Cellar (Top). 5.16: Soil Map of Bighorn Ridge (Bottom). 
or silt-sized particles. These materials tend to be extremely well sorted and free of coarse fragments. Some rounding and frosting of mineral grains is detectable" (Soil Formation and Parent Material, n.d.). Following the soil analysis, Geoscience Canada was consulted in order to get a better idea of what types of grapes may be planted on the site.

\subsubsection{Grape Varieties}

According to Geoscience Canada, the geographical location of Bighorn Ridge "is planted predominantly with white varieties", and "more than a third of the total area is planted with the whites Chardonnay, Pinot Blanc and Pinot Gris"(View of Geology, n.d.). Of the red varieties that are planted in the Penticton region, Bordeaux varieties are the most dominant, especially Merlot (View of Geology, n.d.). Blasted Church, a winery adjacent to Bighorn Ridge, states, "here at Blasted Church we grow Optima, Chardonnay, Gewürztraminer, Pinot Gris, Pinot Noir, Merlot, Lemberger, Cabernet Sauvignon, Ehrenfelser, Sauvignon Blanc, Riesling, Viognier and Pinot Blanc." These varieties were chosen as the "soils are Glacial formed and vary from sand to silt" (J.Bayley, personal communication, August 21, 2019). From recommendations, climate, and geographical conditions it was decided that white wine varieties would be most suitable.

Chardonnay is a popular choice for wine growers, not only in British Columbia, but around the world. However, as it is so popular, some sommeliers have criticized it as the symbolization of globalization. Oz Clarke described Chardonnay as "...the ruthless colonizer and destroyer of the world's vineyards and the world's palates" (Clarke, 2001), criticizing sommeliers for replacing local grape varieties with Chardonnay, and the term "ABC" anything but Chardonnay" was mentioned by Frank Prial in a New York Times article following its increased popularity (Prial, 1995). To this day, Chardonnay remains a popular variety, being one of the most widely planted grape varietals in the world.

Pinot Gris, another popular choice in the Penticton region, "is one of the darkest-skinned grapes producing white wine" (Pinot Grigio, n.d.), with grape colors ranging from grayish blue to brownish pink. This variety is considered to be a mutant clone of Pinot Noir and has been known to be drank since the middle ages (Pinot Grigio, n.d.).

Finally there is Pinot Blanc which is also a white mutation of Pinot Noir, commonly used to produce a powerful, dry white wine. "Pinot Blanc can tend towards apple pit and even smoky flavors; it can also be oaked for a bit more richness" (Bell, 2016). Pinot Blanc became an appropriate candidate as its flavors are a subtle reference to the Okanagan's rich orchard history, and its smoky flavors tie in with the landscape's dry climate. Pawsey states "It's a perfect complement to the richness of sockeye or coho, but has enough of that classic Okanagan (or Similkameen) acidity to also add contrast and pair with the likes of beurre blanc or citrus-based sauces" (Pawsey, 2017). 


\subsection{DESIGN CONCEPTS}

By using terroir as a means to guide architecture, this thesis aims to embrace the Southern Okanagan's geographical particularities, while simultaneously providing a sustainable building which connects both visitor and worker to its unique landscape. From the background research, it was clear that terroir is the amalgamation of geological, ecological, historical, and human factors. Based on these observations, four primary design objectives emerged. They have been labeled "Lithic Gardiner, Taskscape, Architectural Fermentation, and Climate."

These four elements became key determining factors throughout the design process as they each make up a crucial part of terroir's definition. "The Lithic Gardiner" references the importance of soil for grapevines and architecture's connection with the earth, the "Taskscape" acknowledges the winemaker's influence on wine and the layout of spaces in relation to the winemaking process, "Architectural Fermentation" recognizes the effects of weather on the ripening of grapes and the way buildings age, and "Climate" references the orientation of the vineyard as well as the building's form in relation to seasonal changes. Through these concepts, the winery aims to capture the genius loci of the Okanagan, much like the wine itself. 


\subsection{THE LITHIC GARDINER}

The earth is an instrument, "not in the blunt sense that we need it to stand on but also in the sense that without it we would lose much of our capacity to know. If its variations were erased and covered over by a hard surface, we would still be able to stand and walk but could no longer know as we go along" (Marchand, 2011). Visualizing the act of building as lithic gardening considers architecture, not as a finished object which covers the earth, but rather as a nexus of materials in the landscape whose origins are of the earth. This was achieved through locally sourced materials, a topographically sensitive plan, and exposure of the earth's geological layers throughout the structure. Using research from section one's discussion on landscape, this became the starting point for an exploration into architectural terroir, and a guide to creating a geologically sensitive building.

When allocating an area for the winery, the geographical characteristics, climate, views, and soil conditions were considered. Initially, the rocky outcrop at the site's highest elevation was chosen due to its views of Skaha lake, and the potential for a gravity flow system. This was then changed upon realization that the outcrop was too steep, and that the hillside supported sensitive flora and fauna (figure 6.1). One alternative was an area located directly below the outcrop on a terraced West facing hill (figure 6.1/ 6.2). Not only does the location still boast views of Skaha Lake with the potential for a gravity flow winery, but the soil conditions, consisting of Glaciofluvial parent material, make for easier excavation. 
Original Site

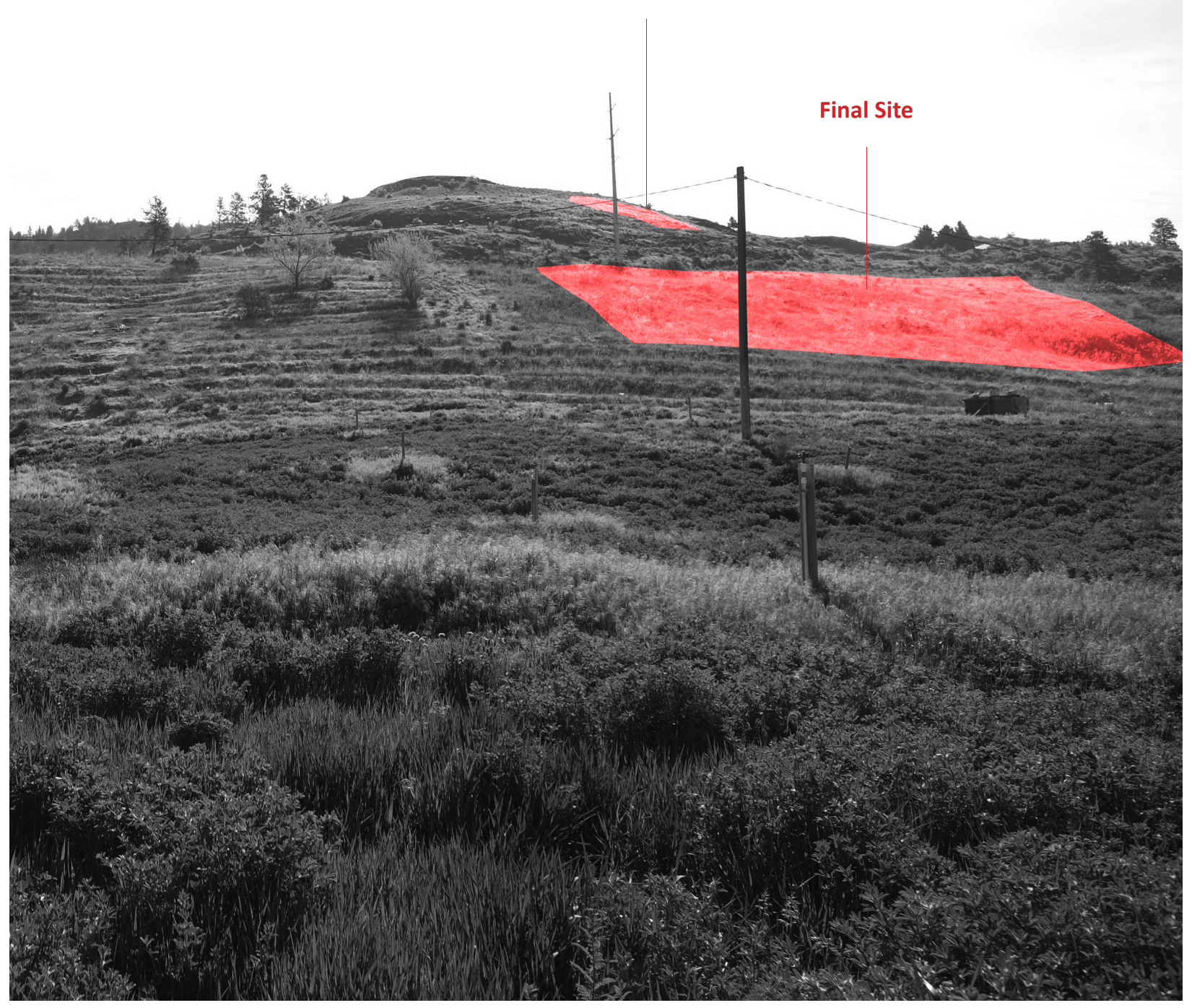

6.1: The Original Location and New Location for the Winery (Image Taken Facing East). 


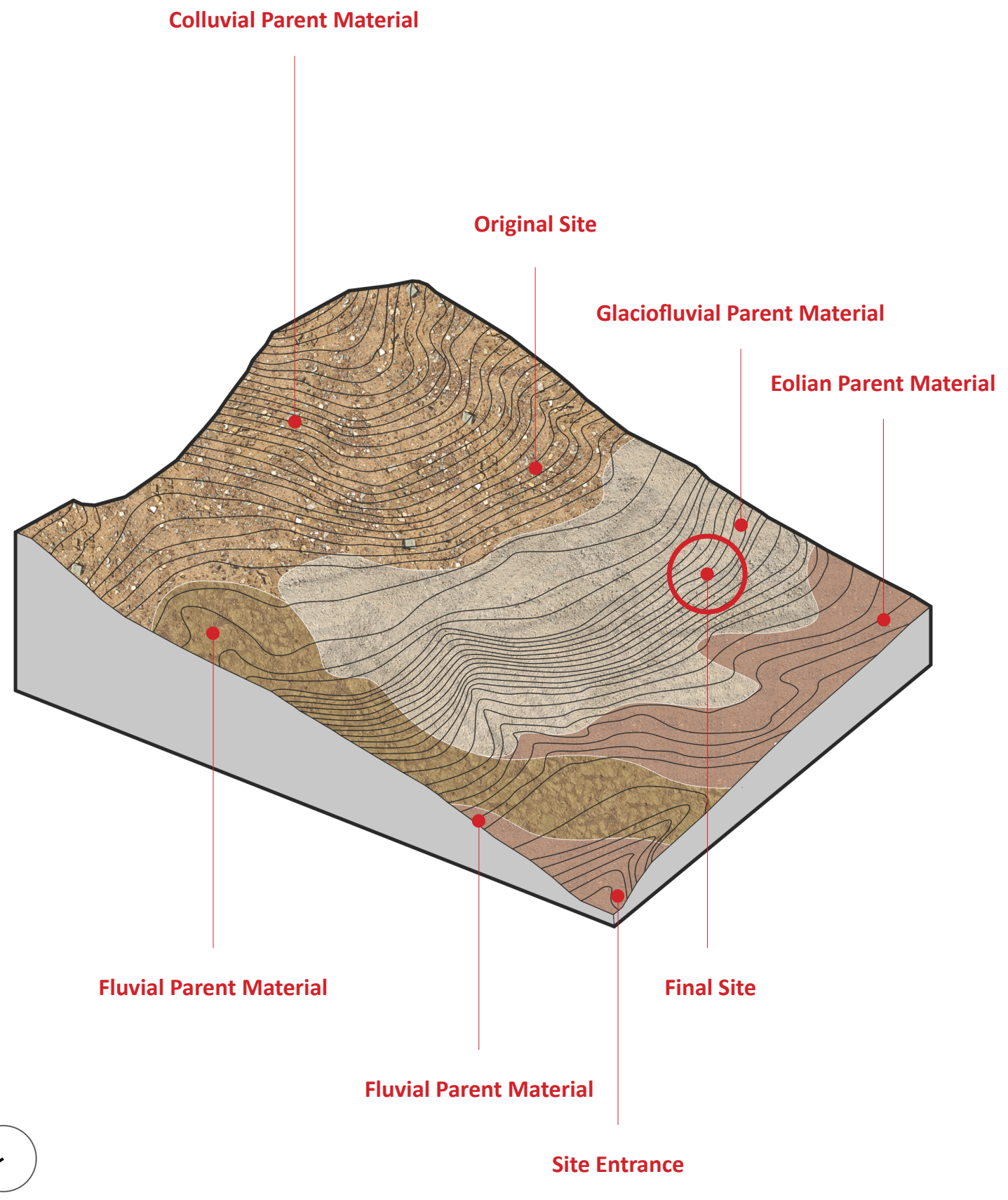

6.2: Soil Map of Bighorn Ridge. 


\subsubsection{Flora}

Native plant species, and plants introduced by previous generations, are as much an essential part of the landscape's terroir as the soil they grow from. As a counteraction to the Okanagan's rapidly disappearing agricultural heritage in exchange for resorts and housing development, existing parcels of Orchard on Bighorn Ridge were preserved, thus acknowledging the Okanagan's history, while retaining the knowledge of those that cared for the site previously (figure 6.3). This became integral to the site's identity.

"When you lose an orchard you sacrifice not simply a few trees... but you might lose fruit varieties particular to that locality, the wildlife, the songs, the recipes... the look of the landscape, the wisdom gathered over generations about pruning and grafting. In short the cultural landscape is diminished by many dimensions with one blow" (Clifford, as cited in Macnaghten and Urry, 1998, pg 170). 


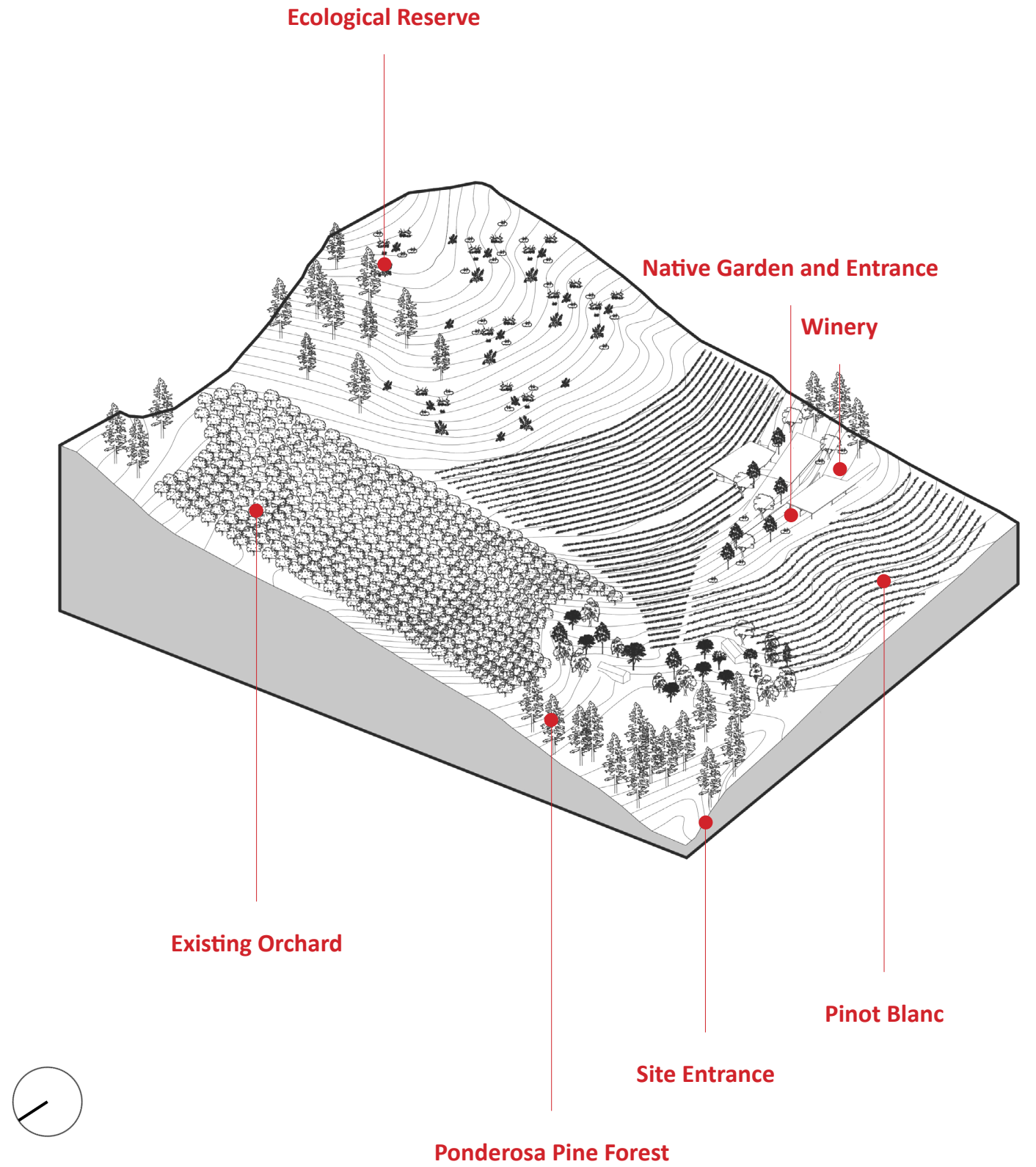

6.3: The Flora of Bighorn Ridge. 


\subsubsection{Site Program}

The site plan for Bighorn Ridge considers the transient nature of tourism, incorporating tourist accommodation. By doing so, this encourages extended stays and an immersive experience of the site. "A place owes its character to the experience it affords to those who spend time there- - to the sights, sounds and indeed smells that constitute its specific ambiance. And these, in turn, depend on the kinds of activities in which its inhabitants engage. It is from this relational context of people's engagement with the world, in the business of dwelling, that each place draws its unique significance" (Ingold, 2011, pg.192). Visitors are provided with a variety of accommodation types based on their needs and desires, from conventional lodging in the site's converted storage barn, to camping, which provides a more intimate connection with the land (figure 6.5).

Buildings are spread apart with the intention of creating a processional entry sequence, encouraging visitors to explore the site, rather than enter the winery immediately. Through its pathways and hiking areas, Bighorn Ridge is best perceived at a leisurely pace. "The ground is perceived kinesthetically, in movement," thus it was imperative that the site feature a variety of path options leading to its unique features (Ingold, pg.S125) (figure 6.4 / 6.6). These paths aren't limited to a small area of the site but run through an ecological reserve, productive pieces of land, and worker's areas, so that visitors can witness the process that goes into making wine and managing the vineyard. Paths are shaded with trellis structures, providing storage for farm equipment, spaces for outdoor events, and protection for visitors from the sun during the summer months (figure 6.7). 


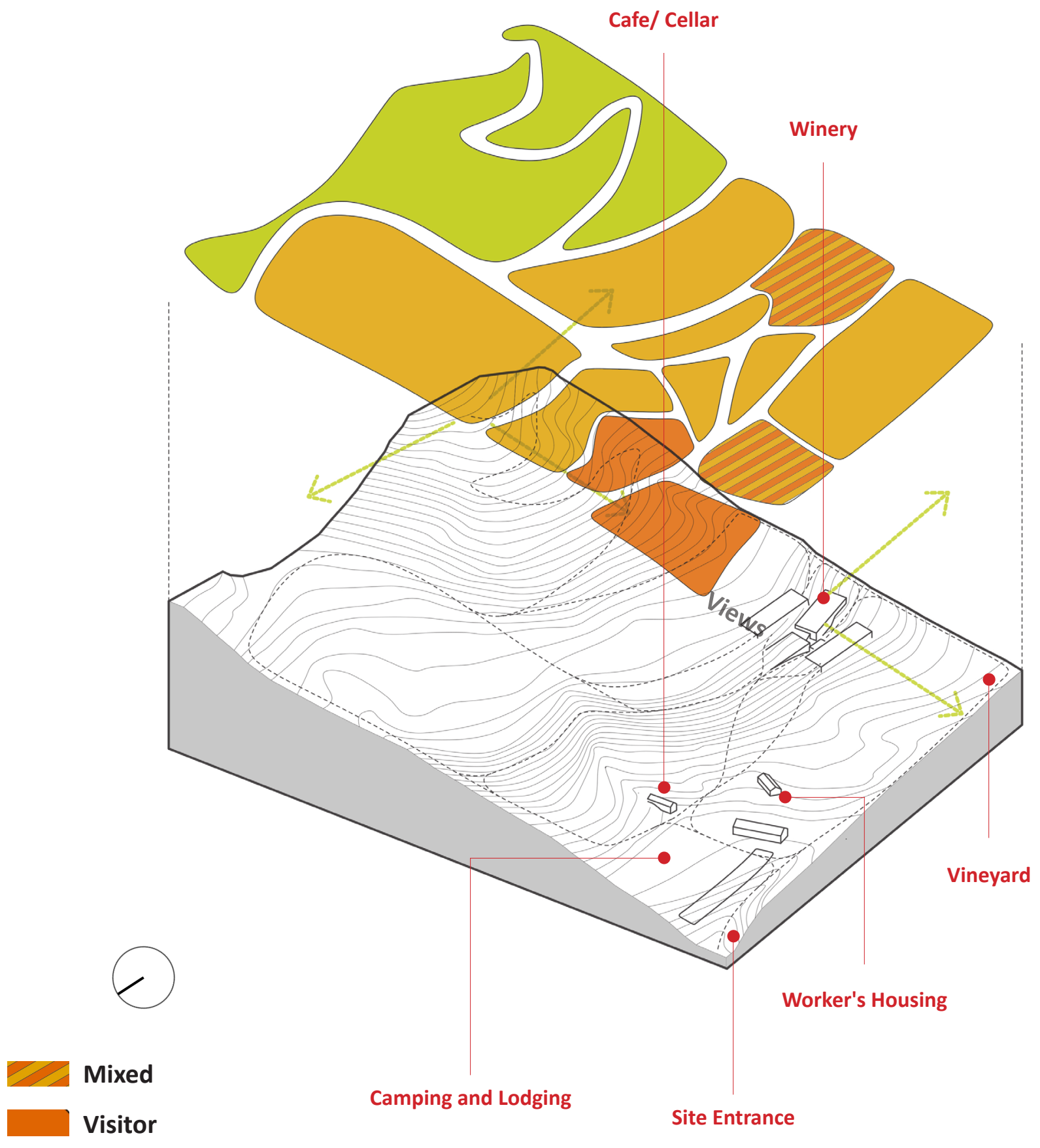

\section{Production}

6.4: The Site's Layout Encourages Landscape Exploration. 


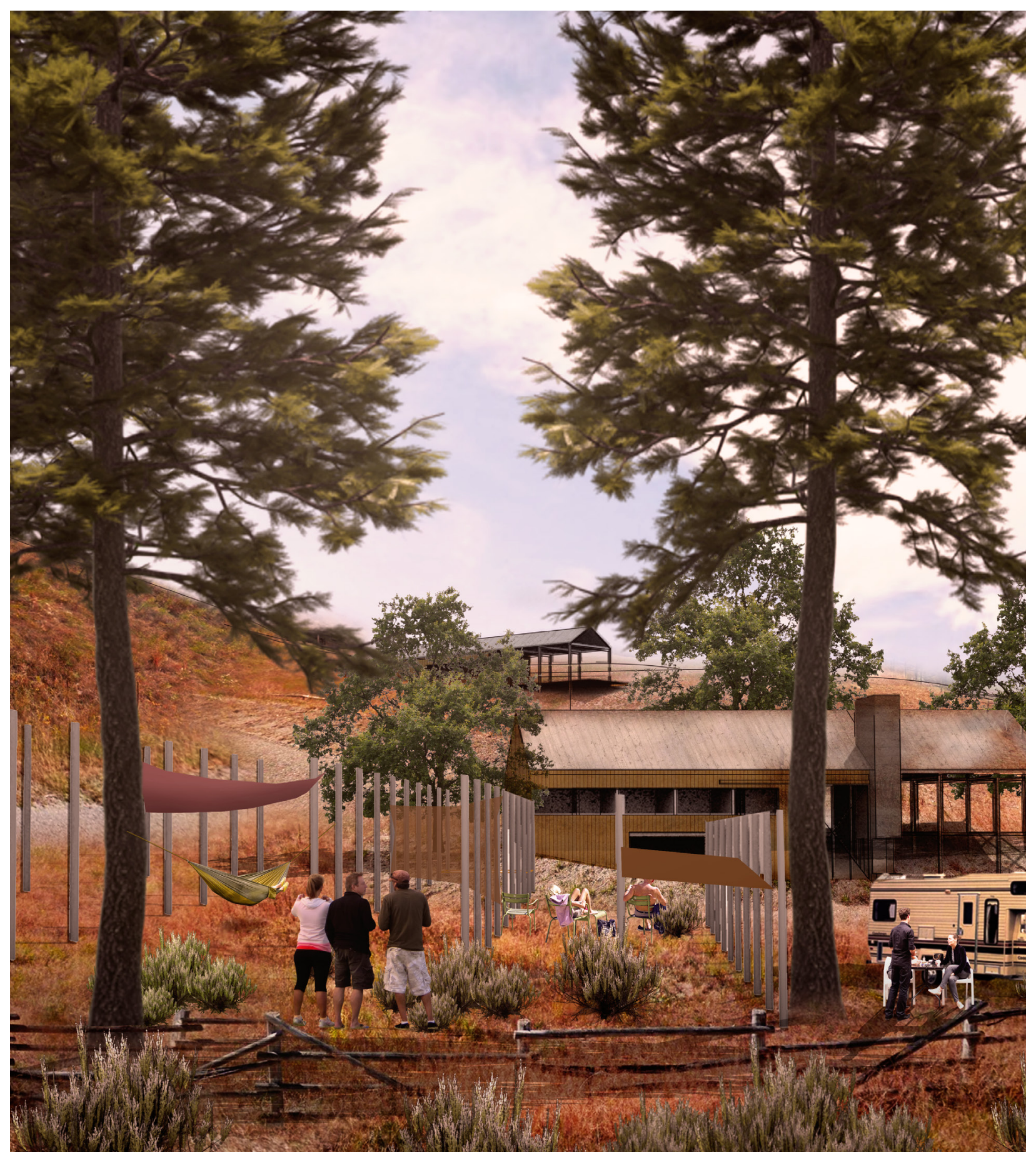

6.5: Tourist Lodging and Campsite. 


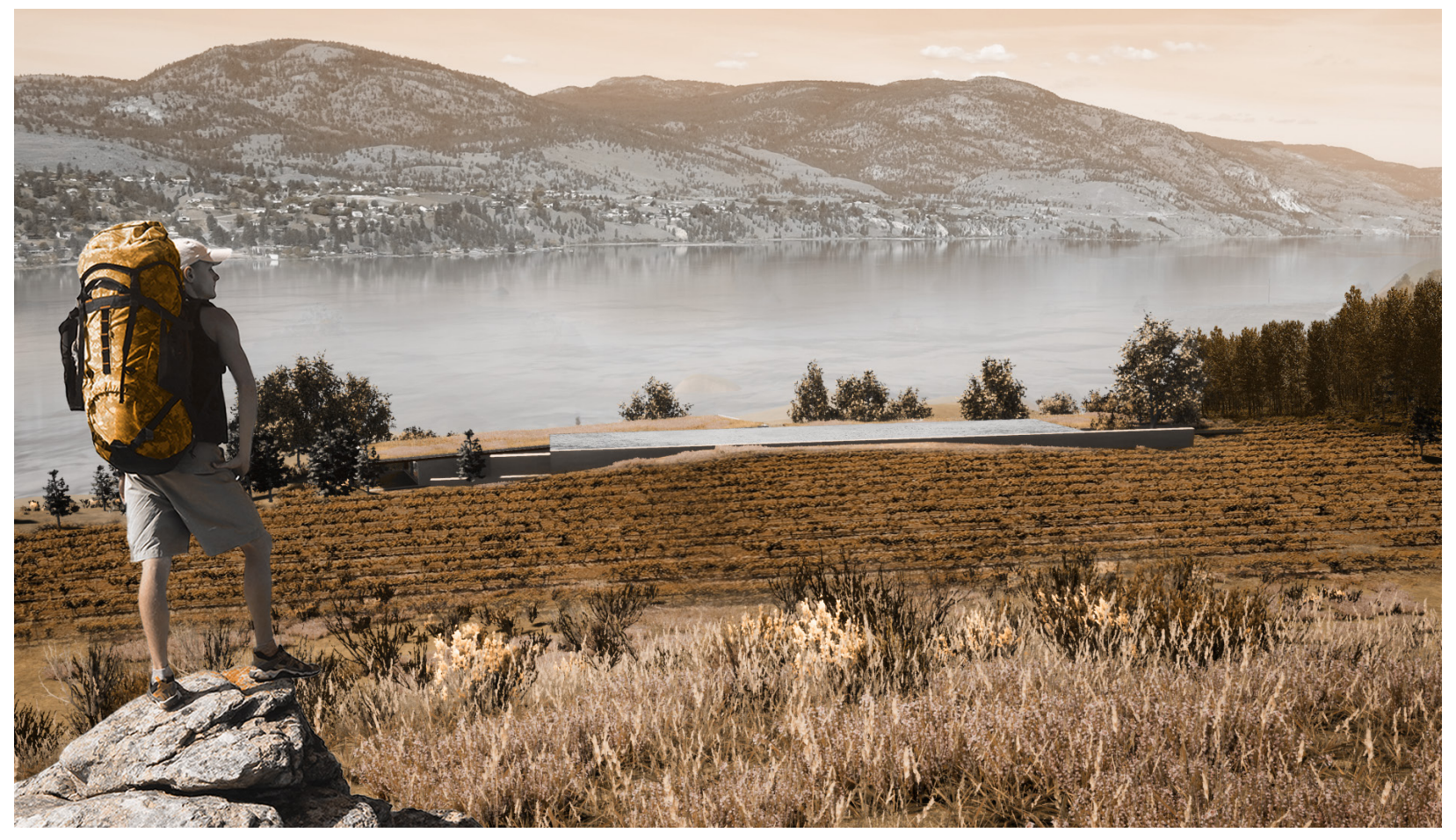

6.6: Hiking Trail Up the Ecological Reserve. 


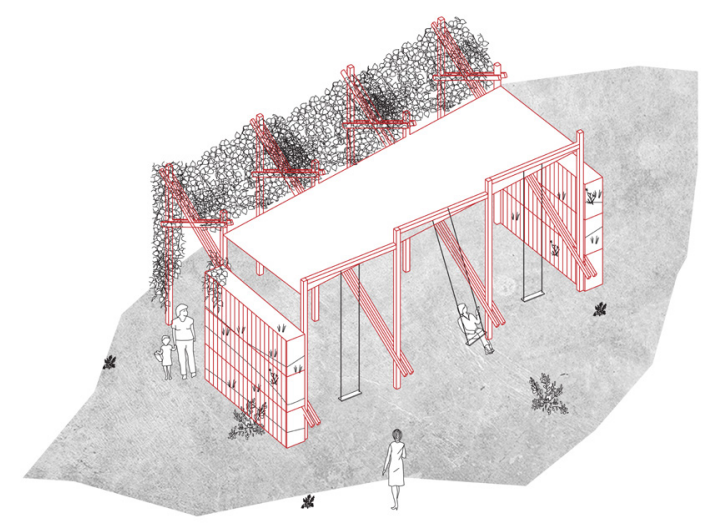

Equipment Storage and Washrooms

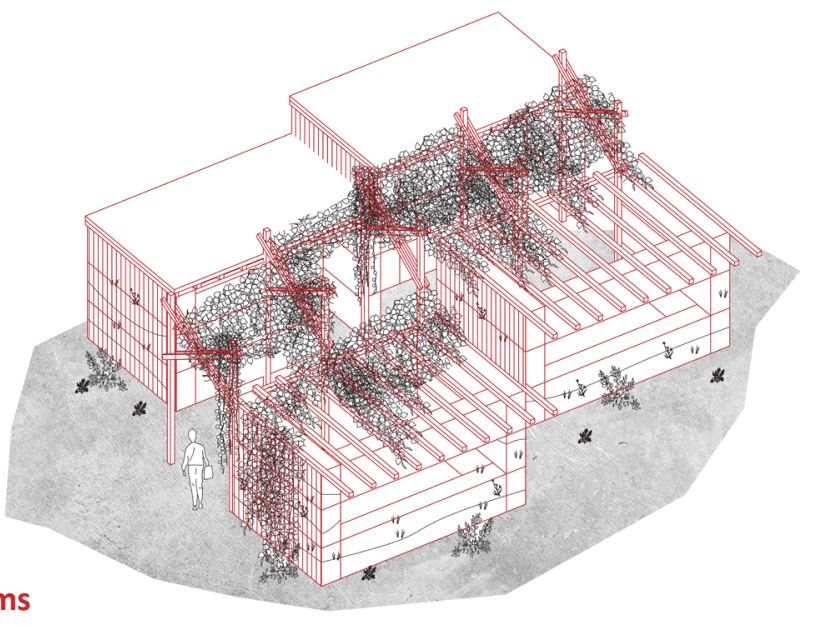

Farmer's Market Kiosks
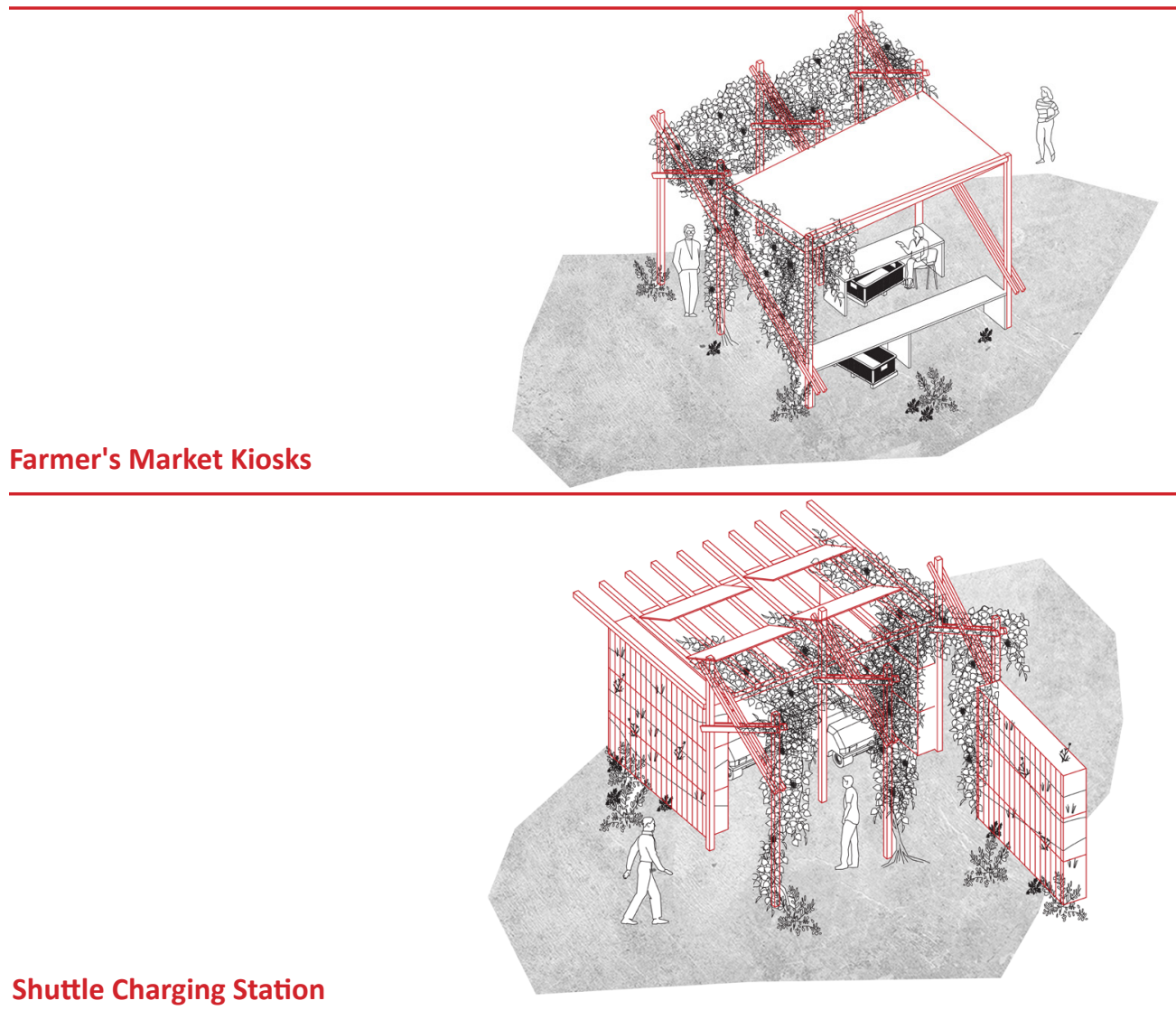


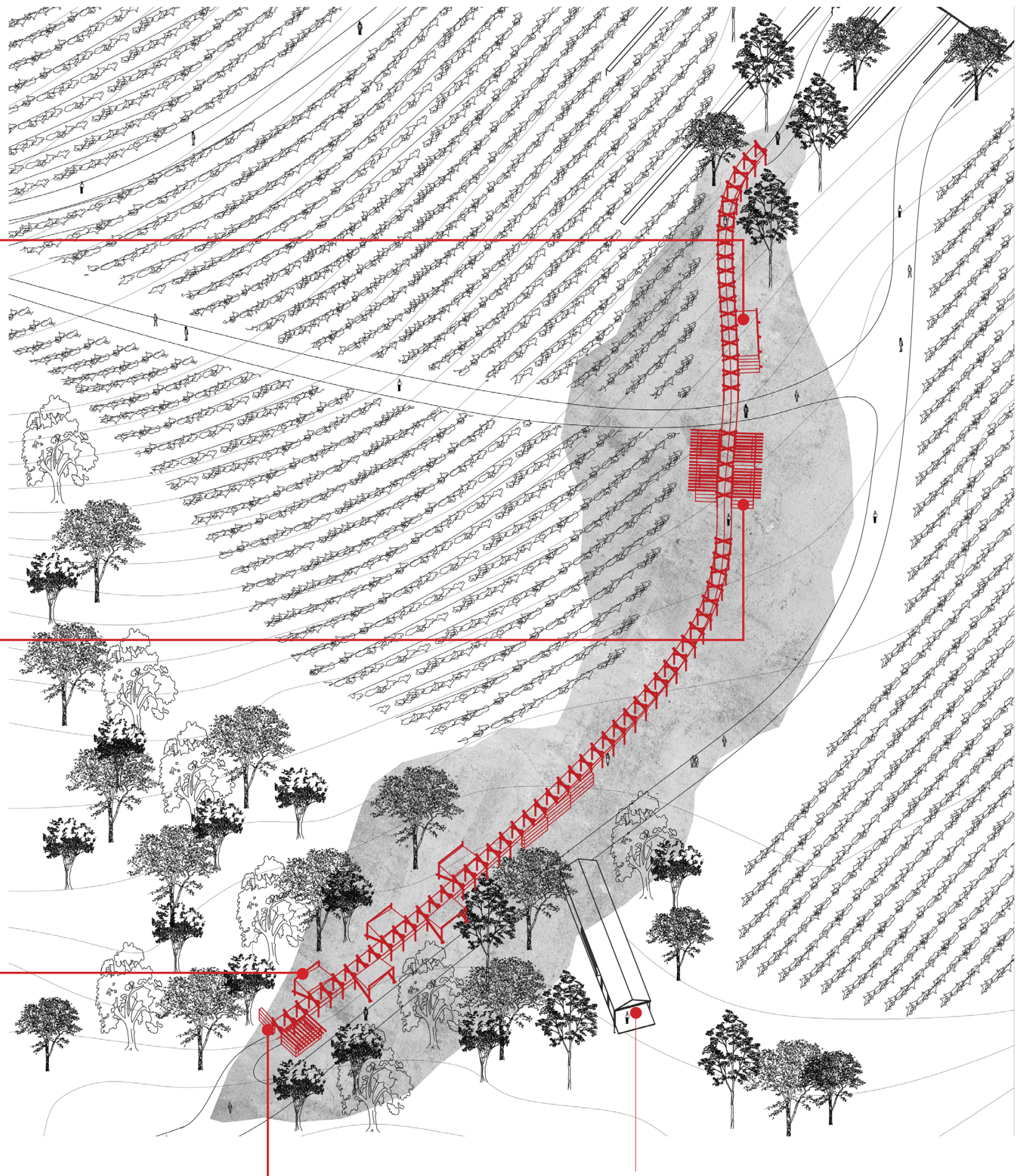

Worker's Housing

6.7: Pathway to the Winery. 
Context beyond the site's property boundaries includes Matheson Creek to the North, Ponderosa Pine forest to the North East, and vineyards on both the North and West sides. The site is setback from Eastside Road, reducing noise pollution from traffic (figure 6.8). The site's altitude provides uninterrupted views of Skaha Lake and adequate sun exposure.

\section{Buildings}

Buildings are spread apart, creating a processional entry sequence on to the site which encourages visitors to explore the landscape. A separate wine cellar, lodge, and campground accommodates guests who wish to stay longer.

\section{Flora}

Bighorn Ridge's native species consist of Ponderosa Pine, Sage Brush, Antelope Brush, and a wide variety of grasses suited to the desert climate. An existing cherry orchard is preserved, paying homage to the Okanagan's agricultural history.

Infrastructure

Bighorn Ridge is situated near Eastside Road; a road that connects Okanagan Falls and Penticton. The site is accessible by either car, bike, or bus.

Soil

There are 4 main soil types which make up Bighorn Ridge, including Colluvial, Eolian, Fluvial, and Glaciofluvial parent material.

\section{Topography}

The site is characterized by its steep topography, providing views of Skaha Lake and the surrounding mountains. A gravity flow winery was implemented as a result of the site's surface relief. 


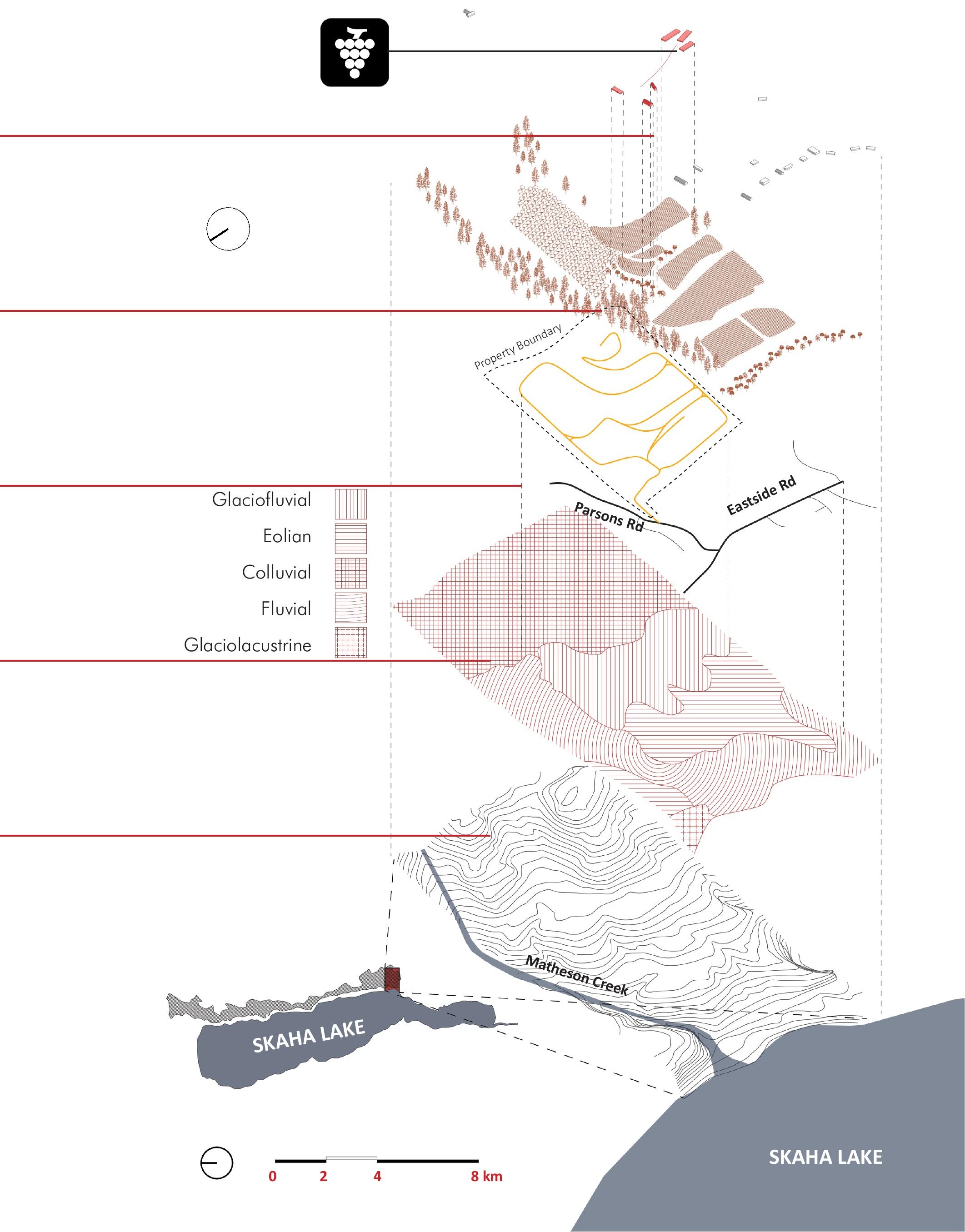




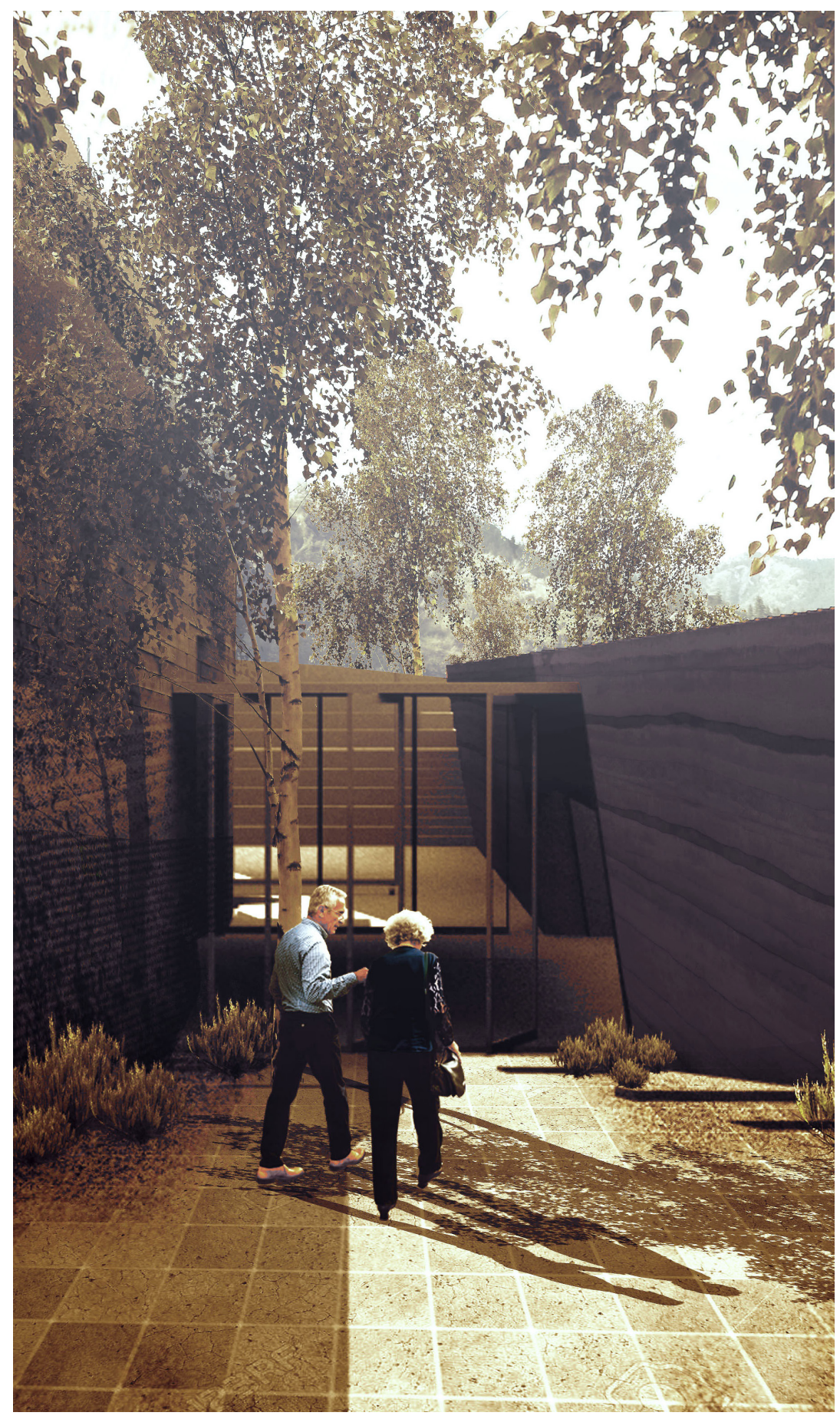

Upon entering the winery, one is greeted by a native landscape which evokes the spirit of the Southern Okanagan. Flanked by rammed earth walls to the West, and biological concrete to the East, the garden stands in stark contrast to the lush vineyard as a reminder of the Okanagan's fragile ecosystem and its semi-arid climate (figure 6.9).

The winery consists of three wings, split by two exterior halls. These exterior halls pay homage to the Okanagan fault lines that define the site's terroir. Through the act of splitting, these spaces introduce natural light farther into the wineries floor plates, exposing elements of the earth, and providing areas for events, relaxation, and the enjoyment of nature (Figure 6.10/ 6.12). Walls on the West side of the exterior hall angle inwards as a nod to the East facing footwalls that characterize the fault line's geological nature. These elements became the focal point of the design, guiding the rest of the spaces. 
The dichotomy in materials on each wall references the contrast in terroir between the East and West sides of Skaha Lake, with the East consisting of metamorphic complex rock, and the West consisting of volcanic sedimentary rock.

Taking ques from the terraces that define the hill, the building follows the contours of the land with a roof pitch that aligns with the hill's surface relief (figure 6.11). Beyond creating a topographically sensitive building, sloping the roofs Westward also reduces facade exposure to the harsh afternoon sun.

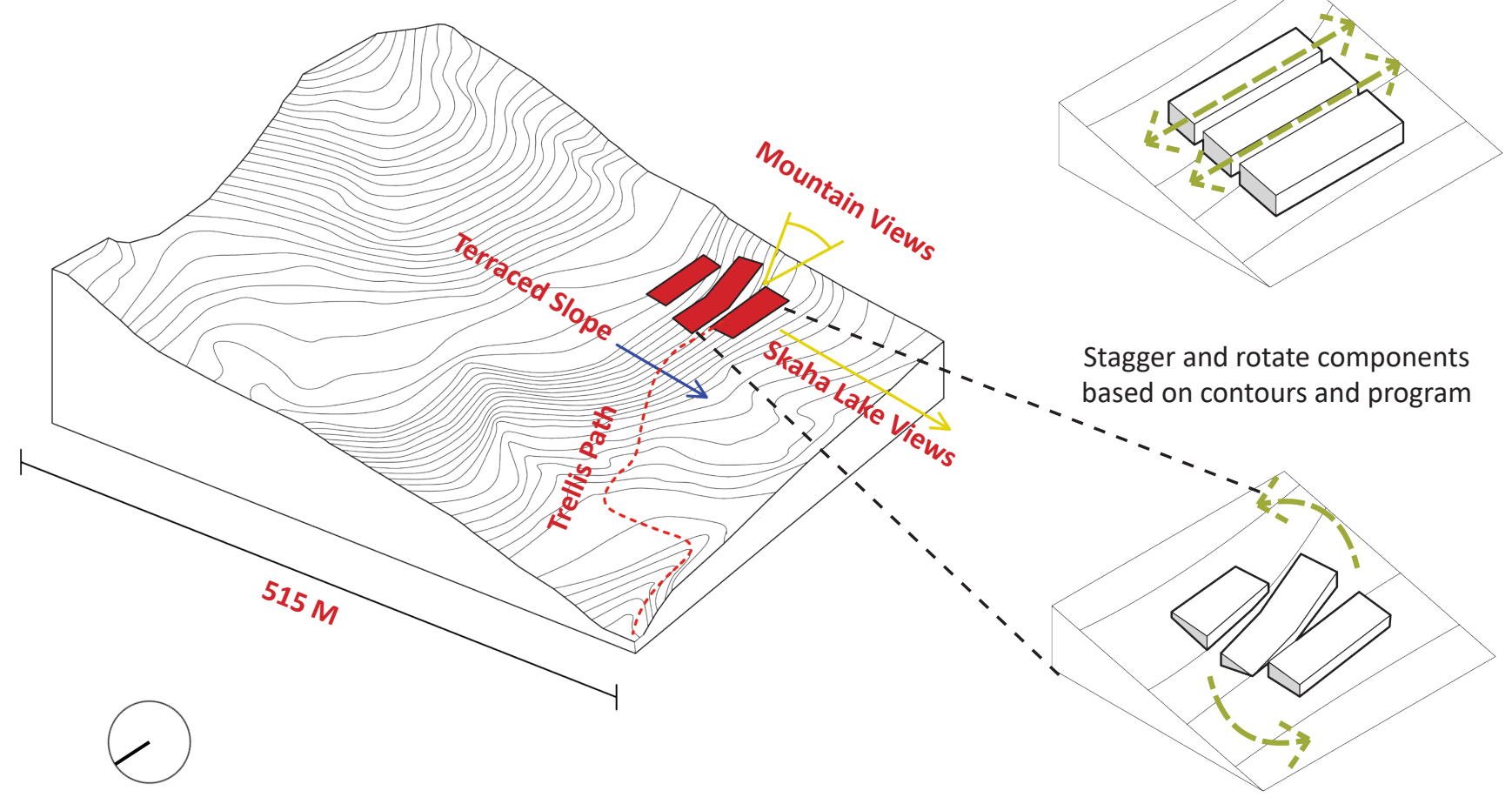

6.10: Massing and Parti. 


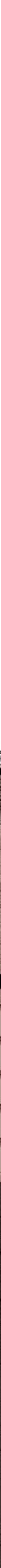

Crush Pad 


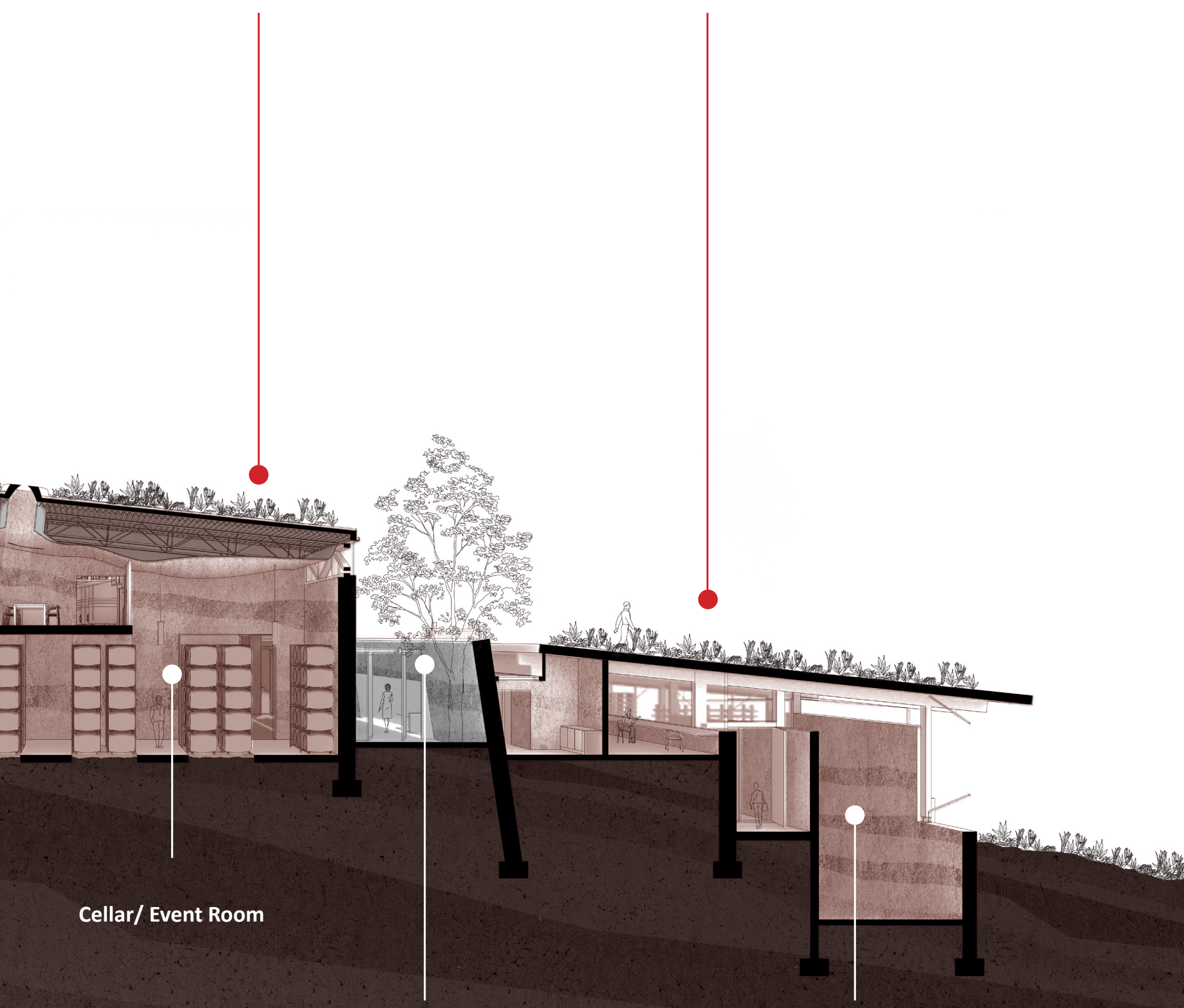




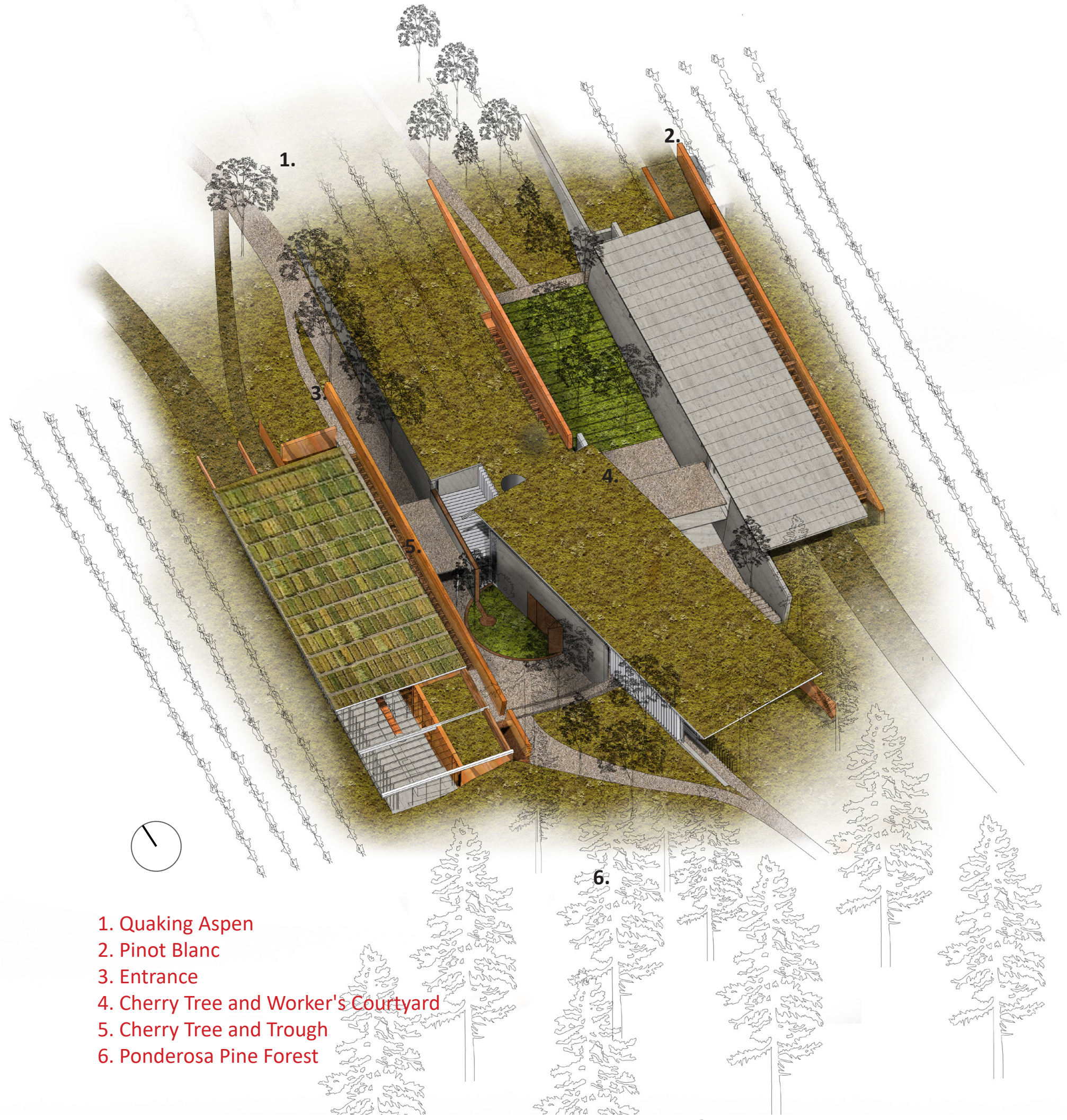

6.12: Axonometric of the Two External Corridors. 


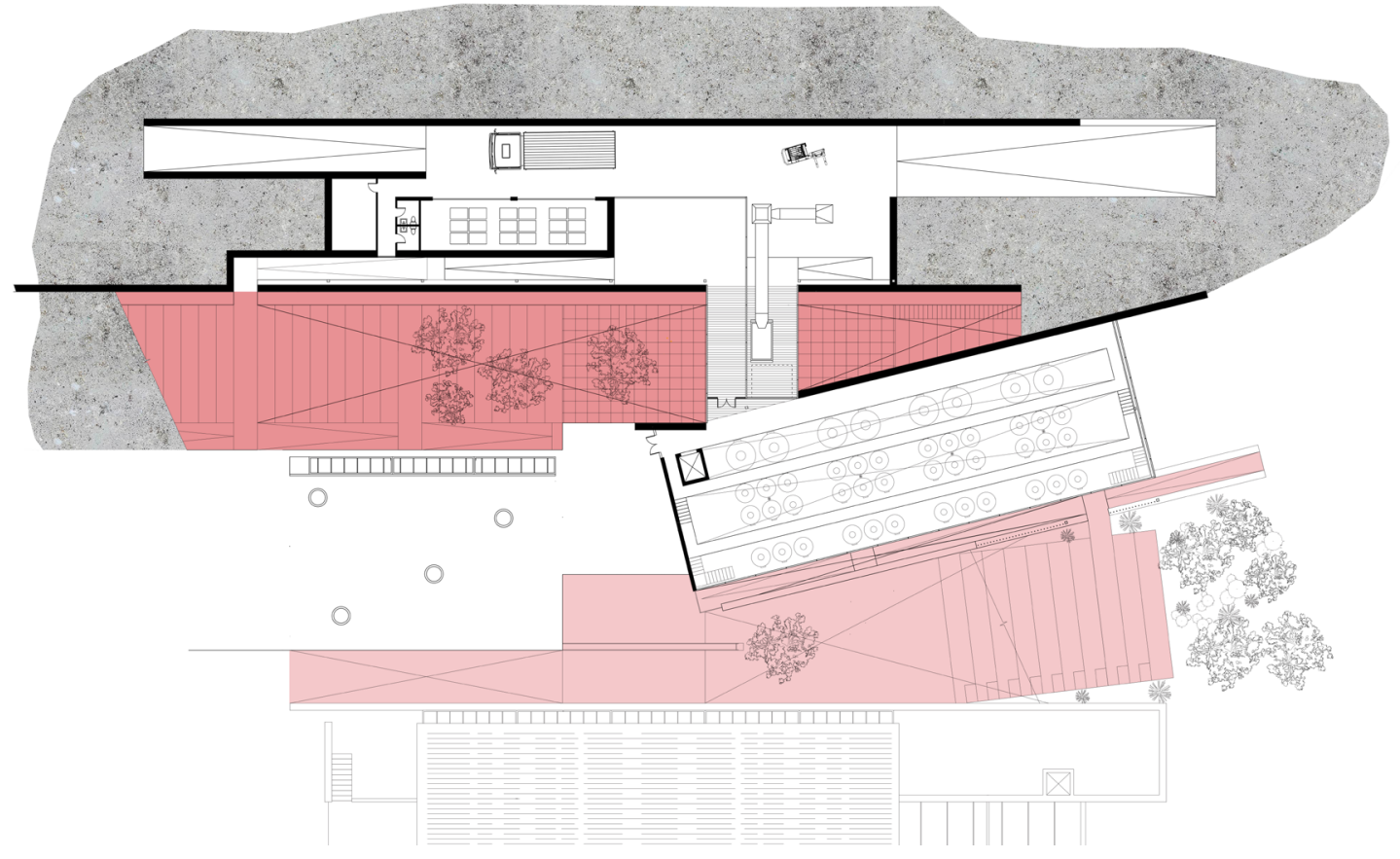

Level 4 (Crush Pad)

Indicates Exterior Hall Space

6.13: Level 4 . 


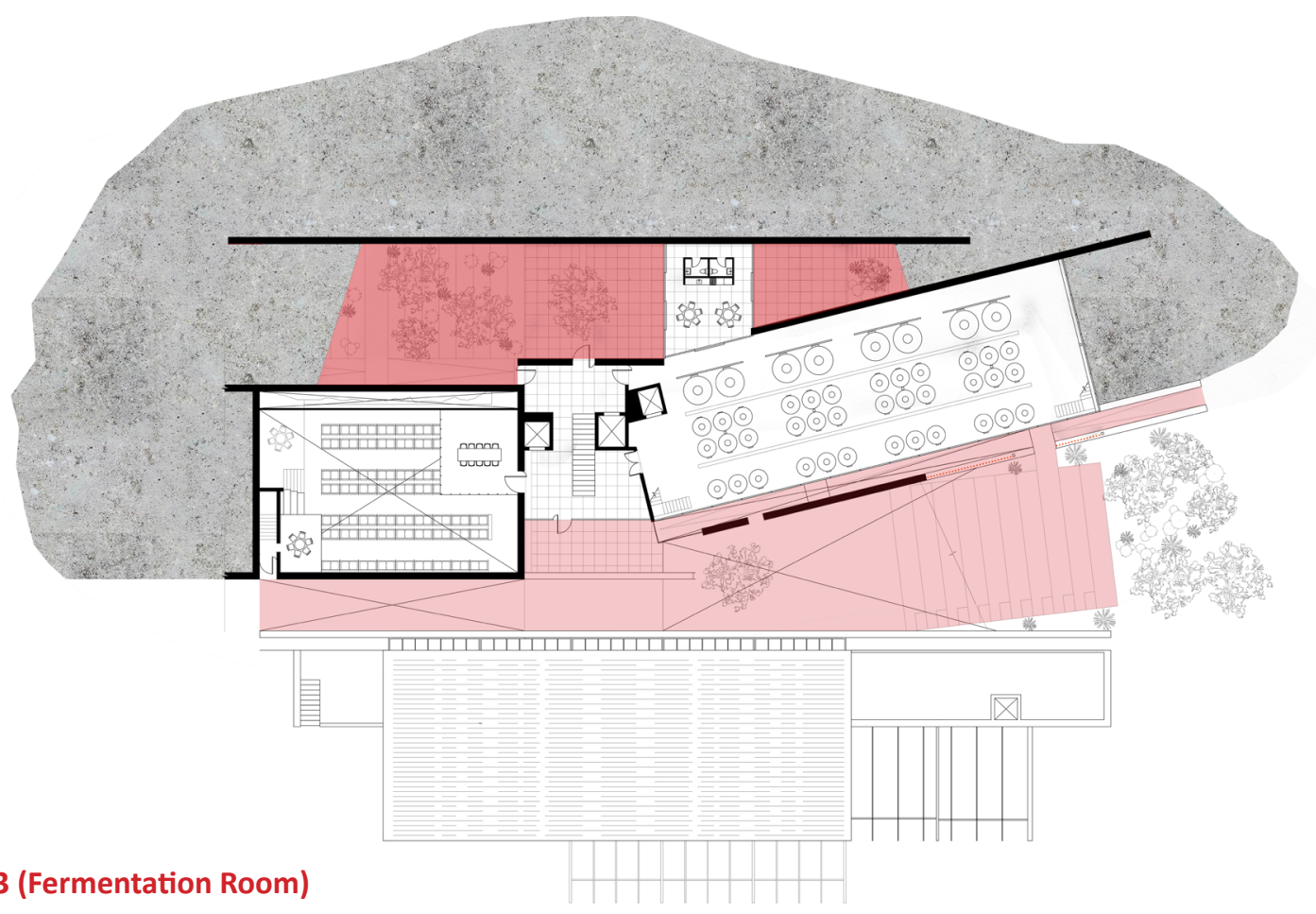

Level 3 (Fermentation Room)

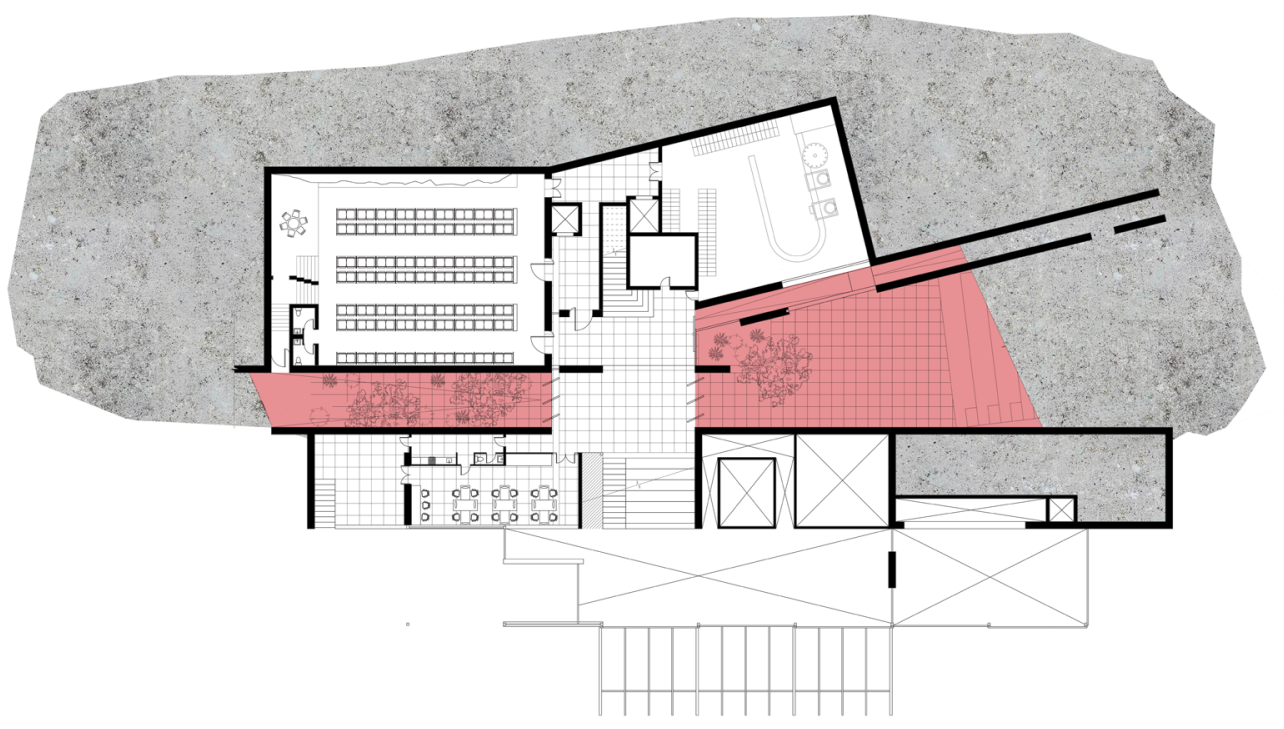

Level 2 (Cellar, Bottling Room, and Level of Arrival)

6.14: Level 2 and 3. 


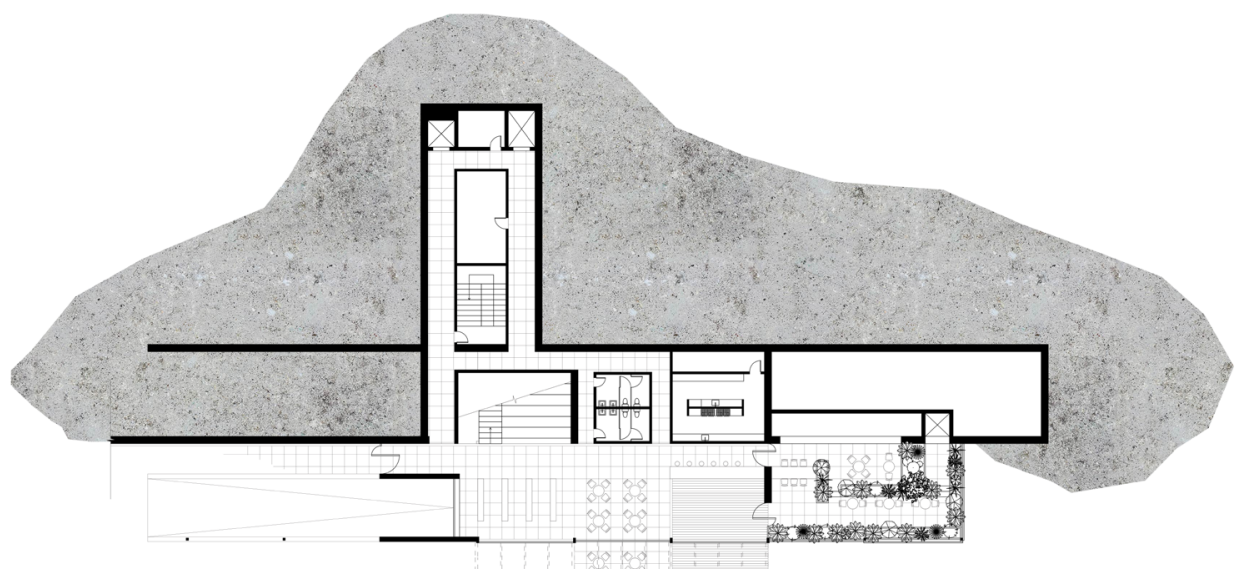

Level 1 (Tasting Room and Green House)

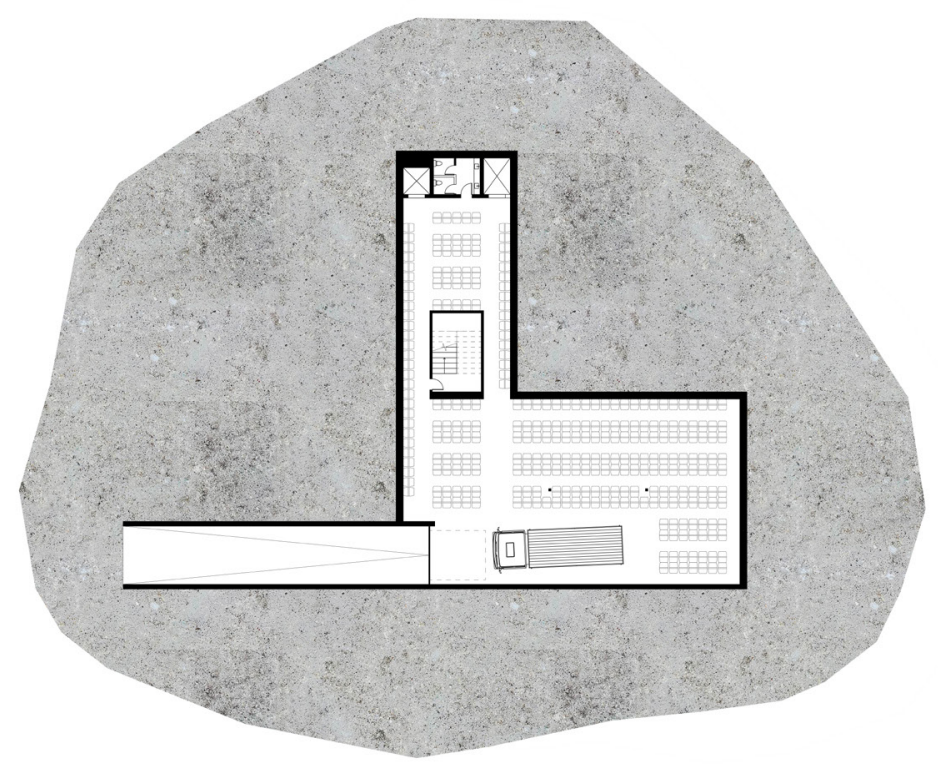

Level 0 (Loading)

6.15: Level 1 and 0. 


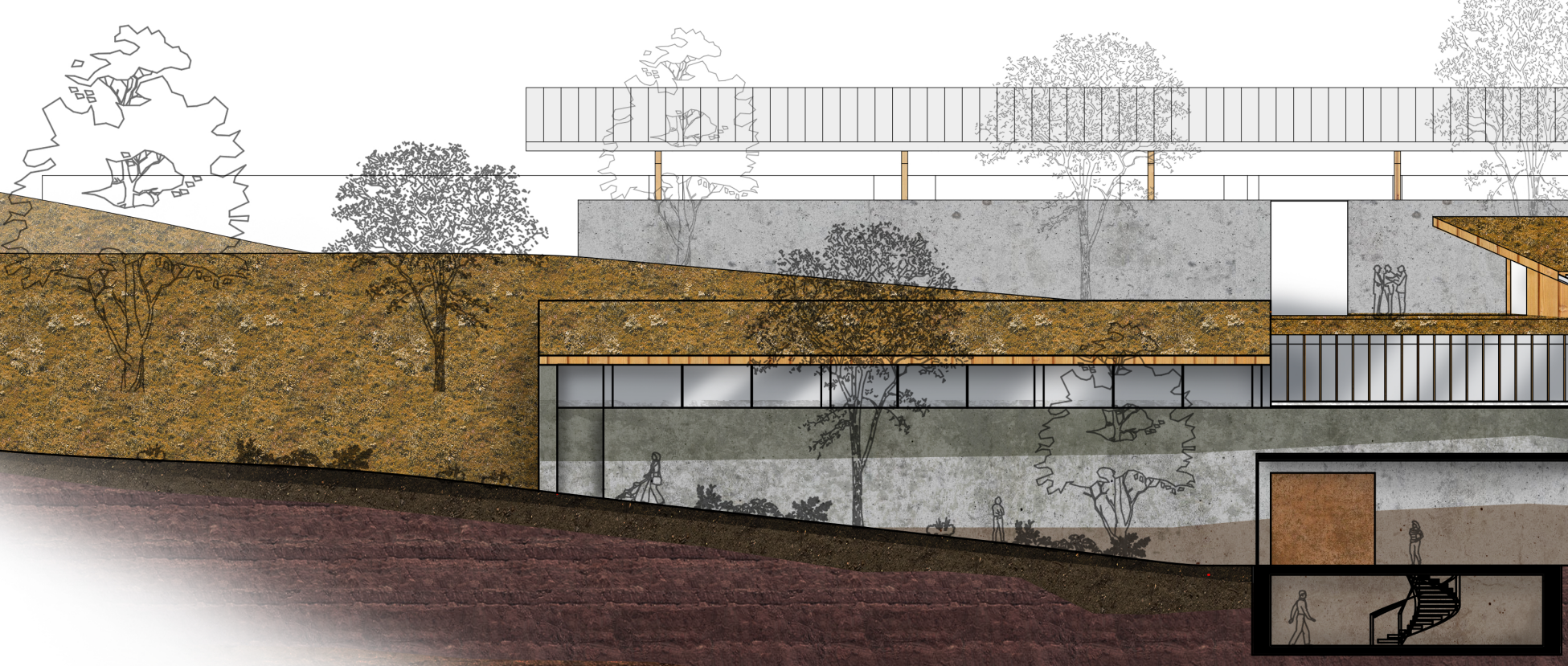




\subsection{THE TASKSCAPE}

"Terroir offers a theory of how people and place, cultural tradition and landscape ecology, are mutually constituted over time. It resembles Tim Ingold's theorization of "land-scape" as a congealed "taskscape," a concretization of practical tasks "carried out by a skilled agent in an environment" (Ingold, 2000, as cited in Paxson, 2010, pg.444). As discussed in part two, terroir comes into being, not only through natural factors, but the perpetual process of human activity. Disregarding the Taskscape, would reduce our engagement with the environment to the visual gaze. It constitutes the anthropological events that occur in daily life, shaping our understanding of the environment, and in return shaping us. It is the component of this winery that considers the relationship between these anthropological events and architectural terroir. "Left uncultivated, the best soil is no different to poor soil", without the winemaker, there is no wine, and without dwelling, architecture ceases to exist (Louis XIV, as cited in Schuilenburg, 2011).

The taskscape unfolds the processes of temporality, whether that be mindfulness of the transient spaces so common in wine tourism today, shifts in the weather, or cultivation of the vine. Terroir as a product of these external factors is a slow process and thus requires time to comprehend. It is why those who spend much of their time in a particular place come to know it so well. With the understanding that place identity is becoming evermore turbulent, especially in the age of globalization, it was important to create an architecture that embraces slowness and encourages visitors to take in the site's terroir, while also connecting them to the ongoing processes of winemaking. 
Bighorn Winery acts as an extension of the site's pathway network where visitors may walk onto the buildings rooftop or through the building itself via two external corridors which slice through the structure. Within the winery, visitor spaces and production spaces overlap, with areas that look onto the fermentation room (figure 6.17), an event room that views onto the cellar (figure 6.18), and a bottling room which opens up onto the winery's external theater. The theater can be used for performances, outdoor dining events, leisure, or as a shortcut to the other side of the vineyard.

These activities are important as "repeated encounters with places, and complex associations with them, serve to build up memory and affection for those places, thereby rendering the places themselves deepened by time and qualified by memory" (Harvey, 1996, as cited from Dwelling place and landscape Orchard, pg.3). The restaurant, and tasting room, adjacent to the building's greenhouse on the South end, are connected so occupants can observe the process of harvesting and cooking food. The tasting room also opens up onto the agricultural landscape so that the interior becomes connected with the immediate landscape (figure 6.19). A composting facility overlaps with the greenhouse so that food waste can be transported easily. Heat produced through the microbial breakdown of organic matter is used to run the tasting room's radiant floor system (figure 6.20). 


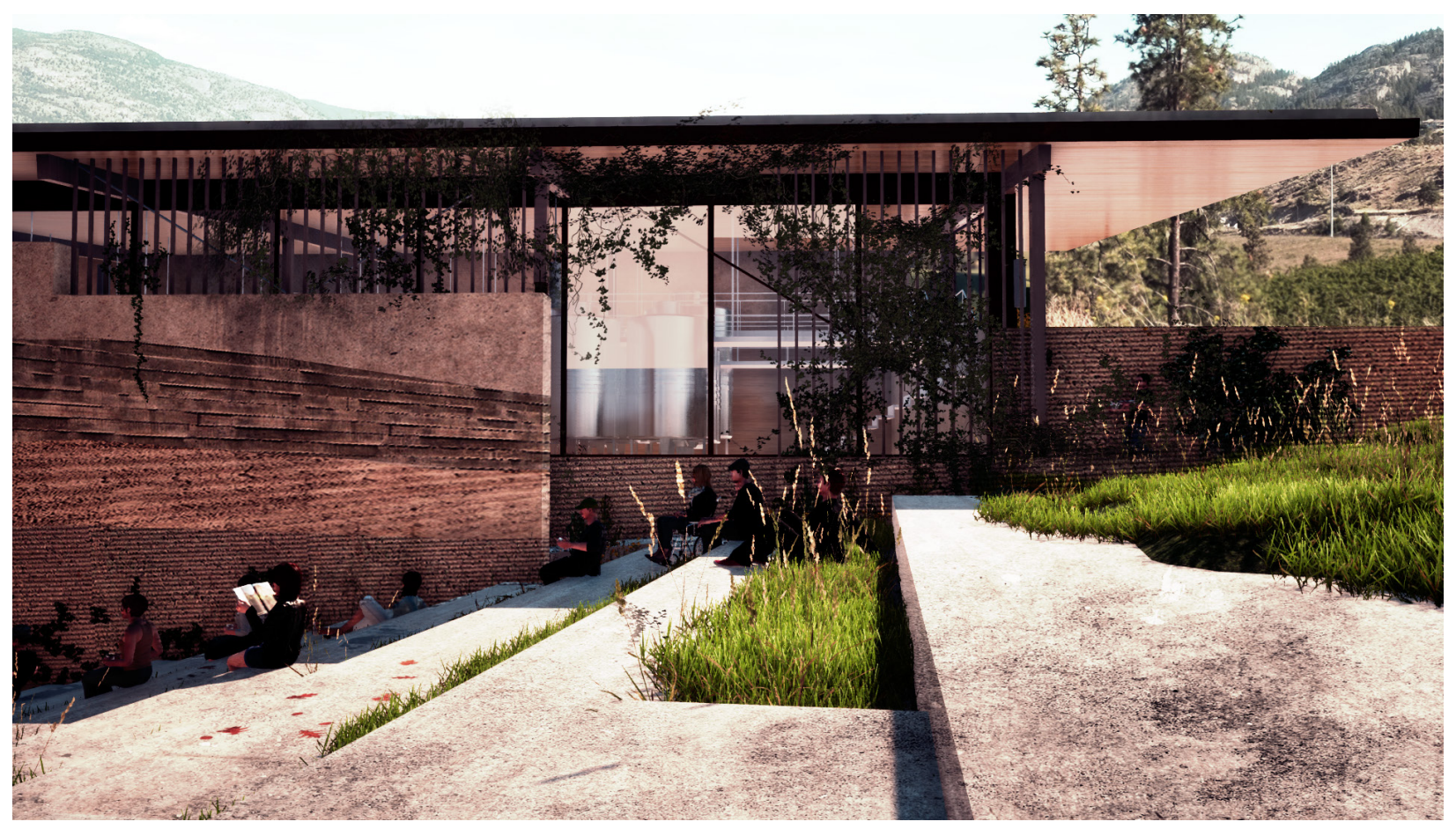

6.17: The Fermentation Room and External Theater. 


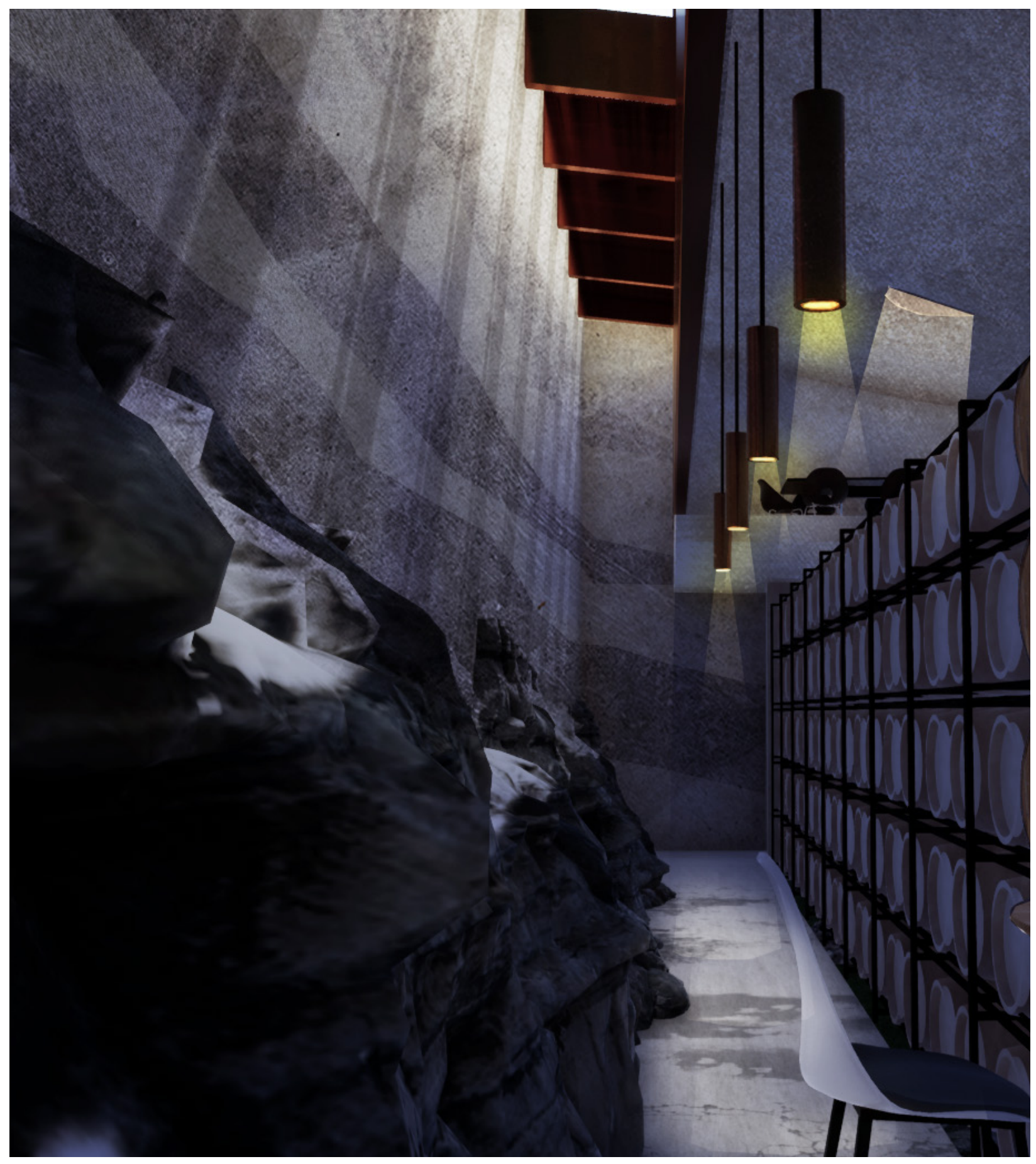

6.18: Cellar and Event Room. 


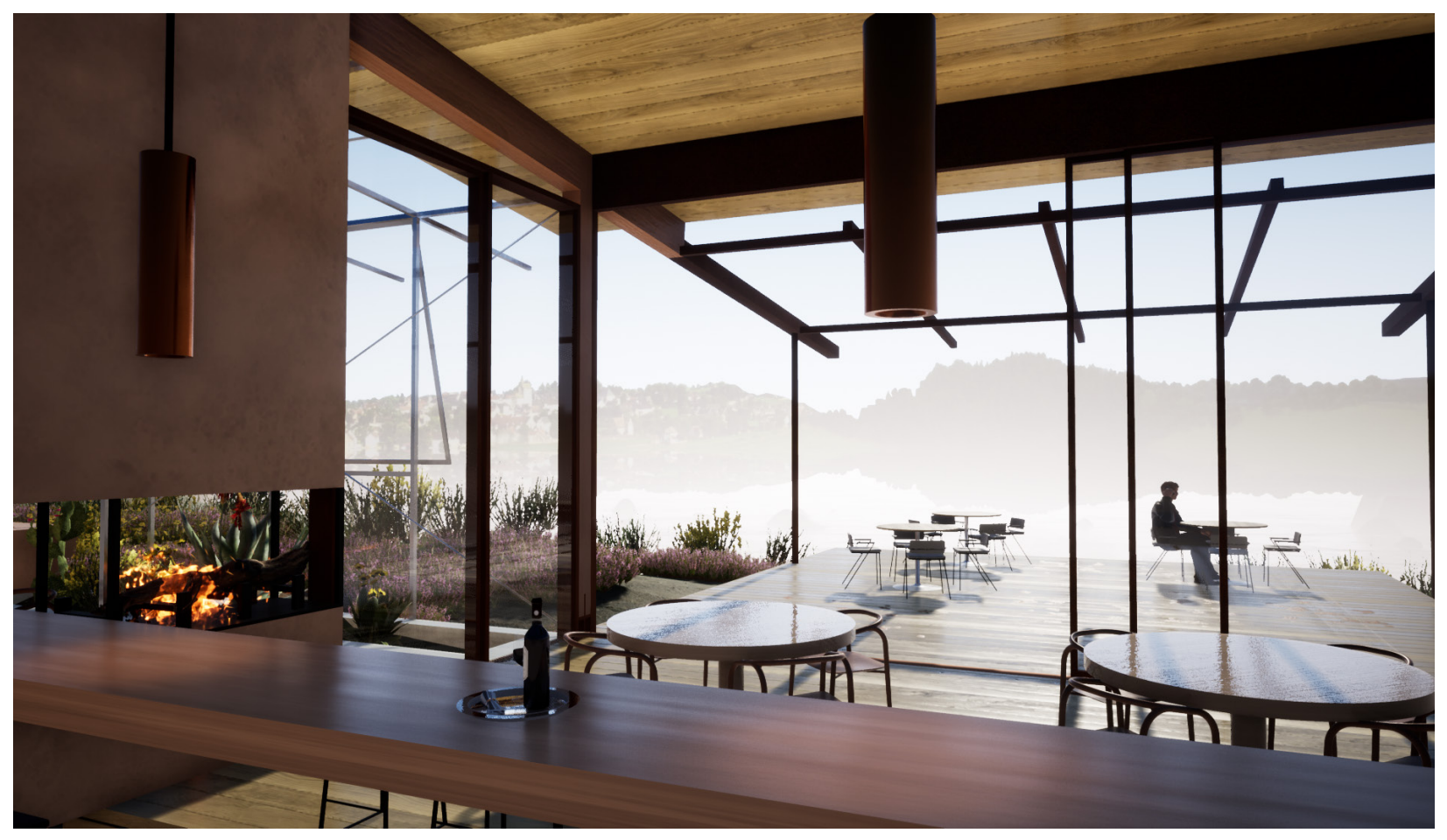

6.19: Tasting Room and Greenhouse. 


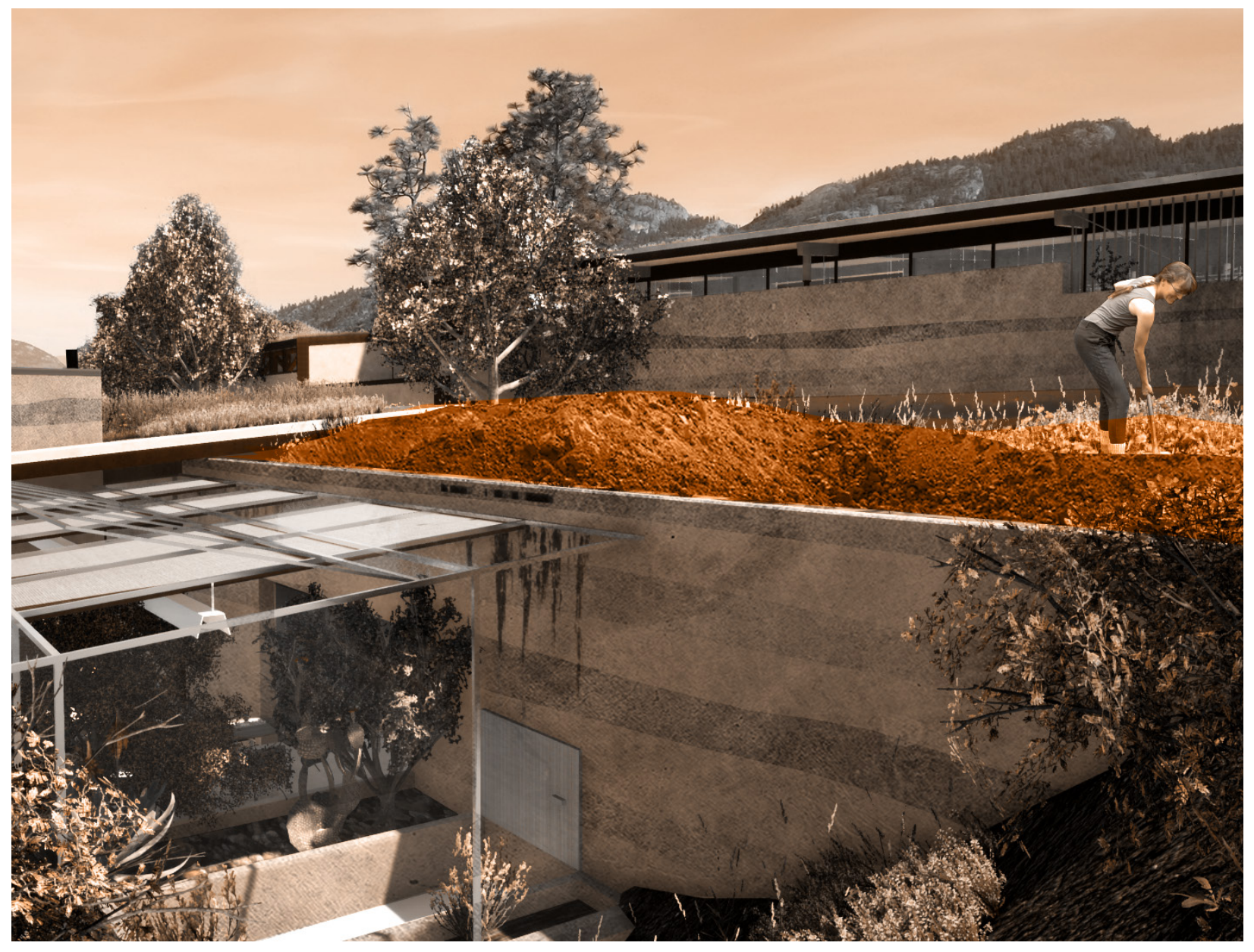

6.20: Composting Area. 
For workers, the attachment for the land on which they till is often related directly to the physicality of their labor. "The farmer's topophilia is compounded of this physical intimacy, of material dependence and the fact that the land is a repository of memory and sustains hope" (Tuan, 1990, pg.96-97). Bighorn winery considers the physicality of this activity interwoven with leisure, and life outside work, incorporating areas of rest adjacent to areas of production. The fermentation room and crush pad flank a courtyard where workers can have lunch and socialize, worker's housing sits adjacent to the campsite and vineyard, and a native garden provides relief from the physically demanding work while allowing employees to take in views of the landscape (figure 6.21). This balance between production and relaxation allows for workers to reflect on their labor and their participation in the taskscape.

Furthermore, the building takes advantage of the landscape to aid it in the process of winemaking. Situated on the terraced hillside, the winery uses gravity to move grapes and juices from one part of production to another. With the crush pad located at the top of the hill, grape juice flows down to the fermentation area, then cellar room, before being bottled and served at the restaurant, or being shipped from the loading room at the lowest elevation of the building. 


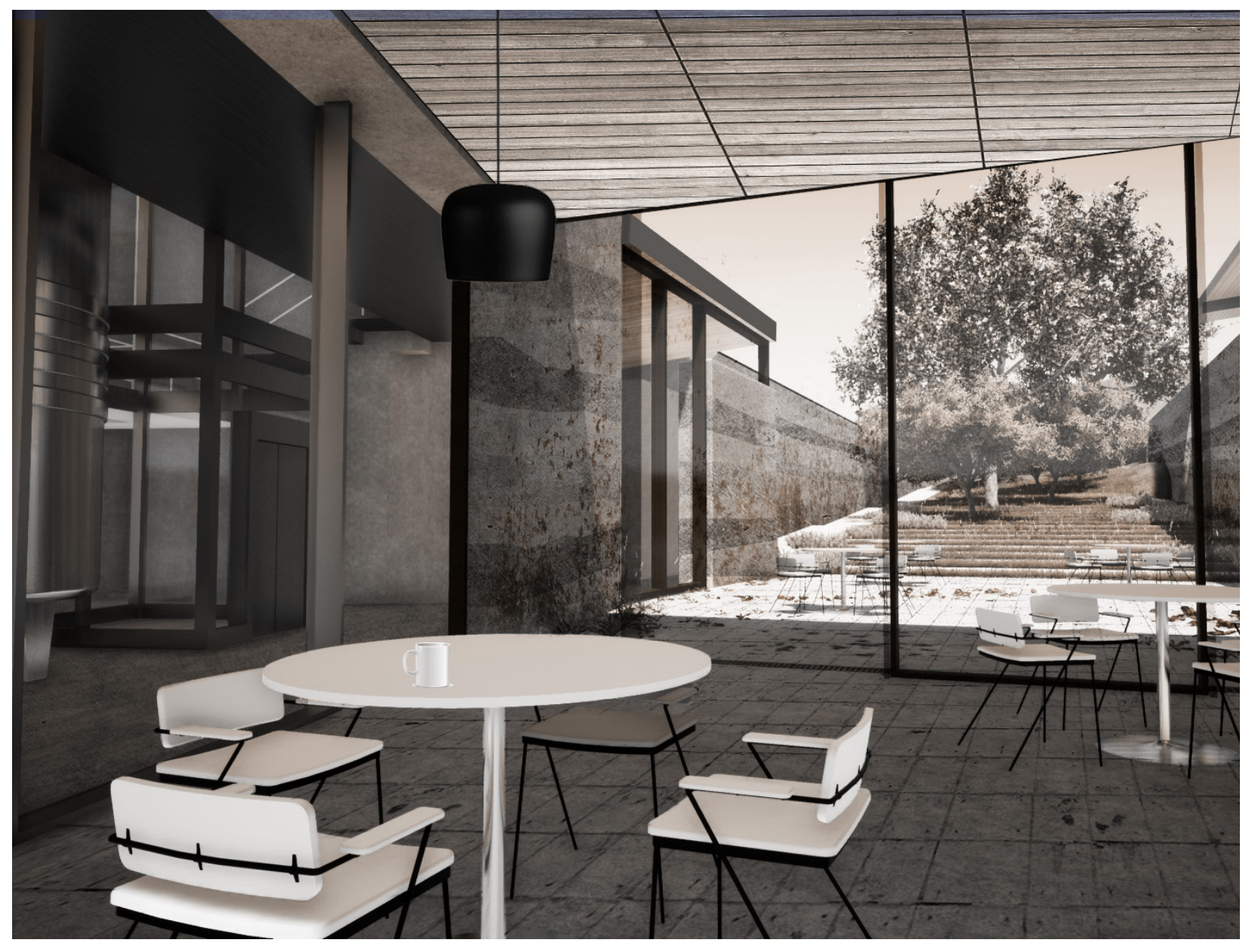

6.21: Staff Room and Courtyard Adjacent to Fermentation Tanks. 


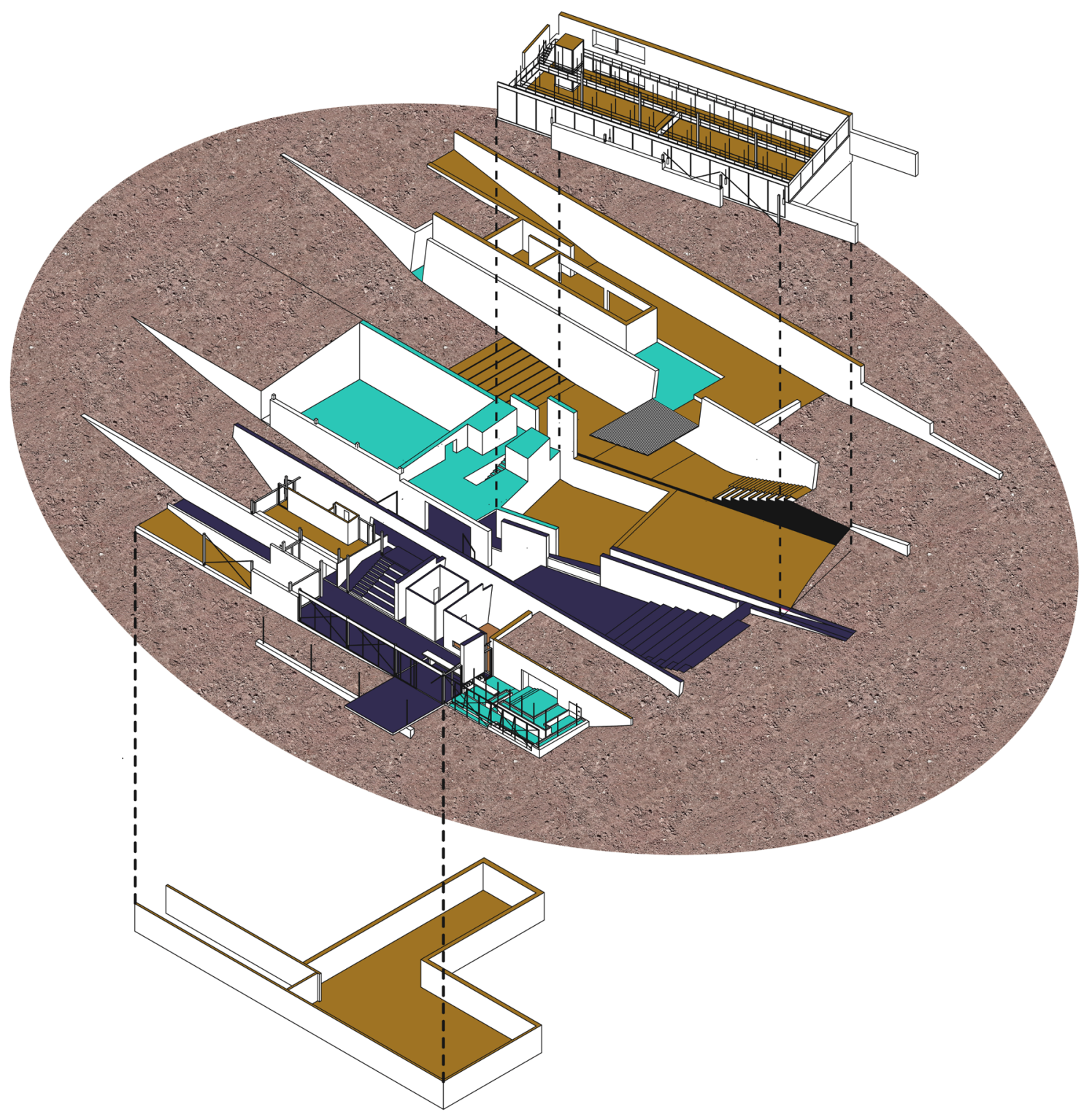

Mixed

Visitor

Production

6.22: Programmatic Axonometric. 


\subsection{ARCHITECTURAL FERMENTATION}

The earth is not inert, but a slow and ever-changing substance, subject to changes in the weather, or in the words of Heidegger, "the earth is the serving bearer, blossoming and fruiting, spreading out in rock and water, rising up into plant and animal" (Heidegger, 1951). It succumbs to the weather, "erosion, decay, and destruction uncover or highlight concealed or unrecognized structure: decay of tree exposes growth rings in its core; weathering exposes" (2000, Spirn, pg. 104). Terroir's slow but gradually changing character evolves through weathering, faulting, and other significant geological processes. This changing character can be seen in architecture that embraces weathering, highlighting its intrinsic temporal nature. In return, the building becomes rooted to place through the processes of decay unique to its climate. Architectural fermentation recognizes that weathering need not be seen as a subtractive process, but rather as an additive one, where "finishing ends construction, weathering constructs finished" (Leatherbarrow and Mostafavi, 2001)

In the case of architecture, materiality bears the brunt of the weather. Embracing rawness through materials void of coatings and chemicals is to appreciate the material's intrinsic qualities, much in the same way one may appreciate a wine that evokes a terroir unaltered by fertilizers. Often most successful in embracing the weather is vernacular architecture which uses local materials that age gracefully with time, and building forms suited to the region's climate. 
Bighorn Winery's material palette is composed as layers, much like the geological makeup of its site (figure 6.23). By mimicking these layers the building not only speaks to Bighorn's archaeological history, but considers its inevitable end of life, gradually returning to the earth from which it came. Materials are placed at different elevations based on the composition of the site's soil. Areas at lower grade, such as the winery's tasting room floor, utilize Mylonitic Gneiss Stone, a material which makes up a majority of the bedrock in the Southern Okanagan. Mylonitic, being the most common type of Gneiss, is highly fractured due to high pressures in the Okanagan Fault zone, and thus fracturing became an architectural expression throughout the building's floor plates (Metamorphic Rocks, n.d.).

Biological concrete was used for some of the exterior load bearing walls. Utilizing a layer of finally tuned cement which holds rainwater and features low PH levels, the concrete promotes the growth of native plant species such as nugget moss, allowing the building to blend with its surroundings overtime. Various stained bands of concrete are placed with the intention of indicating the building's relation to the layers of surrounding earth. Beetle-kill wood is used for the building's shading system, but also for structural support in the form of CLT. By using Beetle-kill wood, the winery sequesters Co2 that would otherwise be emitted from the trees. Over time, any wood that does begin to decay from the shading system is used as mulch in the winery's native garden. Corten steel doors throughout the building's lower levels stain the gneiss flooring overtime. Through weathering, the building becomes a patchwork with a continuously changing quality, much like the land itself (figure 6.24/6.25) 


\begin{tabular}{l} 
Organic Material \\
\hline Surface Soil \\
\hline Roots \\
\hline Sub Soil \\
Maciofluvial Parent \\
\hline Mylonitic Gneiss Bed- \\
rock
\end{tabular}

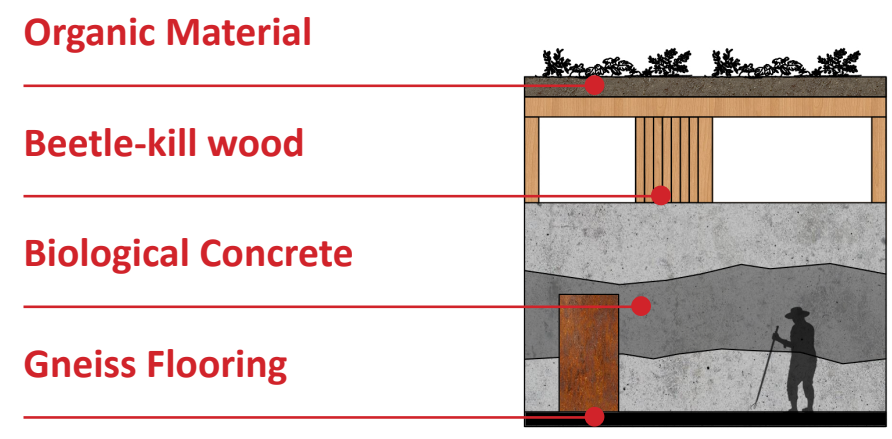

Material Weathering Process
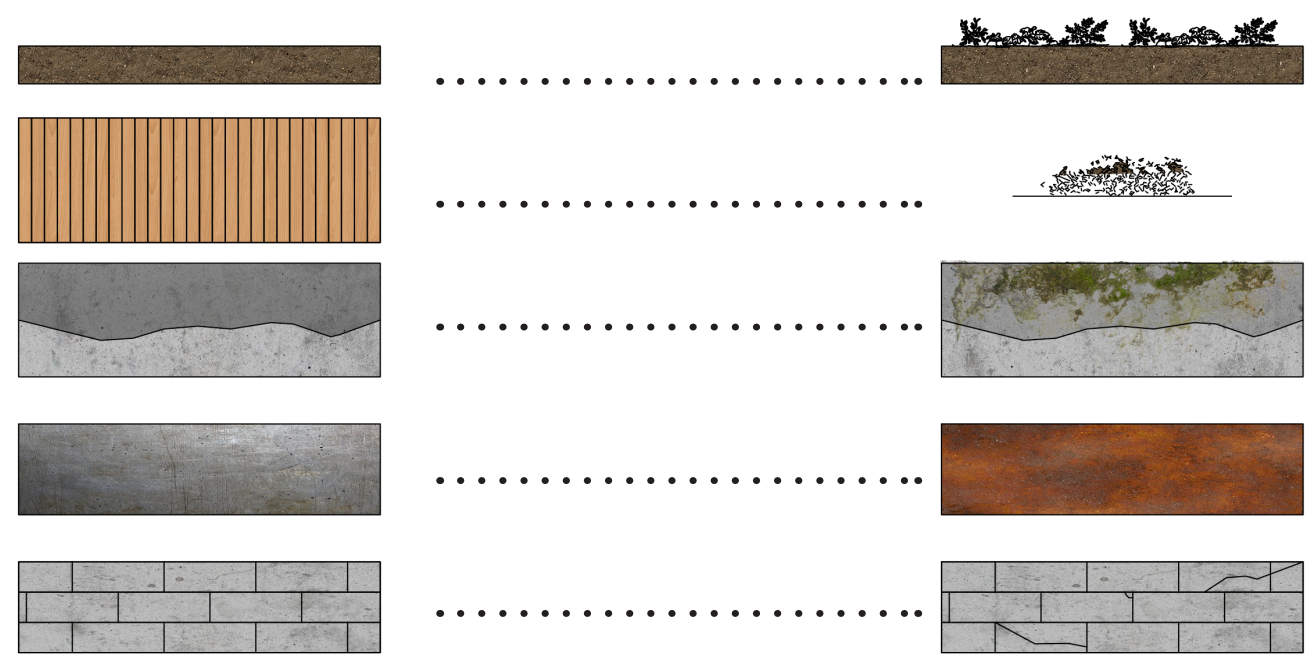

6.23: Elevation Showing Layers of the Building Facade. 


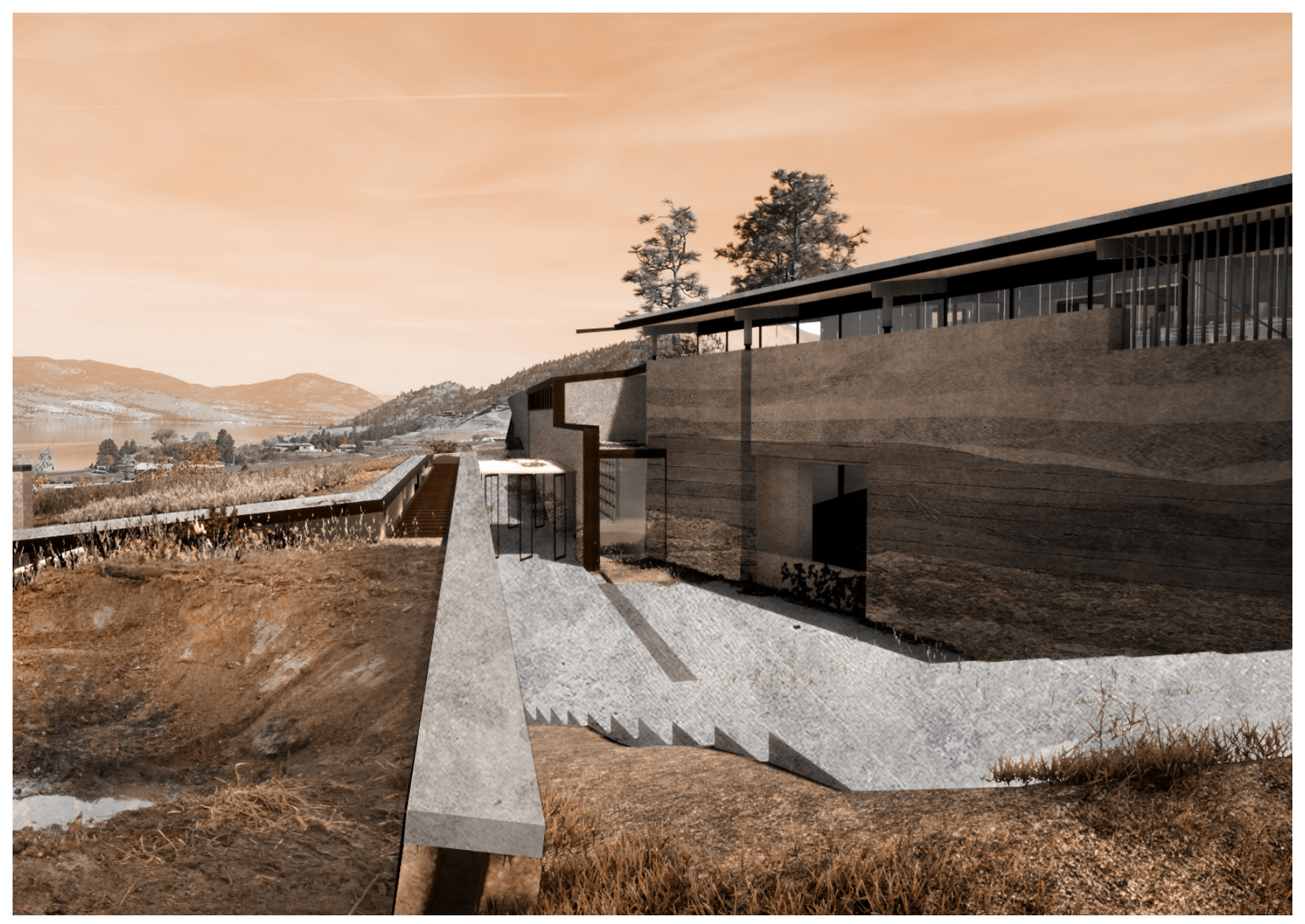

6.24: New Structure. 


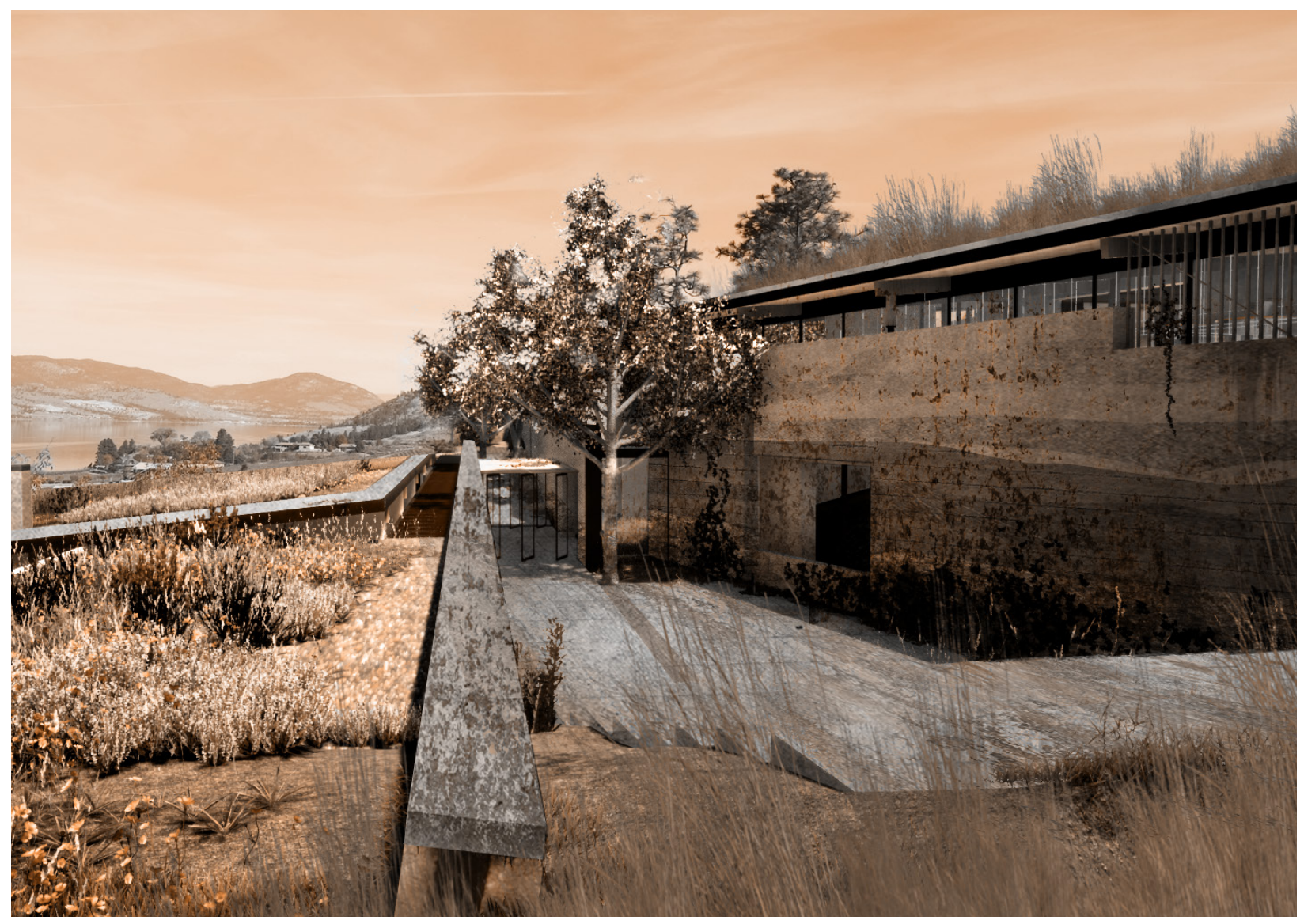

6.25: Gradual Decay. 


\subsection{CLIMATE}

Terroir, although a concept that recognizes its roots in the immediate landscape, extends beyond the vineyard, to include climate, which corresponds with the flora, fauna, and soil unique to its particular site. Climate can influence a grapes acidity levels and the speed at which it ripens, but it also creates "a coherence of human vernacular landscapes" which emerge "from dialogues between builders and place, finedtuned over time. They tell of a congruence between snowfall and roof pitch, between seasonal sun angles and roof overhang, wind direction and alignment of hedgerows, cultivation practices and dimensions of fields, family structure and patterns of settlement" (2000, Spirn, pg.17).

The South Okanagan climate, in which the site is centrally located, can be described as "a dry, continental climate with low levels of precipitation and humidity, short and relatively mild winters, hot summers and high annual sunshine hours" (Area "D" Okanagan, n.d.). Although the Okanagan Valley does not have its own distinct vernacular architecture, it has copied vernacular architecture from other regions with similar climates. The Okanagan commonly utilizes Santa Fe Architecture, native to New Mexico and the South Western United States (Hamilton, n.d.).

Avoiding the creation of faux or Disneyfied copies of Santa Fe architecture, but playing to the desert like climate, Bighorn Winery is a low slung building that hugs the earth, creating a new vernacular for the valley. By placing the winery partially within the hillside, the building's energy usage is reduced and occupant comfort is increased. Walls are thick and heavy, mitigating temperature fluctuations, while appearing as if they emerged from the earth (figure 6.26) 


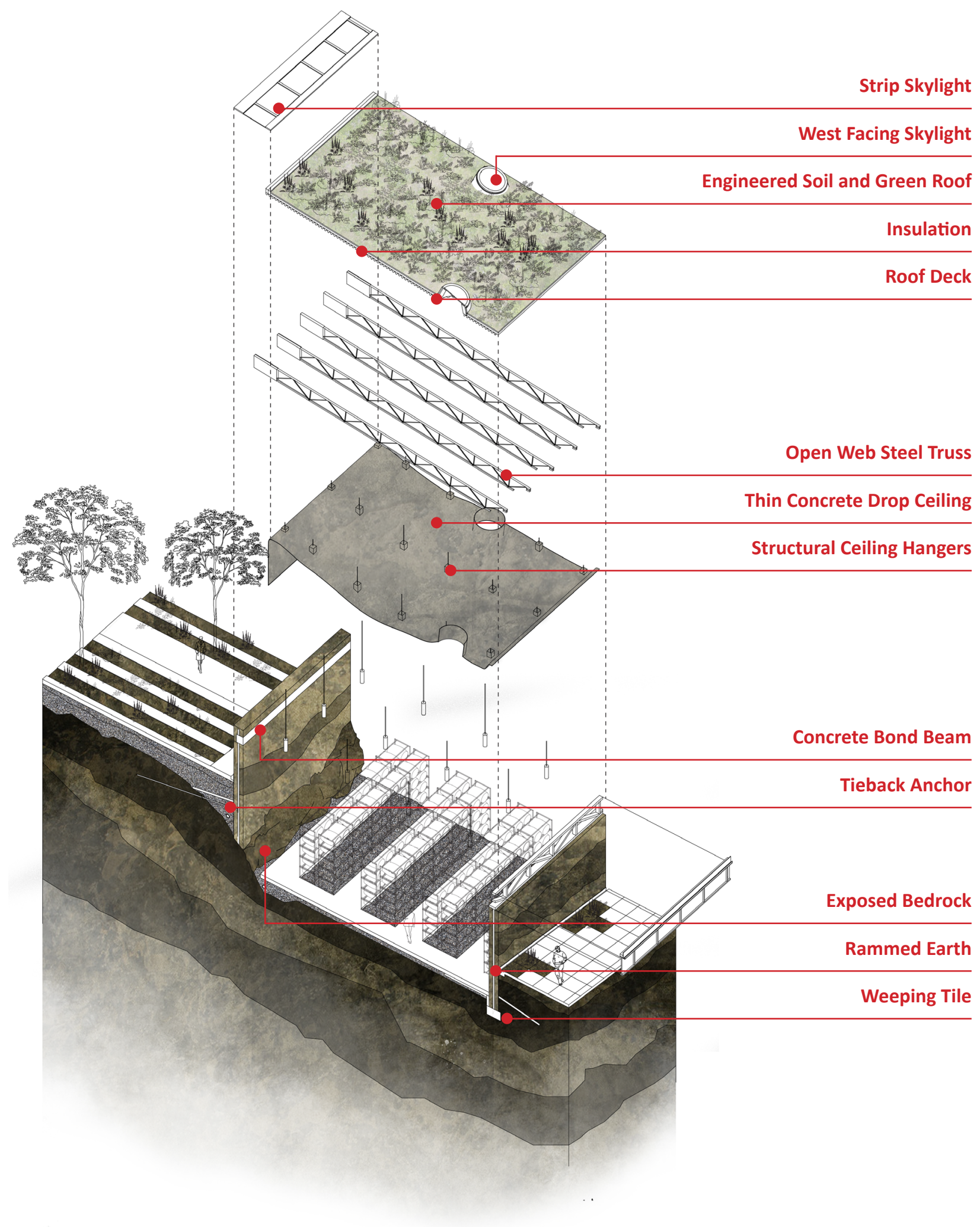

6.26: Cellar Detail Showing the Building's Relationship to the Earth. 
As one of the building's key defining features, the rooftop responds to changes in the sun and contours in the landscape. Over the crush pad the roof lowers towards the West, preventing any harsh afternoon sun from reaching the grapes or juice. Over the fermentation area the roof overhang extends South, keeping direct light out during the summer while allowing for adequate light during the winter months (figure 6.27). The tasting room is flanked on the South end by a greenhouse which utlizes the sun's heat during the winter months and can be opened up in the summer for air circulation (figure 6.28). Screens made from Beetle Kill Wood shade the Western facade, and a series of skylights run parallel with the vineyard, allowing natural light to enter deep into the building's floor plates (figure 6.26). Skylights are operable in order for hot air to escape the building during periods of extreme heat.
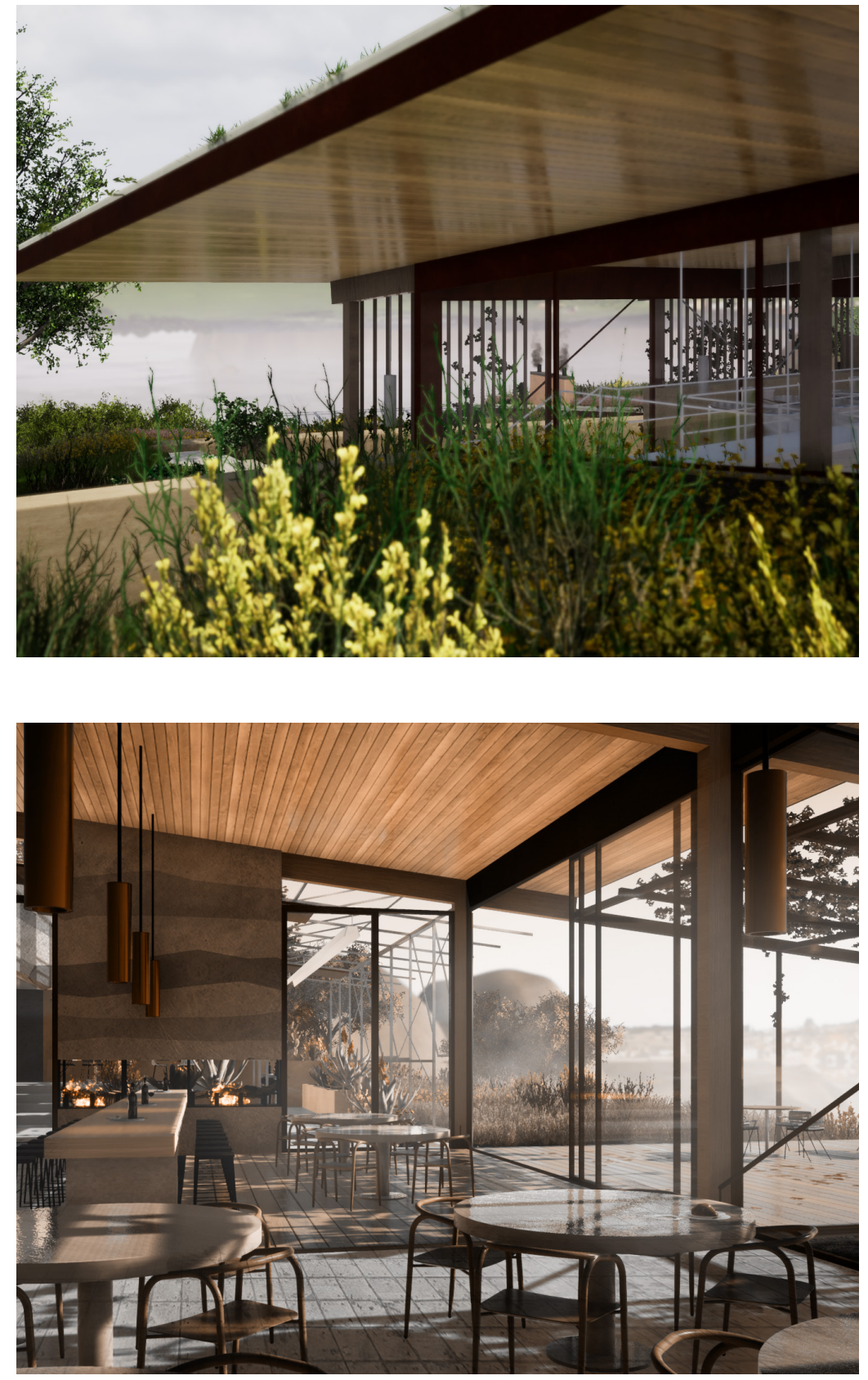
Taking advantage of the opportunities provided by nature, the central corridors that run through the building use native species of deciduous trees. Not only do these trees block harsh western sun during the summer months, they also create a haven for native birds and insects, while increasing occupant comfort. The external theater, located in the entrance corridor adjacent to this native garden, is North facing to reduce glare and eye strain during events. 


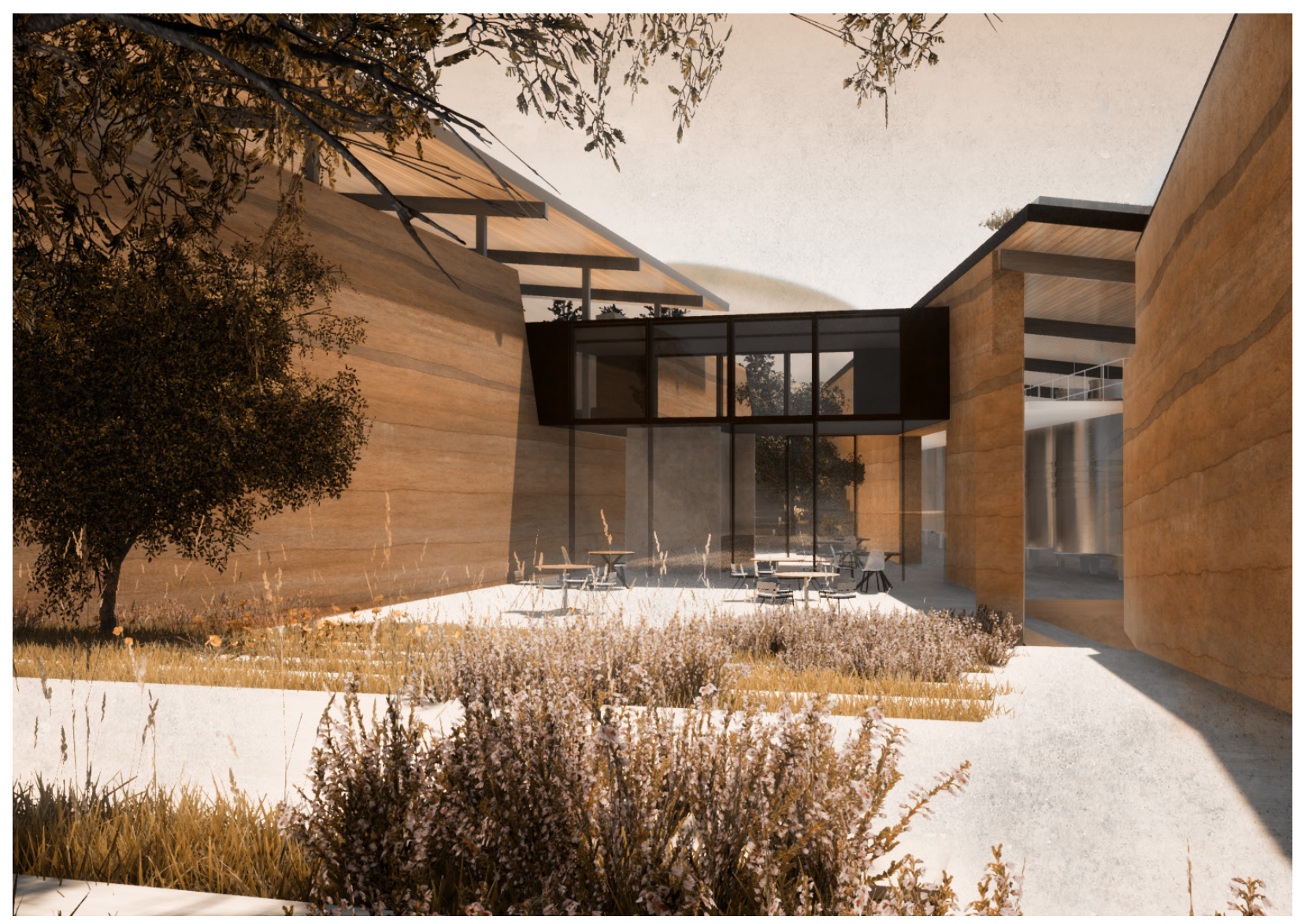

6.29: External Hall and Native Species. 

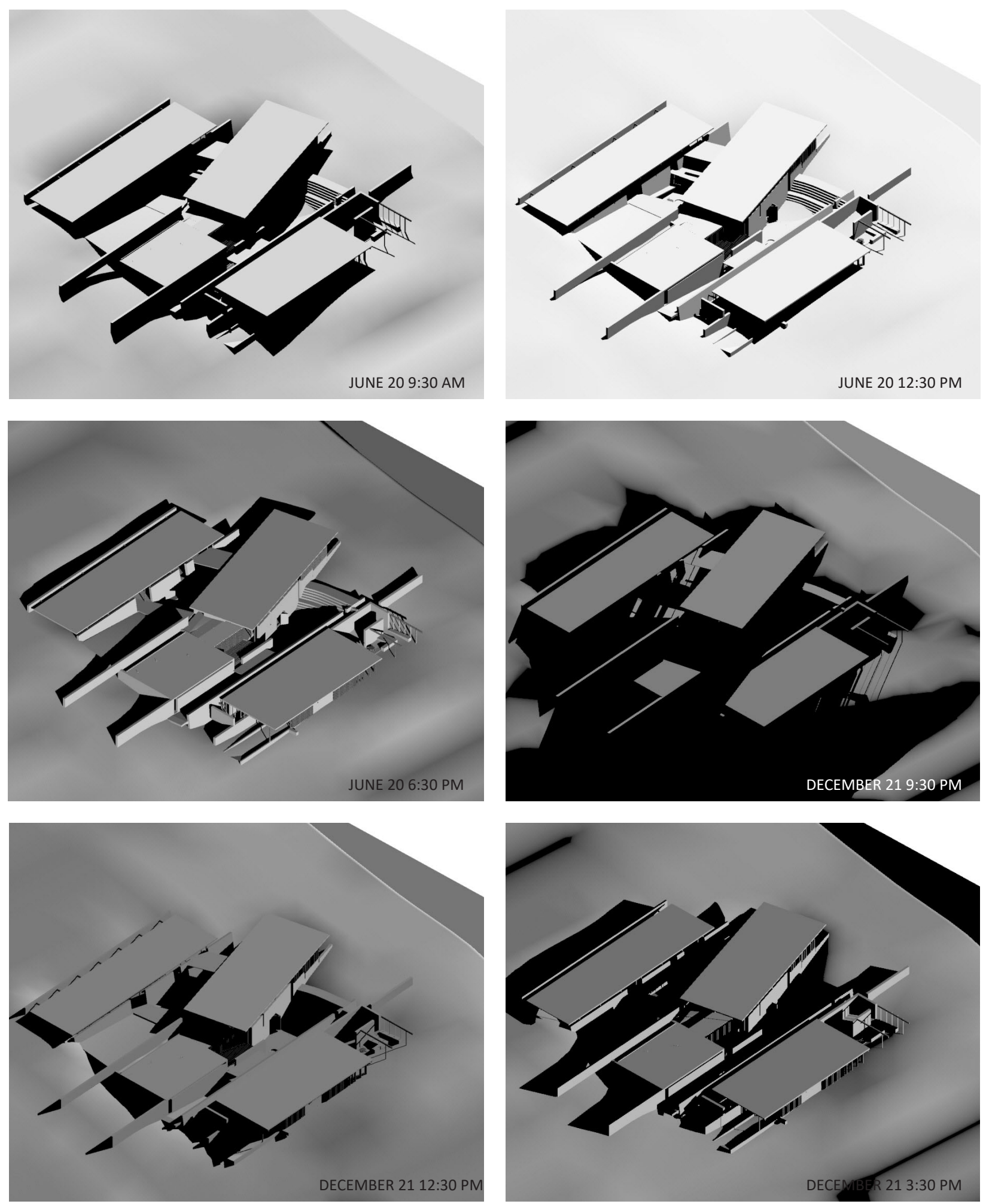

6.30: Sun Study Showing How the External Corridors Protect Occupants from Afternoon Sun. 
Embracing the occasional rain the Valley receives during the fall and winter months, a trough in each external corridor becomes animated (figure 6.31). Water from the rooftop runs down each trough and ends at a cherry tree, paying homage to the agricultural history of the valley. These troughs played an important role in the Okanagan's development as they turned the valley's terroir from a predominantly dry desert landscape to a lush oasis during the early 20th century. Through the trough, water is linked to its source in rain and sky, and excess water is transported to the vineyard for irrigation purposes. As a result these necessary dialogues are made poetic and the everyday experience of rain becomes aesthetic. Bringing occupants in contact with the processes that sustain the winery by making them visible, tangible, and audible, are a key part to being in dialogue with the distinct characteristics of place and its terroir.

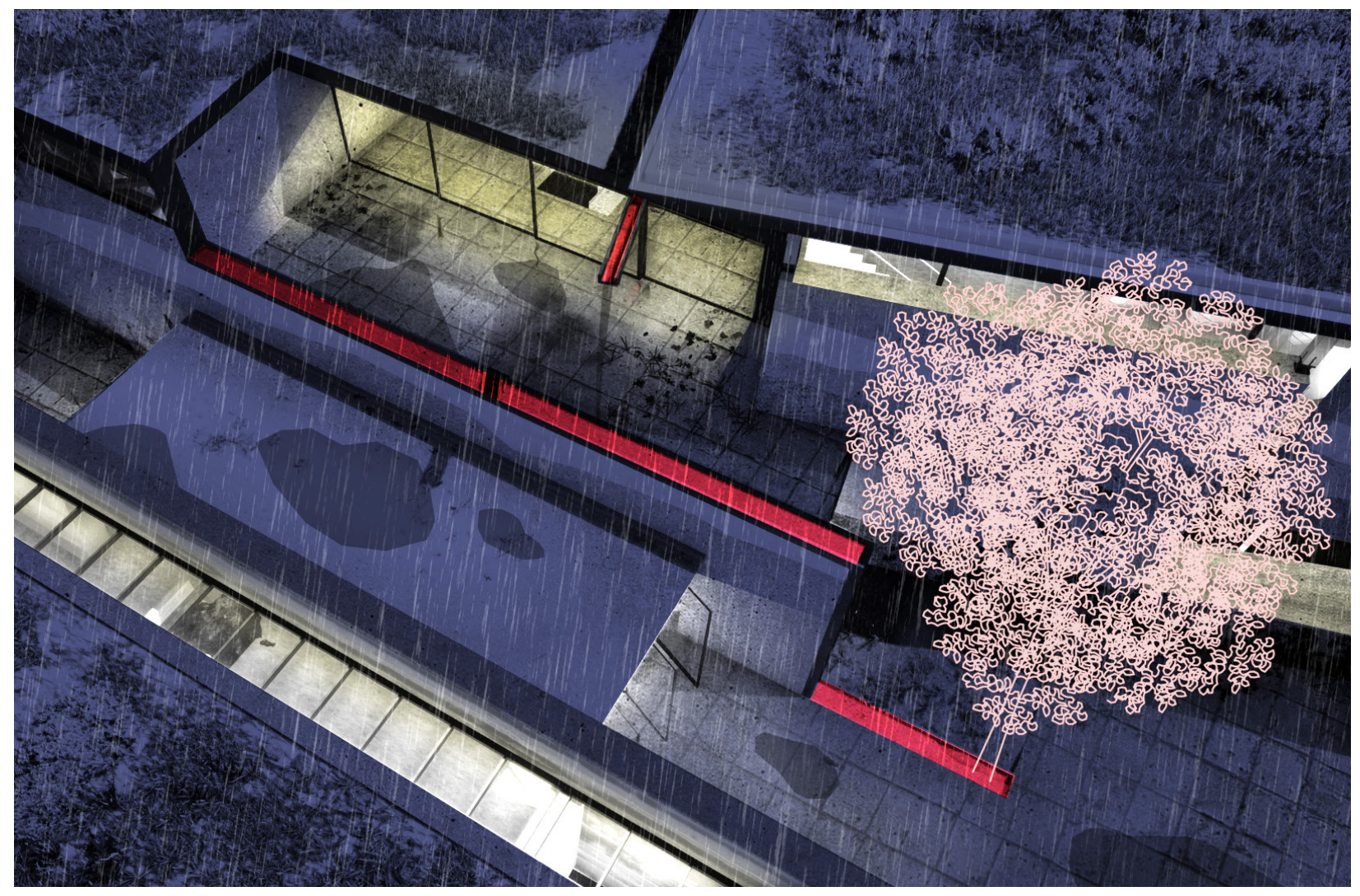

6.31: Trough (Indicated in Red). 


\subsection{CLOSING REMARKS}

Evolution of human estrangement from nature has run parallel with globalization and the increasingly speculative modes through which we experience the world. As globalized western culture continues to influence consumer products, landscapes, and consequently the built environment, it has guided the homogenization of places. This issue became the catalyst for an Investigation into terroir's architectural relevance, and its role in placemaking. Questions such as "how does the transient tourist experience landscapes? How does the turbulent nature of globalization influence our ability to connect with place?" and "how can terroir provide a more authentic, sustainable, and meaningful connection to our environment?", were explored.

Throughout the background and design research, it became apparent that by understanding how terroir driven architecture can engage us with the naturally rich and distinct characteristics of our environments, building can go beyond the quantiative modes of sustainability, capturing the regionalist and cultural aspects needed to regain the spirit of place. Terroir is a lesson in appreciating the real dimensions of the land, and through its use as an architectural concept, it can become the catalyst for appropriate place stewardship. Despite its potential however, it was not without its challenges.

The first obstacle being that terroir is a polysemous word with multiple meanings to multiple people. Over time its definition has become more inclusive and holistic. Creating an architectural project that encapsulated a contemporary understanding of terroir proved to be difficult. Although the project touched on some of terroir's role in an architectural context, there is plenty more to be explored.

Secondly, determining the ways in which terroir as an architectural concept creates a sense of place was more often intuitive than grounded in hard facts. Each person understands and experiences place differently, so creating a building that addresses the particularities of place in order to engage a global demographic proved to be daunting.

Despite the abstract nature of what makes place, and how it is understood by people, it is important more than ever that 
architecture address context as a step forward in creating socially, environmentally, historically, and culturally sustainable places. Terroir as one approach to placemaking presents itself as a useful paradigm for which to foster more meaningful connections with the land. By understanding how terroir driven architecture can reflect the distinct characteristics of our environments, the French concept shows how we may achieve a greater appreciation and stewardship towards our places. 


\section{APPENDEX A: SITE EXPLORATIONS}

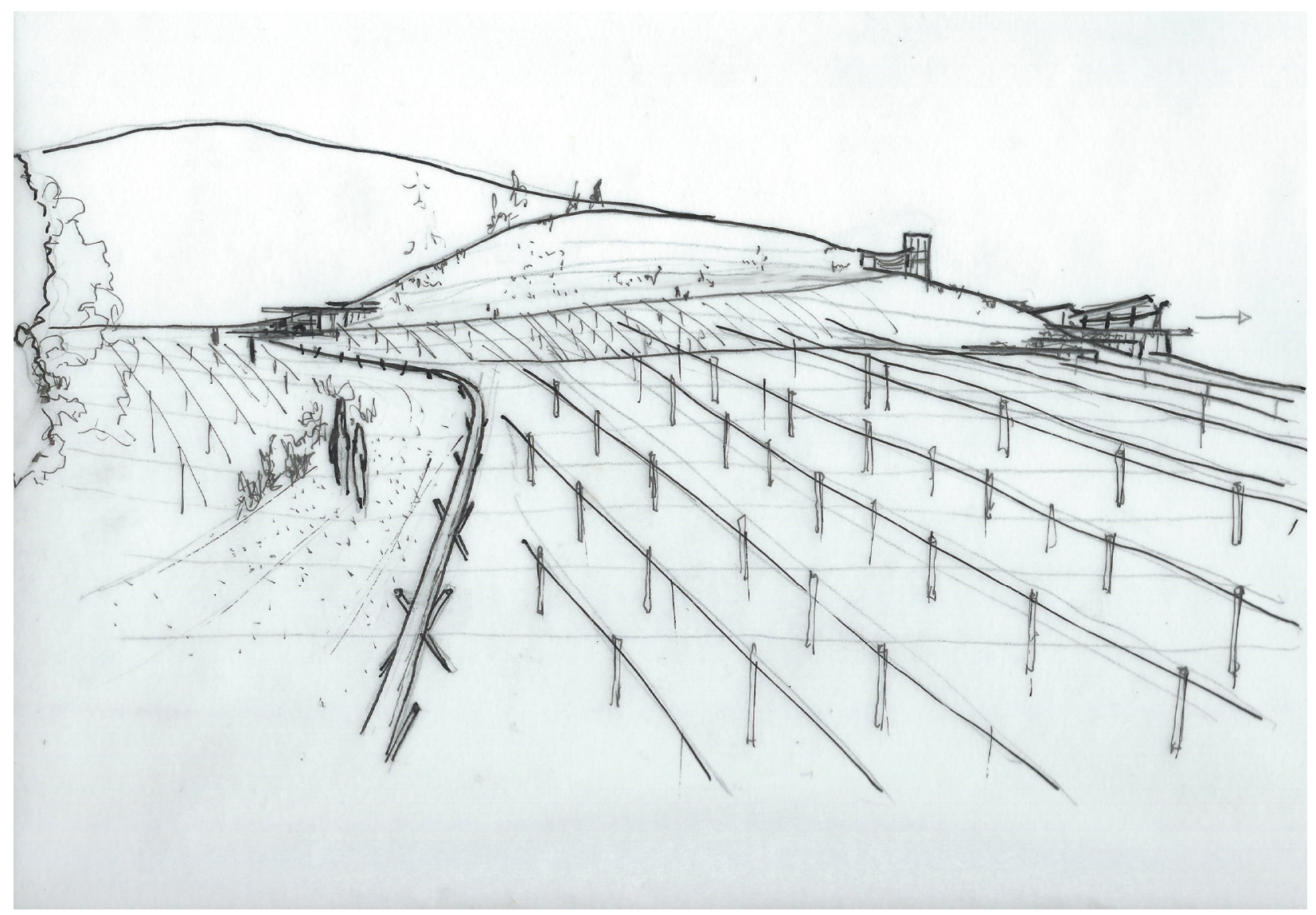

A1: Study of Entry Sequence. 


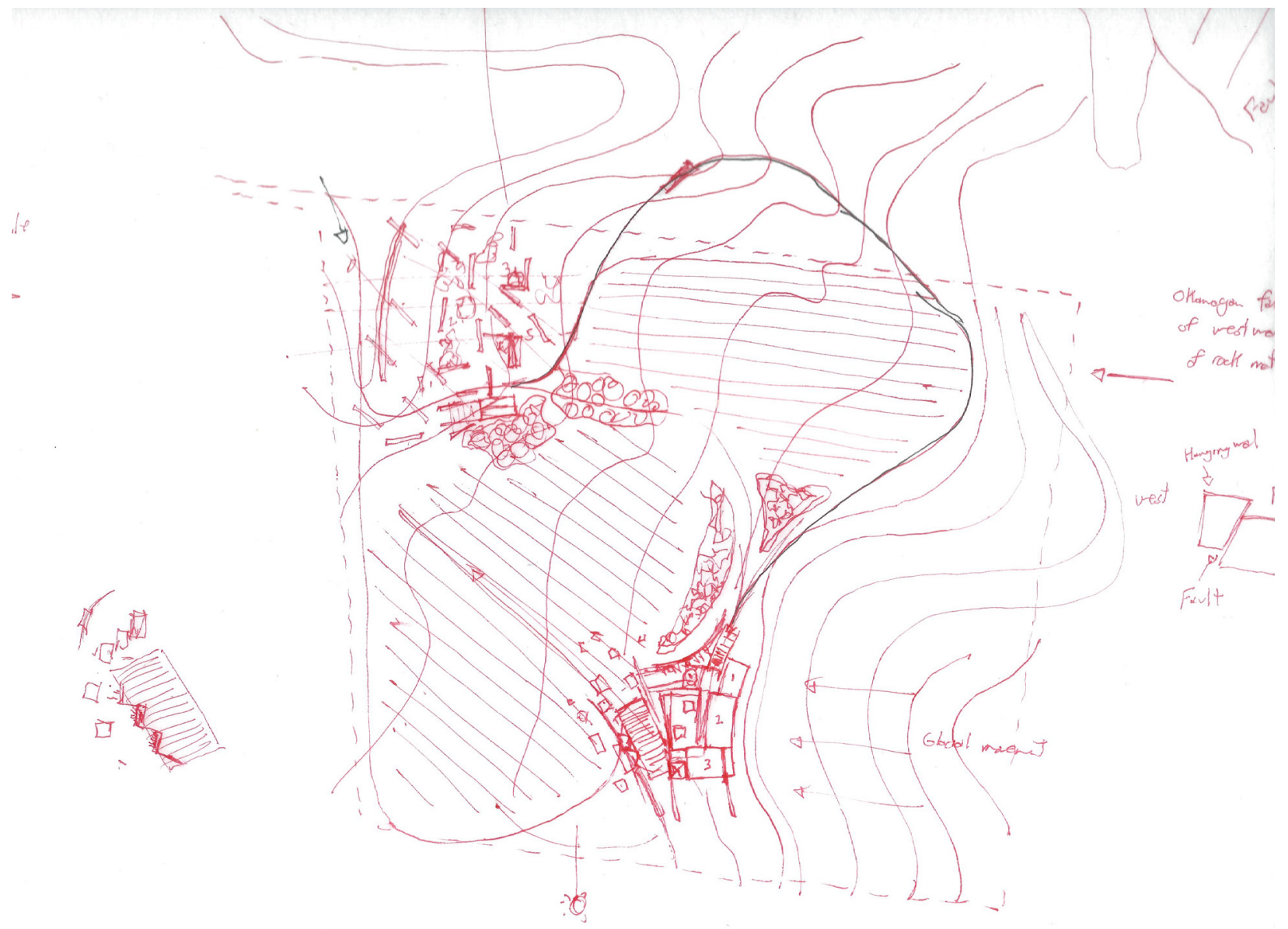

A2: Site Matserplan. 


\section{APPENDEX B: DESIGN EXPLORATIONS}

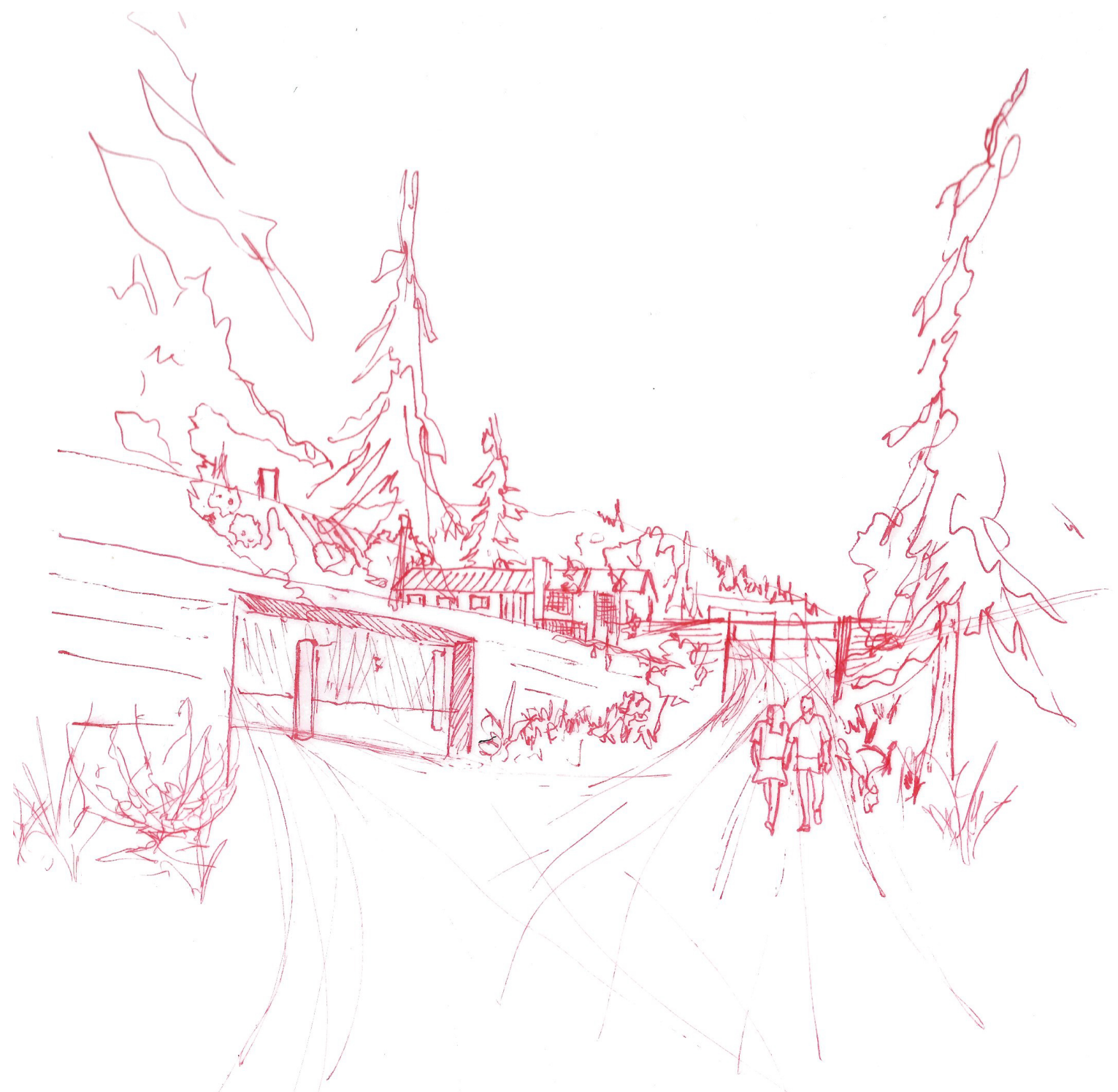

B1: Campground and Entrance. 


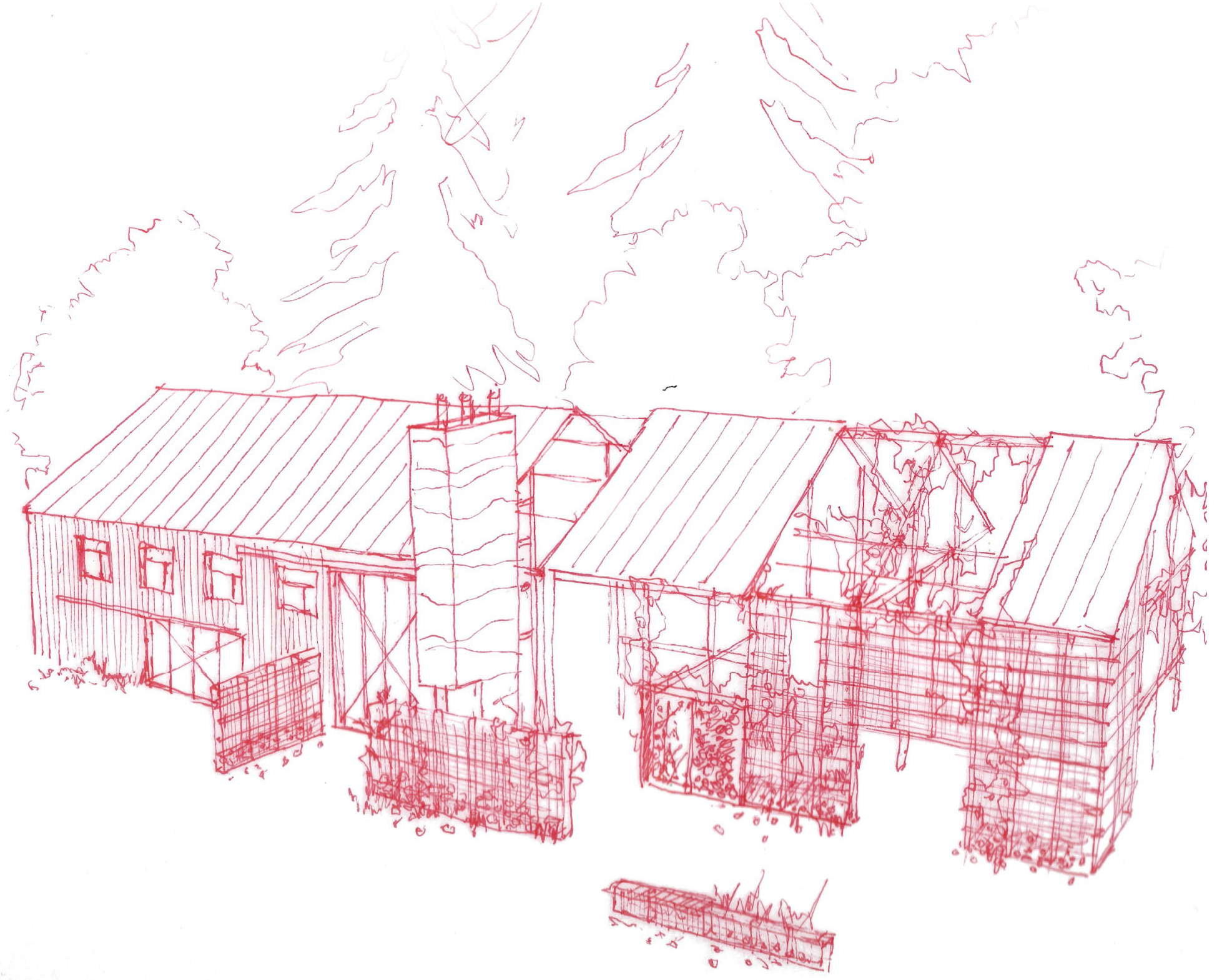

B2: Lodge Iteration. 


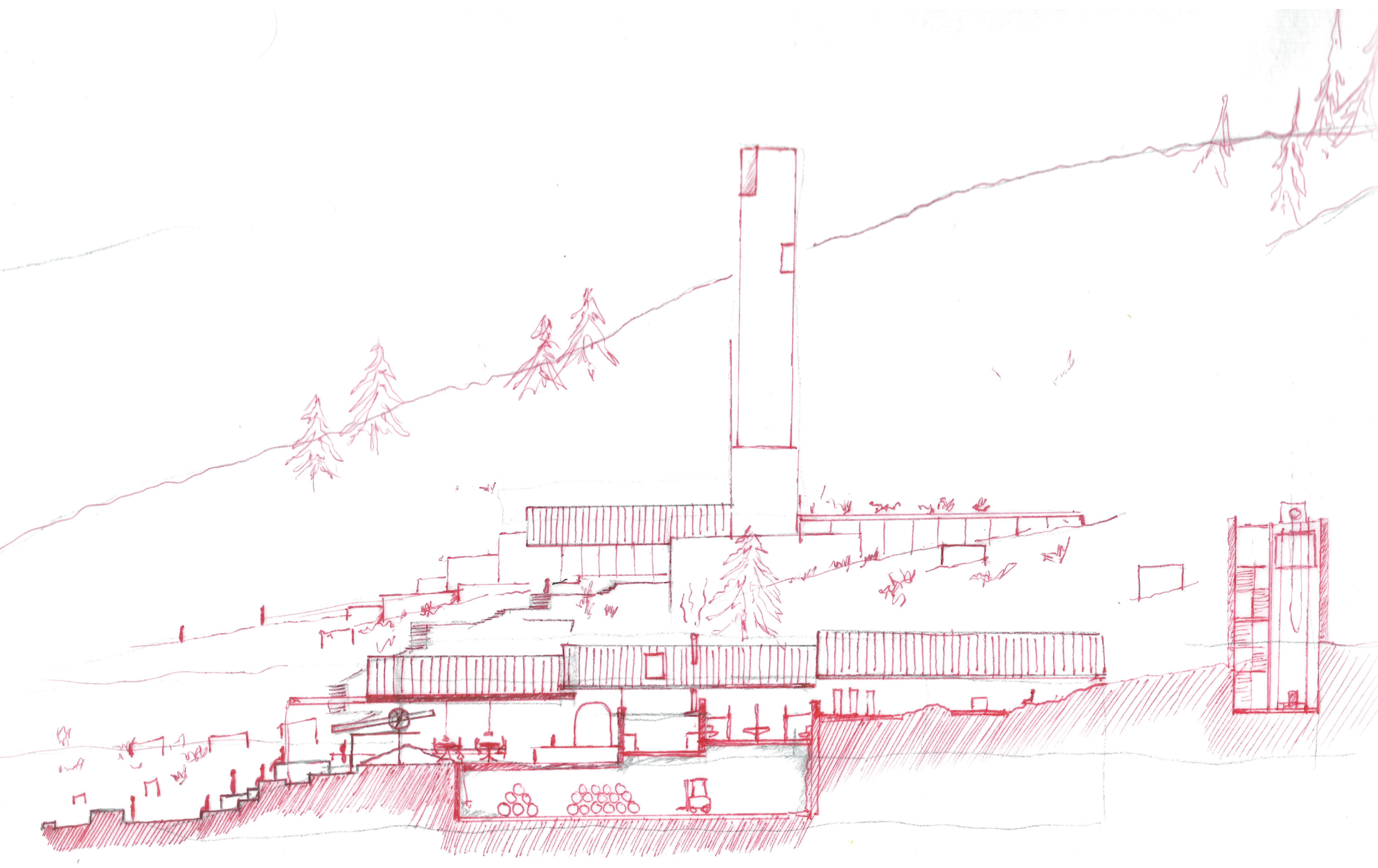

B3: Building and Topography Relationship Study. 


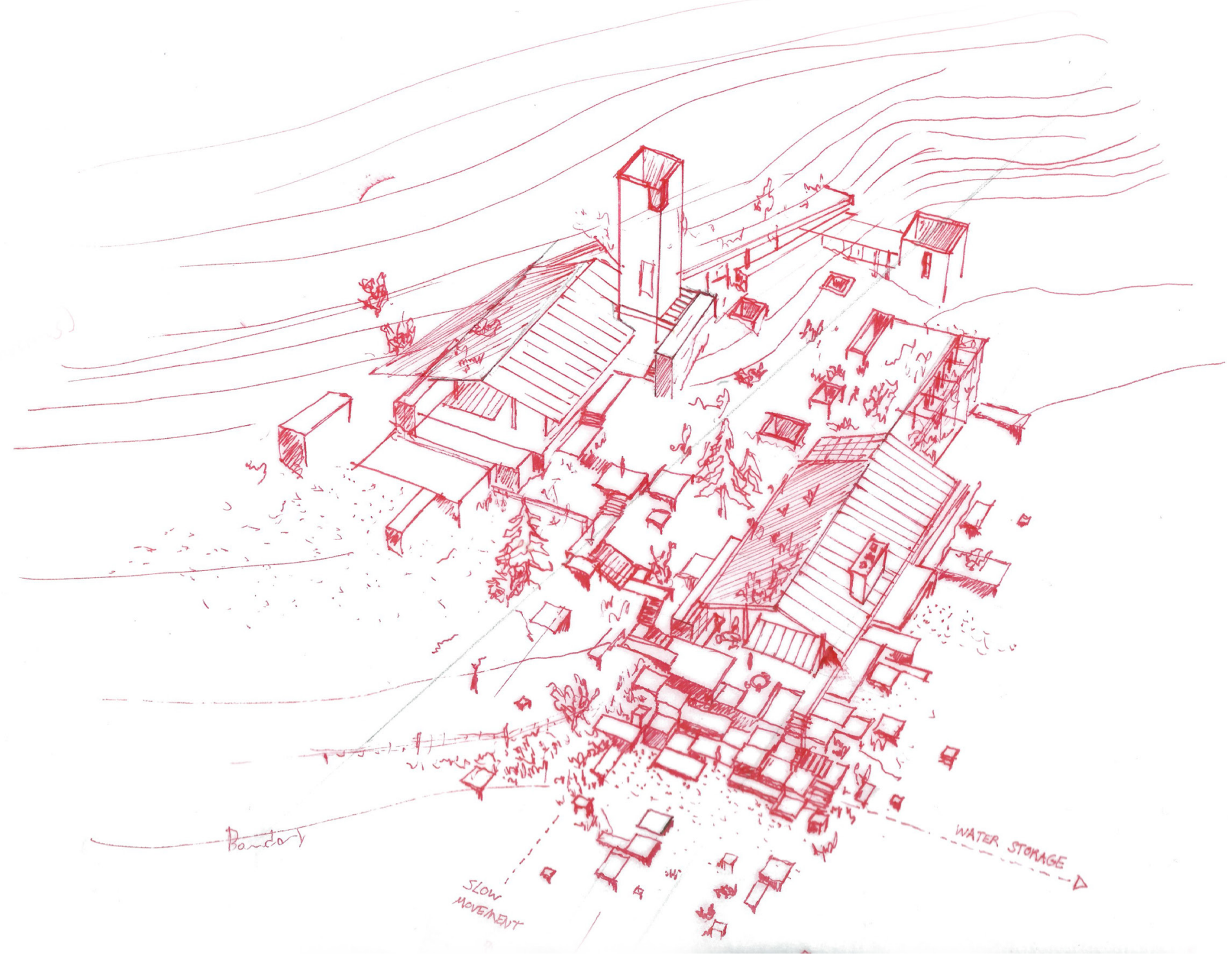

B4: Winery Aerial View. 


\section{APPENDEX C: PHYSICAL MODELS}

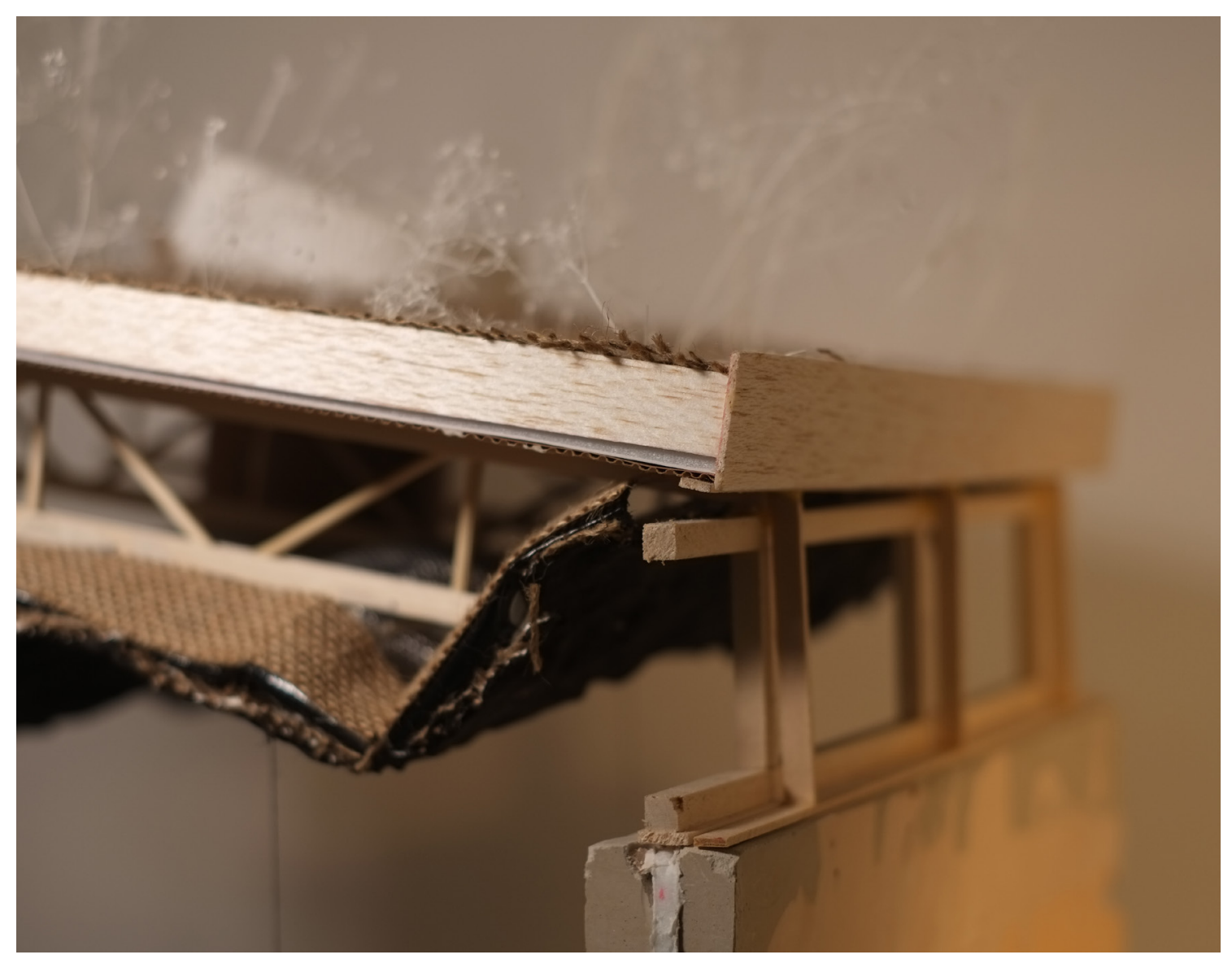




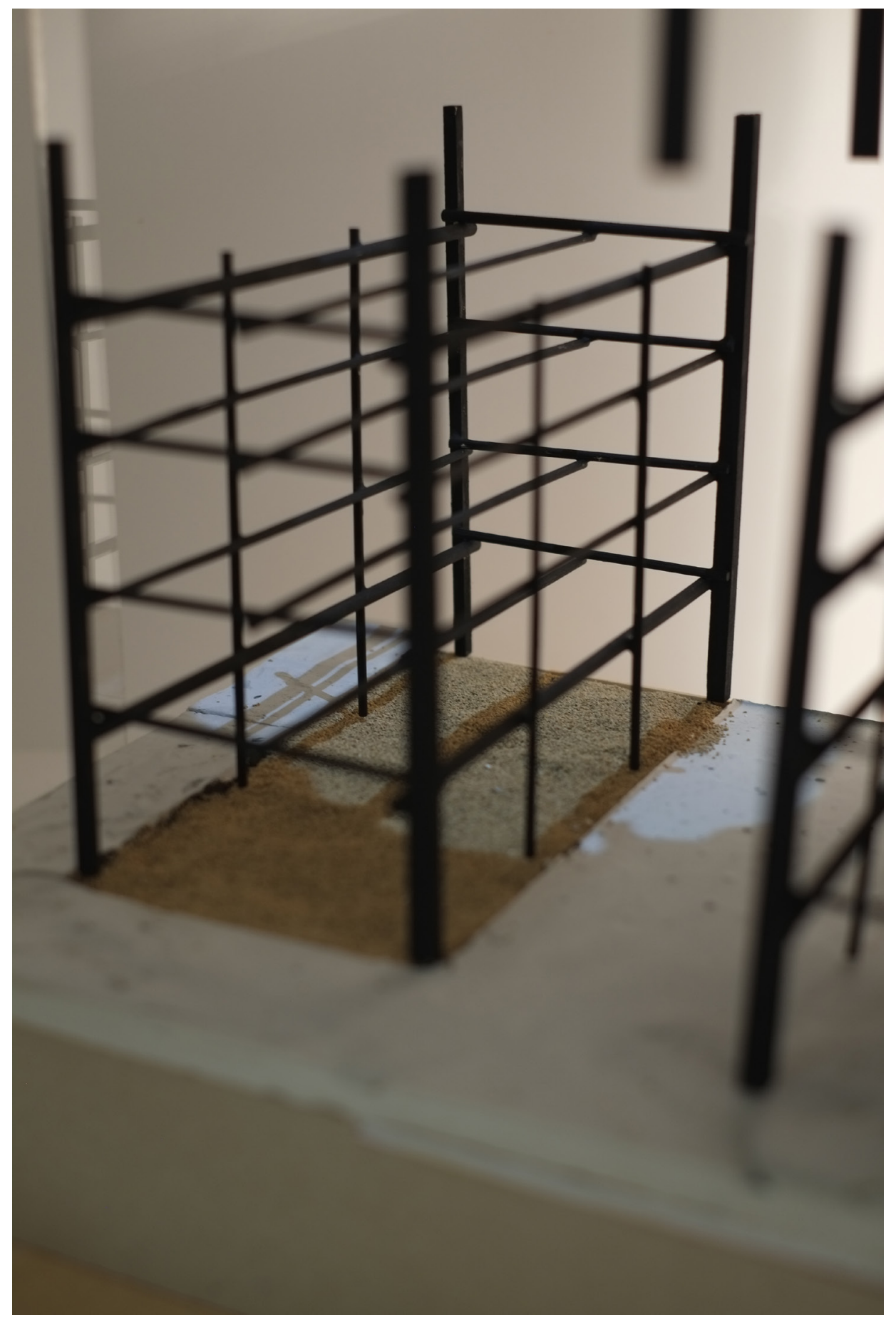




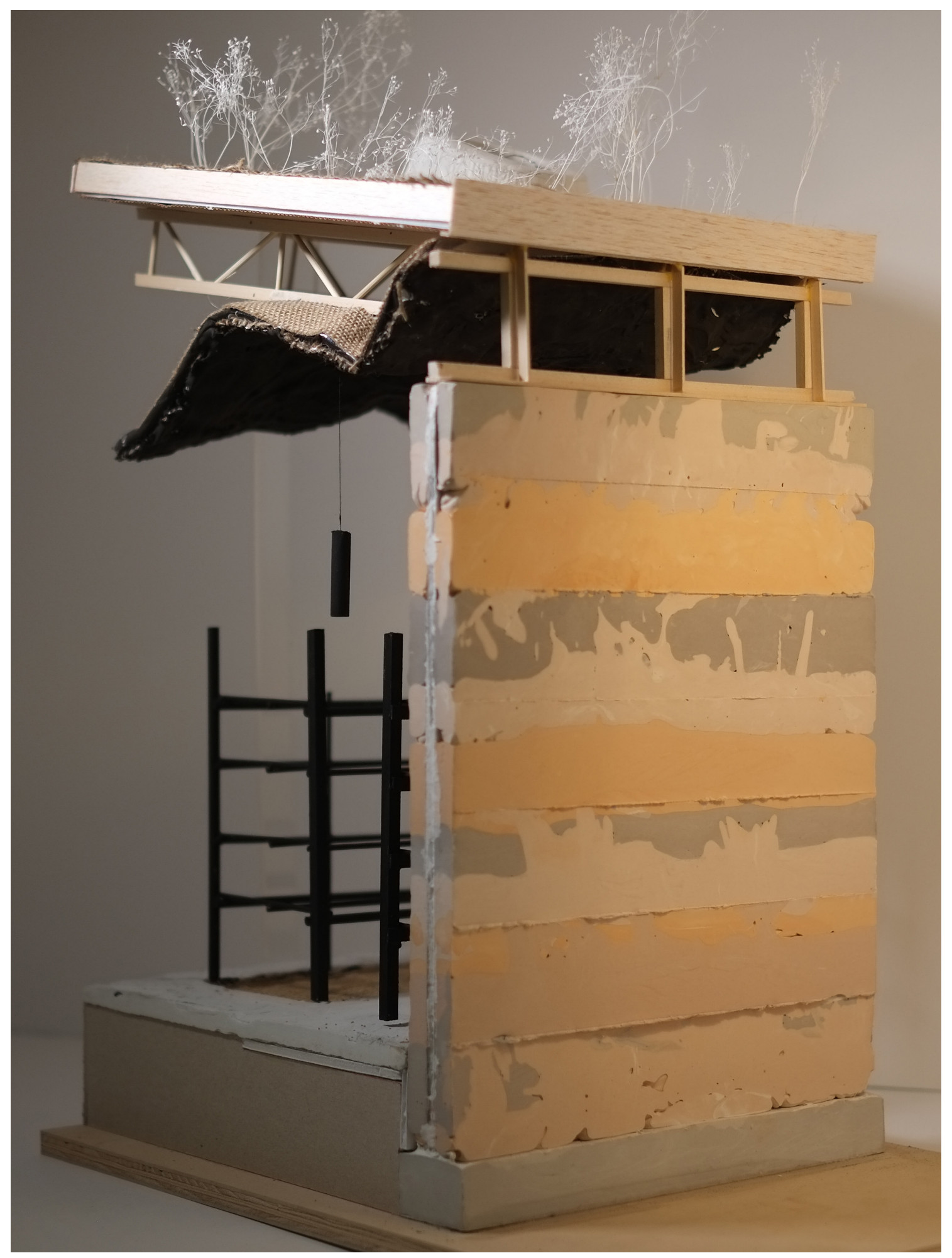




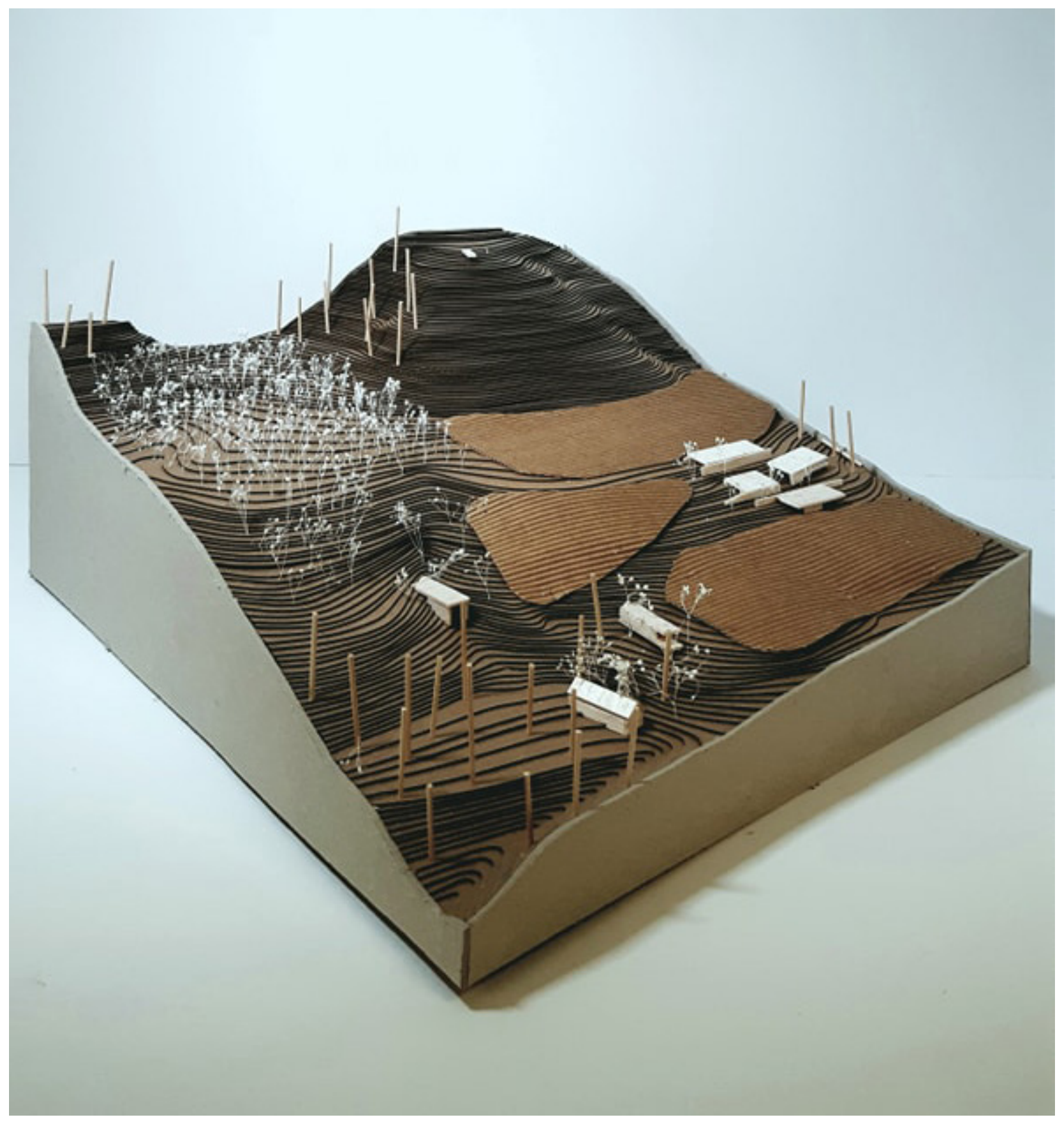




\section{BIBLIOGRAPHY}

Alvarez, E. (2009). Memory of stones: technology, materials and the weathering of buildings. Retrieved from https://www.brown.edu/Departments/Joukowsky_Institute/courses/architectureandmemory/8274.html

Area "D" Okanagan Falls and Surrounding Areas. (n.d.). Retrieved from https://www.okfalls. ca/play/climate/

Arreola, D. D. (2005). Hispanic spaces, Latino places community and cultural diversity in contemporary America. Austin: University of Texas Press.

Azuma House - Row House - Data, Photos \& Plans. (n.d.). Retrieved from https://en.wikiarquitectura.com/building/azuma-house-row-house/

Basar, S. (2016). ESSAY: The Eternal Return of the Primitive Hut. Retrieved from https://pinupmagazine.org/articles/prada-fondazione-the-eternal-of-the-primitive-hut

Bell, E. (2016, July 12). The Difference Between Pinot Grigio, Pinot Gris \& Pinot Blanc. Retrieved from https://vinepair.com/articles/so-whats-the-difference-between-pinot-grigio-grisand-blanc/

Bridgewater, P. (n.d.). Is There a Future for Cultural Landscapes? Retrieved from https://www. researchgate.net/publication/228876881_Is_there_a_future_for_Cultural_Landscapes.

Britannica, T. E. (2016, October 18). International Style. Retrieved from https://www.britannica.com/art/International-Style-architecture

Carlson, A. (2006). The Aesthetic Appreciation of Environmental Architecture under Different Conceptions of Environment. The Journal of Aesthetic Education, 40(4), 77-88. doi:10.1353/ jae.2006.0030

Cattaneo, C. (2014, November 01). How Okanagan's wine industry is taking on the world. Retrieved from https://business.financialpost.com/news/economy/how-okanagans-wine-industry-is-taking-on-the-world

Chambers, E. (2007). :Travels in Paradox: Remapping Tourism. American Anthropologist, 109(3). doi:10.1525/aa.2007.109.3.572.2

Charters, S. (2008). Wine and society: The social and cultural context of a drink. Amsterdam: Elsevier/Butterworth-Heinemann.

Clarke, O., \& Rand, M. (2001). Grapes and wines: an encyclopedia of grape varieties. Lon- 
don: Little, Brown.

Cloke, P., \& Jones, O. (2001). Dwelling, Place, and Landscape: An Orchard in Somerset. Environment and Planning A: Economy and Space, 33(4). doi:10.1068/a3383

Conzen, M. (2001). Cultural Landscape in Geography. International Encyclopedia of the Social \& Behavioral Sciences, 3086-3092. doi:10.1016/b0-08-043076-7/02543-2

Cosgrove, Denis E. 1984. Social Formation and Symbolic Landscape. London: Croom Helm

Craven, J. (2017, October 07). What basic components are necessary to create architecture? Retrieved from https://www.thoughtco.com/primitive-hut-essentials-of-architecture-178084

Cronon, W. (n.d.). The Trouble with Wilderness; or, Getting Back to the Wrong Nature. Retrieved from https://www.williamcronon.net/writing/Trouble_with_Wilderness_Main.html

Crutzen, P. J. (2002). Geology of mankind. Nature, 415(6867). doi:10.1038/415023a

Danesi, M. (2006). Messages, signs, and meanings: a basic textbook in semiotics and communication. Toronto: Canadian Scholars Press.

Dougherty, P. H. (2012). The geography of wine: Regions, terroir and techniques. Dordrecht: Springer.

Eba. (2013, November 16). PROCESS \# MATERIAL :: kevin low 's compost wall for Sibu Pavillon (2006). Retrieved from https://likemyplace.wordpress.com/2013/11/16/process-material-kevin-low-s-compost-wall-for-sibu-pavillon-2006/

Foley, R. (2016). Healing Waters Therapeutic Landscapes in Historic and Contemporary Ireland. London: Taylor and Francis.

Frearson, A. (2017, December 18). Morphosis chosen for hotel by Peter Zumthor's Therme Vals. Retrieved from https://www.dezeen com/2015/02/09/morphosis-7132-hotel-peterzumthor-therme-vals-spa-switzerland

Fulton, R.J., 2003, Geology of Okanagan Valley Wine Region of British Columbia (abs.): Geological Society of America Annual Meeting, Seattle, Washington, Program and Abstracts.

Fulton, R. J., \& Smith, G. W. (1978). Late Pleistocene stratigraphy of south-central British Columbia. Canadian Journal of Earth Sciences, 15(6), 971-980. doi:10.1139/e78-105 
Gaia Theory Anthropocene. (n.d.). Retrieved from http://www.earthboundpeople.com/gaia-theory-anthropocene/

Gare, A. (2004). BEYOND HEIDEGGER. Architecture and the Global Ecological Crisis: From Heidegger to Christopher Alexander.

Geologic History. (2014, February 14). Retrieved from http://okanaganlandscape.weebly. com/geologic-history.html

Giddens, A. (1990). The consequences of modernity. Cambridge: Polity Press.

Gieseking, J. J. (n.d.). Section 8: Landscape: Nature and Culture. Retrieved from https://peopleplacespace.org/toc/section-8/

Glaciation. (2014, February). Retrieved from http://okanaganlandscape.weebly.com/glaciation.html

Gyr, U. (2010, December 03). The History of Tourism: Structures on the Path to Modernity Tourism. Retrieved from http://ieg-ego.eu/en/threads/europe-on-the-road/the-history-of-tourism

Hailey, C. (2008). Campsite: Architectures of duration and place. Baton Rouge, LA: Louisiana State Univ. Press.

Hamilton, W. (n.d.). Santa Fe Style in the Okanagan Valley, British Columbia, by William G. Hamilton : Articles. Retrieved from https://www.terrain.org/articles/2/hamilton.htm

Harvey, D., \& Castree, N. (1996). Justice, nature and the geography of difference. Blackwell.

Harvey, M. (2017). WINE AND IDENTITY: Branding, heritage, terroir. S.I.: ROUTLEDGE.

Heidegger, M. (1951). Building, Dwelling, Thinking in ÒPoetry, Language, ThoughtÓ (1971). New York: Harper \& Row.

Heidegger, M. (1971). Poetry, language, thought: Translations and introduction by Albert Hofstadter. New York: Harper \& Row.

Ingold, T. (2010). Footprints through the weather-world: walking, breathing, knowing. Journal of the Royal Anthropological Institute, 16. doi: 10.1111/j.1467-9655.2010.01613.x

Ingold, T. (2015). The Life of Lines. doi:10.4324/9781315727240 
Ingold, T. (2011). The perception of the environment: Essays on livelihood, dwelling and skill. London: Routledge, Taylor \& Francis Group.

Ingold, T. (1993). The temporality of the landscape. World Archaeology, 25(2), 152-174. doi: 10.1080/00438243.1993.9980235

Jackson, J. B. (1984). Discovering the vernacular landscape. New Haven: Yale University Press.

James, S. P. (2002). Heidegger and the Role of the Body in Environmental Virtue. Retrieved from http://trumpeter.athabascau.ca/index.php/trumpet/article/view/1 17/123

Jack, J. (Ed.). (2014). The People, Place, and Space Reader. Retrieved from https://peopleplacespace.org/

Judd, D. R. (2015). The infrastructure of play: Building the tourist city. Oxfordshire,: Routledge.

Kaplinski, J. (2003, February 11). Globalization: For nature or against nature. Retrieved from https://www.eurozine.com/globalization-for-nature-or-against-nature/

Knox, P. L. and Pain, K. (2010) Globalization, neoliberalism and international homogeneity in architecture and urban development. Informationen zur Raumentwicklung, 2010 (5/6). pp. 417-428. ISSN 0303-2493

Kundig (n.d.). Retrieved from https://www.missionhillwinery.com/estate_winery/architecture/ architect.aspx

Landscape: Definition of Landscape by Lexico. (n.d.). Retrieved from https://www.lexico.com/ en/definition/landscape

Leader-Elliot, L., Maltby, R., \& Burke, H. (2004, July 28). Landscape and cultural exchange. Retrieved from http://ehlt.flinders.edu.au/humanities/exchange/asri/define cl.html/ Leatherbarrow, D., and Mostafavi, Mohsen On Weathering: the Life of Buildings in Time. MIT Press, 2001.

Leatherbarrow, D. (2000). Uncommon Ground: Architecture, Technology, and Topography. Retrieved from https://epdf.tips/uncommon-ground-architecture-technology-and-topography. html

Lopez, B. (1990, February 1). Losing Our Sense Of Place. Retrieved from https://www.edweek. org/tm/articles/1990/02/01/5geo.h01.html 
Marchand, T. H. J. (2011). Making knowledge: explorations of the indissoluble relation between mind, body and environment. Malden, MA: Wiley-Blackwell.

Machotka, E. (2018). Exhibiting the Return to terroir. Ca' Foscari Japanese Studies Rethinking Nature in Post-Fukushima Japan. doi:10.30687/978-88-6969-264-2/007

Marsh, J. (2006). Okanagan Valley. Retrieved from https://www.thecanadianencyclopedia.ca/ en/article/okanagan-valley

Martin-McAuliffe, S. L. (2016). Food and architecture at the table. London: Bloomsbury Academic.

Mclntyre, N., Williams, D., \& McHugh, K. (2006). Multiple dwelling and tourism: Negotiating place, home, and identity. Cambridge, MA: CABI Pub.

Metamorphic Rocks. (n.d.). Retrieved from http://okanaganlandscape.weebly.com/metamorphic-rocks.html.

Mills, N. (2014, May 17). Retrieved April 19, 2019, from https://www.youtube.com/ watch? $v=5 f 5$ SvJJwQic

Mirsepassi, A. (2006). Globalization and Place. Retrieved from https://www.academia. edu/20037128/Globalization_and_place.

Mrozowski, S. A., \& Preucel, R. W. (2010). Contemporary archaeology in theory: the new pragmatism. Malden, MA: Wiley-Blackwell.

Nature Institue. (2015). Of Wines and Compost. Retrieved from http://natureinstitute.org/pub/ ic/ic33/vineyard_compost.pdf

No.15: The Dominus Winery. (2009, March 3). Retrieved from http://mondoarc.designandgo. net/built_with_light/212489/no15_the_dominus_winery.html

Norberg-Schulz, C. (1996). Genius loci: Towards a phenomenology of architecture. New York: Rizzoli.

Olivier, B. (201 1). 'Sustainable' architecture and the 'law' of the fourfold.

Olson Kundig - Mission Hill Family Estate. (n.d.). Retrieved from https://olsonkundig.com/projects/mission-hill-family-estate-winery/ 
Palmer, C. (2018). Being and dwelling through tourism: An anthropological perspective. Milton Park, Abingdon, Oxon: Routledge.

Pawsey, T. (2017, July 12). B.C. Pinot Blanc worth a peek this summer. Retrieved from https:// www.nsnews.com/lifestyle/taste/b-c-pinot-blanc-worth-a-peek-this-summer-1.21061120

Paxson, H. (2010). Locating Value in Artisan Cheese: Reverse Engineering Terroir for NewWorld Landscapes. American Anthropologist, 112(3), 444-457. doi:10.1111/j.15481433.2010.01251.x

Pinot Grigio. Retrieved from https://www.jancisrobinson.com/learn/grape-varieties/white/pinot-grigio

Polo, M. (2001, September 30). In Vino Veritas. Retrieved from https://www.canadianarchitect. com/in-vino-veritas/

Prial, F. J. (1995, August 30). Wine Talk. Retrieved from https://www.nytimes.com/1995/08/30/ garden/wine-talk-465895.html

Relph, E. (1976). Place and placelessness. London: Pion.

Rentmeester, C. (2016). Heidegger and the environment. London: Rowman \& Littlefield International.

Robertson, R. (1992). Globalization: Social theory and global culture. London: Sage.

Saragosa, D. (n.d.). Jackson-Triggs Estate Winery. Retrieved from chrome-extension://oemmndcbldboiebfnladdacbdfmadadm/http://www.tboake.com/sustain_casestudies/edited/Jackson-Triggs-Estate-Winery.pdf

Schuilenburg, M. (2011). Place and Identity in Times of Immigration and Globalization. The Right to Terroir.

Schwann, A. (2018). Ecological wisdom: Reclaiming the cultural landscape of the Okanagan Valley. Journal of Urban Management, 7(3), 172-180. doi:10.1016/j.jum.2018.05.004

Seguin, G. (2006). The Concept of Terroir in Viticulture. Journal of Wine Research, 17, 1-10.

Sharr, A. (2007). Heidegger for architects. London: Routledge.

Smith, S. (2015). A sense of place: Place, culture and tourism. Tourism Recreation Research, 
40(2), 220-233. doi:10.1080/02508281.2015.104

9814

Smith, S. (2018). Technical Description and Geographic Extent. Skaha Bench SubGeographic Indication. Retrieved from http://www.bcrqa.ca/wp-content/uploads/2018/12/2018-September-25-Technical-Report-fo-Skaha-Bench-Gub-Gl.pdf

Soil Formation and Parent Material. (n.d.). Retrieved from https://landscape.soilweb.ca/colluvial-environment

Sooväli, H. (2003). (Traditional) landscape identity-globalized, abandoned, sustained? Transactions on Ecology and the Environment, 64.

Spirn, A. W. (2000). The language of landscape. New Haven: Yale University Press.

Tartaglia, S., \& Rossi, M. (2015). A STUDY ON A LOCAL CULTURE. THE LOCAL IDENTITY FUNCTIONS IN THE AGE OF GLOBALIZATION, 1(1).

Teal, R. (2008). Placing the Fourfold: Topology as Environmental Design. FOOTPRINT, , $65-$ 78. doi:10.7480/footprint.2.2.687

Terroir. (2019). In Oxford Online Dictionary. Retrieved from https://en.oxforddictionaries.com/ definition/terroir

Tomasi, D., Gaiotti, F., \& V., J. G. (2013). The power of the terroir: The case study of Prosecco wine. Basel: Springer.

Tourism: Definition of Tourism by Lexico. (n.d.). Retrieved from https://www.lexico.com/en/ definition/tourism

Tourism Research. (2017). Retrieved from https://www.tourismkelowna.com/industry/tourism-research/

Trubek, A. B. (2008). The taste of place: A cultural journey into terroir (Vol. 20). Berkeley: University of California Preass.

Tschumi, B. (2000). A Landscape of Events. Cambridge, MA: The MIT Press.

Tschumi, B. (1994). Architecture and disjunction. Cambridge, MA: MIT Press.

Tuan, Y.-fu. (1990). Topophilia: a study of environmental perception, attitudes, and values. 
New York: Columbia University Press.

"Urban of Langres" on Revolvy.com. (n.d.). Retrieved from https://www.revolvy.com/page/Urban-of-Langres

View of Geology and Wine 10: Use of Geographic Information System Technology to Assess Viticulture Performance in the Okanagan and Similkameen Valleys, British Columbia: Geoscience Canada. Retrieved from https://journals.lib.unb.ca/index.php/gc/article/view/2718/3167

Wagner, J. (2008). Landscape Aesthetics, Water, and Settler Colonialism in the Okanagan Valley of British Columbia. Journal of Ecological Anthropology, 12(1), 22-38. doi:10.5038/21624593.12.1.2

Wampole, C. (2016). Rootedness: The ramifications of a metaphor. Chicago: The University of Chicago Press.

Webb, M., \& Pfeiffer, E. (2005). Adventurous wine architecture. Mulgrave, Vic.: Images.

Wikström, T., \& Mahmutovic, D. (n.d.). Cities, Architecture and the Everyday. Retrieved from http://www.tomaswikstrom.nu/drupal/node/28

Yeoman, I. (2015). The Future of Food Tourism: Foodies, Experiences, Exclusivity, Visions and Political Capital. Bristol: Channe View. 